\title{
Broadband in Latin America
} Beyond Connectivity

\author{
Valeria Jordán \\ Hernán Galperin \\ Wilson Peres \\ Editors
}

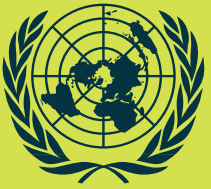

UNITED NATIONS

E C L \& ᄃ

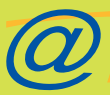

QuLs2-Alliance for the Intormation Society
in Latin Ammerica and the Caribbean, phase 2

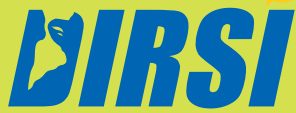
IDRC * CRDI 


\section{Broadband in Latin America \\ Beyond Connectivity}

Valeria Jordán

Hernán Galperin

Wilson Peres

\section{Editors}
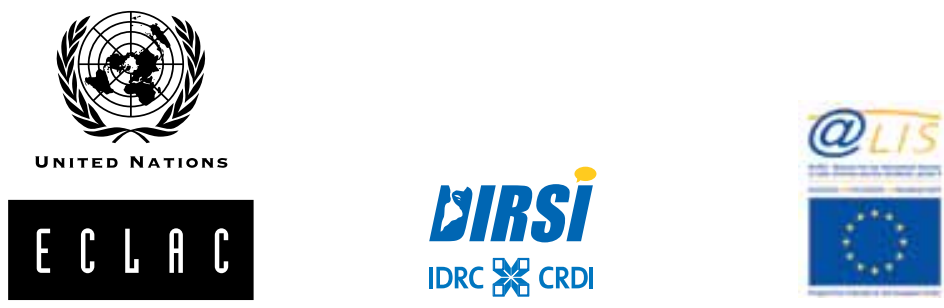

Economic Commission for Latin America and the Caribbean (ECLAC) Santiago, Chile, December 2013 


\section{Libros de la CEPAL}

\section{0}

\section{Alicia Bárcena}

Executive Secretary

\section{Antonio Prado}

Deputy Executive Secretary

\section{Mario Cimoli}

Chief, Division of Production, Productivity and Management

\section{Ricardo Pérez}

Chief, Publications and Web Services Division

The preparation of this document was coordinated by Valeria Jordán and Wilson Peres, of the Economic Commission for Latin America and the Caribbean (ECLAC), and Hernán Galperin, from the Regional Dialogue on the Information Society (DIRSI), in the framework of the project "Inclusive political dialogue and exchange of experiences", under the Alliance for the Information Society programme phase 2 (@LIS2), which is jointly financed by ECLAC and the European Union and implemented by the Division of Production, Productivity and Management of ECLAC.

The opinions expressed in this document, which has not undergone editorial review, are the sole responsibility of the authors and may not coincide with the views of the United Nations.

This document was produced with the financial assistance of the European Union. The opinions expressed herein do not necessarily reflect the official opinion of the European Union.

This work was conducted with the help of a grant from the International Development Research Centre, Ottawa, Canada.

This document may be downloaded at www.cepal.org/Socinfo.

United Nations publication

ISBN: 978-92-1-121836-7 • 978-92-1-056012-2

LC/G.2583-P

Sales No. E.14.II.G.7

Copyright (c) United Nations, December 2013. All rights reserved

Printed at United Nations, Santiago, Chile • 2013-644

Applications for the right to reproduce this work are welcomed and should be sent to the Secretary of the Publications Board, United Nations Headquarters, New York, N.Y. 10017, United States. Member States and the governmental institutions may reproduce this work without prior authorization, but are requested to mention the source and inform the United Nations of such reproduction. 


\section{Contents}

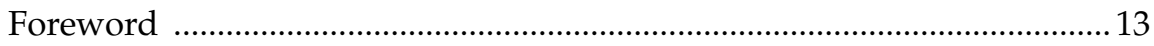

First part

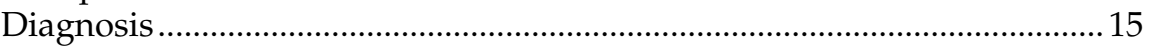

Chapter I

The shifting digital paradigm in Latin America .............................................17

A. The era of cloud computing.......................................................... 18

B. Broadband in the region.............................................................24

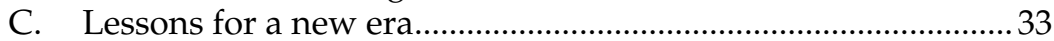

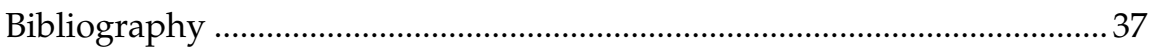

Chapter II

The demand gap: drivers and public policies...................................................39

A. Measuring the digital divide from the demand side .................. 40

B. Understanding the demand gap ………........................................4 44

C. The situation in Latin America...................................................... 48

1. Broadband coverage .................................................................5 50

2. The demand gap ..................................................................... 51

3. Explaining the demand gap ……………………………...... 52

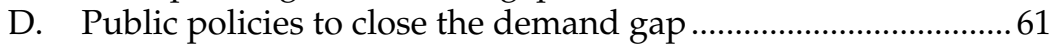

1. Policies for addressing the affordability barrier ...................6 61

2. Policies for addressing the skills barrier ................................ 64

3. Policies for addressing the lack of interest/

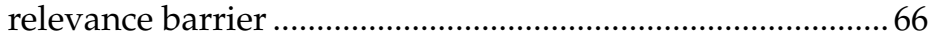

4. Programmes targeting specific population segments ..........67

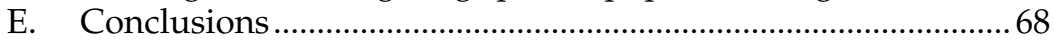




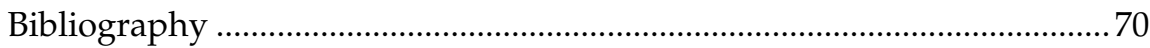

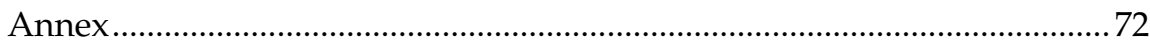

Chapter III

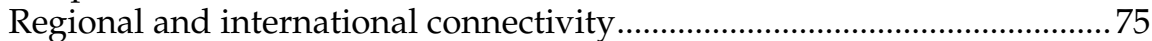

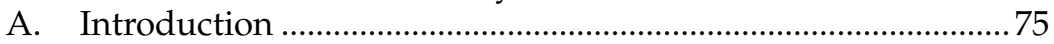

B. Internet connectivity ................................................................. 76

1. Factors that affect connectivity ……..................................... 76

2. Quality parameters...................................................................77

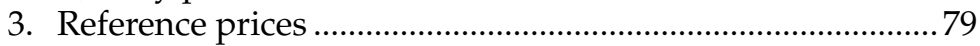

4. Aggregation factor................................................................. 80

C. South America's dependence on international links ..................81

1. The international bottleneck and its

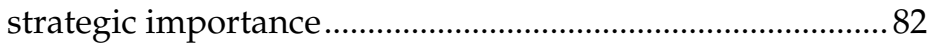

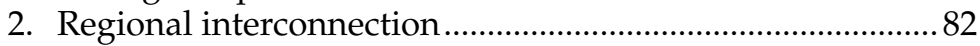

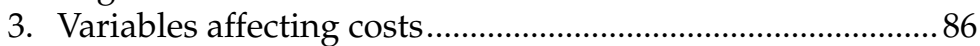

4. Global trends and prices........................................................... 88

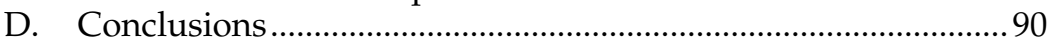

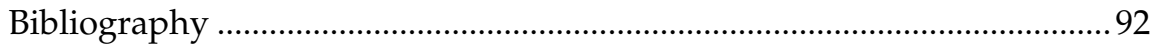

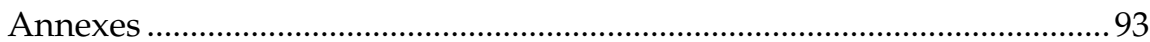

Best operating practices and key performance indicators................. 94

Second part

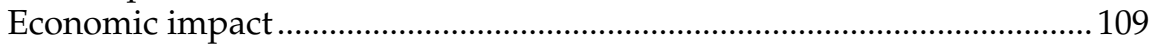

Chapter IV

Broadband, digitization and development ...................................................111

A. Broadband and economic growth............................................111

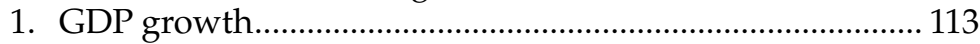

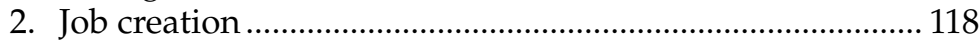

3. Growth of household income ..............................................121

B. Digitization and development ................................................. 124

C. Policy implications ...................................................................... 130

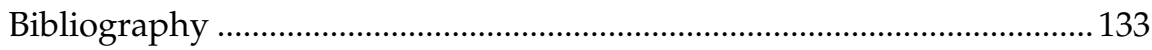

Chapter V

Mobile broadband: the urgent need for speedier roll-out...........................135

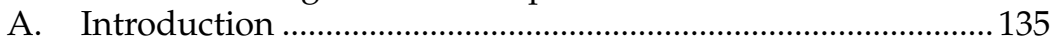

B. Status of mobile telephony in Latin America............................. 137

C. Mobile data networks in Latin America ....................................140

1. Relationship between penetration and wealth creation ...140

2. Introduction of mobile broadband networks

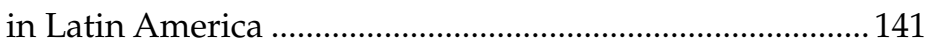

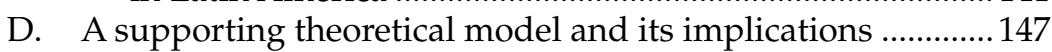

1. The adjustment model ........................................................... 147 


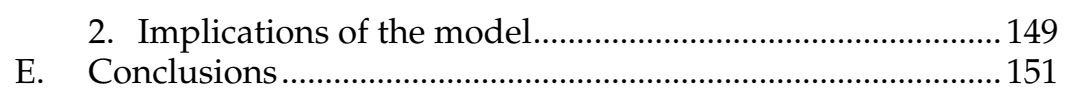

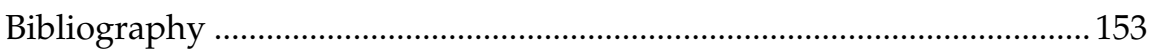

Chapter VI

Cloud computing, structural change and job creation in SMEs................. 155

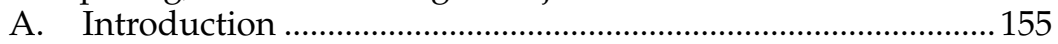

B. What is cloud computing, and how can it affect

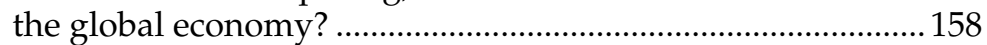

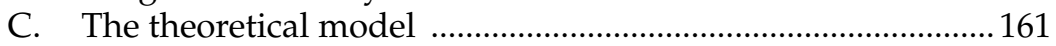

1. Labour market and job matching .......................................... 162

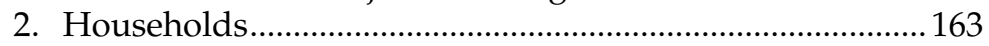

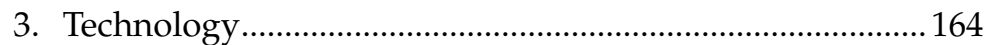

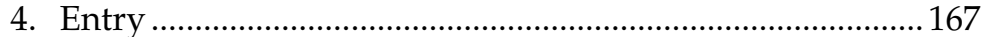

5. Imperfect competition and job creation ...............................167

6. Bargaining over wages and hours.......................................... 169

7. Business creation, hiring and IT policies.............................. 170

D. The introduction of cloud computing .......................................171

1. Aggregation and market clearing ………..............................173

2. The equilibrium in the cloud economy ...............................175

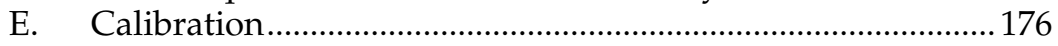

F. Transition to the cloud economy ……………...........................178

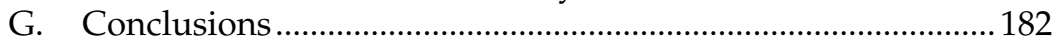

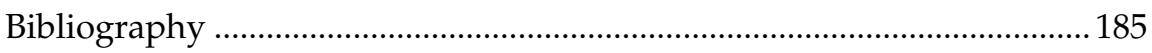

Third part

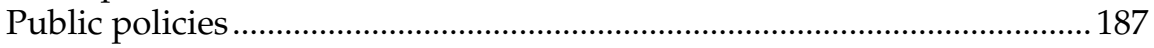

Chapter VII

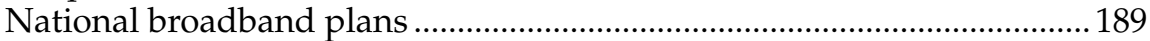

A. Introduction ................................................................................ 189

B. The end of a cycle: the changing role of the State in telecommunications ................................................................ 191

C. Overview of national broadband plans ...................................... 194

1. Argentina: Plan Nacional de Telecomunicaciones

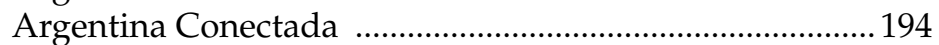

2. Brazil: Plano Nacional de Banda Larga .................................196

3. Chile: Plan Todo Chile Comunicado.................................... 197

4. Colombia: Plan Vive Digital.................................................. 198

5. México: Agenda Digital.mx................................................... 199

D. National broadband plans: different strategies, same goal....201

1. Analysis and objectives.......................................................... 201

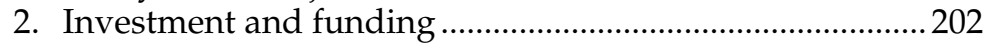

3. Deployment models .............................................................202

4. Regulation and coordination with the private sector.........204 


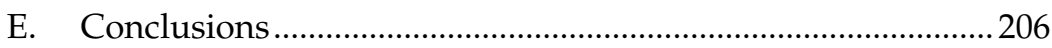

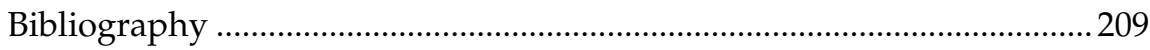

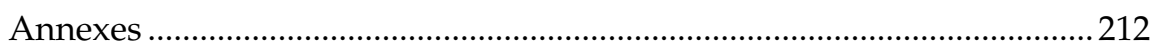

Chapter VIII

Broadband and industrial policy: the Korean experience............................2.215

A. Broadband industrial policy: definition and scope..................215

1. Sectoral industrial policy in the period before the WTO (pre-1995: 1G)............................................................. 220

2. Horizontal industrial policy in the WTO (1995-2005: 2G)

3. Targeted cutting-edge policy in the WTO (2005-2010: 3G)

4. Generative convergence policy in the WTO (2010-2020: 4G-5G).

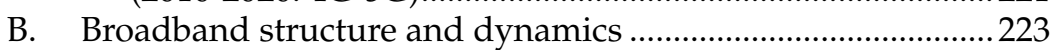

1. Expansion and mass adoption...............................................223

2. Drivers of mass penetration .....................................................226

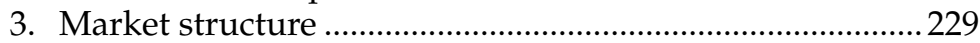

4. ICT goods production and foreign trade …….....................233

C. Policy convergence.........................................................................235

1. Broadband development policy ……………….....................237

2. Competition and regulation.................................................238

3. Broadband industrial policy …….........................................240

4. Technological development policy ........................................2242

D. The Giga Korea Plan 2020 .......................................................... 242

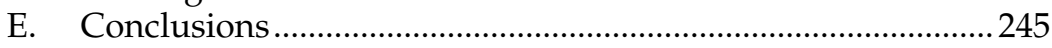

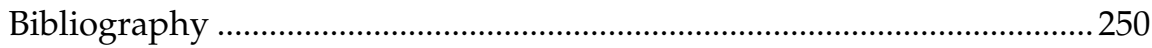

Chapter IX

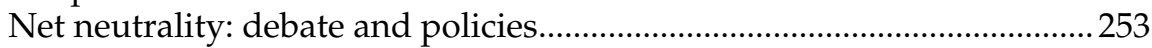

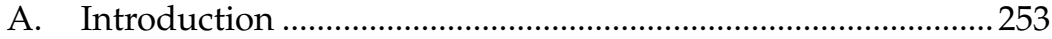

B. What is net neutrality? ................................................................ 254

1. The non-discrimination principle ......................................256

2. The growth of traffic and net neutrality ..............................257

C. The situation in Europe, the United States and Asia-Pacific 529

1. Europe and the United States ..........................................259

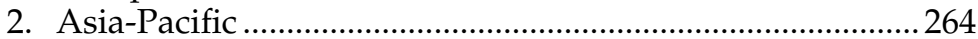

D. Situation and outlook in Latin America......................................266

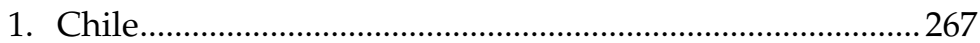

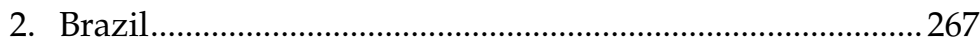

E. Criteria for developing a national policy .................................268

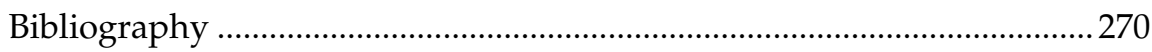


Fourth part

The future of the ecosystem.

Chapter X

The advance ofcloud computing

273

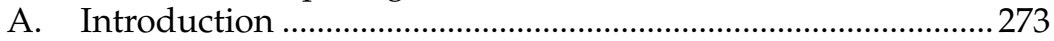

B. What is cloud computing? ..........................................................2 274

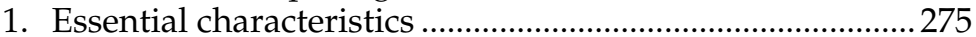

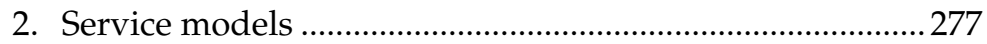

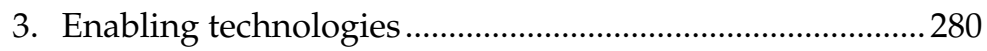

4. Deployment models ............................................................... 282

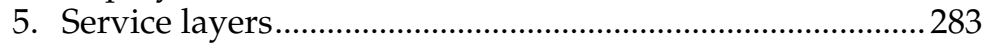

C. Problems and challenges..........................................................284

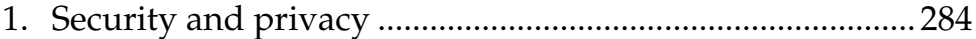

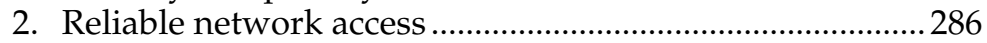

3. Legal and regulatory aspects ...............................................286

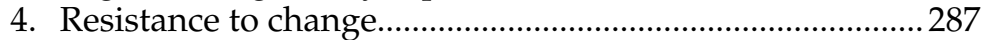

D. Migration to cloud computing ……….....................................28

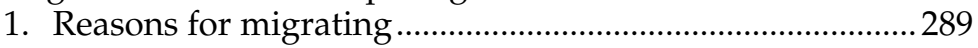

2. Assessing the benefits of cloud computing ........................290

3. Considerations for successful migration..............................2292

E. The situation in Latin America.................................................295

1. Legal and regulatory environment ......................................295

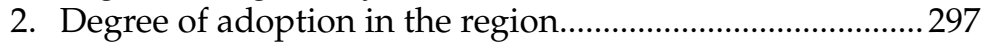

F. Mobile cloud computing …………….........................................300

1. The structure of mobile cloud computing …………............300

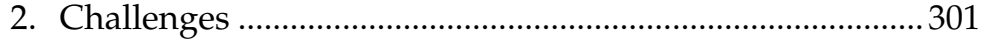

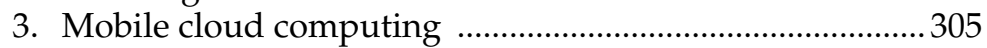

G. "Everything" in the cloud: reality or utopia?...............................306

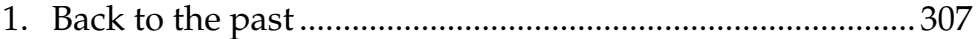

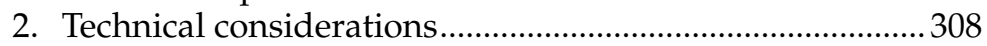

3. Legal and procedural aspects .................................................310

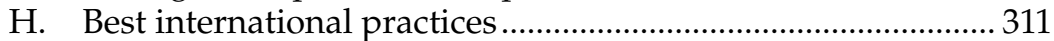

1. Explore cloud benefits..............................................................312

2. Understand and manage cloud-related risks ......................313

3. Promote service transparency ................................................313

4. Clarify and enhance accountability .......................................314

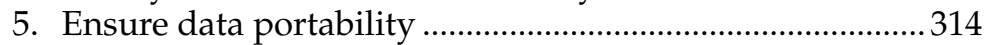

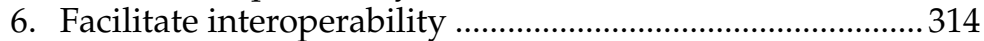

7. Adapt and harmonize regulatory frameworks ....................315

8. Provide sufficient connectivity ……………………...............315

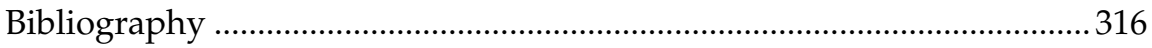




\section{Chapter XI}

The challenge of over-the-top content and services.

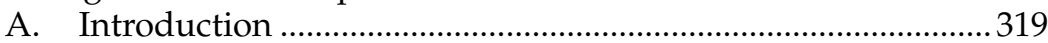

B. Over-the-top services, applications and content .......................321

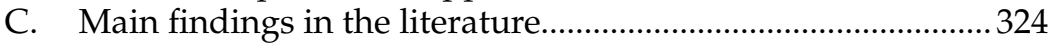

1. Changes in the value chain and the online-industry threat

2. The network neutrality debate ..............................................325

D. The over-the-top market in Latin America.................................327

1. Incumbent operators, OTT strategies and supply ............327

2. Netflix, Skype and WhatsApp ...............................................332

E. The strategy and policy debate .....................................................333

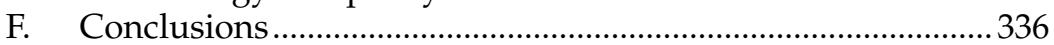

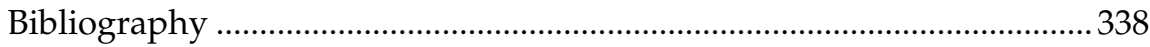

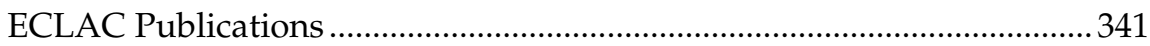

\section{Tables}

II.1 Developed countries: size of the fixed broadband

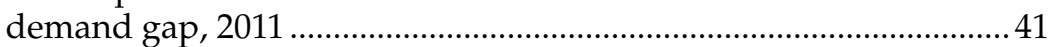

II.2 Developed countries: mobile broadband demand gap, 2011 ...........2 24

II.3 United States: reasons for not adopting broadband

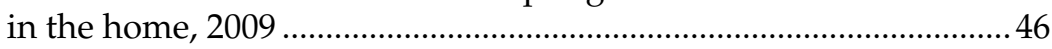

II.4 United States: reasons for not adopting broadband based on the availability of a computer in the home, 2011 ............................ 47

II.5 Spain: reasons for not adopting broadband, by income level, 2011 ....

II.6 Internet users and broadband subscribers

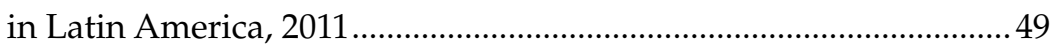

II.7 Broadband coverage in Latin America, 2011-2012 ..............................51

II.8 The fixed broadband demand gap in Latin America, 2011................51

II.9 The mobile broadband demand gap in Latin America, 2011 .............52

II.10 Latin America: factors explaining the demand gap............................54

III.1 Internet speeds in the region according to Ookla,

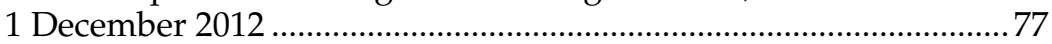

III.2 Internet speeds in the region according to Akamai ............................. 78

III.3 Reference prices for fixed access per Mbps for download speeds of approximately 2 Mpbs, November 2012............................ 80

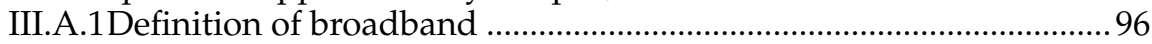

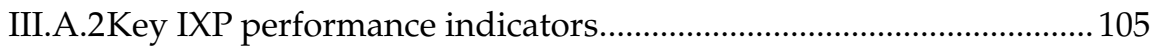

III.A.3Key country performance indicators ………..................................... 107

IV.1 Latin America: contribution of broadband to GDP growth ............ 113

IV.2 Colombia: contribution of broadband to GDP growth ..................... 114

IV.3 Panama: contribution of broadband to GDP growth ...................... 116

IV.4 Chile: impact of broadband on job creation....................................... 119 
IV.5 Colombia: impact of broadband penetration growth on employment growth

IV.6 Dominican Republic: impact of increased broadband penetration on employment growth

IV.7 Costa Rica: impact of broadband on growth in real household income.

IV.8 Colombia: impact of broadband penetration growth on real household income growth.

IV.9 Latin America: estimated economic impact of digitization.............129

IV.10 Latin America: broadband supply and demand gap, 2011.............. 130

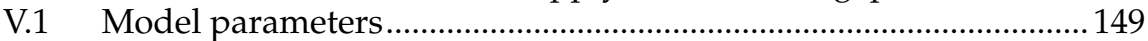

V.2 Regression and variance analysis statistics........................................ 149

VI.1 Change in the number of employed persons due to the introduction of cloud computing in Argentina

VI.2 Business creation due to the introduction of cloud computing in Argentina.

VI.3 Change in number of employed persons due to the introduction of cloud computing in Brazil.

VI.4 Business creation due to the introduction of cloud computing in Brazil.

VI.5 Job creation and business creation in the United States and in the 27 European Union member countries................................... 182

VII.A.1

VIII.1 Drivers of broadband development in the OECD and the Republic of Korea

VIII.2 ICT sector trade balance, 2010-2011 .................................................. 234

VIII.3 Republic of Korea: master plans and strategic frameworks for broadband development .....................................237

VIII.4 Broadband regulatory policies.......................................................2239

VIII.5 The Giga Korea Plan 2020................................................................ 244

VIII.6 Industrial and technological development model in Latin America and the Republic of Korea, 1960-2020

IX.1 Internet services according to delay sensitivity, bandwidth consumption and economic value.

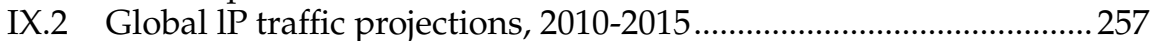

IX.3 Global consumer Internet traffic, 2010-2015 ..................................258

X.1 Characteristics of cloud computing …………..................................2278

X.2 Comparison between conventional models and cloud computing. 288

X.3 Chilean regulation of cloud computing ..........................................297

X.4 Mobile cloud computing challenges and solutions ...........................302

XI.1 Description of over-the-top-services...................................................321

XI.2 Service bundles including TV and first-generation strategies ........328

XI.3 Second-generation strategies ..........................................................330 


\section{Figures}

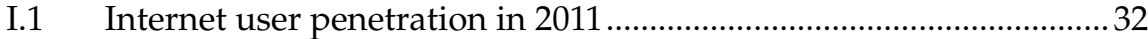

I.2 Fixed and mobile broadband penetration in 2011 ...............................33

I.3 Fixed and mobile broadband penetrationin Latin America and the Caribbean and in OECD, 2006-2011 .......................................34

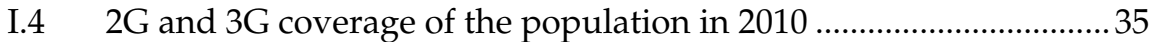

I.5 Households with Internet access in urban areas,

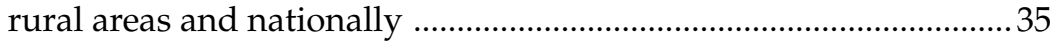

I.6 Households with Internet access, by income quintile.........................36

I.7 Households with Internet access, by gender of the head of household ............................................................................ 37

I.8 1Mbps fixed broadband tariffs with relation

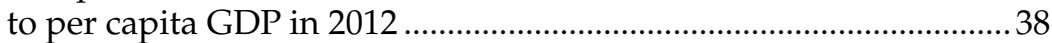

I.9 Mobile broadband tariffs in relation to per capita GDP in 2012 2......38

I.10 Broadband connection speeds in 2012 .................................................39

I.11 Percentage of broadband connections, by speed range ...................... 40

I.12 Bandwidth connected to the United States............................................ 41

II.1 United States: states with the lowest broadband

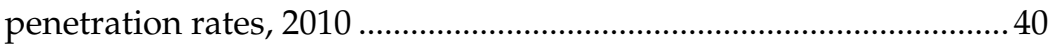

II.2 Quantification of the fixed and mobile demand gap...........................36

II.3 Latent fixed and mobile broadband demand in Latin America, 2011.

II.4 Brazil: reasons for not subscribing to Internet in the home, 2007-2011

II.5 Brazil: home Internet adoption by socioeconomic

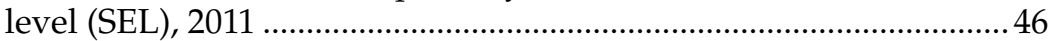

II.6 Mexico: home Internet adoption by income decile, 2008-2010 ........ 47

II.7 Home Internet adoption gap by income quintile (Q5/Q1) ............... 48

II.8 Costa Rica: residential Internet and computer use by educational level of the household head, 2010

II.9 Chile: residential Internet and computer use by educational level of the household head, 2009

II.10 Costa Rica: residential broadband penetration by education level and income decile, 2010.

II.11 Costa Rica: home Internet and computer use, by age group, 2010 .

II.12 Latin America: concentration of fixed broadband supply and average download price per Mbps.................................................. 54

III.1 Median monthly prices on North Pacific routes for 10 Gbps, second quarter 2010 to second quarter 2011

III.2 Trends in median prices in major cities of Latin America ..................81

III.3 Trends in median prices in major world cities ...................................82

IV.1 Comparative contribution of broadband to economic growth .......109

IV.2 Typology of countries by stage of digitization, 2011 ...................... 117

IV.3 Digitization and economic growth.................................................... 118 
IV.4 Returns to scale from digitization ……………................................. 119

IV.5 Digitization and employment..........................................................120

IV.6 Digitization and innovation in a sample of 125 countries............... 121

V.1 Mobile telephony penetration rate in the United States and the European Union compared with Latin America

V.2 Statistical significance of the parameters, 1995-2011 ........................ 133

V.3 Number of 3G networks in operation in Latin America .................. 134

V.4 Comparison between network launches ...........................................135

V.5 Growth in the number of 3G users................................................136

V.6 Penetration of 3G services as of June 2012 ….................................. 136

V.7 Correlation of penetration with time in service and GDP per capita

V.8 Relationship between GDP per capita and time in service as of June 2012 .................................................................... 138

V.9 Average quarterly increase in penetration, by network age .......... 139

V.10 Cost in economic well-being of a one-year delay in the launch of high-speed networks

V.11 Cost in economic well-being of a one-quarter delay in the launch of high-speed networks

VI.1 Transition of the main macroeconomic variables from the steady state of the pre-cloud economy to that of the cloud economy ........170

VIII.1 OECD: fixed-line broadband subscriptions (wired)per 100 inhabitants, by technology, December 2011 ........................................215

VIII.2 Selected OECD countries: fixed broadband penetration ..................216

VIII.3 OECD: ratio between broadband penetration per 100 inhabitants and GDP per capita in PPP dollars, 2011 ...........................................217

VIII.4 Broadband rates per Mbps of advertised speed,

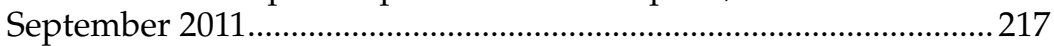

VIII.5 Business adoption of broadband, 2010 or latest available year .....218

VIII.6 Fixed-line telephone subscribers by service provider.......................221

VIII.7 Number of subscribers by service and mobile technology .............222

VIII.8 Mobile service providers: number of subscribers and market share

VIII.9 High-speed broadband providers: number of subscriptions and market share ............................................................224

VIII.10 High-speed broadband coverage subscribers by technology....... 225

IX.1 Fixed broadband access, by technology, 2011 ..................................... 251

X.1 Why cloud computing?.......................................................................28

X.2 Benefits of cloud computing in five European countries.................283

X.3 Savings from cloud computing......................................................284

X.4 Cloud computing regulation preparedness scorecard ....................288

X.5 Adoption of cloud computing around the world ............................290

X.6 Growth of cloud computing in Brazil by level of processing.........2290

X.7 Cloud services used in Colombia .......................................................291

X.8 Outlook for data centre growth in Latin America ............................291 
X.9 Access speed by type of connection in the region ............................2295

X.10 Mobile cloud computing revenue by region .....................................2298

\section{Diagrams}

II.1 Fixed and mobile broadband substitution

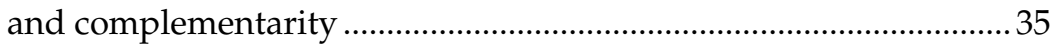

II.2 Impact of fiscal policy on broadband penetration ...............................55

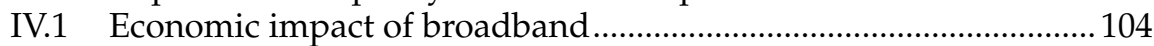

IV.2 How broadband contributes to job creation ...................................... 110

IV.3 Components of the digitization index ............................................. 117

VIII.1 Analytical framework for broadband industrial policy................... 211

VIII.2 Main areas of broadband industrial policy ……................................. 233

X.1 Cloud computing model........................................................................ 266

X.2 Flexible platforms for adjusting data and applications

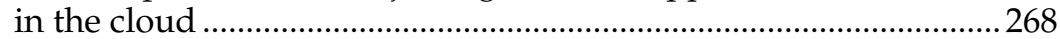

X.3 Development of cloud computing and software platform infrastructure (SPI) .......................................................... 270

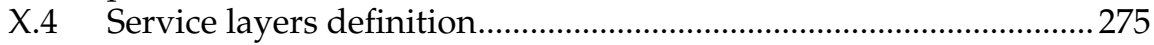

X.5 The extended data centre value chain .............................................28

X.6 Architectures of mobile cloud computing .......................................2292

X.7 Architecture of a CloneCloud system................................................2297

X.8 Evolution of computing technologies and networks ....................... 299

X.9 Action areas for promoting cloud computing ....................................304

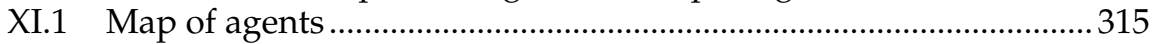

\section{Boxes}

V.1 Service penetration and unique subscribers....................................130

VIII.1 Broadband industrial policy approaches ............................................228

\section{Maps}

III.1 Capacity of principal international routes in Latin America.............76

X.1 Average Internet connection speed around the world.....................273 


\section{Foreword}

In November 2010, the editors of this book published Fast-tracking the digital revolution: Broadband for Latin America and the Caribbean, which put forth that broadband is the cornerstone of a system for economic, organizational and social innovation that, in conjunction with complementary assets (infrastructure, skills, production structure), was driving a positive dynamic across all economic and social sectors.

They noted that achieving that synergy called for a new policy approach with a comprehensive, flexible, long-term view combining the objectives of greater productivity, innovation, social inclusion and sustainability. This approach needed for the State to play an active role, building capacities that would enable it to design instruments and coordinate actions for addressing the challenges of the information society.

The editors saw that technological change was gathering momentum, particularly in information and communication technologies (ICTs). Their judgment was borne out by the growing penetration of 3G telephony among the population, expanding access to broadband and the spread of new technologies, such as cloud computing and big data analytics. There was a clear need to step up efforts in order to meet the demands of a hyperconnected world.

The countries of Latin America and the Caribbean have responded to this call. The region's public and private sectors have boosted investment in the infrastructure needed to deploy new networks and in programmes which encourage broadband use by individuals and businesses. 
Despite this progress, the efforts have not been enough. Although access to fixed and mobile broadband has expanded, the digital divide with the advanced countries is still far from closed. And broadband use is concentrated in applications for personal use and basic ICTs for business. The impact on productivity is, therefore, low.

There are still significant economic, territorial and gender disparities in terms of access, and bridging these gaps is going too slowly. Digital policies currently in force do not attach due importance to making infrastructure building and mass uptake of broadband part of national industrial policy strategies.

This is crucial, because the structural change advocated by the Economic Commission for Latin America and the Caribbean (ECLAC) depends on a close link between digital strategies, broadband development and sectoral industrial policy design. Only then will it be possible to make significant strides towards a new, more knowledge-intensive production structure that can generate the high-quality jobs needed for making steady progress towards greater equality and more sustainable economic and social development.

This publication, the result of a joint effort by the Regional Dialogue on the Information Society (DIRSI) and the Division of Production, Productivity and Management of ECLAC, was undertaken as part of a research and policy proposal programme on issues relating to the information society. ECLAC has been working on this effort since 2009, with financial support from the European Union through the Inclusive Political Dialogue and Exchange of Experiences Project of the @LIS2 Programme (Alliance for the Information Society phase 2).

DIRSI and ECLAC have made this publication available to governments and citizens of the countries of the region in an effort to provide an overview of the latest broadband developments in Latin America and of the new economic and social challenges and opportunities coming from ever faster technological change.

\author{
Alicia Bárcena \\ Executive Secretary \\ Economic Commission for Latin \\ America and the Caribbean (ECLAC)
}


"Do. Or do not.

There is no try."

Yoda D’Kana

First part

\section{Diagnosis}



Chapter I

\section{The shifting digital paradigm in Latin America}

Roxana Barrantes, Valeria Jordán and Fernando Rojas ${ }^{1}$

Since the release of Fast-tracking the digital revolution: Broadband for Latin America and the Caribbean, governments in the region have accelerated policy design and implementation to expand broadband access for the public and for businesses (Jordán, Galperín and Peres, 2010). Two years is a relatively short time in which to evaluate progress on expanding the infrastructure that is so important for broadband development. And the growing array of promising services based on applications requiring broadband increasingly calls for urgent policy measures. However, because of advances in Internet-based applications and services, policies alone will not expand access. While important, they must be viewed in a broader context within a vision of future that considers the impact of the hyperconnected world on the global economy (World Economic Forum, 2012).

Because of its permeable and convergent effects on the whole of the economy and society, broadband infrastructure must be viewed not only as a connectivity tool but also as a means of pursuing policies designed to enhance social inclusion and economic competitiveness. The timing of

Roxana Barrantes is the chief researcher at the Instituto de Estudios Peruanos in Lima; Valeria Jordán and Fernando Rojas are staff members of the Economic Commission for Latin America and the Caribbean (ECLAC), in Santiago. Fernando Rojas is coordinator of the Regional Broadband Observatory (ORBA). 
policymaking is crucial in view of the shifting digital paradigm, ${ }^{2}$ which has transformed models of production, organization and social interaction faster than any previous technological paradigm.

The commercialization of the Internet in the mid-1990s and its expansion thanks to narrowband technology brought about radical changes, particularly in the field of communication, with e-mail applications and the proliferation of online sites and information in hypertext format based on the World Wide Web. A first generation of policies emerged, focused primarily on expanding Internet and computer access in the countries of Latin America, which in the early 2000s lagged far behind in adoption of these technologies. This gap came to be called the "digital divide".

Between 2005 and 2010, major advances in access technologies led to significant increases in data transmission speeds. Broadband emerged, bringing with it network, device and content convergence and enabling the development of cloud applications. These are more interactive and audio- and video-intensive and can deliver all types of services online, ranging from gaming and entertainment to business and social interest. At the global level, this ushered in a second generation of access policies: those relating to broadband.

Today, technology paths are consolidating as high-speed access networks continue to develop and devices for accessing network services become more widely available. The combination of cloud services and total mobility is the backdrop for this book and this introduction. The first section describes the main ongoing trends, focusing on the explosive quantitative and qualitative proliferation of structured and unstructured data that is a virtually automatic by-product of daily activities (digital exhaust or digital footprint). The second section describes in detail the situation of broadband services and infrastructure in the region. And the third section summarizes the content of the subsequent chapters and the main conclusions of the book.

\section{A. The era of cloud computing}

As Jordán, Galperín and Peres (2010) suggested, the digital paradigm must be examined as a set of general-purpose technologies evolving in an asynchronous manner, with constant feedback innovations creating a virtuous circle which generates a very dynamic technology system. Data digitalization enables for four basic activities: generation and acquisition of data in various formats (text, audio and video), transmission, computing and storage. These functions are closely linked and interdependent and make up the information and communication technologies (ICT) system.

2 See chapter V by Ernesto Flores-Roux, on mobile broadband. 
The increase in information generation and collection, especially in audio and video format, is exerting pressure on the three other activities, which have different response times. These path asymmetries are at the same time obstacles to the full use of each component in isolation and incentives for the lagging paths to catch up with the most advanced one. For example, throughout most of the 1990s computing capacity was far ahead of transmission and storage capacity. The situation started to reverse in the early 2000s, when broadband drove system development and storage bottlenecks appeared. These are now easing as cloud computing progresses. The end result of this process was an increase in the operating capacity of devices and a reduction in costs, which are high considering the cost per unit of service provided. ${ }^{3}$

The amount of data which individuals and organizations generate, process, consume and store has grown exponentially in recent years. Two forces are driving this trend. The first force is direct information generation by users, facilitated by the proliferation of devices and convergent systems, such as smartphones, tablets and phablets, netbooks, smart TV, social networks and audio and video applications. The second is the information emerging from interactions between individuals and objects, between objects (M2M) and between Internet-connected devices with sensors (the Internet of Things). This information can be mined to customize and target activities such as marketing, advertising and other services connected to social media and social graphing, which compile and use this information on individual behaviour as a basic tool for advanced manufacturing and new business processes such as crowdsourcing.

The amount of digital information accumulated doubles every 20 months, echoing Moore's Law, which states that microprocessor computing capacity doubles every 18 months. According to Gantz and Reinsel (2011), over 1.8 zettabytes (1.8 trillion gigabytes) of information were created and replicated in 2011, having grown more than nine-fold in five years. Each second of high-definition video generates 2,000 times more bytes than are needed to store one page of text. Businesses generate trillions of bytes of transactional information from their clients, suppliers and other operations. For example, according to McKinsey (2011), in 2011Walmart's data warehouses had a capacity of over 2.5 petabytes (about half the letters delivered by the United States Postal Service in 2010).

This mass of information is not only coming directly from users but also from computers and objects, which in 2011 generated more data

3 For example, in 1997 one gigaflop of processing power cost US $\$ 42,000$; by 2011 the cost had fallen to $\$ 1.80$. In 1980, one gigabyte of storage cost about US\$200,000; by 2011 the cost of one terabyte $(1,024$ gigabytes) had fallen to US $\$ 100$. Thus two basic conditions were met for the artifacts spearheading a new technological and productive paradigm: ongoing technical progress combined with plummeting costs. 
than people. According to Cisco (2012), that year almost one quarter (22\%) of IP traffic originated from non-PC digital devices; the figure is expected to increase to $31 \%$ by 2016 . It is estimated that $95 \%$ of the data explosion consists of unstructured information, such as voice and video messages, rather than structured information consisting of words and numbers (The Economist, 2010).

In addition to being one of the driving forces of the digital system, this trend has become especially important in the last five years as it takes the form of big data, which must be the subject of new analytics going beyond the traditional management of relational databases (SQL). Here too, there have been huge cost reductions. In 2011, new technologies such as data deduplication, compression and analysis tools had driven the cost of creating, capturing, managing and storing information down to one sixth of what it was in $2005 .{ }^{4}$ In addition, the increase in the amount of information was not accompanied by an equivalent increase in the capacity to process and store it, creating what is known as "data deluge".

This data explosion is significant in the context of three major trends: the spread of broadband and emergence of high-speed broadband, cloud computing, and big data management and analysis.

The spread of broadband (the technology for dedicated Internet access allowing high-speed data transfer $)^{5}$ is snowballing. It is the outcome of new technologies feeding back (supply factor) to increase transmission speed over a short period of time, and of burgeoning demand fuelled by more advanced applications made possible by higher-speed, lower-cost devices and programmes. The number of Internet users increased from nearly 360 million in 2000 to 2.7 billion 13 years later. In 2013, broadband subscriptions (an option which did not exist in 2000) numbered 2.8 billion.

In the early days of commercial Internet (the 1980s and 1990s), the only access mode was dial-up modem over conventional telephone lines at a maximum speed of $56 \mathrm{kbps}$. With this type of connection, it would have taken about 12 minutes to download one song $(5 \mathrm{MB})$ and over 28 hours to download a low-resolution movie (700 MB). In this context, Internet use was basically limited to exchanging e-mails and text files, as well as web surfing, following the emergence of the World Wide Web in mid-decade.

See [online] http://www.emc.com/leadership/programs/digital-universe.htm.

A broadband connection is generally defined as one with a transmission speed of at least $256 \mathrm{kbps}$. However, in 2011, the Broadband Commission of the International Telecommunication Union (ITU) fine-tuned some of the central concepts of broadband, as a service that is always on (a user does not need to reconnect to a server each time in order to go online) and has a large capacity, able to carry a large amount of data per second, instead of adopting a set data transmission speed.

http://www.broadbandcommission.org/Reports/Report_2.pdf. See also the second annex to chapter III, by Omar de León. 
In the 2000s, the development of cable modem allowed broadband connectivity at theoretical speeds ranging from $256 \mathrm{kbps}$ to $20 \mathrm{Mbps}$. But high tariffs limited its expansion despite the improved user functionalities associated with better connectivity. It was not until 2005-2007 that broadband came into widespread use, with fixed (generally, wired) and then mobile technologies allowing theoretical transmission speeds of over 100 Mbps.

It was against this backdrop that the concept of cloud computing emerged over the last five years as a way to combine distributed computing with access to data centres over a network. This made it possible to expand utility computing and to access advanced converged applications and services delivered in real time by streaming (ITU, 2009).

Cloud computing is a way of providing convenient, demand-based access over a network to a shared set of configurable computing resources (for example, networks, servers, storage, applications and services) which can be provided and released rapidly with minimal management effort or interaction with a service provider. As noted by René Bustillo in chapter $X$ hereof, this model has five main features: on-demand self-service, rapid network access, resource pooling, elasticity and measured service. It provides three types of service: Software as a Service (SaaS), Platform as a Service (PaaS) and Infrastructure as a Service (IaaS). These may be private, community, public or hybrid. ${ }^{6}$

Cloud computing is forecast to grow by $18 \%$ a year between 2010 and 2016, while the information technology market is expected to grow no more than $4 \%$. However, by the end of this period, public cloud services will account for only $5 \%$ of all services connected with these technologies (Gartner, 2012). By 2014, it is expected that cloud services in the United States will be dominated by SaaS (62\% of total revenue of almost 12 billion dollars), followed by IaaS (34\%) and PaaS (only 4\%) according to the March 2011 issue of Telecom Intelligence Series. The importance of SaaS led the technical report Above the Clouds: A Berkeley View of Cloud Computing to say that "cloud computing" refers both to applications delivered as services over the Internet and to hardware and software systems at data centres providing those services (Armbrust and others, 2009).

Migration to cloud computing occurs for many reasons -usually because it costs less than operating a proprietary computing infrastructure. In addition, it is easier to meet demand peaks because of the greater flexibility allowed by the conversion of fixed costs (equipment) into variable costs (lease of service based on use), economies of scale and

The essential facilitating technologies are rapid wide area networks (WANs), low-cost servers and virtualization for high-performance commodity hardware. 
of use, and lower costs of entering new markets with consequent positive effects on the creation of businesses, particularly small ones, job creation and competency building. ${ }^{7}$

Evaluating the benefits of cloud computing is a complex proposition because it can impact different sectors of the economy in different ways. The main beneficiaries of the growing adoption of cloud computing are, in addition to the businesses implementing it, the providers of storage, virtualization, networked services and security.

Like any paradigm shift, cloud computing poses problems and challenges when first implemented in ICT environments which were used to keeping "everything under control". Many potential users report that concerns about portability (avoiding vendor lock-in) and data security and privacy make them reluctant to use cloud services for sensitive data. There is widespread frustration among market participants regarding the regulatory framework, especially in respect to data privacy and support system reliability, such as data centre power supply (Telecom, 2012).

Big data analytics for decision-making concerns data sets which exceed the capacity of typical database software tools to capture, store, manage and analyze information. ${ }^{8}$ It is a response to the exploding quantity (speed and frequency) and diversity of digital data generated in real time because of the growing importance of technology in daily activities. Often these data are semi-structured or unstructured, such as data obtained from voice communications or images. ${ }^{9}$ In this universe, continuous data stream mining, using tools to extract data and process them in real time (in other words, in time to change decisions before they become irreversible), plays a crucial role, as does the combination of rapid data streaming with slower access to historical data warehouses.

Of course, the main use of the analytics is to generate information and knowledge based on complete information in real time. Dealing with this new era and its abundance of data provides an opportunity to create

See chapter VI, by Andrea Colciago and Federico Etro.

8 Technically, big data analytics refers to tools and methodologies for converting huge volumes of raw data into "data about data" for analytical purposes. It combines algorithms (to detect patterns, trends and correlations with different time horizons) with advanced visualization techniques. It often requires high-performance computing systems -in other words, systems operating at more than one teraflop $\left(10^{12}\right)$, with parallel processing in order to perform advanced applications (particularly applications for transaction processing and data warehousing) efficiently, reliably and rapidly.

9 The data in question come, for example, from purchases and transactions (including credit card information), corporate operations, information retrieval (querying, tracking, history), social networks (identity, friendships), personal interests (tastes, favourites, links), location, physical sensors (GPS, traffic patterns, Internet of Things) and content (SMS, voice calls, e-mails) - in other words, information generated by traditional sources, particularly businesses and individuals, in their daily activities. 
value through innovation and increased efficiency and competitiveness, to anticipate and learn about behaviour and to increase the consumer surplus and individual and collective well-being. For example, estimates put the revenue generated by business data analysis in 2010 upwards of US\$ 100 billion, growing at an annual rate of $10 \%$.

Big data analytics creates value mainly by enabling greater market and population segmentation in order to target supply and products. It also allows greater innovation in business models, products and services, which improves existing goods, facilitates development of new products (combining mass production with customization) and new business and government service models. In general, in addition to enhancing transparency and efficiency because data are shared, it yields a better and more timely analysis of the performance of organizations of all kinds and makes it possible to adjust structures and behaviours in real time.

In the area of economic and social development, as suggested by the United Nations Global Pulse initiative, big data analytics turns imperfect, unstructured and complex data on the well-being of people into actionable information which narrows time and information gaps for public policy decision-making, providing a timely response to specific situations and for rapid feedback on the effectiveness of policy actions (Global Pulse, 2012).

Latin America is only just beginning to understand and disseminate this technology path, although it is often used by major financial and retail sales organizations, as well as by public sector agencies dealing with taxation and security. According to McKinsey (2011), the geographical distribution of new data stored in 2010 places the region on the sidelines, with just over 50 petabytes out of a total of about 7,000 petabytes throughout the world, of which 5,500 are stored in the United States and Europe.

Big data analytics is not without problems, particularly because of differences in data retrieval and mining capacity and the lack of incentives for businesses to open their data on a scale similar to what has been done by governments (open government data) and social networks. As in the case of cloud computing, there is also serious concern about privacy and the extent to which data are anonymized..$^{10}$

All these paths (data explosion, cloud computing, big data analytics) are based on and dependent on the deployment and use of high-speed network infrastructure.

10 There are two additional, technical, issues: much of the data from sources like social networks reflect perceptions, intentions or desires and not facts; and the increase in type I statistical error and the resulting apophenia (seeing patterns where there are none) because in huge volumes of data, connections open up in all directions. 


\section{B. Broadband in the region}

If the opportunities described in the preceding section are to become a reality for the region, policies must be based on the state of broadband. This section identifies and explains the challenges using a set of indicators shown below.

On average, only $40 \%$ of the total population of Latin America uses the Internet, compared with almost $80 \%$ in the OECD countries as a whole. ${ }^{11}$ However, the averages mask substantial inequalities, as shown by the data. Countries such as Mexico and Peru, which are important economically, are below average. And no countries in the region even reach the levels of Spain, which is one of the OECD countries lagging farthest behind. Chile and Uruguay, with the highest percentage, barely exceed $50 \%$. In countries such as Nicaragua and Guatemala only $10 \%$ of the population uses the Internet.

Figure I.1

INTERNET USERS PENETRATION IN 2011

(Percentages)

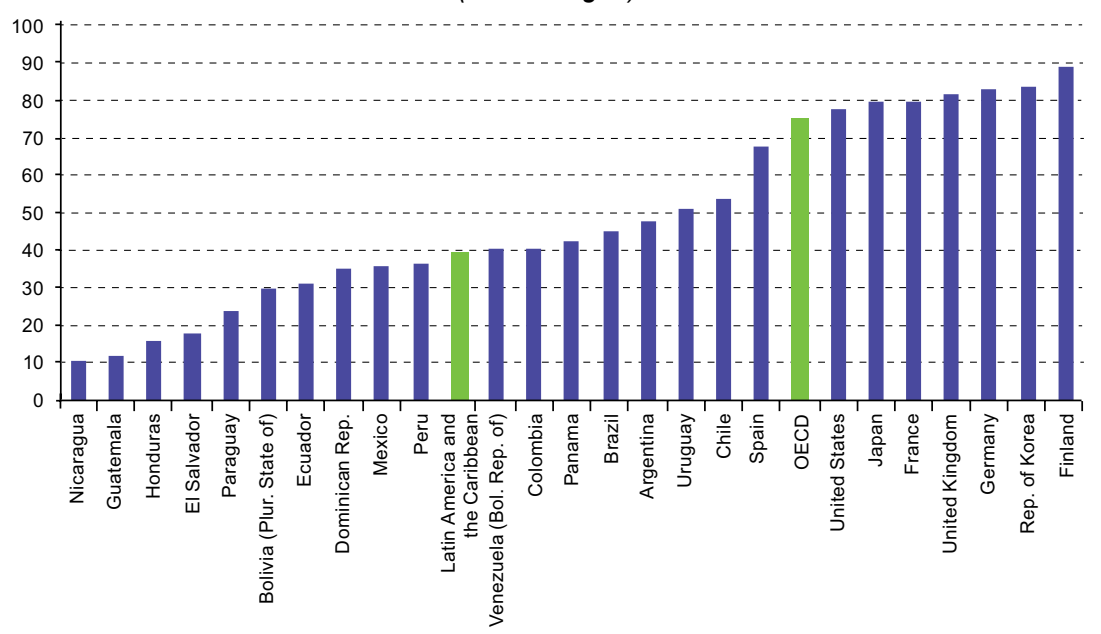

Source: Economic Commission for Latin America and the Caribbean (ECLAC), on the basis of International Telecommunication Union (ITU), World Telecommunications Indicators Database, 2012.

Note: The data for OECD do not include Chile or Mexico.

The number of users is clearly related to broadband connectivity, and this may, in turn, depend on whether the connection is fixed or mobile. 11 In order to avoid duplication, in this chapter the data for OECD do not include Chile
or Mexico. 
Figure I.2 shows the importance of mobile connections with respect to fixed connections. In OECD countries there are, on average, almost twice as many mobile connections as fixed ones. But in Latin America and the Caribbean there are only slightly more mobile ones, although a number of countries still have mostly fixed connections. There could be an inverse correlation between Internet usage penetration and mobile broadband dissemination. In six of the seven countries in the region with lower penetration rates (Ecuador, El Salvador, Guatemala, Honduras, Nicaragua, Paraguay and the Plurinational State of Bolivia) mobile broadband is more widespread than fixed broadband. This could be due to the insufficient deployment of wired networks or to the cost of the various types of connection, as will be seen later when examining service affordability.

Figure 1.2

FIXED AND MOBILE BROADBAND PENETRATION IN 2011

(Percentages)

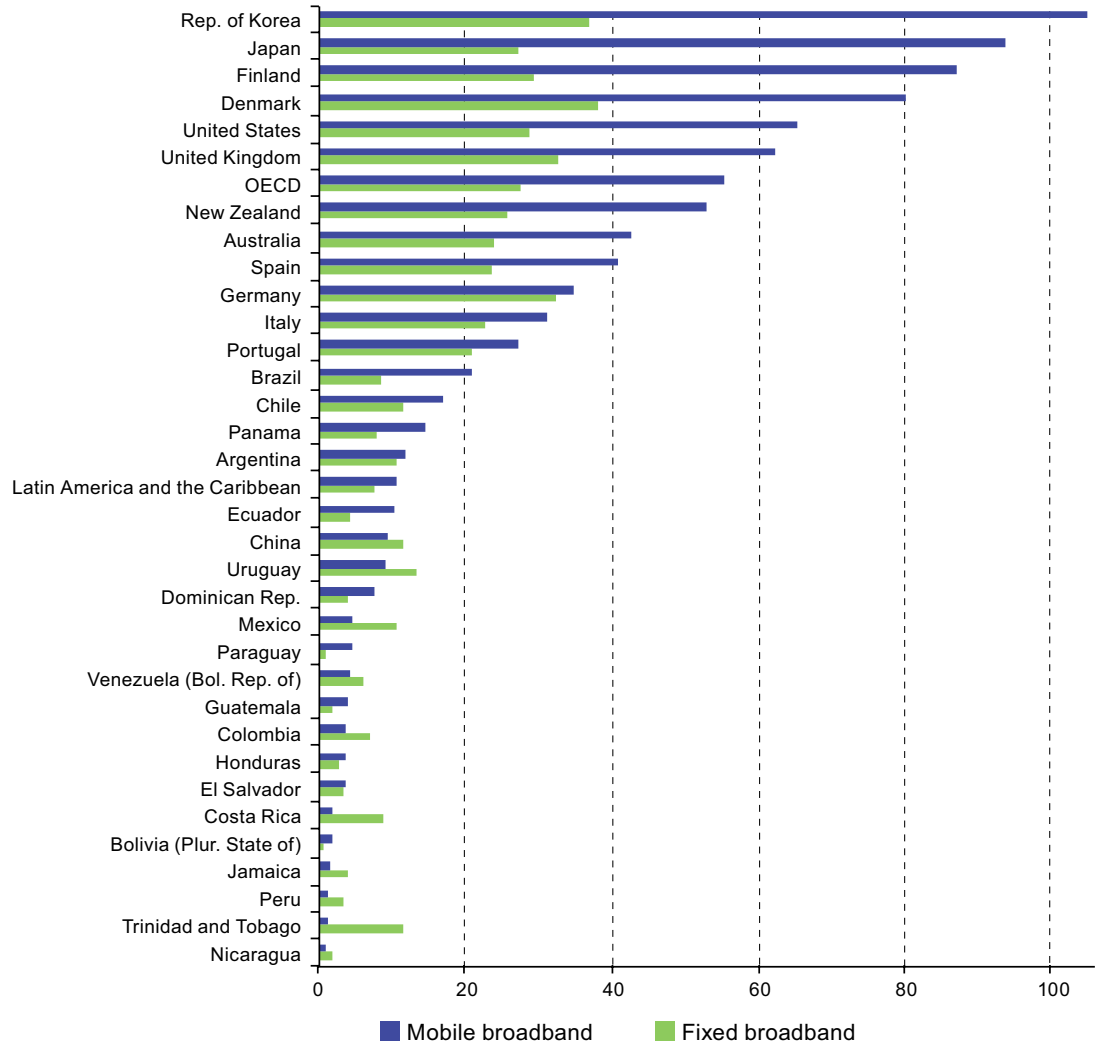

Source: Economic Commission for Latin America and the Caribbean (ECLAC), on the basis of International Telecommunication Union (ITU), World Telecommunications Indicators Database, 2012.

Note: The data for OECD do not include Chile or Mexico. 
The fixed and mobile broadband penetration rates for 2011 were reached from different starting points (2006) and at different speeds in OECD countries and in the region, as shown in figure I.3. During the five-year period from 2006, mobile broadband penetration in OECD grew exponentially and caught up with fixed broadband penetration in the space of two years. In Latin America and the Caribbean the process was slower; mobile connections took four years to catch up with fixed connections.

Figure I.3

FIXED AND MOBILE BROADBAND PENETRATION IN LATIN AMERICA AND THE CARIBBEAN AND IN OECD, 2006-2011

(Percentages)

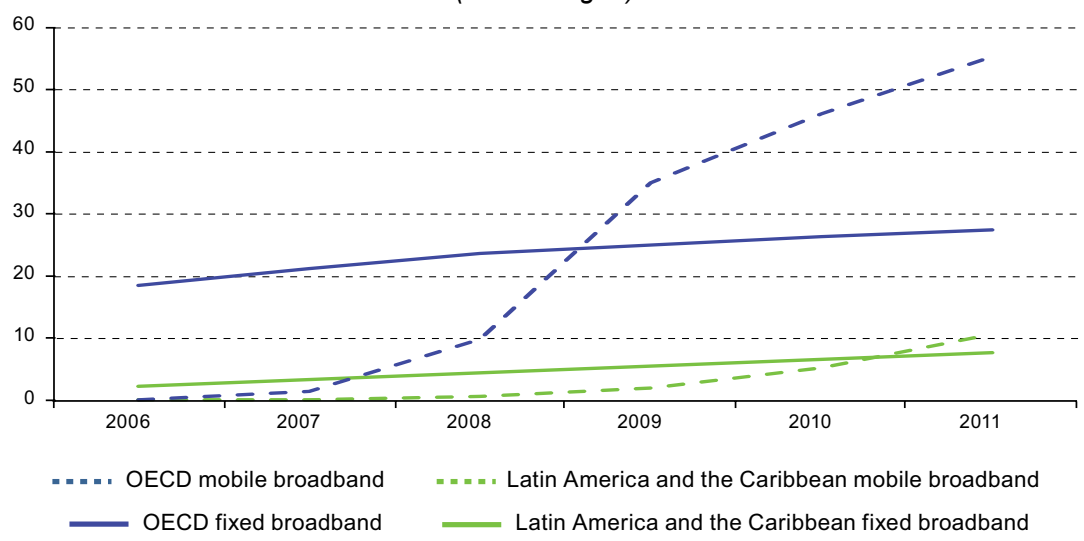

Source: Economic Commission for Latin America and the Caribbean (ECLAC), on the basis of International Telecommunication Union (UIT), World Telecommunications Indicators Database, 2012.

Note: The data for OECD do not include Chile or Mexico.

In addition to considering these connectivity indicators, it is important to identify the type of network available - second generation (2G), with limited access to data, or third generation (3G), allowing more high speeds - and coverage, expressed as a percentage of the population with potential access to a mobile network. Figure I.4 shows the major differences in 3G coverage in five selected countries in the region (Argentina, Brazil, Colombia, Mexico and Peru) in 2010. While almost all the population in those countries has $2 \mathrm{G}$ network coverage, Mexico and Colombia lag significantly behind in investing in $3 \mathrm{G}$ networks, with only $39 \%$ and $52 \%$, respectively, of the population covered by this technology.

National data mask substantial territorial (between the urban and rural population), socioeconomic (between income quintiles) and genderbased inequalities. The figures below clearly show these inequalities within countries, using household connection rates as the unit of analysis. 
Figure 1.4

2G AND 3G COVERAGE OF THE POPULATION IN 2010 (Percentages)

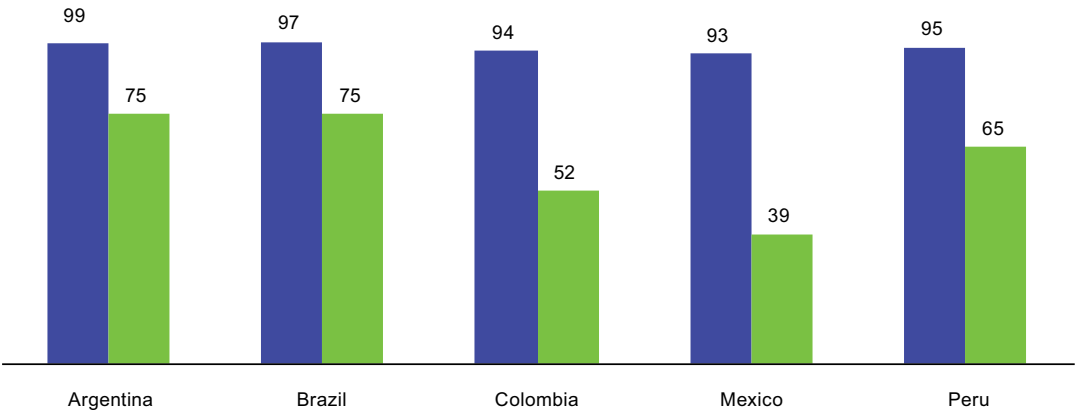

$2 G \quad 3 G$

Source: Latin American Mobile Observatory (GSMA), 2011.

At the territorial level, where disaggregated data are available, households in rural areas of the countries of the region clearly lag behind with regard to Internet access. The exception are Uruguay and Costa Rica, where over $10 \%$ of rural households have access, compared with an urban access rate of $31 \%$ and $35.6 \%$, respectively. In none of the other countries for which data are available does rural access even reach 7\% (see figure I.5).

Figure 1.5

HOUSEHOLDS WITH INTERNET ACCESS IN URBAN AREAS, RURAL AREAS AND NATIONALLY

(Percentages)

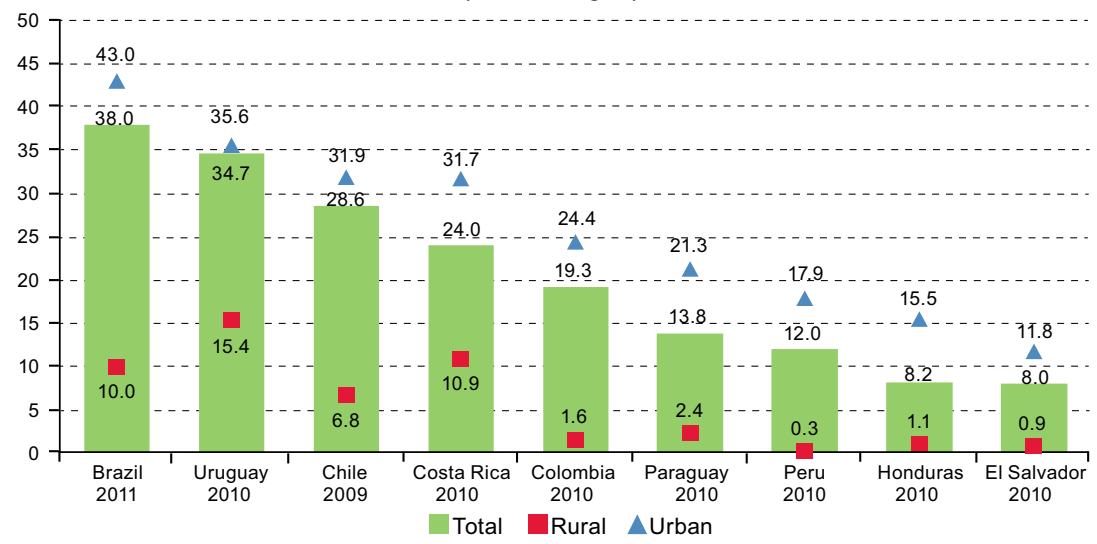

Source: Economic Commission for Latin America and the Caribbean (ECLAC), Observatory for the Information Society in Latin America and the Caribbean (OSILAC), on the basis of information from household surveys conducted by the national statistical institutes. Most recent available year. 
As regards the socioeconomic dimension, dividing the population into income quintiles reveals even more significant inequalities in access (see figure I.6). In Chile, the penetration rate for quintile $\mathrm{V}$ is almost $70 \%$; for quintile I it is below $10 \%$. In the country with the lowest penetration rate (El Salvador), quintile V is below $30 \%$, quintile IV is below $10 \%$, and there is almost no penetration in quintile I. These inequalities reflect the fact that, in several countries of the region (for example, Ecuador and Peru), the main point of access are telecenters, where connection speeds tend to be slower.

Figure I.6

HOUSEHOLDS WITH INTERNET ACCESS, BY INCOME QUINTILE

(Percentages)



Source: Economic Commission for Latin America and the Caribbean (ECLAC), Observatory for the Information Society in Latin America and the Caribbean (OSILAC), on the basis of information from household surveys conducted by the national statistical institutes. Most recent year available. Note: Households with Internet access as a percentage of total households in each quintile. 
Lastly, data on household Internet access according to whether the head of household is a man or a woman reveal clear inequalities (see figure I.7). Chile has the widest gender gap: households headed by men have a penetration rate of over $30 \%$; the rate for those headed by women is below $25 \%$. At the other extreme, the gap is very small or non-existent in countries such as El Salvador and Honduras, where total penetration is extremely low.

Figure 1.7

HOUSEHOLDS WITH INTERNET ACCESS, BY GENDER OF THE HEAD OF HOUSEHOLD

(Percentages)

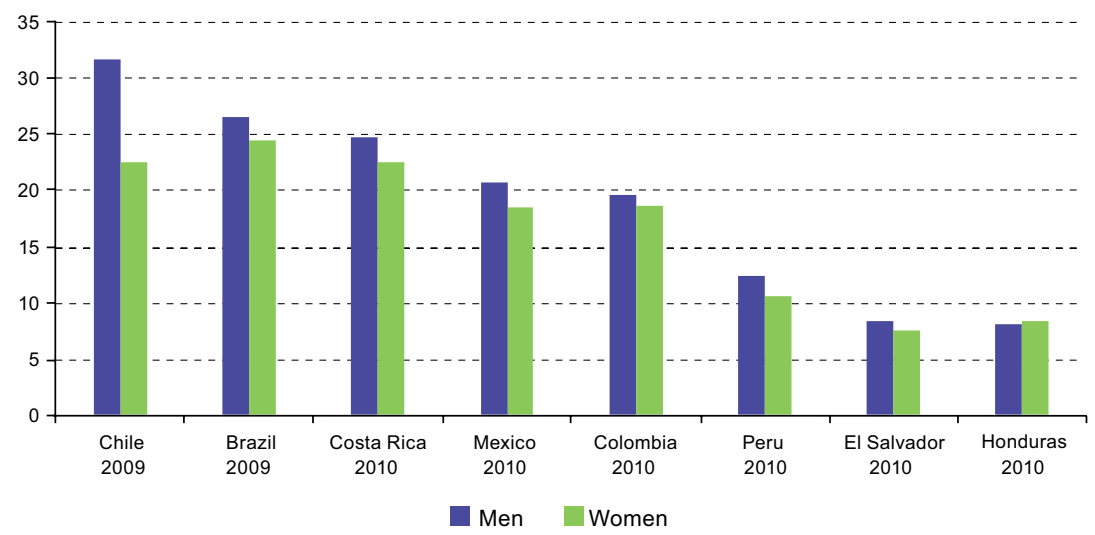

Source: Economic Commission for Latin America and the Caribbean (ECLAC), Observatory for the Information Society in Latin America and the Caribbean (OSILAC), on the basis of information from household surveys conducted by the national statistical institutes. Most recent year available.

Note: Households with Internet access as a percentage of total households, by gender of the head of household.

These gaps, particularly the socioeconomic gap, reflect an affordability problem. Internet and broadband connections are very expensive with relation to household income levels, or they require consumption of additional goods such as computers or cell phones, which are also costly. Figure I.8 shows an indicator expressing tariffs for $1 \mathrm{Mbps}$ fixed broadband as a percentage of per capita GDP, which is a measurement of personal income. In the more advanced countries, such as the United Kingdom, Japan, France, Spain, Italy and Portugal, this figure is lower than $0.20 \%$. In the highest-ranked countries of the region, such as Uruguay, Panama, Chile, Argentina, Mexico, Brazil and Costa Rica, the figure is between $1 \%$ and $2 \%$; for the lowest-ranked ones it is over $10 \%$ (11\% in Guatemala and $16 \%$ in Nicaragua) and as high as $31 \%$ in the Plurinational State of Bolivia. 
Figure I.8

1MBPS FIXED BROADBAND TARIFFS WITH RELATION

TO PER CAPITA GDP IN 2012

(Percentages)

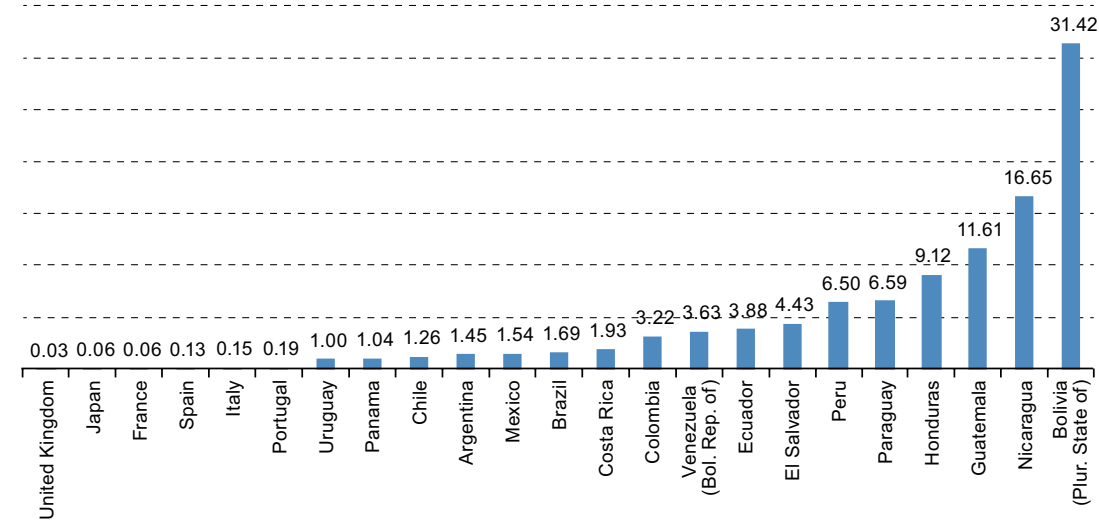

Source: Economic Commission for Latin America and the Caribbean (ECLAC), Regional Broadband Observatory (ORBA), on the basis of tariffs published by operators as at September 2012.

But the large gaps between developed countries and the countries of the region narrow somewhat when the indicator is for mobile broadband. Although no country is below $0.5 \%$, none are above $25 \%$ (see figure I.9). In the region, countries can be divided into those where the cost is equivalent to more than 5\% of per capita GDP (El Salvador, Peru, Paraguay, Ecuador, Guatemala, Honduras, the Plurinational State of Bolivia, Nicaragua) and those where it is more affordable (Uruguay, Panama, the Bolivarian Republic of Venezuela, Chile, Mexico, Argentina, Colombia, Costa Rica and Brazil).

Figure 1.9

MOBILE BROADBAND TARIFFS IN RELATION TO PER CAPITA GDP IN 2012 (Percentages)

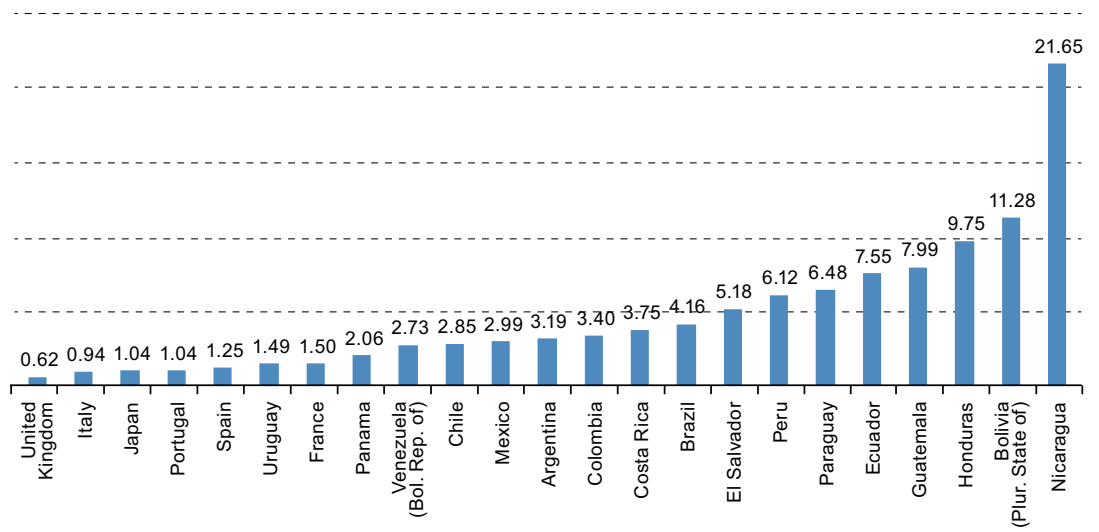

Source: Economic Commission for Latin America and the Caribbean (ECLAC), Regional Broadband Observatory (ORBA), on the basis of tariffs published by operators as at September 2012. 
Estimates of benchmark rates for 1 Mbps connections as a percentage of per capita GDP use a standardized speed offered and mask differences in download or upload speeds actually observed. The data in figure I.10 yield two findings. Firstly, regardless of country and speed, there is a significant difference between download and upload speed. Secondly, speeds in the countries of the region are very slow. Chile ranks best, with average download speeds of $8 \mathrm{Mbps}$ and upload speeds of just over $2 \mathrm{Mbps}$. Ecuador is an exception in that the two speeds are similar.

Figure I.10

BROADBAND CONNECTION SPEEDS IN 2012

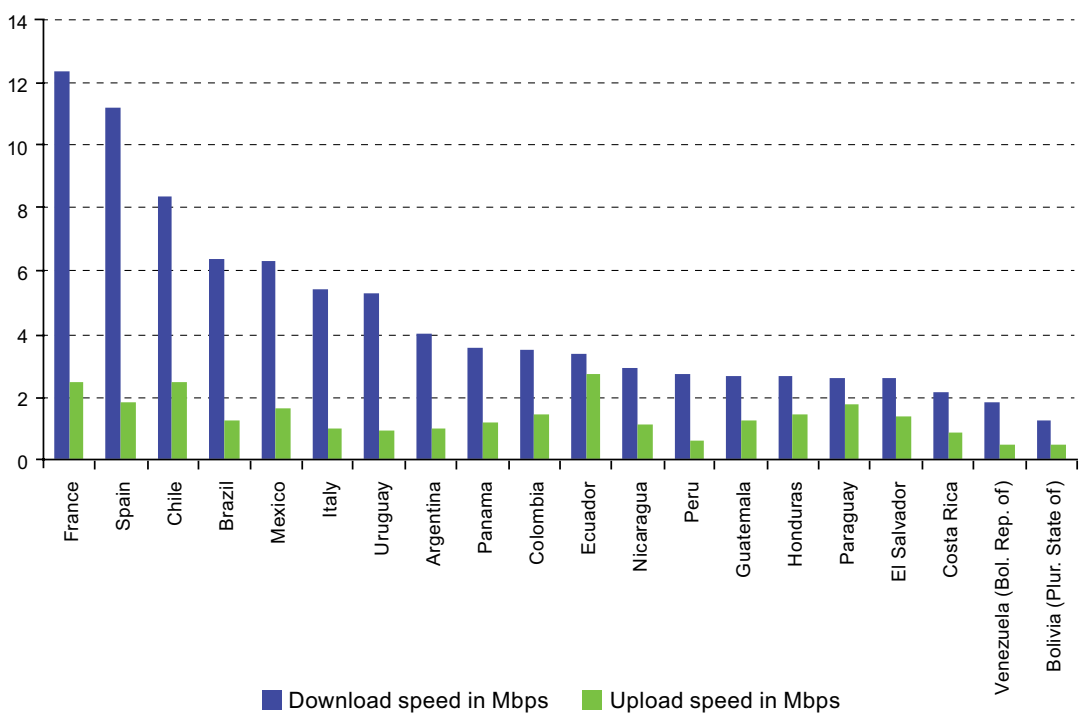

Source: Economic Commission for Latin America and the Caribbean (ECLAC), Regional Broadband Observatory (ORBA), on the basis of Ookla data as at 1 September 2012.

Again, national averages mask differences between countries as regards availability. Figure I.11 shows the distribution of connections by benchmark or offered speed: over $10 \mathrm{Mbps}$, between $4 \mathrm{Mbps}$ and $10 \mathrm{Mbps}$ and under $4 \mathrm{Mbps}$. In several countries of the region, more than half the connections exceed $4 \mathrm{Mbps}$. With the exception of Guatemala, these are all middle-income countries. However, not all middle-income countries are in the group with connections mainly over 4 Mbps. In Costa Rica and Peru, only 30\% of connections are, and it is surprising to see that neither Argentina nor Brazil top 40\%. Indeed, connections delivering over $10 \mathrm{Mbps}$ account for no more than $10 \%$ of the total in any country in the region. 
Figure I.11

PERCENTAGE OF BROADBAND CONNECTIONS, BY SPEED RANGE

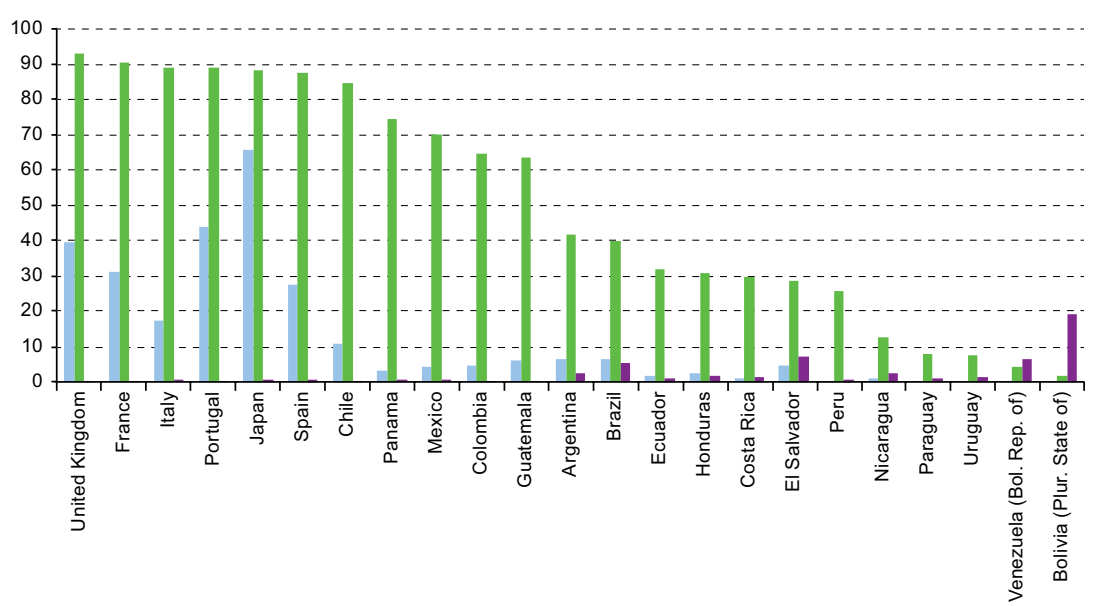

Adoption of high-speed broadband (> $10 \mathrm{Mbps}$ ) Adoption of broadband (>4 Mbps)

Adoption at less than $256 \mathrm{Kbps}$

Source: Economic Commission for Latin America and the Caribbean (ECLAC), Regional Broadband Observatory (ORBA), on the basis of Akamai data, September 2012.

Note: The three ranges in the figure should not add up to $100 \%$ because the percentage for connection speeds over $4 \mathrm{Mbps}$ includes all speeds above that level.

These country indicators already give an idea of the magnitude of the effort required to move to the next phase of economic and social development that comes with broadband. As was seen in the first section, high-speed Internet access and the services it can provide, such as cloud computing and big data analytics, currently have substantial connection requirements. The countries of the region should broaden their approach to include all the variables linked to national and regional connectivity, especially the concentration of international bandwidth in the United States (see figure I.12), ${ }^{12}$ where over $40 \%$ of the cloud servers are located. This is in contrast to the situation in Asia and Africa, which have diversified their international broadband connections (Kende, 2011).

The policy conclusion to be drawn from the figures given in this section is clear: the countries of Latin America must commit to policies, preferably public policies, designed to close internal and external gaps and to own the development opportunities created by the ongoing technological revolution.

12 This concentration affects connection costs, as shown in chapter III by Omar de León. 
Figure I.12

BANDWIDTH CONNECTED TO THE UNITED STATES

(Percentages)

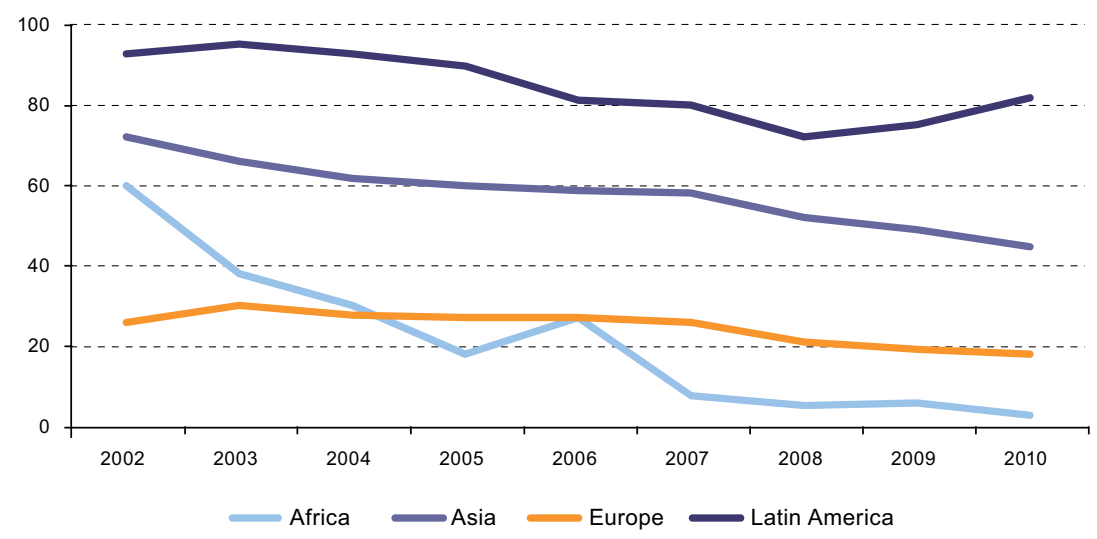

Source: Telegeography, Global Internet Bandwidth, 2011.

\section{Lessons for a new era}

This publication contributes to an ongoing discussion, providing evidence and recommendations on a set of aspects relevant to more efficient policymaking. Public policy must reflect the supply and demand scenario described in the first part hereof.

Chapter II, written by Raúl Katz and Hernán Galperín, shows that the demand gap (households with an available connection which do not sign up for the service) is wide in the region, but it is in developed countries such as Germany, the United States and the United Kingdom, as well. This is true not only for fixed connections but also for mobile ones, which are usually the vehicle for universal access to telecommunications in general and to broadband in particular. Considering the high proportion of shared access in the region, the research shows a demand gap of $63 \%$ for mobile broadband and 50\% for fixed broadband. Why this very high percentage? Explanations can be found in aspects linked to socioeconomic status, mainly education level and age. This again raises the issue of affordability: people still find the service expensive for their income level and do not sign up although supply exists. The public policy implications of these findings are clear. In the first place, there is a need for targeted programmes aimed at closing the interest and skills gaps among specific segments (for example, women heads of household). In the second place, regulatory policies to close the affordability gap are needed.

If policies designed to close the demand gap were to succeed in the very short term (in other words, if all those with available broadband were to 
sign up), the result would be very congested networks. Chapter III, by Omar de León, shows that the supply of high-capacity networks in the region lags behind what is available elsewhere, particularly as regards connections to the main information and knowledge production hubs. It also explains that economies of scale justifying major investments have not yet been achieved, that the costs of international access are significant and high in relation to capacity to pay, that regional connectivity is imperfect, and that content is usually hosted remotely. All of this adversely affects average broadband quality in the region and exacerbates the major differences between and within countries. With poor average quality that varies considerably from country to country, potential applications are very limited and cloud computing is difficult. The challenge for supply expansion policies is to address the factors directly impacting costs by expanding traffic interchange points, promoting web caching, and hosting content on servers located in countries of the region.

What use will all this be? The second part of the book deals with economic impact. As shown in chapter IV, written by Raúl Katz, in addition to the direct effect of investment in infrastructure when networks are built, the economic impacts of broadband expansion are based on business productivity increases that create a producer surplus. But communication and consumer access to information and services expand as well and create a consumer surplus. Econometric studies for Latin America show that a 10-percentage-point rise in broadband penetration increases GDP by $0.158 \%$. Using a digitization index as an independent variable instead of just measuring penetration, a 10-point rise in the indicator increases GDP by $0.81 \%$ and decreases unemployment by $0.82 \%$. This index is interesting in that it combines some dimensions studied in connection with the demand gap while including broadband quality and the human capital needed for ICT use, among other variables.

These effects do not distinguish between the type of broadband system (wired or wireless). If the focus is only on how much is lost owing to lagging deployment of wireless networks for data or broadband in general, Ernesto Flores-Roux estimates in chapter V that there would be a loss of approximately $1 \%$ of GDP in the region (not including Costa Rica). He also calculates that each inhabitant of the region would lose US\$ 27 (2012 PPP) for every three months' lag in adopting more powerful networks.

Broadband as a platform for cloud services creates enterprise opportunities by reducing the cost of fixed capital investment in information technologies for small and medium-sized start-ups. In the case studies for Argentina and Brazil (chapter VI), Andrea Colciago and Federico Etro see promise in the adoption of cloud services because, in addition to reducing start-up costs, they make the cost function flexible 
(converting fixed costs into variable costs), bring more new players into the market and increase competition. As a result, new businesses are opened and jobs are created. The estimates in the model used by the authors show that about 900,000 jobs could be created in Brazil and 100,000 in Argentina if cloud services were widely adopted by the business sector.

Once the impact is known and verified, the next step is to look at the public policy scenario. Because of the large-scale investment required and in the absence of installed and ubiquitous high-speed networks, the public sector is becoming increasingly involved as a driver of investment, as shown by the review of current policies in the region set out in chapter VII written by Hernán Galperín, Judith Mariscal and María Fernanda Viecens. The State could resume providing telecommunication infrastructure, either in response to declining confidence in the full privatization model (which did not succeed in providing universal services) or because the recent economic upswing, mainly in South America, has made sizeable resources available. An analysis of the broadband development policies of six countries (Argentina, Brazil, Chile, Colombia, Mexico and Peru) shows strong government commitment reflected in an increase in resources devoted to the deployment of backbone networks. Thus the pendulum is swinging back and creating an important challenge for the private sector, which has so far not fully met the need for investments to expand service so that it can operate in information societies.

As far as broadband development policies pursued by developed countries are concerned, the experience of the Republic of Korea analyzed by Daewon Choi in chapter VIII is noteworthy because of its comprehensive nature and because of the joint implementation effort by various areas of government with the private sector, which would explain its success. Any attempt to emulate the policies pursued by the Republic of Korea as regards scope, targeting, sustainability and commitment of public resources must acknowledge that they were part of an industrial policy effort and therefore directly involved large industrial firms and not only human capacity-building and infrastructure expansion programmes. The experience of the Republic of Korea clearly shows the paradigm shift in broadband development policies: conceived as a pillar of national production development, they moved higher up the priority agenda and became more holistic in scope.

Networks, which are the basis of the transmission infrastructure, must be neutral in order for users, whether consumers or producers, to effectively benefit from their full potential and take advantage of the paradigm shift towards cloud computing services, as shown in chapter IX by René Bustillo. Among the possible ways to understand network neutrality, the two most important ideas are that operators should not 
select the content to which users can have access or block users from visiting any Internet site. Since the region has not made much progress in regulating neutrality, policymakers need to put the item on their agendas and follow best practices. This is particularly important at a time when cloud computing is expanding, as the same author shows in chapter $\mathrm{X}$.

Policies are already in place, but the changing situation is outpacing policymaking. Cloud-based services are advancing, particularly those provided by the online content industry, known as over-the-top (OTT) applications, services and content, such as Skype, WhatsApp and Netflix. Chapter XI, by Juan José Ganuza and María Fernanda Viecens, shows that operators in the region providing the infrastructure for such content are not profiting from this growing demand. On the contrary, they are facing major investment needs to expand bandwidth with no expectation of private profitability, precisely because the revenue is going to the players in the content industry. As a result, operators are devising strategies to keep themselves in the market. Among them are bundling (which could be challenged by regulators) and development of proprietary OTT services, requiring an important shift in operators' strategic planning. The big question mark is still the speeds offered by operators and the public and regulatory policy options for increasing them.

The lessons from the different parts of this book (diagnosis, economic impact, policies and paradigm trends) confirm that the region must redouble its efforts to insert itself competitively in a world where technology is changing at a dizzying pace. Simply maintaining current investment and expansion commitments provides no assurance that the region will have the basic infrastructure and services needed to operate in the information society. Once again, fast-tracking the digital revolution was and is the way to narrow gaps and take advantage of the ongoing technological revolution. As the title of this book says: DO. OR DO NOT. THERE IS NO TRY. 


\section{Bibliography}

Armbrust, M. and others (2009), Above the Clouds: A Berkeley View of Cloud Computing, Electrical Engineering and Computer Sciences, University of California at Berkeley, 10 February.

Cisco (2012), Cisco Visual Networking Index: Forecast and Methodology, 2011-2016, May. Gantz, J. and D. Reinsel (2011), "Extracting Value from Chaos", IDC IVIEW, June.

Gartner (2012), IT Spending Forecast 2Q12 Update y Public Cloud Services Forecast 2Q12 Update.

Global Pulse (2012), “Big Data for Development: Challenges and Opportunities", New York, United Nations, May.

ITU (International Telecommunication Union) (2009), “Distributed Computing: Utilities, Grids \& Clouds", ITU-T Technology Watch Report, No. 9.

Jordán, V., H. Galperín and W. Peres (coordinators) (2010), Fast-tracking the Digital Revolution: Broadband for Latin America and the Caribbean (LC/R.2167), Santiago, Chile, Economic Commission for Latin America and the Caribbean (ECLAC)/ Regional Dialogue on the Information Society (DIRSI).

Kende, M. (2011), Overview of recent changes in the IP interconnection ecosystem, Analysis Mason, 23 January.

McKinsey (2011), Big data: the next frontier for innovation, competition, and productivity, McKinsey Global Institute, June.

ORBA (Regional Broadband Observatory) (2012), Status of broadband in Latin America and the Caribbean, 2012, Report of the Regional Broadband Observatory (ORBA), Santiago, Chile, Economic Commission for Latin America and the Caribbean (ECLAC).

Telecom (2012), Cloud computing in Latin America - Towards a virtualized reality, Telecom, Intelligence Series, September.

The Economist (2010), "Data, data everywhere", 23 August.

World Economic Forum (2012), The Global Information Technology Report 212. Living in a Hyperconnected World, Geneva, INSEAD. 

Chapter II

\title{
The demand gap: drivers and public policies
}

\author{
Raúl L. Katz and Hernán Galperin ${ }^{1}$
}

The debate about the digital divide in Internet use and broadband has largely revolved around the statistics on households that own a computer and have adopted broadband (service penetration, in other words). Thus, political discussion and public opinion have turned on the need to increase take-up by expanding telecommunication network coverage. The underlying premise is that the digital divide would be narrowed if the issues holding up infrastructure investment were resolved. Without denying that there is some causal relationship between investment and the divide, it is important to stress that one of the fundamental variables accounting for the digital divide lies on the demand side rather than the supply side. The purpose of this chapter is to analyse the divide from this perspective, both in industrialized countries and in Latin America.

First, quantitative information is presented to show that there is a demand gap, even in industrialized countries. On this basis, the chapter reviews the research carried out in the developed world, using statistics from different countries to identify common causal variables. It then examines the situation in Latin America, concentrating first on quantifying the demand gap for countries on which information is available. Following

Raúl L. Katz is an Adjunct Professor with the Division of Finance and Economics at Columbia Business School and Director of Business Strategy Research at the Columbia Institute for Tele-Information. Hernán Galperín is an Associate Professor at the University of San Andrés in Buenos Aires. 
the same process as for developed countries, it presents the results of research done in Latin America with the aim of explaining the nature of the demand gap. This diagnosis provides the basis for public policy recommendations to address some of the barriers to adoption.

\section{A. Measuring the digital divide from the demand side}

The digital demand gap is defined as the number or percentage of households or individuals who could subscribe to broadband but do not. Such statistics are not easy to calculate because technology coverage (i.e., households and individuals with access to broadband) is not usually measured by public-sector entities or regulatory agencies. A large number of national broadband strategies have been developed in recent years, however, and in-depth analysis of the size of the service coverage shortfall has been required for diagnostic purposes.

In the United States, according to the Federal Communications Commission (FCC), $96 \%$ of households had access to broadband via a cable modem in early 2008 and $82 \%$ via DSL. Current penetration statistics indicate that $64 \%$ of United States households have purchased the service. Thus, $32 \%$ of households could access broadband but do not. This gap naturally varies by state (see figure II.1).

Figure II.1

UNITED STATES: STATES WITH THE LOWEST BROADBAND

PENETRATION RATES, 2010

(Percentages)

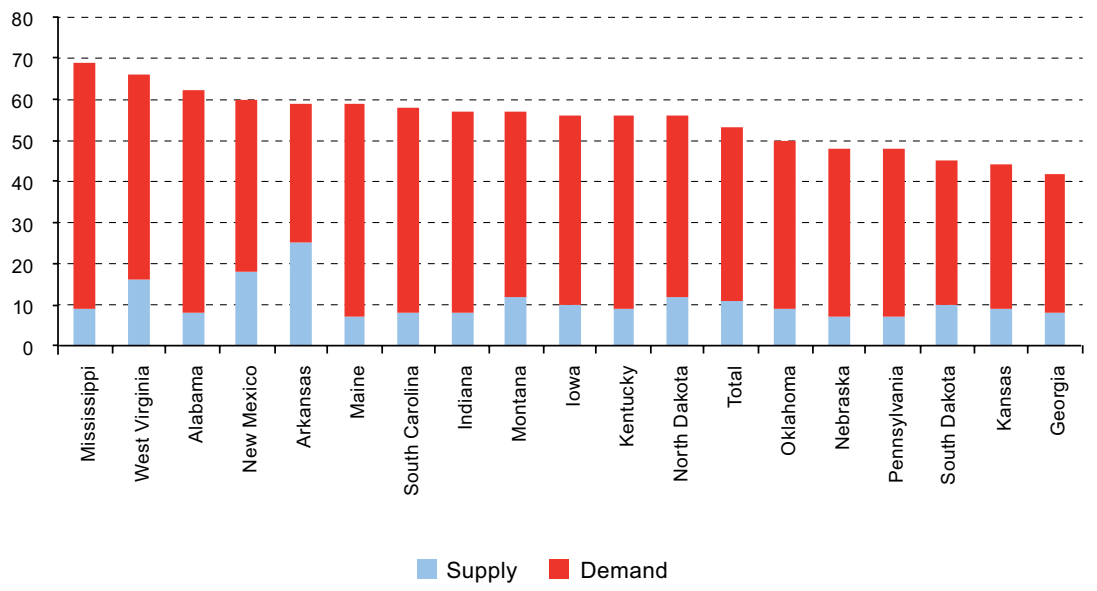

Source: Prepared by the authors on the basis of data from the Federal Communications Commission (FCC), HSPD1207, table 14, and the United States Census Bureau. 
As can be seen, the demand gap in a state like Mississippi is $60 \%$ while the supply gap (households not covered by the service) is just $9 \%$. In Georgia, where the service adoption rate is higher, the supply gap is $8 \%$ of households while the demand gap is $34 \%$.

In Germany, the National Broadband Strategy published in February 2009 reported that $98 \%$ of households (39.7 million) were in a position to access broadband. Of these, 36.7 million were covered by DSL platforms, 22 million had cable television (meaning they could access broadband via cable modem) and 730,000 could access the Internet using wireless platforms such as satellite. Despite this coverage, just $58 \%$ had taken up the service. Information for other developed countries confirms that there is a gap of this kind everywhere (see table II.1).

Table II. 1

DEVELOPED COUNTRIES: SIZE OF THE FIXED BROADBAND DEMAND GAP, 2011 (Percentages)

\begin{tabular}{lccc}
\hline Country & $\begin{array}{c}\text { Households } \\
\text { covered }\end{array}$ & $\begin{array}{c}\text { Households } \\
\text { connected }\end{array}$ & Demand gap \\
\hline Germany & 98 & 58 & 40 \\
Australia & 89 & 69 & 20 \\
Republic of Korea & 100 & 93 & 7 \\
Denmark & 96 & 76 & 20 \\
Spain & 93 & 61 & 32 \\
United States & 96 & 61 & 35 \\
France & 100 & 77 & 23 \\
Israel & 100 & 83 & 17 \\
Italy & 95 & 55 & 40 \\
United Kingdom & 100 & 68 & 32 \\
Sweden & 100 & 89 & 11 \\
\hline
\end{tabular}

Source: Prepared by the authors on the basis of data from the International Telecommunication Union (ITU), the European Union (EU), the Federal Communications Commission (FCC), the German Federal Ministry of Economy and Technology (BMWi), the Organisation for Economic Cooperation and Development (OECD).

In some developed countries (especially Germany, Italy, Spain, the United Kingdom and the United States), a large proportion of people who do not access the Internet via fixed broadband in the home are not prevented from doing so by lack of service availability but refrain for other reasons. So what are the factors accounting for this?

The demand gap issue becomes more complex when mobile broadband is viewed as a platform capable of providing Internet access. 
First of all, what is mobile broadband? The term can be applied to service subscriptions that include the acquisition of a modem enabling a computer to connect to the Internet (these are called USB modems, dongles or aircards). It also applies to technologies that allow Internet access via mobile phones. In this case, smartphones are suitable terminals because their screen formats and interface systems provide an adequate platform for browsing the web, answering e-mails and accessing platforms such as Facebook, Google and YouTube. From the point of view of network technology, third- and fourth-generation ( $3 G$ and $4 \mathrm{G}$ ) network coverage provides the speed necessary for efficient access.

The second issue where mobile broadband is concerned is how to measure the demand gap. Since in this case the connection is provided to individual users (laptop or smartphone owners), the parameters used to measure the demand gap should be different to those used for fixed broadband: the population coverage of $3 \mathrm{G}$ and $4 \mathrm{G}$ networks and the percentage of subscribers who have a smartphone or mobile modem. This assumes that most smartphones operate on $3 \mathrm{G}$ or $4 \mathrm{G}$ networks, which is not necessarily the case, although the number of subscribers using terminals of this type on 2.5G networks is falling rapidly. Table II.2 presents estimates of the mobile broadband demand gap for some developed countries.

Table II.2

DEVELOPED COUNTRIES: MOBILE BROADBAND DEMAND GAP, 2011

\begin{tabular}{lccc}
\hline Country & $\begin{array}{c}\text { Population } \\
\text { covered (3G) }\end{array}$ & $\begin{array}{c}\text { Mobile broadband } \\
\text { penetration }\end{array}$ & $\begin{array}{c}\text { Mobile } \\
\text { demand gap }\end{array}$ \\
\hline Germany & 86.0 & 34.7 & 51.2 \\
Australia & 97.0 & 89.1 & 7.9 \\
Republic of Korea & 99.0 & 97.1 & 1.9 \\
Denmark & 97.0 & 57.5 & 39.5 \\
Spain & 90.6 & 36.7 & 53.9 \\
United States & 98.5 & 71.9 & 26.6 \\
France & 98.2 & 32.9 & 65.3 \\
Israel & 99.0 & 54.4 & 44.6 \\
Italy & 91.9 & 48.2 & 43.7 \\
United Kingdom & 95.0 & 42.6 & 52.4 \\
Sweden & 99.0 & 85.1 & 13.9 \\
\hline
\end{tabular}

Source: Prepared by the authors on the basis of data from Wireless Intelligence and the International Telecommunication Union (ITU).

Note: Population coverage is based on $3 G$ networks on the assumption that Long Term Evolution (LTE) networks will be rolled out in the same areas, at least initially. 
Another dimension to be considered in measuring the demand gap is the degree of substitution or complementarity between fixed and mobile broadband. For example, mobile broadband subscribers often subscribe to fixed broadband too, so that the two technologies complement each other by providing Internet users with an environment of total connectivity. In other cases, and especially in emerging countries, mobile broadband may be a substitute for fixed broadband in three types of situations: (i) no fixed service is available in the user's area, (ii) the quality of the fixed service puts it at a disadvantage to the mobile service (low speeds, for example), or (iii) the user opts to consolidate by acquiring only a mobile service that provides connectivity and mobility. Where substitution has taken place, it is important to include mobile broadband-only subscribers in the total for broadband users before looking at the demand gap. Diagram II.1 illustrates the two types of demand gap.

Diagram II.1

FIXED AND MOBILE BROADBAND SUBSTITUTION AND COMPLEMENTARITY

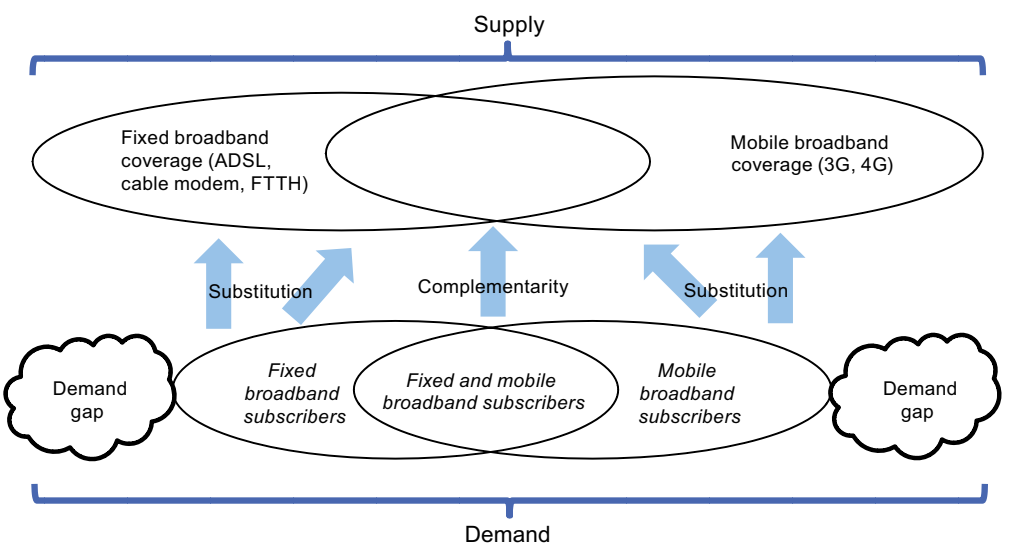

Source: Prepared by the authors.

There are two types of demand gap: users who only have access to a fixed broadband service and do not acquire it (this is fairly unusual, since fixed and mobile broadband tend to be rolled out in the same areas) and those for whom the only option would be mobile broadband but they do not acquire it. Mobile broadband users should therefore not be included in the population that is considered to be part of the demand gap because they are already purchasing an Internet access service that either complements or substitutes fixed broadband (see figure II.2). 
Figure II.2

QUANTIFICATION OF THE FIXED AND MOBILE DEMAND GAP

(Percentages)

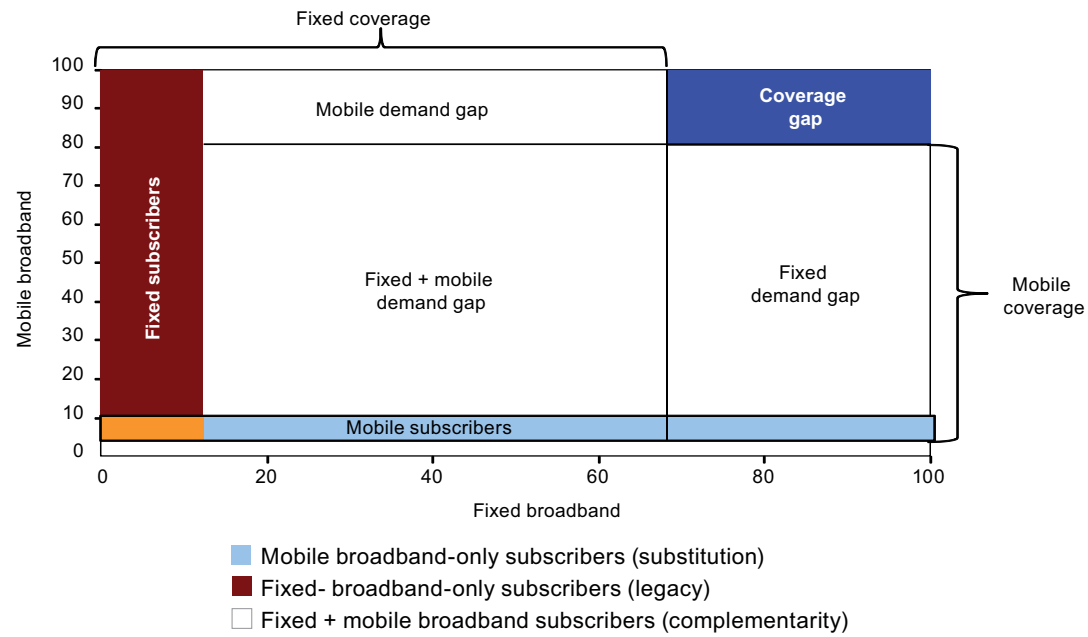

Source: Prepared by the authors. formulas:

Thus, the demand gap should be quantified using the following

Demand gap = broadband coverage (C) - broadband subscriptions (S)

where

$C=$ population covered by fixed and mobile broadband + population covered by fixed broadband only + population covered by mobile broadband only

$S=$ fixed and mobile broadband subscribers (complementarity) + fixed broadband subscribers (legacy) + mobile broadband subscribers (substitution)

Using this formula to calculate the demand gap requires a firm understanding of parameters such as technological complementarity. The current lack of statistics of this kind makes it necessary to analyse the demand gap by technology type.

\section{B. Understanding the demand gap}

There is an extensive literature on the drivers of Internet adoption, particularly for broadband. These studies concur in identifying income, educational attainment and household age structure as the main predictors for adoption of these services (Hauge and Prieger, 2010). A number of studies suggest that other factors are also involved, many of them specific to particular countries or regions. For example, Navarro 
and Sánchez (2011) have shown that, all other things being equal, the likelihood of Internet use drops by $6 \%$ in Latin America if the potential user is a woman. In the United States, studies have shown the importance of factors such as ethnicity and proficiency in English (Ono and Zavodny, 2008; NTIA, 2011). Other factors such as geographical location (rural versus urban), the presence of school-age children and the penetration rate in the individual or household's geographical area (essentially, the network effect) have also been identified in the academic literature as drivers of Internet adoption (Chaudhuri and Flamm, 2005; Vicente and López, 2006; Grazzi and Vergara, 2011).

Identifying the socioeconomic factors behind Internet adoption provides a first approach to the demand gap issue. Nonetheless, an analysis based on econometric studies does not allow a distinction to be drawn between non-adoption due to supply constraints (in rural or lowincome areas, for example) and demand factors. Nor do these studies have much to say about the reasons for non-adoption when there is an adequate supply of services.

Studies based on surveys of people who are not Internet users do permit some progress in this direction. This section reviews the findings of studies in the most developed countries, where there is a substantial literature on the subject. As will be seen, findings regarding the factors that explain non-adoption in different countries are surprisingly consistent. The evidence for Latin America will be analysed in the following section.

To start with the United States, data from the most recent surveys show that $78 \%$ of adults use the Internet "at least occasionally" (Pew Center, 2012). Of the $22 \%$ of the population who are not users, most are individuals over 65 years of age, adults who have not completed secondary education, members of households earning less than US\$30,000 a year and those with limited English proficiency, corroborating the findings of the studies cited above. What are the reasons for non-adoption? The responses of non-users reveal that the main factor is lack of interest or relevance $(42 \%)$, followed by factors related to the affordability of devices and services (22\%) and lack of usage skills (21\%).

Focusing on the adoption of broadband in the home, the most recent data show that $62 \%$ of adults in the United States live in households with broadband service. ${ }^{2}$ However, this percentage drops to $22 \%$ for adults who have not completed secondary education, 30\% among those aged 65 and over and $41 \%$ among those with incomes of less than US\$30,000 per year, replicating the patterns of adoption cited above (Pew Center, 2012).

This figure comes from the Pew Internet Project survey and is for August 2011. Subscription data reported by operators yield essentially similar results: according to the FCC, $64 \%$ of households that have access to broadband subscribe to it (FCC, 2012). 
As table II.3 shows, the main reasons cited by those who do not have broadband at home fall into a pattern similar to those reported by nonusers of the Internet, most notably a lack of interest or relevance $(50 \%)$ and affordability constraints (19\%).

Table II.3

UNITED STATES: REASONS FOR NOT ADOPTING BROADBAND

IN THE HOME, 2009

(Percentages and number of observations)

\begin{tabular}{lcccc}
\hline Reason & $\begin{array}{c}\text { Have narrowband } \\
\text { service in the } \\
\text { home }\end{array}$ & $\begin{array}{c}\text { No } \\
\text { Internet in } \\
\text { the home }\end{array}$ & $\begin{array}{c}\text { Weighted } \\
\text { total }\end{array}$ & $\begin{array}{c}\text { Percentage } \\
\text { of adult } \\
\text { population }\end{array}$ \\
\hline Lack of relevance/interest & 32 & 45 & 50 & 13 \\
$\begin{array}{l}\text { Cost (computer or } \\
\text { connectivity service) }\end{array}$ & 35 & 15 & 19 & 5 \\
Service unavailable & 17 & 16 & 17 & 4 \\
Difficulty of use & 16 & 22 & 13 & 3 \\
Number of observations & 92 & 566 & 658 & \\
\hline
\end{tabular}

Source: J. Horrigan, Home Broadband Adoption 2009, Washington, D.C., Pew Internet and American Life Project, 2009.

A government report on the population that does not have broadband in the home corroborates these findings (NTIA, 2011). The main reason cited by individuals living in households without broadband is a lack of interest in the service $(47 \%)$, followed by reasons related to affordability (24\%) and lack of proper equipment (15\%). If households that have a computer but do not subscribe to the service and households without either a computer or broadband are considered separately, service affordability reasons are more prominent in the first group, while the lack of relevance or interest predominates in the second (see table II.4).

In Spain, the most recent data show that $61 \%$ of households have a broadband connection (ONTSI, 2012). Among unconnected households, the main reasons cited for not accessing the service are lack of interest $(66 \%)$, the cost of equipment or connectivity (42\%) and lack of the skills or knowledge required to use the service (29\%). ${ }^{3}$ Interestingly, as table II.5 shows, the lack of relevance/interest is still a significant determinant even at the lowest income levels, where affordability and usage skills are, as would be expected, the most important factors. These findings confirm the importance of digital literacy initiatives aimed at lower-income sectors of the population.

3 Survey on the Equipment and Use of Information and Communication Technologies in Households 2011 (INE). Percentages exceed 100\% because respondents could select more than one reason. 
Table II.4

UNITED STATES: REASONS FOR NOT ADOPTING BROADBAND BASED

ON THE AVAILABILITY OF A COMPUTER IN THE HOME, 2011

(Percentages and number of observations)

\begin{tabular}{lccc}
\hline Reason & $\begin{array}{c}\text { Households with } \\
\text { a computer }\end{array}$ & $\begin{array}{c}\text { Households without } \\
\text { a computer }\end{array}$ & Weighted total \\
\hline $\begin{array}{l}\text { Lack of relevance/interest } \\
\begin{array}{l}\text { Cost (computer or } \\
\text { connectivity service) }\end{array}\end{array}$ & 28 & 52 & 47 \\
$\begin{array}{l}\text { Lack of suitable equipment } \\
\text { (computer) }\end{array}$ & 87 & 21 & 24 \\
$\begin{array}{l}\text { Other } \\
\begin{array}{l}\text { Number of households } \\
\text { (millions) }\end{array}\end{array}$ & 27 & 17 & 15 \\
\hline
\end{tabular}

Source: National Telecommunications and Information Administration (NTIA), Exploring the Digital Nation, Washington, D.C., 2011.

Table II.5

SPAIN: REASONS FOR NOT ADOPTING BROADBAND, BY INCOME LEVEL, 2011 (Percentages and number of observations)

\begin{tabular}{lccccc}
\hline $\begin{array}{l}\text { Reason/monthly } \\
\text { household income }\end{array}$ & $\begin{array}{c}<1100 \\
\text { euros }\end{array}$ & $\begin{array}{c}1100 \text { to } \\
1800 \\
\text { euros }\end{array}$ & $\begin{array}{c}1800 \text { to } \\
2700 \\
\text { euros }\end{array}$ & $\begin{array}{c}>2700 \\
\text { euros }\end{array}$ & Total \\
\hline $\begin{array}{l}\text { Lack of relevance/ } \\
\text { interest }\end{array}$ & 67 & 65 & 48 & 42 & 66 \\
$\begin{array}{l}\text { Cost (computer or } \\
\text { connectivity service) }\end{array}$ & 52 & 39 & 42 & 16 & 42 \\
$\begin{array}{l}\text { Lack of usage skills } \\
\begin{array}{l}\text { Number of households } \\
\text { (millions) }\end{array}\end{array}$ & 35 & 27 & 18 & 12 & 29 \\
\hline
\end{tabular}

Source: National Institute of Statistics (INE), Survey on the Equipment and Use of Information and Communication Technologies in Households, 2011.

a The difference is due to the remaining respondents (1.4 million) not reporting their income.

In the United Kingdom, the most recent figures show that $80 \%$ of households have an Internet connection, overwhelmingly broadband (76\% of all households) (OFCOM, 2012a). In line with the findings of other studies, those living in households without a connection tend to be older (aged over 65) and on low incomes. The vast majority expressed no intention of subscribing to the service in the next 12 months, suggesting that the demand gap is persistent. Again, the main reason cited is lack of relevance $(66 \%)$, well above cost-related factors $(16 \%)$ and lack of usage skills (4\%). 
In 2010, cost-related factors were cited by $23 \%$ as the main reason for not subscribing to the service, while in 2011 the figure dropped to $16 \%$. This suggests that as access and equipment costs decline, a gap increasingly associated with cultural or educational factors persists. Another significant finding is that $23 \%$ of non-users report that they have asked someone else to perform a task on the Internet (such as sending e-mail or searching for information) on their behalf. This indicates that, regardless of relevance, important barriers associated with usage skills persist (OFCOM, 2012b).

The review of studies on non-adoption of Internet and broadband in the most developed countries reveals results that are essentially consistent from one country to another and yield both a sociodemographic profile of unconnected households and the main reasons for non-adoption of the service. In sociodemographic terms, the results of survey-based studies bear out the evidence from econometric studies: unconnected households tend to be composed of older persons (over 65), low-income individuals and those who have not completed secondary education. In the United States, ethnicity and English proficiency factors (among the population of Spanish-speaking recent immigrants) also come in.

The findings of the different studies also concur on the reasons given for not adopting broadband in the home. Lack of relevance or interest consistently appears as the primary factor in non-adoption. As suggested by OFCOM (2010a), this response may mask reasons related to costs or a lack of usage skills, factors that consistently rank second and third in order of importance. However, the trend seems to indicate a decline in the importance of factors related to the affordability of equipment and connectivity services. Thus, the persistence of a core of between $20 \%$ and $40 \%$ of households not connected to broadband in developed countries suggests the need for long-term digital literacy policies aimed at promoting demand for services among the households described above.

\section{The situation in Latin America}

In the case of Latin America, it is important to first consider the role of shared Internet access at locations such as the workplace, school and public access facilities, both free (typically called telecentros in Spanish) and commercial (public kiosks and Internet cafés). While this type of access is marginal in more developed countries, the most recent figures for Latin America show that shared Internet access continues to be very significant, despite the sharp increase in the number of individual broadband subscriptions. As an example, the most recent figures in Peru show that $65 \%$ of Internet users use it at work or at public access facilities (INEI, 2012). In comparison, the most recent figure for Spain is a bare $17 \%$ of users (ONTSI, 2012). 
The influence of shared access in the region has resulted in a significant gap between the number of Internet users and the number of broadband subscriptions, as shown in table II.6. This gap can be interpreted as latent broadband demand: demand for Internet access that does not turn into service subscriptions.

Table II.6

INTERNET USERS AND BROADBAND SUBSCRIBERS IN LATIN AMERICA, 2011 (Percentages)

\begin{tabular}{lccc}
\hline Country & Internet users & Fixed subscribers & Mobile subscribers \\
\hline Argentina & 47.7 & 10.5 & 11.7 \\
Bolivia (Plurinational State of) & 30.0 & 0.7 & 1.9 \\
Brazil & 45.0 & 8.6 & 20.9 \\
Chile & 53.9 & 11.7 & 17.1 \\
Colombia & 40.4 & 6.9 & 3.7 \\
Costa Rica & 42.1 & 8.7 & 2.0 \\
Dominican Republic & 35.5 & 4.0 & 7.7 \\
Ecuador & 31.4 & 4.2 & 10.3 \\
El Salvador & 17.7 & 3.3 & 3.6 \\
Guatemala & 11.7 & 1.8 & 4.1 \\
Honduras & 15.9 & 2.7 & 3.7 \\
Jamaica & 31.5 & 3.9 & 1.5 \\
Mexico & 36.2 & 10.6 & 4.6 \\
Nicaragua & 10.6 & 1.8 & 1.0 \\
Panama & 42.7 & 7.9 & 14.5 \\
Paraguay & 23.9 & 0.9 & 4.5 \\
Peru & 36.5 & 3.5 & 1.4 \\
Uruguay & 51.4 & 13.5 & 9.0 \\
Venezuela (Bolivarian & 40.2 & 6.1 & 4.2 \\
Republic of) & & & \\
\hline Sourc:Intrnatona Telo & & \\
\hline
\end{tabular}

Source: International Telecommunication Union (ITU), Telecommunications Database 2012.

As figure II.3 shows, latent demand measured by the difference between users and subscribers (per 100 inhabitants) is higher in some of the region's more mature markets. This suggests that despite a network effect which stimulates Internet adoption in countries with higher penetration, the market equilibrium point keeps this latent demand from turning into subscriptions. 
Figure II.3

LATENT FIXED AND MOBILE BROADBAND DEMAND IN LATIN AMERICA, 2011 (Percentage points)

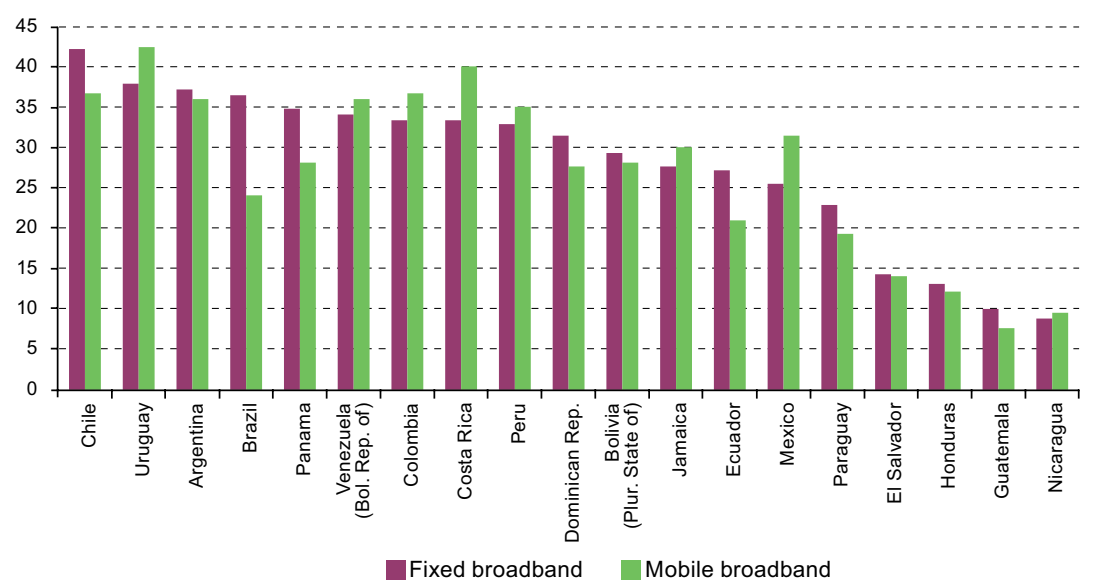

Source: International Telecommunication Union (ITU), Telecommunications Database 2012.

The barriers preventing this latent demand from being converted into subscriptions are associated with several factors. First, determining whether there are coverage gaps that explain the magnitude of the latent demand observed in the region will then make it possible to estimate the effective demand gap (i.e., discounting coverage shortfalls) for several countries in the region. Lastly, the factors accounting for this demand gap are analysed on the basis of surveys conducted in various countries.

\section{Broadband coverage}

Broadband coverage in Latin America is relatively extensive. The following analysis of population coverage was carried out by extrapolating information provided by operators and regulators (see annex II.1).

As table II.7 shows, other than in some Andean countries, the broadband supply gap in Latin America is not large. The population coverage of fixed broadband ranges from $98 \%$ in Uruguay to $40 \%$ in the Plurinational State of Bolivia, with an average of $79 \%$ for all the countries analysed. This is because ADSL services over the copper network have benefited from the historical deployment of telecommunication networks. As might be expected, cable television network coverage is concentrated in areas of higher population density and so overlaps with ADSL access.

For mobile broadband, this analysis is based on the deployment of 3G networks (based on EVDO and HSPA standards), which are by definition more suitable for Internet access. In this case, population coverage ranges from $96 \%$ in Colombia to $29 \%$ in the Plurinational State of Bolivia (with an average of $76 \%$ for all the countries surveyed). 
Table II.7

BROADBAND COVERAGE IN LATIN AMERICA, 2011-2012

(Percentage of population)

\begin{tabular}{lcc}
\hline Country & Fixed broadband & Mobile broadband \\
\hline Argentina & 96 & 92 \\
Bolivia (Plurinational State of) & 40 & 29 \\
Brazil & 94 & 84 \\
Chile & 78 & 82 \\
Colombia & 81 & 96 \\
Costa Rica & 95 & 93 \\
Ecuador & 87 & 66 \\
Mexico & 62 & 77 \\
Peru & 59 & 63 \\
Dominican Republic & $\mathrm{n} / \mathrm{a}$ & 70 \\
Uruguay & 98 & n/a \\
\hline
\end{tabular}

Source: Prepared by the authors on the basis of the methodology detailed in annex II.1.

\section{The demand gap}

Comparing broadband penetration and service coverage makes it possible to estimate the size of the demand gap (table II.8). In the fixed broadband segment, the average demand gap for the countries analysed is 50 percentage points: less than half the households covered by a fixed broadband service choose to subscribe to it.

Table II. 8

THE FIXED BROADBAND DEMAND GAP IN LATIN AMERICA, 2011 (Percentages)

\begin{tabular}{lccc}
\hline Country & Coverage & $\begin{array}{c}\text { Household } \\
\text { penetration }\end{array}$ & Demand gap \\
\hline Argentina & 96 & 39 & 57 \\
Bolivia (Plurinational State of) & 40 & 3 & 37 \\
Brazil & 94 & 29 & 65 \\
Chile & 78 & 44 & 34 \\
Colombia & 81 & 27 & 54 \\
Costa Rica & 95 & 32 & 63 \\
Ecuador & 87 & 20 & 67 \\
Mexico & 62 & 47 & 15 \\
Peru & 59 & 16 & 43 \\
Uruguay & 98 & 34 & 43 \\
Average & 79 & 29 & 50 \\
\hline
\end{tabular}

Source: International Telecommunication Union (ITU), Telecommunications Database 2012. 
The demand gap is even larger in the mobile segment, averaging 63 percentage points in the countries examined (see table II.9). In accordance with the theoretical framework explained in the first section, a significant portion of mobile broadband users are also fixed broadband users owing to the complementarity effect. As a result, the contribution of mobile broadband to reducing the demand gap has, so far, been smaller. Although exact figures cannot yet be calculated because the numbers using each technology are unknown, the rapid rate of deployment of mobile broadband suggests that the substitution effect will increase in importance. A progressive reduction in the overall demand gap can therefore be anticipated for the coming years.

Table II.9

THE MOBILE BROADBAND DEMAND GAP IN LATIN AMERICA, 2011 (Percentages)

\begin{tabular}{lccc}
\hline Country & Coverage & Subscriber penetration & Demand gap \\
\hline Argentina & 92 & 19 & 73 \\
Bolivia (Plurinational State of) & 29 & 3 & 26 \\
Brazil & 84 & 21 & 63 \\
Chile & 82 & 17 & 65 \\
Colombia & 96 & 9 & 87 \\
Costa Rica & 93 & 11 & 82 \\
Ecuador & 66 & 11 & 55 \\
Mexico & 77 & 14 & 63 \\
Peru & 63 & 9 & 54 \\
Dominican Republic & 70 & 5 & 65 \\
Average & 75 & 12 & 63 \\
\hline
\end{tabular}

Source: Prepared by the authors on the basis of table II.7 data for coverage and the total number of HSPA, LTE and EVDO connections divided by the population, as reported by Wireless Intelligence.

In summary, the demand gap in the region remains large; a detailed analysis of the underlying factors is required so that policies can be developed to address it.

\section{Explaining the demand gap}

Studies conducted in different countries of the region have yielded relatively consistent results regarding the determinants of the demand gap. Figure II.4 presents the findings of the survey conducted by the Internet Management Committee in Brazil (CGI.br) to analyse why households with computers do not subscribe to a broadband service. As can be seen, the main reason is affordability, followed by (perceived) lack 
of availability, lack of interest and lack of skills. There was a 10 percentagepoint decrease in reasons associated with service cost between 2007 and 2011, suggesting rising incomes in the country, falling prices and greater segmentation of supply. Meanwhile, lack of interest and lack of usage skills are factors that have remained relatively stable over time, suggesting the impact of structural factors linked to deficiencies in the education system.

Figure II. 4

BRAZIL: REASONS FOR NOT SUBSCRIBING TO INTERNET

IN THE HOME, 2007-2011

(Percentages of households with a computer)

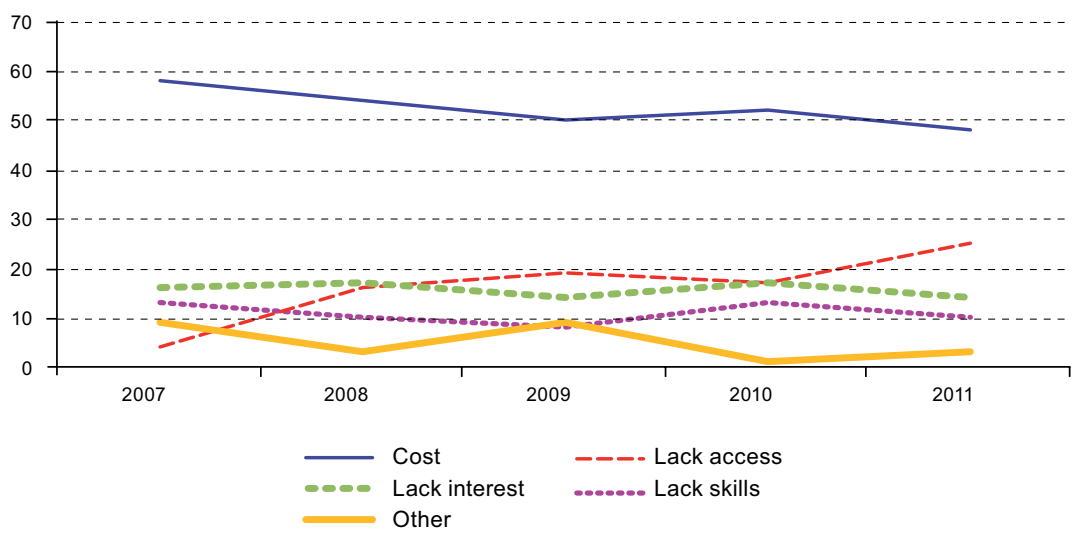

Source: CGI, Home ICT Survey.

Research results in Mexico reveal a similar pattern: among households with a computer but no Internet connection, the main reason cited is the cost of connectivity $(60 \%)$, followed by lack of interest $(19 \%)$. In Chile, reasons associated with connectivity costs are less to the fore, being cited by $37 \%$ of households with a computer, followed by lack of interest (24\%) and lack of usage skills ( $8 \%$ ). In Costa Rica, by contrast, the cost factor is more prominent at $60 \%$, followed by lack of skills $(12 \%)$ and interest (7\%). Table II.10 summarizes these results. As can be seen, with the possible exception of Chile, service costs are the main factor explaining the demand gap in Latin America, confirming the results obtained by Galperín and Ruzzier (2010). However, longitudinal analysis in the case of Brazil shows that as access costs fall, structural factors associated with human capital gain in prominence.

The results of these studies make it possible to identify dimensions of the demand gap associated with sociodemographic factors that are discussed separately below. 
Table II.10

LATIN AMERICA: FACTORS EXPLAINING THE DEMAND GAP

(Percentages)

\begin{tabular}{lcccc}
\hline $\begin{array}{l}\text { Reasons cited for not having an Internet } \\
\text { connection in the home } \\
\text { (only homes with a computer) }\end{array}$ & $\begin{array}{c}\text { Chile } \\
(2009)\end{array}$ & $\begin{array}{c}\text { Brazil } \\
(2011)\end{array}$ & $\begin{array}{c}\text { Costa } \\
\text { Rica } \\
(2011)\end{array}$ & $\begin{array}{c}\text { Mexico } \\
(2010)\end{array}$ \\
\hline Price of the service & 37 & 48 & 60 & 60 \\
Lack of interest & 24 & 14 & 12 & 19 \\
$\begin{array}{l}\text { Lack of usage skills } \\
\begin{array}{l}\text { Other reasons (lack of availability, use in } \\
\text { other locations, etc.) }\end{array}\end{array}$ & 31 & 10 & 7 & n/a \\
\hline
\end{tabular}

Source: Chile: Survey on Internet Broadband Access, Use and Users in Chile, Universidad Alberto Hurtado/ SUBTEL, June 2009. Costa Rica: Second Assessment of the Digital Divide in the Use of Telecommunications Services in Costa Rica, Telecommunications Directorate, February 2011. Mexico: Survey on the Availability and Use of Information and Communication Technologies in Households, INEGI (2010). Brazil: Survey on the Use of Information and Communication Technologies in Brazil, CGI.br, November 2011.

\section{(a) The socioeconomic dimension of the demand gap}

As the results discussed have shown, analysis of the demand gap by income level corroborates the importance of affordability as a determinant of Internet adoption within households. Beginning with Brazil, figure II.5 shows the disparity between the highest-income group (socioeconomic level A), in which household Internet adoption is almost universal, and the lowest-income group (socioeconomic level D/E), in which household access is marginal. The trend among households of the so-called new middle class (socioeconomic level $\mathrm{C}$ ) is striking, with home access more than doubling between 2008 and 2011.

Figure II. 5

BRAZIL: HOME INTERNET ADOPTION BY SOCIOECONOMIC LEVEL (SEL), 2011

(Percentages)

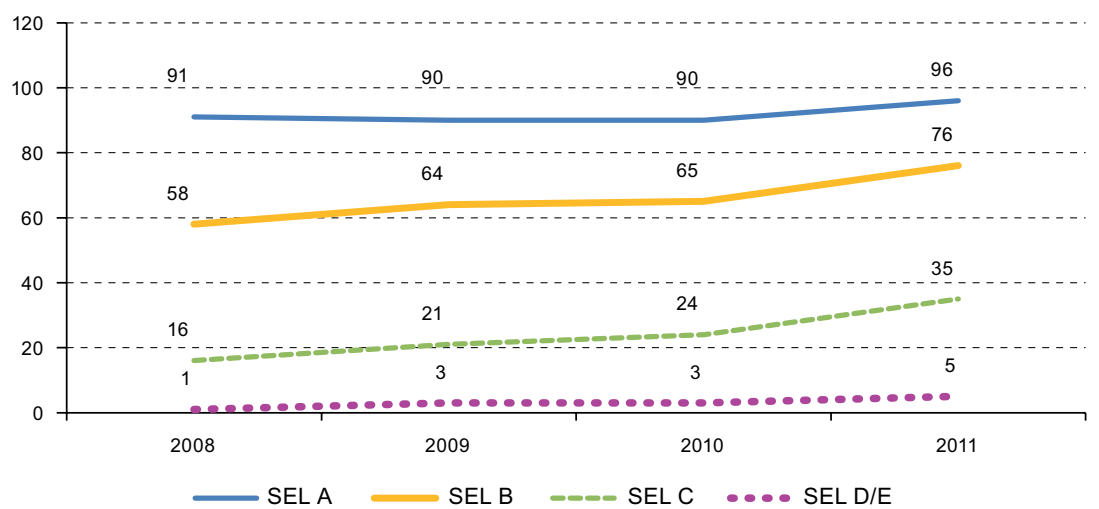

Source: Survey on the Use of Information and Communication Technologies in Brazil, CGI.br. 
For Mexico, figure II.6 shows that the home Internet penetration growth rate between 2008 and 2010 was greater in higher-income deciles, suggesting a widening of the adoption gap between socioeconomic groups.

Figure II.6

MEXICO: HOME INTERNET ADOPTION BY INCOME DECILE, 2008-2010

(Percentages)

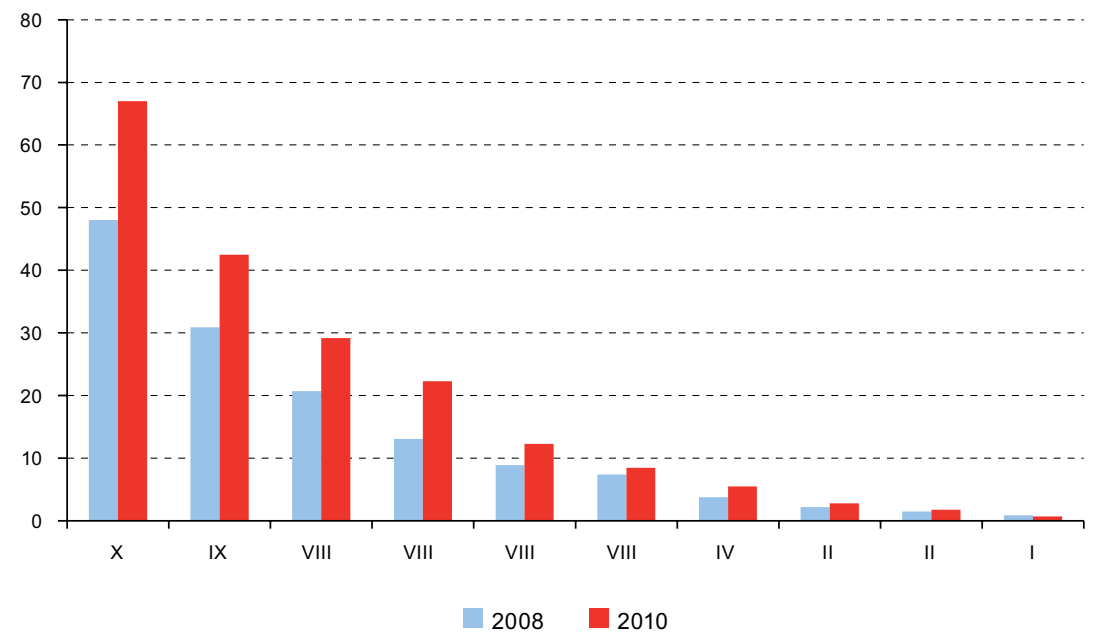

Source: National Institute of Statistics and Geography (INEGI), Estadísticas sobre disponibilidad y uso de tecnologías de la información y comunicación en los hogares, Mexico City 2010.

The findings confirm the importance of economic variables in explaining the demand gap in the countries of the region. The conclusions regarding trends are not decisive, however: whereas in Brazil the increase in adoption among lower middle-class households suggests a progressive narrowing of the penetration gap by socioeconomic level, the trend in Mexico reveals a widening of the gaps between income deciles. In general, as figure II.7 shows, there has been a gradual convergence in access levels by socioeconomic level, particularly in medium-high income countries such as Brazil, Costa Rica, Chile and Uruguay. In any event, these findings merit more comprehensive longitudinal studies, which would also make it possible to identify the factors accounting for differences in trends between countries, which could be associated with changes in household income, developments in service supply or policies aimed at universalizing access. 
Figure II.7

HOME INTERNET ADOPTION GAP BY INCOME QUINTILE (Q5/Q1)

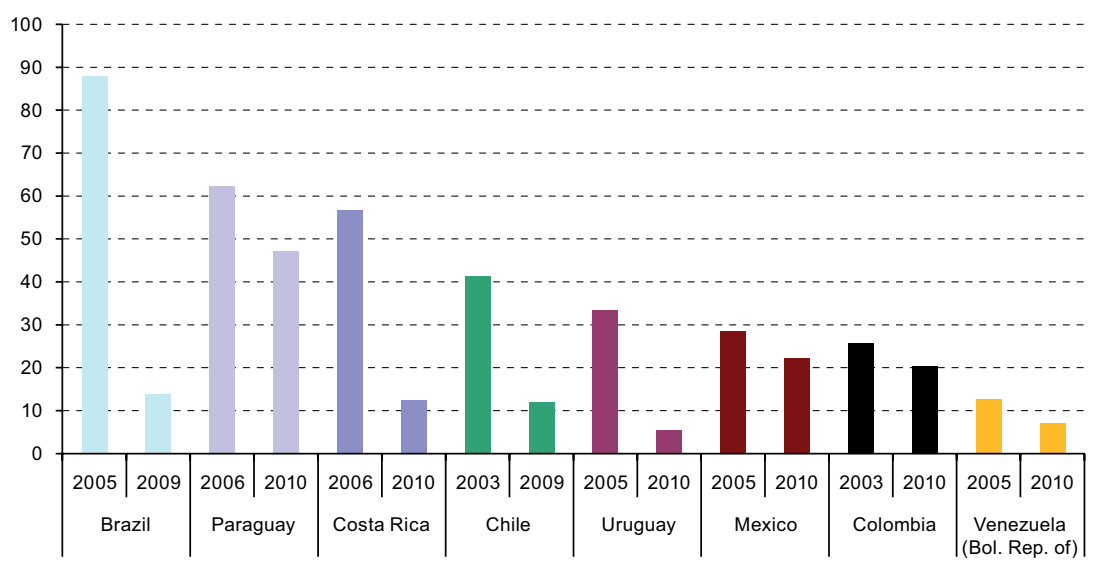

Source: Observatory for the Information Society in Latin America and the Caribbean (OSILAC), on the basis of household surveys conducted in the respective countries.

\section{(b) The education dimension}

Survey findings suggest that, after affordability, non-adoption of home Internet services is mainly due to interest and usage skill factors that are closely connected with the stock of human capital. This points to the education dimension of the demand gap, which operates as a proxy for determinants related to interest and usage skill.

In all the countries analysed, there are access gaps between individuals with different levels of education. As an example, figure II.8 shows that the level of home Internet adoption in Costa Rica is more than twice as high among those who have completed secondary education as among those who have not.

The Chilean case supports this finding, as figure II.9 shows. The home Internet adoption rate in Chile is less than $25 \%$ among those who have not completed secondary education but as high as $42 \%$ among those who have. This confirms that completing secondary education is an important educational threshold that fosters interest and promotes the usage skills needed to take advantage of Internet access in the home. 
Figure II.8

COSTA RICA: RESIDENTIAL INTERNET AND COMPUTER USE BY EDUCATIONAL LEVEL OF THE HOUSEHOLD HEAD, 2010

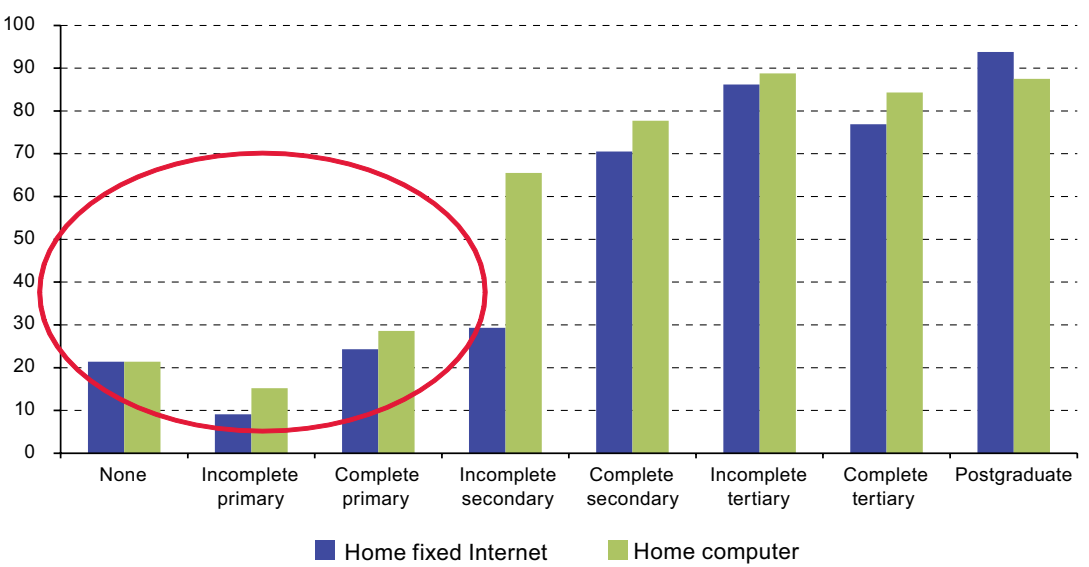

Source: Costa Rica, Telecommunications Directorate, 2011.

Figure II.9

CHILE: RESIDENTIAL INTERNET AND COMPUTER USE BY EDUCATIONAL LEVEL OF THE HOUSEHOLD HEAD, 2009

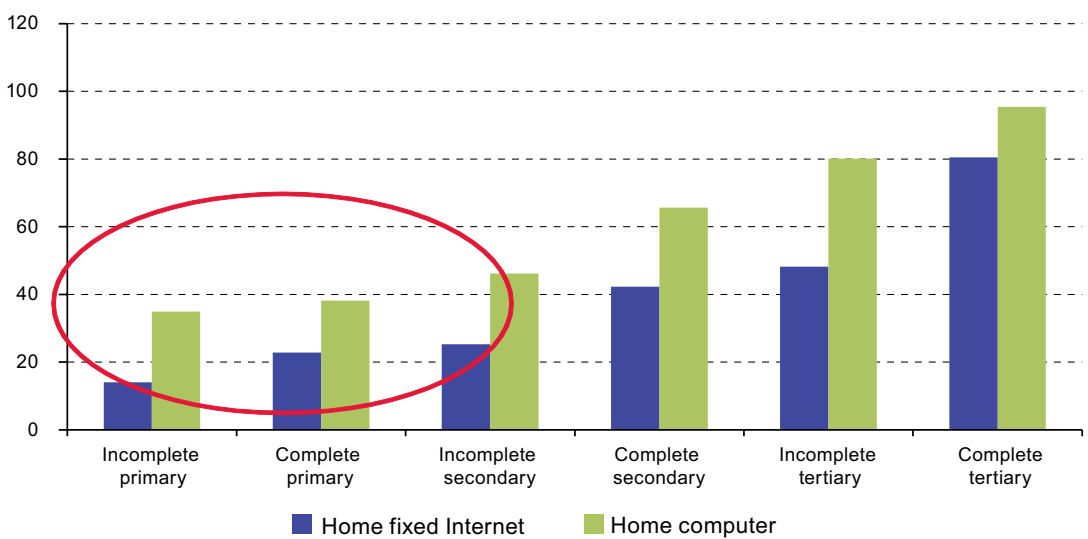

Source: Universidad Alberto Hurtado, Encuesta sobre acceso, uso y usuarios de Internet banda ancha en Chile, Santiago, Chile, 2009. 
The problem with these results is the strong correlation between education attainment and socioeconomic level, making it difficult to isolate the effect of education on adoption by discounting the known effect of socioeconomic level. While this type of analysis is beyond the scope of the present paper, figure II.10 shows that the effect of education persists even after income deciles are controlled for.

Figure II.10

COSTA RICA: RESIDENTIAL BROADBAND PENETRATION BY EDUCATION LEVEL AND INCOME DECILE, 2010

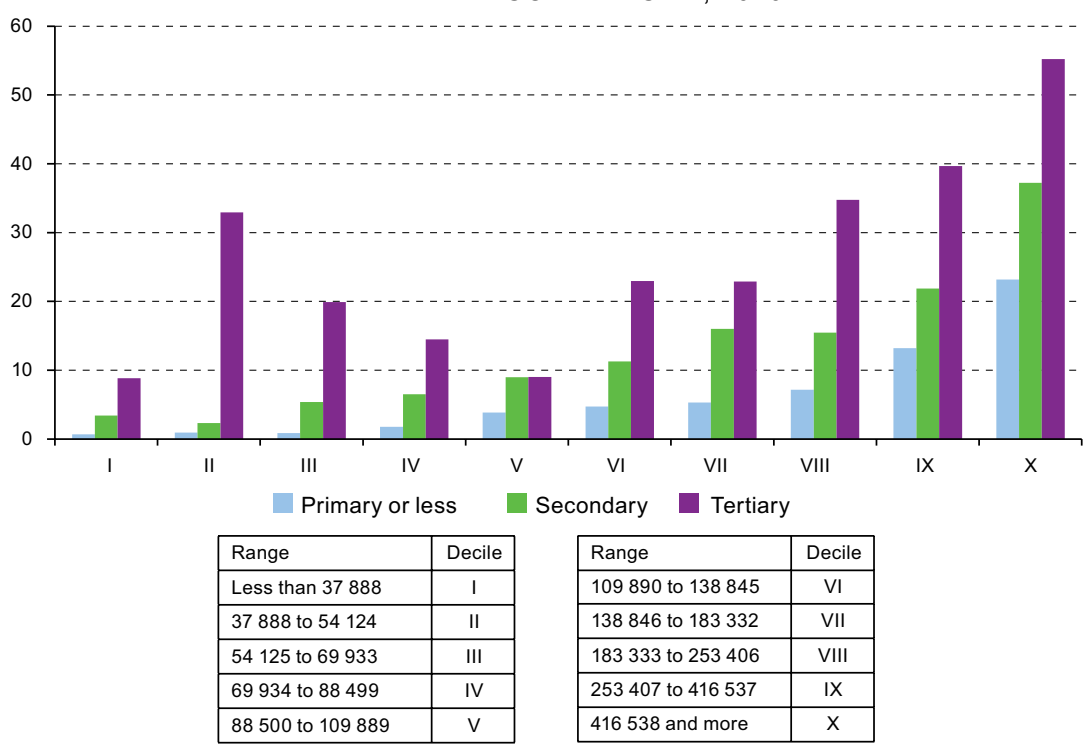

Source: Prepared by the authors on the basis of National Institute of Statistics and Census (INEC), Household Survey, July 2010.

This analysis yields two conclusions. First, it highlights the direct relationship between income level and access to ICTs in the home. The cutoff would appear to be around an average income for the seventh decile. From this decile up, the higher the level of education, the greater the Internet and broadband adoption rate. In households with incomes below the sixth decile, a higher level of education does not result in a significant increase in service penetration, except in decile II.

Second, the educational level of the household head is an important variable for the level of broadband adoption in Costa Rica; the level of service take-up is more than $30 \%$ in decile II households with universitylevel education. This would indicate that the influence of education in decile II is significant. One hypothesis could be that this decile includes recent university graduates whose incomes have not increased significantly. 
Meanwhile, groups with higher levels of secondary and tertiary education and incomes above decile VIII levels have a utilization rate of around $50 \%$.

The interaction between the two variables (socioeconomic status and education) thus reveals a complex relationship: while income is crucial, education acts as an adoption incentive, especially in middle- and upper-class households.

\section{(c) The generational dimension}

As discussed above, all studies show a strong generational component to Internet adoption. While young people tend to use new technologies intensively regardless of their level of education or income, adoption is significantly lower among older persons. Internet usage data suggest that there is a threshold at around the age of 30, after which the adoption rate for this technology falls off significantly both in the home and elsewhere. The case of Chile is illustrative: above the age of 30, the percentage of non-Internet users doubles (Universidad Alberto Hurtado, 2009). In Peru, the percentage of Internet users drops from $61 \%$ among young persons aged 19 to 24 to $37 \%$ among adults aged 25 to 40 (INEI, 2012). In Brazil, $81 \%$ of young people aged up to 24 use the Internet, while less than half ( $48 \%$ ) of adults aged 35 to 44 do.

Consequently, the likelihood of a household subscribing to an Internet service is associated with two factors related to household age composition. First, the age of the household head is a determinant of the penetration level. As figure II.11 shows, the older the household head, the lower the level of service penetration. What is at work in this case is a direct effect linked to the adoption drivers discussed earlier.

Figure II.11

COSTA RICA: HOME INTERNET AND COMPUTER USE, BY AGE GROUP, 2010

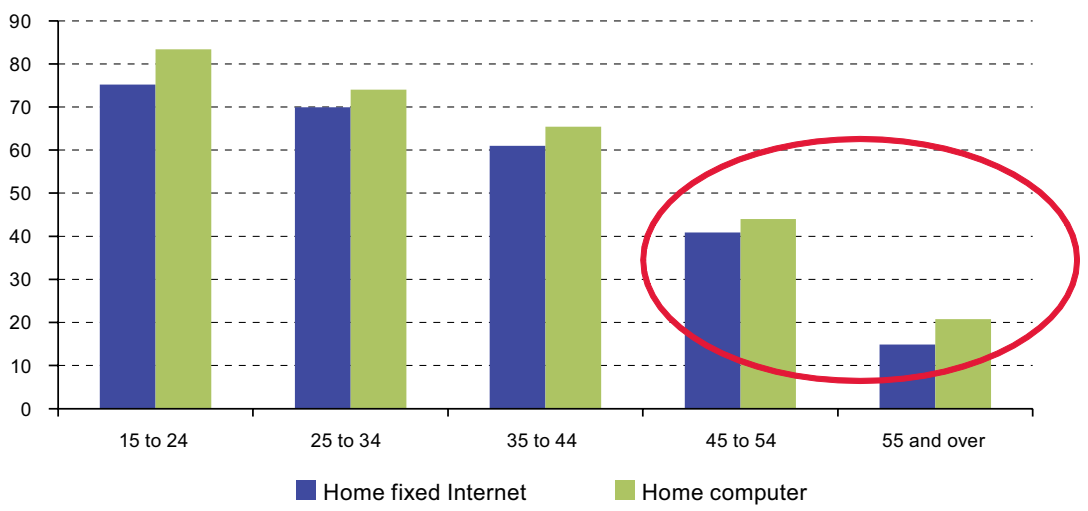

Source: Costa Rica, Telecommunications Directorate, 2011. 
On the other hand, studies suggest an indirect effect linked to the presence of school-age children in the home. Data for 2009 confirm this effect in Chile, as the percentage of households with Internet access rises from $39 \%$ to $43 \%$ among those with school-age children (Universidad Alberto Hurtado, 2009). In Peru, the effect is even more significant: the proportion of Internet-connected households is $57 \%$ among those with school-age children, as against $43 \%$ among households without school-age children (INEI, 2012). This effect is replicated in Costa Rica, although when income and education are controlled for it is not found consistently but is associated primarily with households whose heads have a lower level of education.

In summary, the evidence bears out findings on what are known as "digital natives", showing that there is a strong age effect on the likelihood of Internet adoption. Despite the differences in the age groups used by different countries, the results suggest that the threshold separating the digital natives group (among whom Internet usage is widespread) from the so-called digital immigrants is located at around the age of 30. Regarding the household access demand gap, the evidence suggests that the presence of school-age children in the home has a positive effect on the expected adoption rate, but the magnitude of this effect is small compared to that of the factors discussed earlier. These results highlight the importance of implementing digital literacy programmes to offset any age-related disadvantages and thereby reduce the demand gap.

\section{(d) Other dimensions of the demand gap}

The analysis reveals that the demand gap is associated, in the following order, with factors of income, education and household age composition. While the evidence indicates that these factors are common to all countries in the region, some studies also point to other factors operating more specifically in particular contexts or countries. This suggests a need to tailor demand-boosting initiatives to the unique characteristics of the demand gap in the different countries of the region.

In some countries, evidence suggests that there is still a gender gap in Internet adoption. This is the case in Chile, where the data for 2009 indicate that the likelihood of a household having Internet access is reduced by 7 percentage points if the household head is female (Universidad Alberto Hurtado, 2009). The magnitude of the gender gap is similar in Peru, where Internet usage is also 7 percentage points lower (31\% as against 38\%) among women (INEI, 2012). The result in Costa Rica is consistent with this: while $63 \%$ of men use the Internet in the home, only $54 \%$ of women do (Telecommunications Directorate, 2011).

Brazil and Mexico, by contrast, do not present any significant gender differences in penetration levels, suggesting that the gap tends to disappear in countries with higher penetration. This is consistent with the 
findings of Hilbert (2011), who ascertained in a recent paper reviewing evidence from 25 countries in Latin America and Africa that differences in ICT adoption by gender tended to disappear when controlled for education and income.

In countries where a significant portion of the population is indigenous, data reveal the existence of a usage gap associated with Spanish-language proficiency, replicating the findings in the United States regarding English-language proficiency among immigrant populations. In Peru, for example, just $8 \%$ of the population whose childhood language is other than Spanish uses the Internet, compared with $40 \%$ of those for whom it is Spanish. These results need to be analysed in greater depth, however, given that ethnic factors are strongly associated with economic and educational factors and therefore do not provide a prima facie basis for determining the marginal effect of language or ethnicity on the demand gap. Nonetheless, the results are indicative of a need for development initiatives to target demand in these groups, as they labour under a number of disadvantages with regard to Internet use.

\section{Public policies to close the demand gap}

The analysis presented above provides a framework for designing public policies to stimulate broadband adoption. The following recommendations are organized in accordance with the different dimensions of the demand gap identified in the previous section.

\section{Policies for addressing the affordability barrier}

The evidence shows affordability to be one of the main determinants of the demand gap in the region. In other words, for a significant portion of households in Latin America (even those that already have a computer), the supply of connectivity is not aligned with income. Considering this, three types of tools should be considered to better match supply to income levels and characteristics in this segment of the population.

A first set of policy tools aims to encourage competition in order to bring down access prices. The tools available to achieve this goal can be divided, generally speaking, into two major groups: those designed to increase competition between platforms, and those that encourage competition between services on a single platform (Cambini and Jiang, 2009). While the first model is associated with policies in the United States, the second is particularly applicable in the European Union.

As Katz (2009a) has shown, for various reasons the competitionbetween-platforms model dominates in Latin America. The first question to ask, therefore, is how likely it is that competition between vertically 
integrated operators might bring about a significant reduction in prices. The second is what should be done if competition between operators does not bring prices down far enough. In this case, what kind of public initiatives can be deployed to encourage the introduction of price plans designed to make broadband more affordable?

The Latin American experience shows that healthy competition between broadband platforms does lead to a race to introduce better services (competition for speed) and lower prices. The downward price trend resulting from competition can be observed in many countries of Latin America: the lower the level of industry concentration (as measured by the Herfindahl-Hirschman index), the lower the average price of fixed broadband service (see figure II.12). ${ }^{4}$

Figure II.12

LATIN AMERICA: CONCENTRATION OF FIXED BROADBAND SUPPLY AND AVERAGE DOWNLOAD PRICE PER MBPS

(Herfindahl-Hirschman index and PPP dollars)

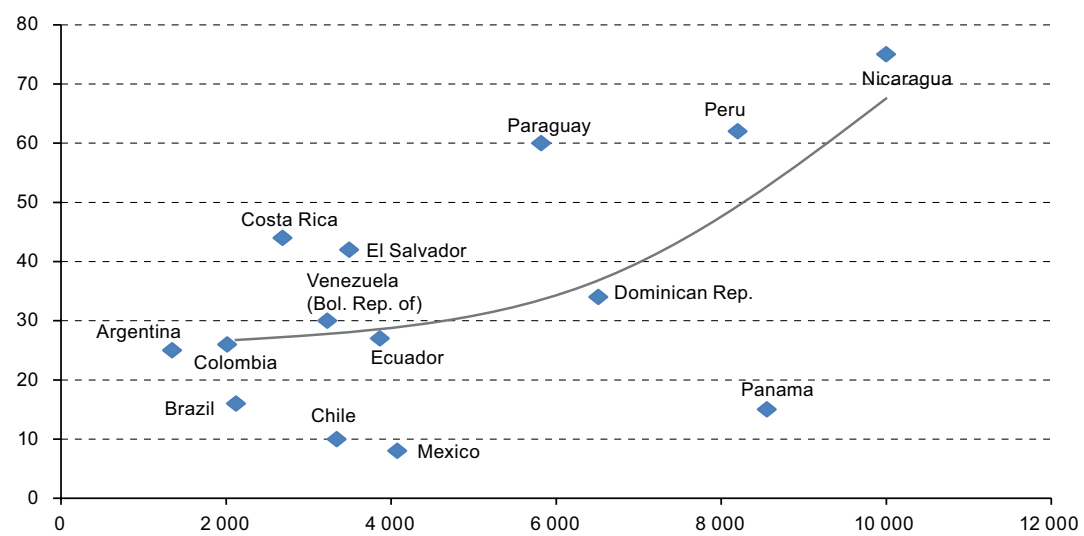

Source: Prepared by the authors on the basis of data from H. Galperín, "Precios y calidad de la banda ancha en América Latina: Benchmarking y tendencias", Documento de Trabajo, No. 12, Buenos Aires, Centro de Tecnología y Sociedad/ Universidad de San Andrés, 2012; and R. Katz, 2010-2012: Avances importantes en el desarrollo del sector de telecomunicaciones en América Latina, Caracas, Andean Development Corporation (ADC), 2012.

There is evidence that this process is under way in the region. As Galperín (2012) shows, the implicit download price per Mbps of fixed broadband plans in Brazil dropped by 40\% between 2010 and 2012. This trend, spurred by competition between cable operators such as Net Serviços and telephone operators such as Telefônica and $\mathrm{Oi}$, is the result of The chart excludes the countries with prices at either extreme (the Plurinational State of
Bolivia and Uruguay). 
strategies designed to capture what is the largest market in terms of size and growth, the so-called C-segment of the population. However, the lower prices resulting from competition may not be sufficient to ensure that the most disadvantaged can access the service. This requires consideration of a second set of more closely targeted tools designed to stimulate demand and reduce financial barriers to access among these sectors. The main element in this toolkit needs to be the reduction or elimination of taxes on basic connectivity plans, either across the board or for low-income individuals and households.

Studies have shown that the tax burden associated with broadband services is particularly high, discouraging consumption in both the fixed and mobile segments. ${ }^{5}$ The tax impact on broadband is negative across several dimensions (see diagram II.2). According to this analysis, which is borne out by the tax reduction policy and tax incentives introduced in the United States to promote broadband adoption, a high tax burden raises barriers to adoption by impacting affordability. Broadband network externalities further constrain adoption. Then, because of the high fixed costs involved in delivering broadband, a low adoption rate raises the average cost, reduces margins and prevents operators from cutting prices, generating a third limitation on adoption.

Diagram II.2

IMPACT OF FISCAL POLICY ON BROADBAND PENETRATION

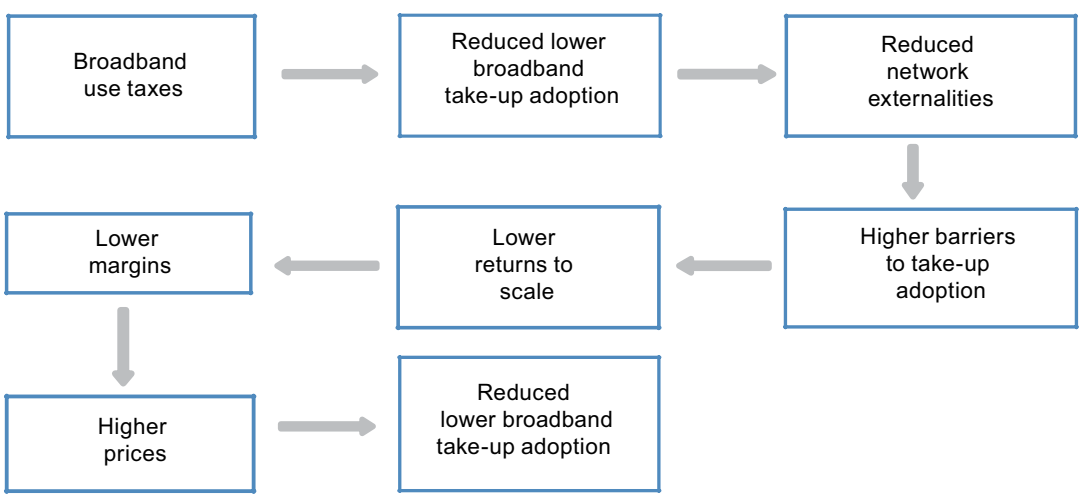

Source: R. Katz, “La brecha digital: oferta o demanda?”, Notas Enter, No. 135, Madrid, 7 July, 2009.

Considering the significant price elasticity of broadband services in the region, as revealed by studies such as those of Galperín and Ruzzier (2010) and Macedo and Carvalho (2011), reducing the tax burden could

See Galperín and Ruzzier (2010) for an analysis of the fixed segment and Katz and others (2011) for the mobile segment. 
have an immediate impact on the level of service adoption. Several countries in the region have implemented such initiatives, notably Brazil, where basic access plans in several states have been exempted from the ICMS, a state goods and services tax with rates of up to $35 \%$, as part of the National Broadband Plan, and Colombia, where broadband services for lower income strata have been exempted from value added tax (VAT).

A third set of tools involves a more proactive role for government in the broadband supply structure. In countries where the incumbent telephone operator is government-controlled, supply initiatives involving very low-cost connectivity plans have been implemented. While offering a limited service in terms of speed (between $256 \mathrm{kbps}$ and $512 \mathrm{kbps}$ ) and data download capacity, they do provide basic access options that work as a first connectivity step for low-income households. Uruguay (the Universal Hogares plans offered by ANTEL) and the Bolivarian Republic of Venezuela (the ABA plans of CANTV) furnish notable examples. It is noteworthy that these plans involve a mixed payment system (a fixed monthly payment with the option to purchase incremental data download capacity on top of the monthly allowance), a model that has been crucial in achieving mass adoption of mobile telephony services.

In other cases, governments have opted for direct investment in backbone infrastructure initiatives, making it possible to structure a supply of low-cost connectivity plans in which the private operator commits to providing the service in accordance with government-mandated quality and price parameters in exchange for access to the network backbone. Examples are the National Broadband Plan in Brazil and the Argentina Conectada plan in Argentina. Lastly, there are the more traditional supply subsidies in areas of low private-sector return, where governments set service features in advance and tender out the service to a private operator which then receives the subsidy. Todo Chile Comunicado in Chile and Vive Digital in Colombia operate in this way (see the chapter by Galperín, Mariscal and Viecens in this book).

In conclusion, there is a wide range of public policy tools that can encourage lower prices and the segmentation of supply into products that are attractive to households with limited budgets. Experience suggests that the combination of healthy competition between access platforms, a reduced tax burden and strategic State investment in non-competitive segments of the network can significantly lower barriers to broadband affordability in the region.

\section{Policies for addressing the skills barrier}

The usage skills dimension of the demand gap presents enormous challenges for the countries in the region, as it is associated with structural 
deficiencies in education systems. Without attempting to cover the broad debate on the issue, it can be said that there are two types of initiatives to meet these challenges. First, there are instruments designed to address specific gaps in computer and Internet usage skills. These initiatives are usually implemented outside the formal education system and are often associated with vocational training plans or other types of social integration initiatives.

There are several examples of such initiatives, both in the region and in more developed countries. They typically involve provision of shared access by the State, combining connectivity with digital training at access points. Vive Digital in Colombia, Pontos de Cultura in Brazil and Puntos de Acceso Digital in Argentina are just some examples. Implementation often targets specific population segments, examples being programmes that seek to integrate young persons into labour markets by providing ICT training (Mariscal, Gutiérrez and Botelho, 2009).

Despite the benefits yielded by these initiatives, there are no rigorous studies of the outcomes of such programmes in the region. This type of analysis is important because these programmes compete in several respects with the wide range of shared access and training options that exist in the private sector. Moreover, as Garrido and others (2012) have argued in their review of the literature on ICT skills and applicability, the success of such programmes largely depends on a good match between the type of training received and the characteristics of the target population, as well as demand in the local job market.

In the second place, there are longer-term initiatives tied to the national education system that seek to equip people with the long-term ability to use and adopt new technologies. The most ambitious initiatives involve efforts to generate ICT skills within the education system by seeing to it that all State schools have equipment and broadband connectivity. Programmes of this type have been widely adopted in the region, including in Uruguay (the Ceibal plan), Argentina (the Conectar Igualdad plan) and Chile (the Enlaces programme).

These plans have been the subject of a great deal of debate that is beyond the scope of this chapter. In particular, the evidence on the educational results of these initiatives has been much discussed. ${ }^{6}$ However, there is consensus on the need to adapt the education system to the new technology skill requirements created by Latin America's ongoing integration into a world that is increasingly interconnected from both an economic and a cultural point of view. Conceptually, this change should take place at all the different levels of education (primary,

See IDB (2011), among others. 
secondary and tertiary) and be supplemented by training initiatives for segments of the adult population that are at a disadvantage in terms of their ICT training opportunities.

In this regard, initiatives undertaken by some countries that have been leaders in broadband adoption deserve a close look. These include digital literacy initiatives implemented in the Republic of Korea, which has launched an online education programme for 10 million people (about $20 \%$ of the population) focused on promoting skills among older persons, housewives, members of the armed forces, prisoners, persons with disabilities and other groups that have fallen behind in Internet adoption.

\section{Policies for addressing the lack of interest/ relevance barrier}

Lack of interest or relevance consistently comes up as one of the reasons cited by non-Internet users, regardless of their usage skills or income. This factor does not represent a barrier as such, and it is associated with preferences and incentives that vary from person to person. This represents a challenge for the development of public initiatives to address this dimension of the demand gap. However, Internet adoption studies have revealed a variety of mechanisms that come into play in the adoption decisions made by potential users, suggesting several possible public policy tools.

First, Internet access is of little worth in itself in the absence of so-called complementary goods that confer value on such access. They include applications and content that users value and should therefore be attractive enough to encourage people to purchase the service. With applications whose main function is communication between users (e-mail, social networking and file sharing programs), usage value increases with the number of users (the classic network effect), suggesting that the very dynamics of adoption will lead to a gradual closing of the demand gap in the medium term. However, the evidence indicates that this may not be enough of an incentive for certain groups of users to become broadband subscribers, particularly when many of these occasional users prefer to avail themselves of the numerous public access points that exist in the region.

This being so, public initiatives should aim at providing high valueadded applications and demonstrating tangible benefits to potential users in the form of time or money savings or skills acquisition. This is the case with e-government applications that are designed to optimize citizen interaction with government and offer benefits in terms of user access to government services. The linkage between broadband connectivity 
plans and the development of e-government platforms is a cornerstone of national broadband plan design. There are numerous ongoing experiences of this type in the region that should be monitored so that best practices can be shared with the rest of the countries.

A similar dynamic arises with content. A decade ago, the lack of content in Spanish and Portuguese was a barrier to the widespread adoption of Internet services. Today, the content available in both is very extensive, if less so than in other languages, and government initiatives should therefore be aimed at high-impact social content (like that designed to complement ICT initiatives in schools) or content aimed at specific segments of the population (in the region's indigenous languages, for example).

Public initiatives play an important role as catalysts for new privatesector ventures to provide local digital content and applications. Where applications are concerned, a regulatory environment conducive to the development of e-commerce is vital to provide legal security for providers and customers alike. For content, the region has a substantial installed capacity for audiovisual production that has, in recent years, expanded to multimedia content along with information technology services, another industry that has grown significantly over the last decade. Programmes to foster closer ties between university-based research and the production sector are also needed for the development of larger private ventures in the local content creation sector. Promotion of these high innovation content activities and the skilled jobs they provide is essential and forms part of several national broadband development plans in the region.

Lastly, bandwidth consumption is akin to what is known in the literature as an "experience good" (Shapiro and Varian, 1999). This means that consumers lack information about the quality and value associated with a good, the only known information being its price. It is in the act of consumption that the value of the good is revealed and demand for it generated. In policy terms, this highlights the importance of public access initiatives that can successfully bring technology to segments of the population with limited opportunities to experience the service in other areas such as the workplace or school.

\section{Programmes targeting specific population segments}

The evidence set out above suggests that the demand gap has specific sociodemographic components calling for demand promotion policies designed to target different population groups. The data reviewed here have revealed three groups on which such policies should operate. First comes the strong generation component of the demand gap, manifested 
in a progressive decline in the likelihood of adoption from the age of 30, with a sharp drop in the adoption rate after age 55. Clearly there is a need for digital literacy plans designed for adults and older persons, like those implemented in the Republic of Korea. In several cases, these programmes have proved more effective when they have combined training with subsidies for the purchase of computers and the provision of distance learning programmes.

Secondly, there is some evidence of a persistent gender gap, albeit one that is significantly smaller than in the past. The gap is particularly noticeable among households headed by women compared with maleheaded households, as the data for Chile show. Digital literacy and equipment programmes for this segment should consider the particular characteristics of such households, taking advantage of the possible presence of children there, which evidence shows to be a factor that boosts the incentives for adoption, albeit marginally. Again, there have been success stories with vocational training for women linked to ICT training that has addressed the gender gap as part of a broader issue of employment opportunities.

\section{E. Conclusions}

While recognizing that investment in broadband infrastructure plays an important role in reducing the digital divide, this chapter has studied a topic that is less often mentioned: the demand gap. The statistical information that is beginning to be generated by national studies has made it possible to reach an incipient understanding of the importance of this gap. Of the variables accounting for the demand gap, some are structural (e.g., household age composition and education level) while others reflect the intensity of competition in the broadband market and economic performance in general (e.g., affordability).

As regards the most important barrier identified in national studies (the issue of affordability), two types of initiatives can address this. On the one hand, competition between platforms over the long run is the right model to trigger price reductions among the operators serving the market. This will involve not only the traditional telecommunications operators and cable television service providers, but also, in the coming years, operators providing mobile broadband. While this was originally conceived as a technology that would be acquired by the same population sector that subscribed to fixed broadband (complementary), various indications suggest that this product will become a substitute for fixed broadband and bring prices down over the medium term. 
The second initiative to address the affordability barrier is government intervention in broadband provision, either directly (as in Uruguay and the Bolivarian Republic of Venezuela), through backbone infrastructure investments and agreements with private operators (Brazil and Argentina), or by means of traditional systems of supply subsidies (Chile and Colombia). These initiatives aim to provide basic access plans at a very low cost, allowing low-income households to gain an appreciation of the service and turning many users who now access the Internet at shared access points into subscribers. By reducing the demand gap, these initiatives can generate the economies of scale and network externalities necessary for the healthy development of the broadband ecosystem in the region's markets.

The skills barrier, for its part, can be influenced by public policiesnot just traditional ones involving the formal education system, for instance, but continuing education initiatives as well. Some governments have made significant progress in this area as they have pursued universal broadband policies. Others, facing a need to create jobs in the short term, have preferred to allocate resources to infrastructure deployment to cover households that are served poorly or not at all by existing networks. This chapter has highlighted the need to support such initiatives with others that target the factors inhibiting increased penetration among the population already covered by broadband. Ultimately, an understanding of both aspects of the digital divide is required for public policymaking based on the goals to be maximized.

Because broadband is a complex general-purpose technology, its adoption involves the management of a larger number of variables than is the case with mobile telephony, whose exponential growth in the region has made up for the shortcomings of fixed telephony service coverage. Closing the demand gap seen not only in Latin America but in many countries of the industrialized world will require more active participation by governments and the private sector in order to address and remove the barriers to adoption. 


\section{Bibliography}

Cambini, C. and Y. Jiang (2009), "Broadband investment and regulation: a literature review", Telecommunications Policy, vol. 33.

Chaudhuri, A. and K. Flamm (2005), "An analysis of the determinants of Internet access", Telecommunications Policy, vol. 29.

FCC (Federal Communications Commission) (2012), Eight Broadband Progress Report, Washington, D.C.

Galperín, H. (2012), "Precios y calidad de la banda ancha en América Latina: benchmarking y tendencias", Documento de Trabajo, N 12, Buenos Aires, Centro de Tecnología y Sociedad/Universidad de San Andrés.

Galperín, H. and C. Ruzzier (2010), "Las tarifas de banda ancha: benchmarking y análisis", Acelerando la revolución digital: banda ancha para América Latina y el Caribe, LC/R.2167), Valeria Jordán, Hernán Galperin and Wilson Peres (coords.), Santiago, Chile, Economic Commission for Latin America and the Caribbean (ECLAC)/Regional Dialogue on the Information Societyn (DIRSI), November [online] http:/ / www.eclac.cl/publicaciones/xml/7/41727/LCR.2167.pdf.

Garrido, M., J. Sullivan and A. Gordon (2012), “Understanding the links between ICT skills training and employability: an analytical framework", Information Technologies and International Development, vol. 8, No. 2.

Grazzi, M. and S. Vergara (2011), "Determinants of ICT Access", ICT in Latin America: A Microdata Analysis (LC/R.2172), M. Balboni, S. Rovira and S. Vergara (eds.), Santiago, Chile, Economic Commission for Latin America and the Caribbean (ECLAC).

Hauge, J. and J. Prieger (2010), "Demand-side programs to stimulate adoption of broadband: what works?", Review of Network Economics, vol. 9, No 3 .

Hilbert, M. (2011), "Digital gender divide or technologically empowered women in developing countries? A typical case of lies, damned lies, and statistics", Women's Studies International Forum, vol. 34, No. 6 .

Horrigan, J. (2009), Home Broadband Adoption 2009, Washington, D.C., Pew Internet and American Life Project.

INEGI (National Institute of Statistics and Geography) (2010), Estadísticas sobre disponibilidad y uso de tecnologías de la información y comunicación en los hogares, Mexico City.

INEI (Instituto Nacional de Estadística e Informática) (2012), Las tecnologías de información y comunicación en los hogares, Lima.

Katz, R. (2012), 2010-2012: Avances importantes en el desarrollo del sector de telecomunicaciones en América Latina, Caracas, Development Bank of Latin America. (2009), "La brecha digital: oferta o demanda?", Notas Enter , No. 135, Madrid, 7 July.

(2008), La competencia entre plataformas: teoría y resultados, Madrid, Enter.

Katz, R. L., E. Flores and J. Mariscal (2011), The Impact of Taxation on the Development of the Mobile Broadband Sector, Londres, GSMA.

Macedo, H., and A. Carvalho (2011), Broadband Economic Impact in Brazil: A Simultaneous Equations Analysis, paper presented at the Acorn-Redecom Conference, Lima, November. 
Mariscal, J., L. Gutiérrez and A. Botelho (2009), "Employment and youth inclusion into the labor force via training in information and communication technologies: the cases of brazil, colombia, and mexico", Information Technologies and International Development, vol. 5, No. 2.

Navarro, L. and M. Sánchez (2011), "Gender differences in Internet use", ICT in Latin America: A Microdata Analysis (LC/R.2172), M. Balboni, S. Rovira and S. Vergara (eds.), Santiago, Chile, Economic Commission for Latin America and the Caribbean (ECLAC).

NTIA (National Telecommunications and Information Administration) (2011), Exploring the Digital Nation, Washington, D.C.

OFCOM (2012a), Adults Media Use and Attitudes Report, London. (2012b), The Communications Market, London.

Ono, H. and M. Zavodny (2008), "Immigrants, English ability, and information technology use", Social Forces, vol. 86, No. 4.

ONTSI (Observatorio Nacional de las Telecomunicaciones y de la Sociedad de la información) (2012), La Sociedad en Red. Informe Anual 2011, Madrid.

Pew Center (2012), Digital Differences, Washington, D.C., Pew Internet and American Life Project.

Shapiro, C. and H. Varian (1999), Information rules: A Strategic Guide to the Network Economy, Cambridge, Massachusetts, Harvard Business School Press.

Telecommunications Directorate, Government of Costa Rica (2011), II Evaluación de la Brecha Digital en el Uso de Servicios de Telecomunicaciones en Costa Rica, San Jose.

Universidad Alberto Hurtado/SUBTEL (Department of Telecommunications) (2009), Encuesta sobre acceso, uso y usuarios de internet banda ancha en Chile, Santiago, Chile.

Vicente, M. and A. López (2006), "Patterns of ICT diffusion across the European Union", Economic Letters, vol. 93. 


\section{Annex}

\section{Annex II.1 \\ Methodology and sources used to calculate broadband coverage}

The methodology and sources used to estimate broadband coverage are listed below. Estimates were calculated at the lowest possible level of disaggregation considering the availability of data in each case. They are based on the total population of each administrative unit and therefore tend to overstate coverage, since in many cases the population residing in a given administrative unit (usually municipal or departmental) is not fully served.

Fixed broadband coverage:

- Argentina: authors' estimate based on 2012 coverage data published by the Ministry of Planning for towns, except in the provinces of Córdoba and La Rioja, where the estimate was carried out at the departmental level.

- Bolivia (Plurinational State of): authors' estimate based on 2012 coverage data from the operator Entel. The estimate was carried out at the whole city level, so coverage is overstated.

- Brazil: 2010 information published by ANATEL.

- Chile: authors' estimate based on SUBTEL data for 2011.

- Colombia: authors' estimate based on municipalities with at least 50 fixed broadband connections as of the second quarter of 2011, according to Ministry of Information Technology and Communications data (based on SIUST).

- Costa Rica: authors' estimate based on coverage data from providers per district in "Estrategia Nacional de Banda Ancha", book 2, Diagnóstico.

- Ecuador: authors' estimate based on the cantons where providers reported having at least one customer in service for 2011.

- Mexico: Ministry of Communications and Transport estimate for 2011.

- Peru: calculated from the number of residents in districts where there was at least one client with ADSL as of December 2010.

- Uruguay: information provided by ANTEL, November 2012. 
Mobile broadband coverage:

- Argentina: authors' estimate based on 2012 coverage data from operators published by the Ministry of Planning for towns, except in the provinces of Córdoba and La Rioja, where the estimate was carried out at the departmental level.

- Bolivia (Plurinational State of): authors' estimate based on 2011 coverage data from Entel.

- Brazil: 2011 information published by ANATEL.

- Chile: authors' estimate based on SUBTEL data for the population without access to 3G coverage in 2011.

- Colombia: authors' estimate based on 2012 municipal coverage data from Movistar.

- Costa Rica: authors' estimate based on SUTEL 3G coverage testing of ICE.

- Dominican Republic: authors' estimate based on Orange 2011 coverage data.

- Ecuador: based on Movistar coverage; a canton is considered to have $3 \mathrm{G}$ service if the provider covers the most populated part of it.

- Mexico: based on COFETEL information on the population with 3G service coverage for 2011.

- Peru: calculated from the number of residents in districts where there is a $3 \mathrm{G}$ connection (348 districts covered by $3 \mathrm{G}$ out of a total of 1,833) as of December 2010 for mobile telecommunications. The estimate matches the one reported by the ITU. 



\section{Chapter III \\ Regional and international connectivity}

Omar de León

\section{A. Introduction}

This chapter examines Internet connectivity in Latin America and the Caribbean, looking at IP capacity and transit between points in the region and in comparison with the Northern Hemisphere, as well as wholesale and end-user pricing. It identifies the main quality parameters for broadband optimization, their impact on applications and content, and the technical factors, such as aggregation, that influence prices. ${ }^{1}$

Present-day international connectivity and the bottleneck in the Northern Hemisphere are analysed, along with the price levels revealed by ad hoc studies. Physical routes between countries in this region are scarce, and many - if not most - logical routes between countries, even neighboring ones, are through connection points in the Northern Hemisphere. Even Internet service providers (ISPs) in the same country often connect to one another through other countries, which makes for a very inefficient use of resources. This situation is the result of a shortage of Internet Exchange Points (IXPs) in many countries, and in Latin America as a whole. ${ }^{2}$

For a detailed analysis of the concept of broadband and a proposal for Latin America, see annex III.1, in which broadband is defined in relation to its use.

2 Annex III.2, describes the main characteristics of IXPs and criteria for evaluating them based on international best practices. 
This chapter identifies the main factors influencing quality and prices, including IXPs, difficulties in local hosting of national and foreign content, the lack of efficient connectivity between countries and the lack of competition in international connectivity, due, among other things, to limited demand. On this basis, it suggests that policy actions should be oriented towards improving conditions for supply and demand.

The international comparison with Europe illustrates differences in supply and demand that, in turn, influence wholesale and end-user prices. Data on wholesale pricing in three regions (Europe and the United States, Latin America and South-East Asia) show that Latin America is at a pricing disadvantage compared with Europe and the United States, where Internet access is highly concentrated. As for Asia, the price difference is on the order of 2:1, which is smaller than the approximately 6:1 ratio with the United States and Europe.

\section{B. Internet connectivity}

This section examines Internet connectivity in the countries in South America with respect to available connection speeds, service quality parameters and reference rates. It also evaluates the types of services that can be provided and the quality of access offered by operators.

\section{Factors that affect connectivity}

The development of Internet access in South America poses a number of problems that have a direct impact on connection speeds, quality parameters, teledensity and rates.

Economies of scale. The economies of scale seen in the more advanced countries are not found in most of the countries of South America, whether due to total population size or to the distribution of income and per capita income in relation to the intrinsic costs of broadband.

Cost of international Internet access. The longer distances involved in connecting the countries of South America (and Latin America in general) to the global Internet (transit on Tier 1 ISPs in Northern Hemisphere countries) necessarily entail higher costs because of the capacity required for such connections.

Imperfect direct regional connectivity among the countries of the region, and within each country as well, makes it difficult to optimize enduser prices because of unnecessary additional transmission costs. IXPs are one solution for interconnection within the same country, and they are the basis for regional connectivity.

Remote content hosting. Because hosting prices are relatively high in the countries of the region, most regional content is hosted outside 
the region, which increases access costs. In any case, mass remote data hosting by small-scale content providers differs from that of large-scale content providers that use intelligence provided by content distribution or delivery networks (CDN). These providers carry between $30 \%$ and $40 \%$ of worldwide residential traffic, so policies favouring hosting at nodes in the region would significantly improve Internet quality and pricing.

\section{Quality parameters}

The main quality parameters are download speed, upload speed and network latency. Another important parameter, though it does not have much impact on the region's networks because of its high quality, is the packet loss rate. Data on access speed in Latin American countries are presented below (see table III.1). ${ }^{3}$ The figures are based on actual measurements carried out by Ookla, an engine that gauges quality parameters. The average values per country date are as of 1 December 2012.

Table III. 1

INTERNET SPEEDS IN THE REGION ACCORDING TO OOKLA, 1 DECEMBER 2012 (Mbps and percentages)

\begin{tabular}{lcccc}
\hline Country & $\begin{array}{c}\text { Download } \\
\text { speed }\end{array}$ & $\begin{array}{c}\text { Upload } \\
\text { speed }\end{array}$ & $\begin{array}{c}\text { Change in download } \\
\text { speed March- } \\
\text { December 2012 }\end{array}$ & $\begin{array}{c}\text { Change in upload } \\
\text { speed March- } \\
\text { December 2012 }\end{array}$ \\
\hline Argentina & 4.23 & 1.13 & 12.5 & 19.0 \\
Bolivia (Plurinational & 1.24 & 0.53 & 96.8 & 76.7 \\
State of) & 6.79 & 1.46 & 10.9 & 10.6 \\
Brazil & 9.37 & 2.66 & 32.3 & 46.2 \\
Chile & 3.92 & 1.55 & 21.4 & 19.2 \\
Colombia & 2.57 & 0.73 & 15.3 & 10.6 \\
Costa Rica & 3.78 & 2.98 & 44.3 & 40.6 \\
Ecuador & 3.21 & 1.67 & 17.6 & 7.1 \\
El Salvador & 2.63 & 1.26 & 0.4 & 10.5 \\
Guatemala & 2.81 & 1.77 & 7.7 & 14.9 \\
Honduras & 6.98 & 2.09 & 41.0 & 25.9 \\
Mexico & 3.38 & 2.03 & 6.0 & 0.5 \\
Nicaragua & 3.67 & 1.26 & 24.8 & -3.8 \\
Panama & 2.90 & 1.94 & 22.9 & 50.4 \\
Paraguay & 2.89 & 0.65 & 114.1 & 109.7 \\
Peru & 7.83 & 2.04 & 165.4 & 200.0 \\
Uruguay & 1.95 & 0.45 & 27.5 & 15.4 \\
Venezuela (Bolivarian & & 1.54 & 32.1 & 28.6 \\
Republic of) & & & & \\
Latin America average & 4.13 & & & \\
\hline Sourc: Ook & & & & \\
\hline
\end{tabular}

Source: Ookla.

The data are published by Netindex [online] www.netindex.com. 
There is a wide range of speeds, with some countries attaining only a third of the regional average. In general, Latin American ISP download and upload speeds are one third and one half, respectively, of those in Europe. The rates of change are very similar for the two speeds, which indicates that the trend is for the gap to remain the same.

Akamai's findings are presented as an alternative measure. They are based on 1 trillion direct daily measurements of content requests supported by its 100,000 servers distributed throughout the world (see table III.2). ${ }^{4}$ The table shows average values as well as percentages of providers adopting speeds greater than $4 \mathrm{Mbps}$ and $10 \mathrm{Mbps}$ (includes speeds greater than $4 \mathrm{Mbps}$ ) and those under $256 \mathrm{Kbps}$. The differences between these and the Ookla values may be due to the fact that Akamai directly measures the download speed of its sites, no matter where they are located, whereas Ookla measures against servers that are usually close to the end-user.

Table III.2

INTERNET SPEEDS IN THE REGION ACCORDING TO AKAMAI

\begin{tabular}{lcccc}
\hline & $\begin{array}{c}\text { Average } \\
\text { connection } \\
\text { speed (Kbps) }\end{array}$ & $\begin{array}{c}\text { High-speed } \\
\text { broadband } \\
\text { adoption rate } \\
(>10 \mathrm{Mbps})\end{array}$ & $\begin{array}{c}\text { Broadband } \\
\text { adoption rate } \\
(>4 \mathrm{Mbps})\end{array}$ & $\begin{array}{c}\text { Adoption rate } \\
\text { for speeds } \\
\text { below } 256 \\
\text { Kbps }\end{array}$ \\
\hline $\begin{array}{l}\text { Argentina } \\
\text { Bolivia (Plurinational }\end{array}$ & 2244 & 6.35 & 41.80 & 2.67 \\
State of) & 572 & 0.09 & 1.67 & 19.06 \\
Brazil & 2168 & 6.44 & 39.94 & 5.56 \\
Chile & 3406 & 10.84 & 84.76 & 0.21 \\
Colombia & 2653 & 4.69 & 64.47 & 0.43 \\
Costa Rica & 1805 & 1.22 & 29.77 & 1.47 \\
Ecuador & 1740 & 1.93 & 32.07 & 1.18 \\
El Salvador & 1847 & 4.62 & 28.60 & 7.12 \\
Guatemala & 2647 & 5.98 & 63.63 & 1.98 \\
Honduras & 1749 & 2.35 & 30.94 & 1.72 \\
Mexico & 2794 & 4.46 & 70.11 & 0.79 \\
Nicaragua & 1303 & 0.98 & 12.69 & 2.52 \\
Panama & 2783 & 3.33 & 74.28 & 0.89 \\
Paraguay & 1238 & 0.32 & 7.89 & 1.15 \\
Peru & 1644 & 0.42 & 25.64 & 0.87 \\
\hline
\end{tabular}

4 See www.akamai.com and the company's comments at https://blogs.akamai. com/2011/11/the-future-internet.html. 
Table III.2 (concluded)

\begin{tabular}{lcccc}
\hline & $\begin{array}{c}\text { Average } \\
\text { connection } \\
\text { speed (Kbps) }\end{array}$ & $\begin{array}{c}\text { High-speed } \\
\text { broadband } \\
\text { adoption rate } \\
(>10 \mathrm{Mbps})\end{array}$ & $\begin{array}{c}\text { Broadband } \\
\text { adoption rate } \\
(>4 \text { Mbps })\end{array}$ & $\begin{array}{c}\text { Adoption rate } \\
\text { for speeds } \\
\text { below 256 } \\
\text { Kbps }\end{array}$ \\
\hline $\begin{array}{l}\text { Uruguay } \\
\text { Venezuela (Bolivarian }\end{array}$ & 1326 & 0.07 & 7.78 & 1.41 \\
Republic of) & 905 & 0.32 & 4.46 & 6.52 \\
Spain & 4614 & 27.48 & 87.51 & 0.69 \\
England & 5576 & 39.42 & 93.10 & 0.35 \\
France & 4889 & 31.18 & 90.56 & 0.16 \\
Italy & 4147 & 17.43 & 89.16 & 0.65 \\
Portugal & 5366 & 43.89 & 88.81 & 0.28 \\
Japan & 10918 & 65.76 & 88.18 & 0.87 \\
\hline
\end{tabular}

Source: Akamai and data processed by the author.

\section{Reference prices}

Table III.3 shows published reference prices (not those actually charged) for fixed and mobile broadband in the countries of Latin America, expressed in dollars per month. Prices for fixed Internet access with the smallest number of additional services and prices for download speeds closest to $2 \mathrm{Mbps}$ (the speed defined in annex III.1 as advanced broadband) are listed for each country and for major operators. The price per Mbps for these services is calculated including taxes but not including initial promotions. Given that traffic is more important than speed for mobile broadband, within reasonable ranges, prices are for traffic close to 3 gigabytes, regardless of speed.

The wide range of prices can be attributed to factors such as country size, the amount of competition in the access market and in submarine cables, economies of scale and public policies. In Paraguay and the Plurinational State of Bolivia, high prices also reflect their status as landlocked countries. The price difference for mobile broadband is smaller than in more advanced countries because of better use of economies of scale (high teledensity) and less international transit. 
Table III.3

REFERENCE PRICES FOR FIXED ACCESS PER MBPS FOR DOWNLOAD SPEEDS OF APPROXIMATELY 2 MPBS, NOVEMBER 2012

\begin{tabular}{|c|c|c|c|c|}
\hline \multirow[b]{2}{*}{ Country } & \multicolumn{2}{|c|}{ Fixed broadband } & \multicolumn{2}{|c|}{ Mobile broadband } \\
\hline & $\begin{array}{c}\text { Average price } \\
\text { of } 1 \mathrm{Mbps} \\
\text { (dollars) }\end{array}$ & $\begin{array}{c}\text { Price as } \\
\text { percentage of } \\
\text { monthly per } \\
\text { capita GDP }\end{array}$ & $\begin{array}{l}\text { Average price } \\
\text { (dollars) }\end{array}$ & $\begin{array}{c}\text { Price as } \\
\text { percentage of } \\
\text { monthly per } \\
\text { capita GDP }\end{array}$ \\
\hline Argentina & 12.13 & 1.3 & 29.80 & 3.3 \\
\hline $\begin{array}{l}\text { Bolivia (Plurinational } \\
\text { State of) }\end{array}$ & 63.61 & 31.5 & 22.83 & 11.3 \\
\hline Brazil & 19.57 & 1.9 & 34.40 & 3.3 \\
\hline Chile & 13.18 & 1.1 & 33.78 & 2.8 \\
\hline Colombia & 19.53 & 3.3 & 19.99 & 3.4 \\
\hline Costa Rica & 13.07 & 1.8 & 27.12 & 3.8 \\
\hline Ecuador & 14.77 & 3.9 & 28.75 & 7.6 \\
\hline EI Salvador & 13.65 & 4.4 & 16.50 & 5.4 \\
\hline Guatemala & 31.20 & 11.8 & 22.21 & 8.4 \\
\hline Honduras & 16.92 & 9.1 & 18.08 & 9.7 \\
\hline Mexico & 9.48 & 1.1 & 25.11 & 3.0 \\
\hline Nicaragua & 17.25 & 16.7 & 22.43 & 21.7 \\
\hline Panama & 7.26 & 1.0 & 14.95 & 2.1 \\
\hline Paraguay & 20.06 & 6.6 & 19.56 & 6.5 \\
\hline Peru & 32.77 & 6.5 & 30.91 & 6.2 \\
\hline Uruguay & 12.58 & 1.1 & 18.80 & 1.6 \\
\hline $\begin{array}{l}\text { Venezuela (Bolivarian } \\
\text { Republic of) }\end{array}$ & 35.01 & 3.9 & 24.63 & 2.7 \\
\hline Average & 20.71 & 6.3 & 24.11 & 6.0 \\
\hline Spain & 2.88 & 0.1 & 34.52 & 1.3 \\
\hline France & 2.11 & 0.1 & 45.22 & 1.3 \\
\hline England & 0.90 & 0.1 & 20.03 & 0.6 \\
\hline Italy & 4.64 & 0.2 & 28.52 & 1.0 \\
\hline Portugal & 3.50 & 0.2 & 17.19 & 1.4 \\
\hline Japan & 2.15 & 0.1 & 32.48 & 0.9 \\
\hline
\end{tabular}

Source: Economic Commission for Latin America and the Caribbean (ECLAC), Regional Broadband Observatory, on the basis of survey of operators' web pages.

\section{Aggregation factor}

In addition to the speed and latency parameters, there is an important factor about which little is usually known and which is related to service quality at peak Internet use times, such as early evening. It is the aggregation factor, a parameter that operators deal with specifically 
at points in the network where bottlenecks occur. The effect of applying inappropriately high values is packet loss and retransmissions that slow down effective data traffic.

Aggregation is a standard part of ISP network design, especially for international links and shared access such as wireless networks, FTTH GPON (fiber-to-the-home with Gigabit Passive Optical Networks) and HFC networks (hybrid fibre coaxial networks for subscription cable television). It is based on the fact that all users are not usually on the Internet at the same time, and that even when they are online, not all of them download information at the same time. For this reason, ISPs design bottlenecks into their networks, including international access, for average customer use. For international links, the correct value depends on the country, because some countries have a lot of content hosted within their borders, or the ISP may have large caching facilities. Generally it is on the order of 20:1; when international linkage prices rise significantly, ISPs use higher values, which reduces quality during peak hours. When a lot of content is hosted locally, there is less usage of international channels and it is possible to use larger aggregation factors without sacrificing service.

\section{South America's dependence on international links}

This section examines Internet connectivity, how international links impact costs, and factors that have an indirect influence on costs, such as CDN storage.

There is very little competition among international cable operators in Latin America in comparison with regions in the Northern Hemisphere, primarily because demand has been and remains much smaller than in the latter and because existing cables still have the capacity to expand. However, that capacity could decline significantly in the near future.

Demand in Latin America (which, according to Cisco, is rising at a compound annual rate of $51 \%$ ) is likely to gradually exhaust the available supply. This trend in demand could lead to private initiatives and intergovernment or single-government initiatives as well. The same market arguments concerning South America apply to Central America as well, ${ }^{5}$ prices and quality tend to vary for contracts with similar durations, and prices are considered higher than in the Southern Cone.

New cables linking the region to Europe and Africa are under construction, as are cables within the region and connecting to the United States. This could drive prices down further. 


\section{The international bottleneck and its strategic importance}

For historical reasons, the NAP of the Americas was completed a decade ago. Today it is one of several major telecommunications facilities located in the state of Florida. This initiative has generated substantial economies of scale that result in almost all traffic between Latin America and the rest of the world going through Florida, or, to a lesser extent, through the east coast of the United States.

Latin America's traffic with the rest of the world and even among countries in the region is highly dependent on the United States, which creates a strategic infrastructure challenge. Aside from this connection, there is only the Atlantis 2 cable; its maximum capacity is 160 Gbps, an insignificant volume considering current and projected traffic. Brazil recently announced a new cable linking it to Europe that would substantially improve this situation, as well as a cable to Africa that may connect with pan-African cables and provide an alternative access route to Europe.

\section{Regional interconnection}

\section{(a) Types of arrangements}

There are different options for obtaining international and regional connectivity, two of which involve peering:

(i) An ISP contracts with an international carrier for conveyance capacity through a dedicated circuit to an Internet access point, such as an IXP in Miami, and makes a separate purchase for access to Internet transit at the other end. In this case, all traffic that is exchanged uses an international circuit that always goes first through a remote IXP and is then routed to the end destination.

(ii) An ISP contracts with an international carrier, for direct access to the IP network, also known as an IP transit service, for direct access to the IP network. This gives it access to the entire Internet. In this case, the carrier makes (technically or economically) efficient use of its own network by exchanging the ISP's traffic at the point that best suits its needs, using the server with which the ISP exchanges traffic.

(iii) Two ISPs can engage in private peering between themselves by giving each other access to their networks. This option is chosen 
when the ISPs have a mutual interest in interconnecting their networks. They generally do not pay each other. This arrangement tends to occur between major global operators, but sometimes it involves connections between ISPs in neighboring countries.

(iv) In contrast to the private peering discussed in the previous point, public peering is also viable for IXPs. In public peering, an ISP interconnects with other ISPs through a single port.

The choice of one approach or another depends on the prices quoted for capacity, transit, the interest in peering, and each ISP's traffic profile. In general, these four basic types of contract are available for medium-sized and large access providers.

\section{(b) Intra- and extra-regional capacity according to TeleGeography}

The TeleGeography study (2011) of Internet interconnection route capacity is a partial analysis of traffic in Latin America that gives an indication of the actual traffic situation. A link between two countries may be carrying traffic with other destinations, and the same may be true of links used to go from one country to a landing station located in another country. The section below examines traffic itself based on route studies.

The links between Latin America and the United States represent $85.5 \%$ of the capacity of all international links in the region. Intraregional links, some of which are used to access the global Internet, represent $14.3 \%$ of the total, whereas the capacity of links to Europe accounts for only $0.2 \%$. Nearly three quarters of total capacity in Latin America and the Caribbean is in South America, a little less than one quarter is in Central America and Mexico, and approximately 3\% is in the Caribbean. Map III.1 shows the distribution of international traffic capacity by major route.

This marked concentration of interconnection capacity with the United States works to the detriment of intraregional connection capacity. To date there are no reliable overall measures of the percentage of intraregional capacity going through the United States, but it is estimated to be about $15 \%$. On top of that is the traffic that is exchanged with the United States but whose true purpose is to obtain information from regional sites (such as newspapers, TV channels and radio stations) located in that country. It is clear that not all of that traffic needs to pass through the United States. 
Map III.1

CAPACITY OF PRINCIPAL INTERNATIONAL ROUTES IN LATIN AMERICA

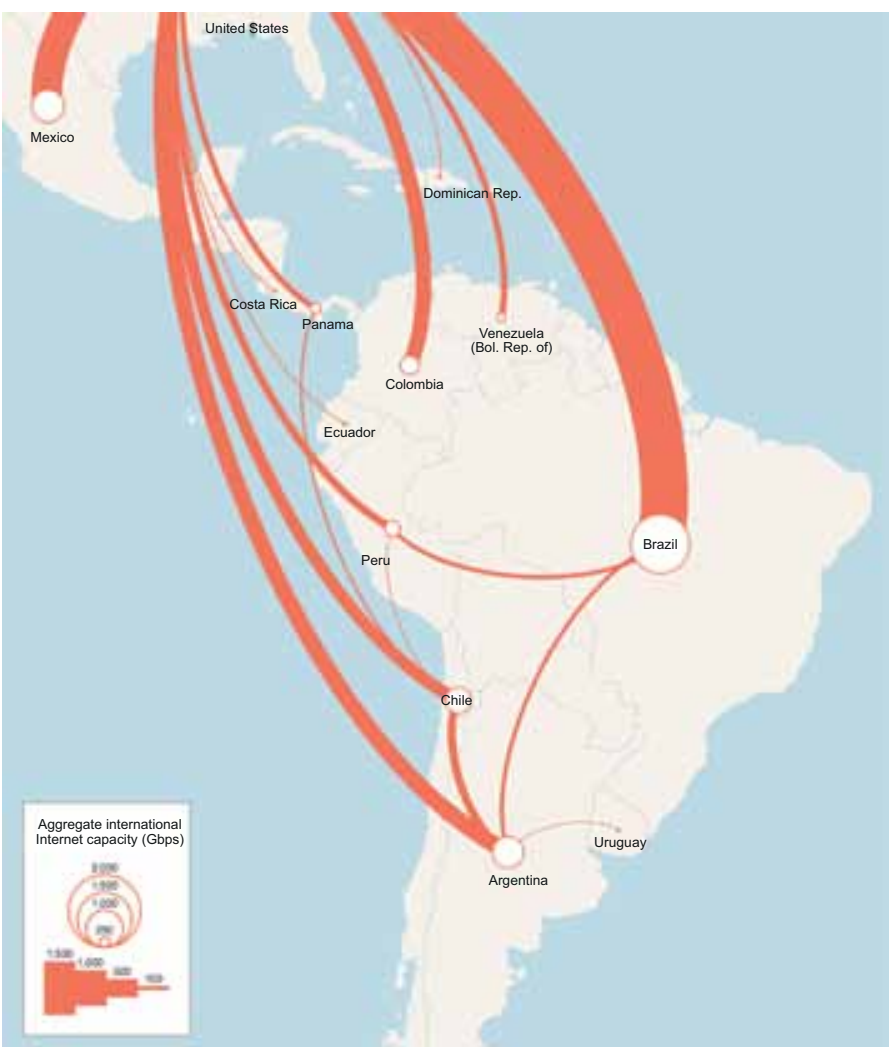

Source: TeleGeography, Global Internet Geography - Latin America, 2011.

Note: The boundaries and names shown on this map do not imply official endorsement or acceptance by the United Nations.

\section{Regional transit routes}

Looking at domestic interconnection, it is difficult to identify all of the interconnection relationships between ISPs. This section examines two partial alternatives. Neither one is a complete alternative - the first one because of practical difficulties and the second one because of problems with the underlying information.

\section{Methodology based on the Tracert command-line utility}

Using the Tracert command-line utility, ${ }^{6}$ a sample of routes was traced from multiple countries to the main content sites used, which in

6 Traceroute is a diagnostic tool for tracking packets that come from a single network point (host). An RTT or network latency statistic is obtained for these packets, which is an 
turn are located in multiple countries, to observe the behaviour of routes in the region. This methodology makes it possible to identify not only national and regional interconnections, but also all of the routes used in the domestic or regional interconnection, by identifying all intermediate routers used. The following behaviours have been identified:

(i) A substantial number of regional-content servers are located in the United States and, to a lesser extent, in Europe.

(ii) CDNs are deploying more and more servers in the region, reducing the number of network hops required to access content.

(iii) ISPs that contract for IP transit from their countries have more direct routes to the countries of the region.

(iv) ISPs that base their connectivity on capacity going to the United States and then transit on an IXP far from that country can access sites located in the region through that IXP.

(v) For several countries in the region, interconnection between ISPs in the same country takes place abroad.

Although this methodology yields clear and verifiable results based on the IP addresses of the interfaces of the routers through which the information travels, it is not scalable for conducting a complete evaluation of domestic and regional interconnection usage, nor does it help determine the volumes of traffic actually exchanged on each route.

\section{Methodology using Default-Free Zone}

Another methodology for evaluating the region's connectivity, which includes domestic connectivity for each country, is based on the analysis of the default-free zone (DFZ) ${ }^{7}$ or public IPv4 routing tables for interconnections between autonomous systems $(\mathrm{AS})^{8}$ in a single country (domestic interconnection) and between different countries in a given region (regional interconnection). This methodology does not encompass all ISPs, so its results are not exhaustive. This limitation is insurmountable because the underlying data are partial at their origin and do not include all interconnections or all ISPs.

estimate of the distance between the two ends of the communication. This tool is called traceroute on UNIX, Mac and GNU/Linux machines; in Windows it is called tracert.

7 The DFZ consists of all routers that have a global routing table and do not require a default route to send a packet to any destination.

8 According to RFC 1930, an Internet autonomous system (AS) is a set of networks operated by one or more network operators which has a single and clearly defined routing policy. It has autonomy with respect to external routing. Every AS has a unique number assigned to it under RFC 4893, called an Autonomous System Number (ASN). 
The application of this methodology, presented by Patara (2010), is intended only to determine the situation in countries that do not have IXPs based on information as of 10 May 2010. The interconnection results are presented in the form of a map for each country showing all ASs and the interconnections between them. This methodology leads to the same conclusion as the first one, though by a different route: many countries that do not have IXPs do not have complete domestic interconnections. IXPs that adhere to world best practices, which will be seen later, are a must for improving Internet quality and reducing prices (by using fewer international links).

\section{Variables affecting costs}

The main factors influencing end-user prices for Internet access are discussed in this section. Some of them, such as IXPs, are analysed in more detail in other sections and in annex III.2.

\section{(a) Importance of traffic exchange points}

This section describes how IXPs reduce Internet access costs. The impact can be seen in Chile, which has 15 years of experience in national interconnection. The high rate of connectivity in Chile makes it possible to differentiate wholesale prices between national and international traffic (with domestic traffic being several times cheaper than that with other countries). The most important aspects to consider with regard to their cost-reduction impact are:

(i) The existence of an IXP in a country can lower the costs of connecting ISPs with each other, because it is enough for each one to be connected to the IXP for all of them to have access to each other's networks through commercial agreements.

(ii) The absence of an IXP means that ISPs may have to set up a grid structure or even connect through other countries' IXPs.

(iii) The IXP is an efficient mechanism for routing domestic traffic, because ISPs usually pay the IXP and interconnection costs; when network differences keep them from peering they enter into transit agreements.

(iv) Aggregating IXP traffic leads to lower prices for long-distance domestic and international IP transit through ISPs, as can be seen in Argentina and Brazil.

(v) IXPs are a natural place to host content, thereby cutting costs to providers and improving the quality of service to the end user, with a significant reduction in delays or transit times. 
(vi) CDNs seek neutral IXPs whose management policies cannot be manipulated to benefit any particular national or international ISP or carrier. This is a principle that has been in place since the early development of IXPs throughout the world.

(vii) CDNs enter into peering agreements for installation on the following economic basis: (i) the CDN brings content to the ISP so that the latter can operate as a "platform" in a bilateral market between the end user and the $\mathrm{CDN}$; (ii) the $\mathrm{CDN}$ provides value to the ISP and thus to the end user by improving the quality of service; (iii) the ISP provides value to the CDN by giving it direct access to the end user; and (iv) the platform's pricing mechanism avoids the use of international channels, cutting costs for both sides.

(viii) The existence of multiple IXPs in a country or region facilitates agreements between carriers so that they can spread the load more evenly across networks and achieve route redundancy.

\section{Web caching}

Web caching, a technology that has been in use for years, is the local storage of content that is located on distant servers and is consulted frequently by users. This reduces the usage of international links, since the content is accessed locally. For example, when a news site is consulted, the system can locally download the standard images on the page that have been stored previously so that it only needs to download from the site the headlines and other text content that is constantly updated. In other cases, such as YouTube, the system downloads videos that are frequently consulted. The savings in international link usage varies, ranging from $20 \%$ to $30 \%$ depending on factors such as user behaviour, the size of the web caching system and the quality of the technology employed.

\section{National and regional content hosting}

The countries of the region generate abundant content that is consulted primarily by domestic users. The majority of this content tends to be hosted at data centres located mainly in the United States, and, to a lesser extent, in Europe. It has already been noted that a significant portion of regional media sites are hosted in the United States, and it is believed that the same is true of other content and application providers. The reason for this tendency is that companies hosting content in advanced countries offer lower costs and greater transmission capacity. Although it is a widespread trend, it is useful to distinguish among the different types of content and application providers.

(i) Major web sites of service provider companies. These include the web sites of large production, commercial or industrial businesses, 
news media, airline customer service centres, online sales sites, e-health management centres and others. For such companies, the quality of the hosting service and proximity to their centre of operations are more important than price. These sites could be hosted locally under the right conditions, mainly in terms of quality, or they could be hosted by CDNs.

(ii) Major content and application distribution networks (CDN). These include providers such as Google-YouTube, Akamai, Microsoft, Limelight Networks, Level3 and others. They have developed CDNs with nodes located in countries that offer incentives for that purpose. Bearing in mind that Google-YouTube accounts for about $10 \%$ of total Internet traffic and Akamai for $20 \%$, it is obviously important to establish favourable conditions for local hosting of their content. The existence of an IXP is an essential part of these companies' decision-making process.

(iii) Small content and application providers. Since their main objective tends to be cost reduction, aside from good quality, it is very difficult for them to compete with the major hosting providers in the northern hemisphere that have economies of scale and low costs for their main business inputs.

\section{Global trends and prices}

In August 2011, TeleGeography published information on changes in pricing for transoceanic links and emphasized that competitiveness on the North Pacific route, where there are at least 14 cables operating and one under construction, is similar to that of the North Atlantic route. In two years (between the second quarter of 2009 and the second quarter of 2011), the median monthly lease for a $10 \mathrm{Gbps}$ lambda cable between Los Angeles and Tokyo fell from US\$ 98,500 to US\$ 36,000 (see figure III.1). This trend is attributed to the deployment of three new cables in 2008-2009 and 2010, which increased competition and available capacity. The monthly lease of US\$ 36,000 per 10 Gbps is equivalent to US\$ 3.60 per Mbps, several times lower than what is paid in South America.

Another approach is to look at the trends in the median price of GigE ports (1 Gbps) to the last four months of 2011. In four years, the price of 1-Gbps ports in New York and Hong Kong SAR fell at a compound annual rate of $17 \%$, while in London and selected cities in Latin America (Buenos Aires, Mexico City, Rio de Janeiro, Santiago and São Paulo) they fell approximately $20 \%$. The relative prices of the two regions are likely to stay on the same trajectory, unless there are significant changes in demand 
for volume and available capacity in Latin America. It is believed that prices will continue to fall in the region as new cables are installed and demand increases.

Figure III.1

MEDIAN MONTHLY PRICES ON NORTH PACIFIC ROUTES FOR 10 GBPS, SECOND QUARTER 2010 TO SECOND QUARTER 2011

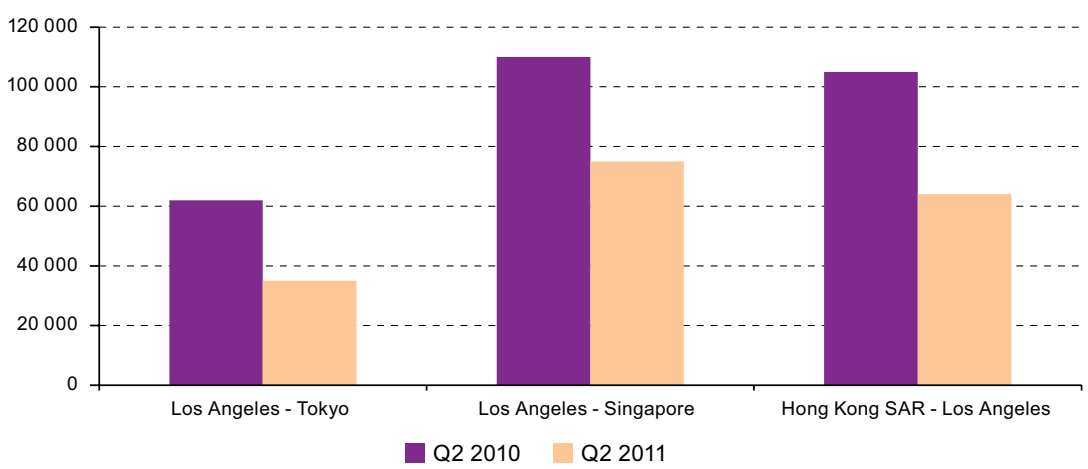

Source: TeleGeography, Global Internet Geography Research Service.

Figure III.2 shows trends in prices in some of the major cities of Latin America since 2008. They are converging towards a rate of US\$ 40 per Mbps per month and so could stand at some US $\$ 30$ per Mbps by the end of 2012.

Figure III.2

TRENDS IN MEDIAN PRICES IN MAJOR CITIES OF LATIN AMERICA

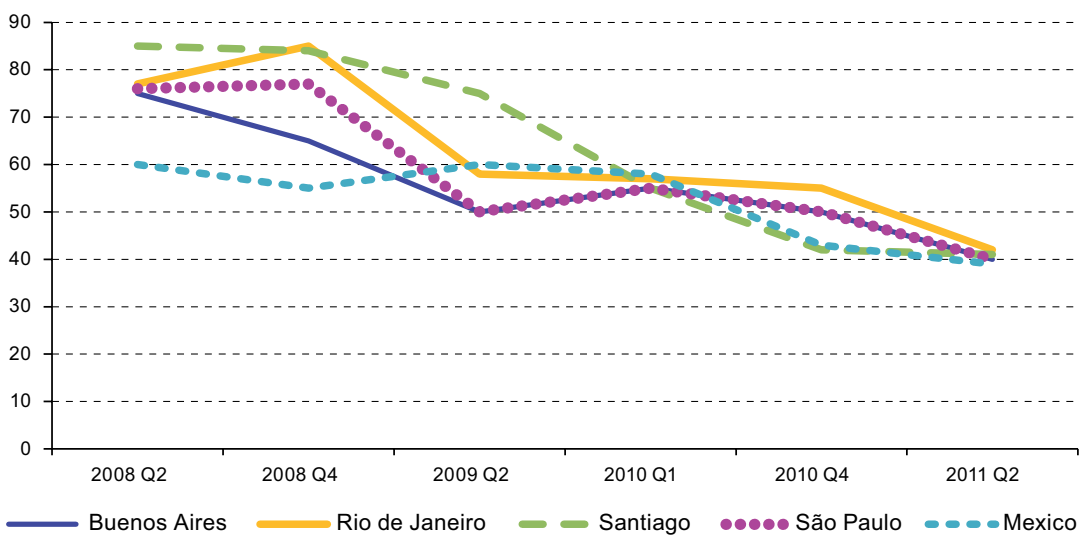

Source: TeleGeography, Global Internet Geography Research Service. 
Figure III.3 provides an intercontinental comparison of pricing trends. Prices in São Paulo have fallen at the same rate as in the Northern Hemisphere, but the ratio of 6:1 with Europe (London) and the United States (New York) is not shrinking, nor is the 2:1 ratio with Asia (Hong Kong SAR).

Supplementary information shows that, in keeping with the worldwide trend, operators in the region are expanding their networks to reach areas far away from their primary markets, so prices are expected to fall in those areas as well.

Figure III.3

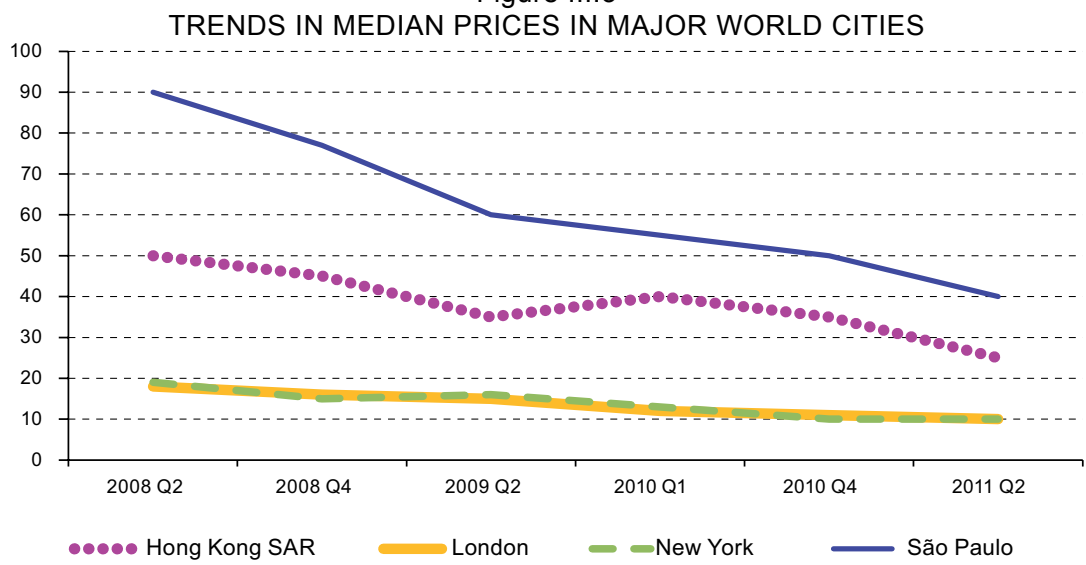

Source: TeleGeography, Global Internet Geography Research Service.

\section{Conclusions}

The following conclusions can be drawn from the analysis presented in this chapter and its annexes.

(i) Although progress has been made in fibre illumination in Latin America, Internet usage is growing at a rate that is likely to lead to saturation in the near future.

(ii) There are a number of initiatives to build international links that could generate more competition and expand capacity in the future.

(iii) The United States continues to predominate as an Internet interconnection centre for Latin America, representing 85.5\% of the capacity of all of the region's international links. Intraregional links account for $14.3 \%$ of the total. 
(iv) There are several different kinds of access agreements at the wholesale level.

(v) Traffic among countries in the region travels predominantly along routes passing through the United States.

(vi) The existence of internet exchange points or IXPs in a country yields many advantages, including lower costs and better quality, the possibility of moving towards lower prices for international IP transit, incentives for local content hosting and the installation of CDNs.

(vii) It is important to prioritize the search for greater local content hosting capacity in two stages: (i) seek the installation of large content and application providers as well as CDNs, and (ii) create a favourable environment to encourage new small content providers to begin hosting locally.

(viii) The median monthly cost per Mbps as of the end of 2011 was US\$ 31 for 10-Gbps ports and US $\$ 41$ for 1-Gbps ports, but these figures are for prices at the cable landing points and do not take local lines into account. As of year-end 2012, they may be $20 \%$ lower. These prices are about six times higher than in Europe and the United States, and twice the levels found in Asia.

(ix) Over the past three years, prices in the Northern Hemisphere and in Latin America have been falling at a similar compound annual average rate of $20 \%$. The relative prices of the two regions are likely to stay on the same trajectory, unless there are significant changes in demand for volume and available capacity in Latin America.

(x) Costs may come down if regional traffic can avoid more costly routes by going through remote exchange points (Miami, for example) rather than direct routes between IXPs in the different countries. This situation may be improved by facilitating regional connectivity for all operators while promoting the installation of IXPs in all countries. 


\section{Bibliography}

Patara, Ricardo (2010), NICbr. Estudio de la relación entre el AS y IXP en la región (LAC). [Study of the relationship between AS and IXP in the region (Latin America and the Caribbean)] Network Access Points Latin America (NAPLA).

TeleGeography (2011), Global Internet Geography Research Service. 


\section{Annexes}

\section{Annex III.1 \\ Broadband definitions}

\section{ITU Recommendation I 113}

This recommendation dates back to June 1997, so it reflects a completely different time and refers primarily to Integrated Services Digital Network (ISDN) technology. It states that "broadband qualifies a service or system requiring transmission channels capable of supporting rates greater than the primary rate of ISDN". The primary rate was equal to $1.54 \mathrm{Mbps}$ (1 T1) in the United States standard and 2,048 Mbps (1 E1) in the European standard.

\section{The ITU report of 2004}

In the report titled ITU and its Activities Related to Internet Protocol (IP) Networks published by ITU in April 2004, broadband is defined as follows: "Although there exist various definitions of broadband that have assigned a minimum data rate to the term, it may be defined as transmission capacity with sufficient bandwidth to permit combined provision of voice, data and video, with no lower limit. ..." Broadband is defined in terms of the services that can be provided through it, especially the combination of services that can require speeds of $2 \mathrm{Mbps}$ or higher.

Later on, in section 7.2, "What is broadband?", the report states: "While the term broadband is used to describe many different Internet connection speeds, Recommendation I.113 of the ITU Standardization Sector (ITU-T) defines broadband as a transmission capacity that is faster than primary rate ISDN, at 1.5 or $2.0 \mathrm{Mbit} / \mathrm{s}$. However, this definition is not strictly followed. The OECD considers broadband to correspond to transmission speeds equal to or greater than $256 \mathrm{kbit} / \mathrm{s}^{\prime \prime}$.

\section{"Definitions of World Telecommunication/ICT Indicators"}

Telecommunications indicators are identified in the document Definitions of World Telecommunication/ICT Indicators, published by ITU in March of 2010. Although the term broadband is not expressly defined, its meaning can be inferred from the indicators that are defined.

Fixed broadband. It is established that the measurement of this indicator should include connections at speeds greater than $256 \mathrm{Kbps}$. ITU has also decided to survey indicators for fixed broadband access at speeds of $256 \mathrm{Kbps}$ to $2 \mathrm{Mbps}$, 2-10 Mbps, 10-100 Mbps, 100-1000 Mbps and more than $1000 \mathrm{Mbps}$ or $1 \mathrm{Gbps}$. The survey of subscriptions at speeds higher than $256 \mathrm{Kbps}$ has been maintained to prevent an interruption of historical series. Thus, allowing for higher-speed indicators means that series can be 
established for the present date while maintaining historical series dating back many years.

Mobile broadband. This indicator encompasses standard mobile subscriptions using data communications at broadband speeds, including subscriptions with advertised speeds of $256 \mathrm{Kbps}$ or higher.

\section{"Measuring the Information Society"}

The document Measuring the Information Society, published by ITU in 2011, states in box 4.1, "Defining broadband - a moving target": "Although many national regulators and international organizations, including ITU and OECD, define broadband as a connection with downstream speeds greater than, or equal to, $256 \mathrm{kbit} / \mathrm{s}$, there remains much debate as to how fast a connection should be to qualify as broadband, and national definitions vary. The United States, for example, just recently redefined broadband as a 'transmission service that [currently] enables an end user to download content from the Internet at $4 \mathrm{Mbps}$ and to upload such content at 1 Mbps over the broadband provider's network'. Some developing countries, for example Djibouti and Morocco, apply definitions of broadband that set a lower speed $(128 \mathrm{kbit} / \mathrm{s})$. However, most national broadband definitions are in line with the ITU/OECD definition.

\section{ITU News. The broadband debate: The need for speed?}

The September 2011 edition of this ITU publication ${ }^{9}$ refers to the need to define broadband speed. Recognizing the importance of speed, it asks what speed is fast enough and what other factors need to be taken into consideration to establish speed and coverage targets. In particular, it notes that basic connectivity still makes a real difference in people's lives, their work and other aspects of economic and social life, without overlooking the importance of high-speed connections.

\section{"Broadband: A platform for progress"10}

The document Broadband: A platform for progress. A report by the Broadband Commission for Digital Development, published by ITU and UNESCO in June of 2011, notes in its section 2.1, "Possible definitions", that several definitions have been debated by the Commission. Three options have emerged in this context: (i) broadband could be defined by quantitative indicators as a function of speed and technology; (ii) broadband could be defined by qualitative indicators, in terms of the applications it enables or the impact it may have on economic and social factors; or (iii) a combination of both can be used. Although it analyses the options, the document does not reach a conclusion on a definition for broadband.

See [online] http://www.itu.int/net/itunews/issues/2011/07/11.aspx.

See [online] www.broadbandcommission.org. 


\section{A proposed definition of broadband for the countries of the region}

This proposal takes into account the documents studied and the objective of arriving at a practical definition that can be quantifiable, taking into account not only user needs in terms of the applications they require, but also possible limitations specific to each country with respect to economies of scale, international costs and geography, among other considerations. This definition was developed within the framework of the Regional Broadband Dialogue, for which ECLAC is the technical secretariat.

The objective is to provide a broadband development indicator not intended for regulatory purposes. In addition, the goal is to translate qualitative objectives into clear and simple quantitative indicators that make it possible to plan, evaluate and follow up on broadband trends so that findings can be compared.

An initial condition for classing Internet access as broadband is that the connection must be permanent, meaning that it is not necessary to establish a connection every time one decides to exchange information ("always on"). There is evidence that when using mobile broadband, customers value "always on" more than speed.

To define broadband, it was considered important to establish three levels of service depending on customer requirements, taking into account each country's social and economic development and issues such as e-health, e-learning and e-government.

Simple activities. These are the simplest activities carried out on the Internet that nonetheless substantially improve quality of life as a means of social integration. They require moderate speeds and are in line with the ITU definition. Simple activities consist primarily of e-mail, reading or downloading documents and general web surfing, written online communication (chatting) and access to government applications with low data content.

Advanced activities. These activities require broadband to take advantage of the main services currently offered on the Internet: social networking, standard definition video streaming with a certain level of compression (for example, approximately $700 \mathrm{MB}$ for a $1 \frac{1 / 2}{2}$ hour film), video conferencing, file sharing, instant messaging, webmail and navigation at speeds that allow for telecommuting or advanced e-health with image or video transfer, among others.

All high-capacity activities. These include video streaming and highdefinition (HD) IPTV, telepresence, sharing large files, telework with easy sharing of large volumes of data, advanced e-health with the transfer of 
large volumes of image and video data, e-learning including HD videos, among others, as well as trouble-free conduct of current activities.

Based on these demands, three levels of broadband service should be included in the definition: (i) basic broadband, which is provided through wired or wireless, fixed or mobile services and enables simple activities on the Internet; (ii) advanced broadband, which makes it possible to engage in all of the advanced activities currently available on the Internet; and (iii) total broadband, which enables users to comfortably engage in their current activities and be in a position to enjoy all high-capacity activities.

In these definitions, the main parameters are download and upload speeds. Other parameters such as latency and jitter ${ }^{11}$ also affect the quality of user experience, but it is not appropriate to include them at this juncture for two reasons. First, they do not have a great impact on quality in the region; and second, it is difficult to survey this information in the region.

The speed currently defined by ITU ( $256 \mathrm{Kbps}$, which is primarily an international benchmark) is considered adequate for simple Internet activities and could be set as the entry or basic level for broadband. Based on experience, it is believed that an effective download speed of $2 \mathrm{Mbps}$ is adequate for advanced activities such as standard definition (SD) video streaming with a certain level of compression. This speed is chosen because it is also the lower limit of the second level of access speed defined by ITU in its surveys. For the third level of service, $10 \mathrm{Mbps}$ is considered suitable, as it is the next level defined by ITU, and it is also close to the $11.25 \mathrm{Mbps}$ that Cisco regards as the minimum for supporting future applications (see table III.A.1).

Table III.A. 1

DEFINITION OF BROADBAND

\begin{tabular}{llll}
\hline Indicator & Basic broadband & $\begin{array}{l}\text { Advanced } \\
\text { broadband }\end{array}$ & Total broadband \\
\hline Download speed & 256 Kbps. & $>2$ Mbps. -2048 & $>10$ Mbps. \\
Upload speed & 128 Kbps. & $>512$ Kbps. & $>768$ Kbps. \\
Availability of use & Always on & Always on & Always on \\
\hline
\end{tabular}

Source: Prepared by the author.

As for upload speeds, the basic broadband service level is set at $128 \mathrm{Kbps}, 512 \mathrm{Kbps}$ for advanced broadband, and $768 \mathrm{Kbps}$ for total broadband. Because $768 \mathrm{Kbps}$ does not allow for activities requiring high

11 Jitter is the term used for digital signal transit time variance. It tends to be regarded as an undesirable signal noise. 
upload speeds, such as SD videoconferencing, it may be considered a little too low. However, it is well suited to the situation in Latin America, where download speeds of $6 \mathrm{Mbps}$ to $10 \mathrm{Mbps}$ and upload speeds of about $800 \mathrm{Kbps}$ are typically offered. In conclusion, $768 \mathrm{Kbps}$ was adopted so as not to leave out operators in the region offering more than $10 \mathrm{Mbps}$ but with upload speeds that are still low compared to what is required for more advanced applications.

For wired connections, published speeds are used because it is difficult to obtain information on real speeds differentiated by bands. In addition, since service quality control is a function that may or may not be exercised by the regulatory authority, the survey-based definition does not take into account the difference between actual and published speeds. For wireless connections, due to technical issues related to the manner in which the resource is shared, the peak speed provided by the base station is considered. In this case, it is impossible to define a quality margin because of the stochastic nature of the data flow, which depends on the number of customers served simultaneously by the same base station and the type of use each customer makes of the connection.

\section{Annex III.2 Internet exchange points}

\section{Description of an IXP}

Every Internet user has access to a certain network controlled by an independent entity, usually called an Internet service provider (ISP). Telecommunications operators in general can also be called ISPs if they provide Internet access. The networks controlled by these ISPs are called autonomous systems (AS). ${ }^{12}$

An IXP is a single physical network structure to which many ISPs connect. Any ISP connected to an IXP through a single interconnection point may exchange traffic with any other ISP connected to the same IXP, thereby solving the scalability problems that would arise if all ISPs had to connect with all others on a grid. Agreements take many different forms throughout the world. The possibility of exchanging traffic among ISPs without going through remote points is important for the development of regional markets, as was shown above.

12 As seen earlier, for an ISP to provide global Internet access to its customers, it must somehow connect its AS to at least one other ISP with global Internet connectivity. The interconnection agreement tends to be one of two types: (i) a contract for IP or Internet transit whereby one ISP pays the other in accordance with the relative interest each has in establishing a connection through peering, or (ii) a peer agreement whereby both ISPs exchange traffic without any payment or other consideration. 


\section{Snapshot of IXPs in the region}

The analysis begins with the list of IXPs published by the Packet Clearing House $(\mathrm{PCH}){ }^{13}$ a non-profit institution that supports operations and analyses Internet traffic exchange areas, the economics of routing and the development of the World Wide Web. Of the IXPs included on the list, the most comprehensive one available, those that are no longer interconnection points or are not currently operating were eliminated. The others were surveyed in detail to gather data. The Member States of the Regional Broadband Dialogue participated in this process. ${ }^{14}$

\section{Information surveyed in each country}

The following information was gathered for analysis and recommendations about IXPs in the region:

(i) Year of establishment and location (address, telephone number, contact person).

(ii) Type of entity (non-profit, commercial, state-owned, among others).

(iii) List of ISPs currently connected to the IXP.

(iv) IXP traffic policies.

(v) Limitations on routes, whether the traffic exchanged is local (one city or nearby cities), national or international.

(vi) Types of bilateral or multilateral agreements among ISPs in a single IXP.

(vii) Payment structure (IXP entry fee, monthly or traffic-based fee, whether a distinction is made between local, national and international traffic, and others) and amounts.

(viii) Terms, if any, under which the ISPs in an IXP can exchange traffic with other IXPs in the same city (peering, etc.) or different cities (peering, transit fees, etc.).

(ix) Whether there are traffic exchanges with other IXPs in the country, or whether the entity's charter allows for them.

(x) Whether the IXP is at a single physical location or at various interconnected sites.

(xi) Requirements ISPs must fulfill to participate in the IXP and general terms for handling traffic (non-discrimination, neutrality, etc.).

13 See [online] http://www.pch.net/home/index.php.

14 Argentina, Brazil, Chile, Colombia, Costa Rica, Ecuador, Paraguay, Peru, Plurinational State of Bolivia and Uruguay. 
(xii) Policies on ISPs' physical links with the IXP: minimum capacity, redundancy, etc.

(xiii) Whether interconnections exist or are planned with other regional IXPs, particularly those in neighboring countries, and the characteristics of these possible interconnections.

(xiv) Improvements in prices or quality for ISPs belonging to the IXP in national or international IP transit agreements.

(xv) Total traffic exchanged at peak times (HP).

(xvi) Conditions required for large CDNs-Akamai, Google, Limelight Networks, Microsoft and others-for storing content for the national or subregional market, with respect to Internet connections in the country, costs, special peering or similar agreements, etc.

(xvii) Other aspects of interest to the IXP for developing its activities appropriately.

\section{Results of the analysis}

The information was compiled primarily from the IXPs' websites, with support from the authorities of the Member States in the Broadband Regional Dialogue. The countries' situations are described below.

- Argentina. There is a single major IXP, CABASE, for which relevant data are available. It is largely compliant with international best practices.

- Brazil. Eight of the IXPs on the PCH list do not operate as such. The IXPs PTT Metro and NAP do Brasil were analysed, so the most relevant information is available for them. PTT Metro upholds best practices.

- Chile. The seven IXPs identified by the authorities have been analysed. Since 1999 interconnection has been mandatory, resulting in a market with good connectivity. Therefore, there is no need for regulation, since the ISPs have internalized the interconnection requirement.

- Colombia. There is little public information on IXPs.

- Costa Rica. There is no IXP, but the Interconnection Act and its regulations provide a framework for its implementation.

- Ecuador. All relevant information has been compiled for AEPROVI, which does adhere to best practices.

- Paraguay. There is no IXP. 
- Peru. There are two main IXPs, but they do not comply entirely with best practices.

- Plurinational State of Bolivia. There are no IXPs, although the country's Telecommunications Act does regulate this area.

- Uruguay. There is no IXP.

\section{Comparative analysis of regulations}

There is international evidence of the importance of installing IXPs, and precedents have been established for setting them up and operating them. There is also information on regulations, and documents have been published by reputable institutions in the field, such as the Internet Society ${ }^{15}$ and the ICT Regulation Toolkit, ${ }^{16}$ emphasizing the importance of regulation.

The following analysis reviews the concepts addressed in the ICT Regulation Toolkit and the regulations of the three Latin American countries (Chile, Costa Rica and the Plurinational State of Bolivia) that have implemented regulations to encourage the development of IXPs.

\section{ICT Regulation Toolkit}

After briefly discussing the advantages of establishing IXPs, this document explains the challenges in installing regional IXPs. It confirms what has already been observed: that developing countries are behind in the implementation of IXPs mainly because of regulatory, coordination and management issues. ISPs within a single country must be convinced that IXPs will not tip the balance towards one or more operators, and neighboring countries' ISPs need to understand the value of routing traffic to the IXP rather than developing private interconnections among themselves. The document concludes that "...it is important to have official legal and regulatory support for the development of IXPs..."

\section{Plurinational State of Bolivia}

Law 164, the General Telecommunications, Information Technologies and Communication Act, was published on 8 August 2011. Article 50 thereof (Interconnection among Internet providers) stipulates: "Internet providers shall establish and accept interconnections among themselves within the national territory through an Internet exchange point in order to manage Internet traffic in accordance with the conditions established by the regulations".

15 See "An Introduction to Internet Interconnection Concepts and Actors", ISOC, www. Internetsociety.org.

16 See [online] http://www.ictregulationtoolkit.org/en/Section.2194.html. 
This law makes it mandatory to establish and accept interconnection among Internet service providers as a general condition. The primary issue of Internet exchange points is established in this manner, with details about procedures and other conditions being subject to regulations. It represents a major step forward in a country with high international costs for Internet access. It is expected that this regulation will bring down costs.

\section{Chile}

The Republic of Chile, in Exempt Resolution No. 1483 of October 1999, set forth the procedure and deadlines for establishing and accepting connections among ISPs. The concepts are addressed in the following main articles, which are supplemented by others related to procedures and quality control: "Article 2. In order to guarantee proper operation and non-discrimination in the quality of Internet access services provided to users, ISPs shall, prior to the commencement of service, establish and accept connections among themselves to manage national Internet traffic, without prejudice to the provisions of article 5 of this law".

"Article 3. ... The foregoing provisions notwithstanding, the connections established among ISPs shall ensure that the customers of the requesting ISP are given access to content providers located both in the requesting ISP and in the ISP receiving the request, of equivalent quality. Similarly, the connections established among ISPs shall assure content providers located in the requesting ISP that customers of the requesting ISP as well as those of the ISP receiving the request have access of equivalent quality to such providers. ...".

"Article 5. In any case, ISPs may establish other connection topologies besides that which is specified in the first paragraph of article 2 above, provided that they ensure that national Internet traffic is exchanged through transmission channels authorized to manage national communication. If a national Internet exchange point is established to combine traffic from one or more ISPs, the provider of such service shall be considered an ISP for purposes of this law". This article, by making interconnection through IXPs mandatory, ensures that all national ISPs are interconnected with each other under the conditions set forth in this resolution.

"Article 6. ISPs shall accept and put in service the aforementioned connections under non-discriminatory conditions. Furthermore, each ISP shall allow the customers of the ISPs that are connected pursuant to this law to have access to all of the content it maintains, under nondiscriminatory conditions". 
As noted above, the Chilean experience is interesting in that it shows the results of an IXP development policy that has been in place for more than 15 years. IXPs began to emerge organically in 1995 and gained strength after 1999 on the basis of specific regulations. Today, there is a favourable national connectivity environment in which IXPs, though they exist, have a rather secondary role in the important interconnection networks that link all ISPs. Thus, the regulation of IXPs could be unnecessary because the market, through its own dynamic, has already established significant connectivity that has even brought national wholesale IP transit prices down to about $10 \%$ of the international transit price.

\section{Costa Rica}

The Interconnection Act and its regulations have created a transparent environment in which mandatory interconnection does not distinguish among technologies. In particular, there is a precise procedure for paying for converged networks or packet-switched networks, offering a variety of alternatives depending on, among other factors, traffic, bandwidth and committed capacity. In any case, operators are encouraged to negotiate with each other before resorting to the regulatory body, the Superintendency of Telecommunications (SUTEL).

\section{Best operating practices and key performance indicators}

\section{Current best practices according to Euro-IX}

Although IXPs are sites where peering among ISPs is optimized, they are not generally involved in the peering agreements that ISPs enter into, nor do they dictate which ISPs each one must peer with or the terms of their agreements. However, because they are shared infrastructures, IXPs have requirements that ISPs must meet in order to use them properly.

There is a set of best practices based on the requirements and characteristics of the IXPs associated with the European Internet Exchange Association (Euro-IX). ${ }^{17}$ These practices, widely recognized in the world of IXPs, cover implementation and maintenance as well as rules that ISPs are expected to follow. They are not strict rules, just a listing of the best practices derived from the experience of the IXPs that already exist. Based on an analysis of the importance of each of these specifications, a minimum number of key performance indicators (KPI) can be defined to evaluate the quality of IXPs and that of interconnection among countries.

The rationale for the indicators lies in the benefits of efficient national interconnection and access to international and national content. For a more thorough analysis, KPIs are divided into two categories: those used for analysing IXPs and those applied to the analysis of interconnection at the country level. For each group, the benefits derived from meeting the

17 See [online] https://www.euro-ix.net/ixp-bcp. 
KPIs are listed, which in and of itself is enough to ensure compliance. All of these indicators are met by the most advanced IXPs. The more efficient the interconnection, the lower the costs and the higher the quality of Internet and content access.

The analysis does not include technical indicators relative to equipment, routing, technologies or other requirements for establishing an IXP node. That is a very well-known subject on which there are internationally accepted standards and with which there is ample experience for choosing the appropriate physical structure. In this section, the emphasis is on aspects of IXP management per se and of commercial relationships, which are the most lacking and which have the greatest impact on Internet prices and quality.

\section{KPIs for IXPs}

The main operating indicators for IXPs are discussed in this section. They are grouped into classifications that can be used to evaluate their impact on improved efficiency in connecting national Internet traffic (see table III.A-2).

- Allows multilateral agreements; this is a minimum requirement for the IXP to exist and to attract the interest of ISPs.

- Allows bilateral agreements among participating ISPs. The IXP becomes a node for ISPs to interconnect freely, depending on each one's assessment of its own interests. It creates more value for ISPs, attracts their participation and improves efficiency. A bilateral agreement allows for greater flexibility, since ISPs with a lot of traffic or with common interests can engage in highcapacity bilateral peering in addition to the lower-capacity multilateral arrangement. These agreements, together with bilateral transit agreements, are the principal infrastructure for ensuring efficient interconnection.

- Allows bilateral agreements for national transit, provided by the IXP itself or by third parties interconnected through the IXP. The benefits are similar to those of the previous case, in that traffic can be aggregated and better prices and quality can be achieved for long-distance national transit. This is an important indicator in vast countries whose cities are Internet usage centres.

- Allows bilateral agreements for international transit, provided by the IXP itself or by third parties interconnected through the IXP. The rationale is similar to that of the previous point, but for international transit.

- Is operated neutrally. It does not belong to and is not associated with any carrier, ISP or connectivity provider. Thus, there are no conflicts of interest that would impinge on efficient operation of the IXP. 
- There are no discriminatory restrictions on participation by ISPs. This indicator ensures that any ISP wishing to exchange traffic through the IXP may do so as long as it meets the standard technical and commercial conditions that are applicable to all ISPs, without discrimination.

- No filtering or discriminatory policies are applied to participating ISPs or to the content made available by each of them. The requesting ISP's customers have access to equivalentquality content providers located both in the requesting ISP and in the ISP receiving the request. It guarantees the quality of the interconnection through the IXP.

- IXP usage prices are cost-oriented, or, more specifically, they are based on the distribution of the IXP's investment and operating costs, depending on how it is owned and managed. In any case, this cost orientation makes it possible to improve Internet access prices, because interconnection through the IXP has a lower price, reflecting opportunity costs. The value added by the IXP is passed on entirely to the ISPs' customers.

- Any ISP wishing to connect to an IXP may contract freely for that access under its own responsibility. This condition ensures that there is no exclusivity in access to the IXP, thereby improving competitiveness. The ISP can achieve the best prices for connecting to the IXP by building or leasing as it sees fit.

- There are no distance limitations for ISPs wishing to interconnect through an IXP, as long as they pay for the link. In some cases, these limitations have been established without any economic justification.

- The IXP provides co-location services. This encourages ISPs to interconnect by helping them optimize resources and reduce costs.

- The IXP is located in places where carriers and ISPs have points of presence nearby. This guarantees the quality of the interconnection at the IXP, since it lowers access costs and creates incentives for expansion. In deciding whether to use an IXP or engage in private peering, paid or not, ISPs are heavily influenced by the cost of access to the IXP (physical access dependent on distance and membership costs). Ideally, an IXP that has carrier points of presence at its location can facilitate access and may also make it possible to buy transit if bilateral agreements are allowed. The State may adopt policies that provide incentives for locating in appropriate places. For example, it may sponsor meetings where the importance of proper location is stressed, 
or it may facilitate the installation of IXPs near those points of presence. This is an indicator that should be taken into account, among others, when designing policies and actions.

- The IXP has equipment and ISP connection redundancy. This guarantees the availability of connections at the IXP and prevents an equipment failure at the IXP from totally disrupting interconnection. This is a quality indicator in the operation of the IXP.

- The IXP offers robust security services, such as a continuous power supply, access controls and fire and flood protection equipment. This is how the quality of the site can be determined and the availability of national connections to the Internet can be assessed in the country.

- The IXP has multiple sites. This guarantees the quality and availability of the interconnection and also improves costs for ISPs, which can select the nearest node, or, if they want to connect to more than one node, they can select the best quality.

- The IXP makes available, at the ISPs' request, information on IXP and member traffic. This information is valuable for ISPs when conducting cost-benefit analyses of IXP usage. The more members there are and the more traffic is exchanged, the greater the value to the ISP of linking to an IXP, and the more efficient its decisions.

- $\quad$ The IXP has CDN nodes.

Table III.A.2

KEY IXP PERFORMANCE INDICATORS

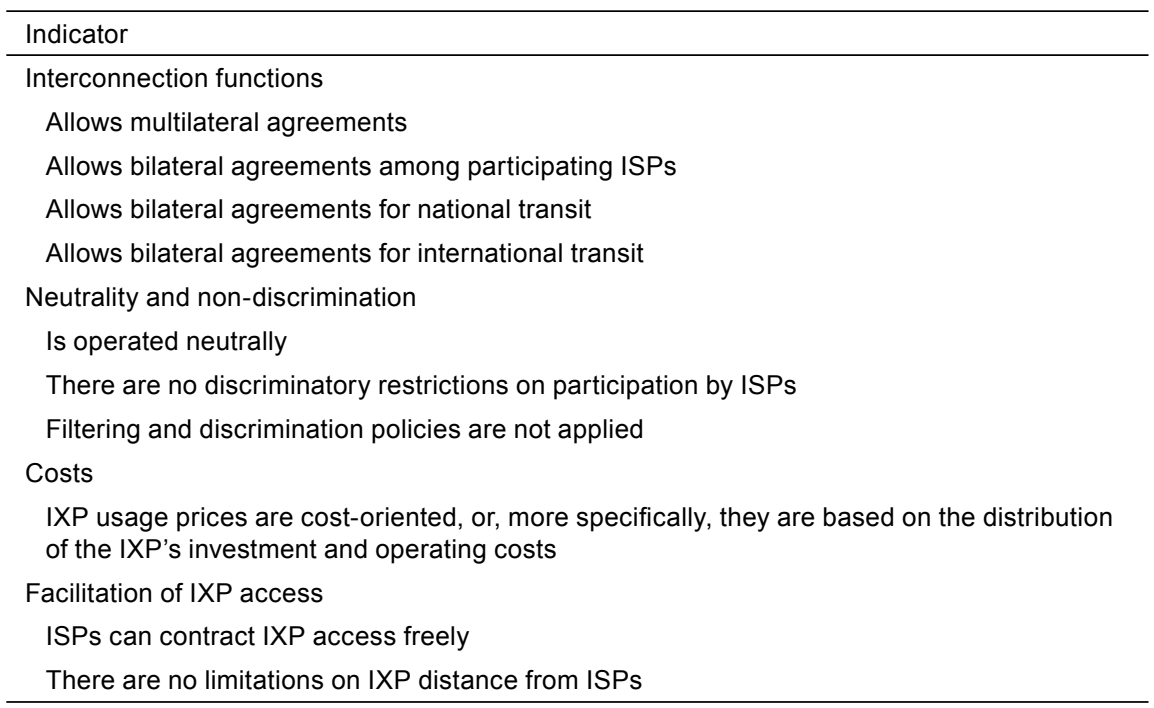




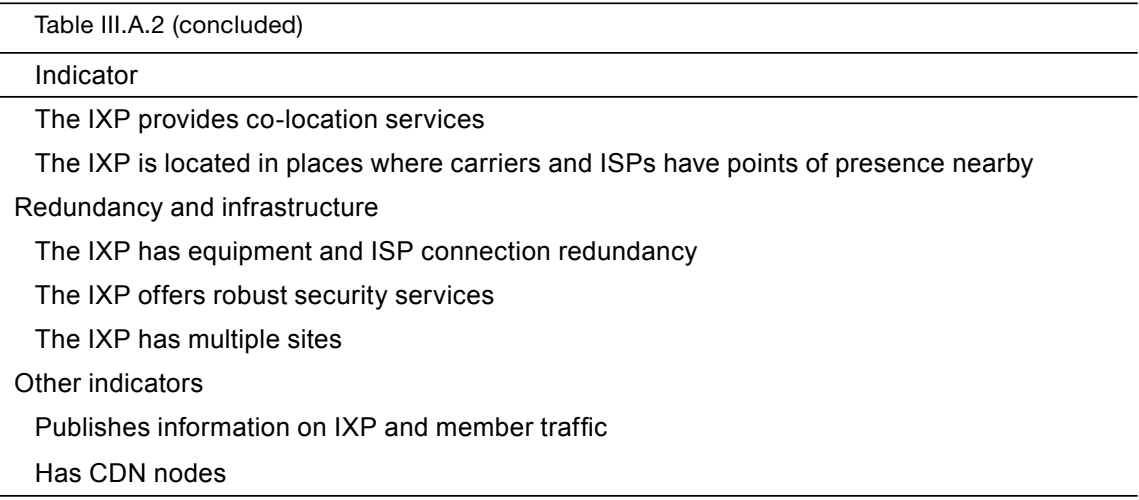

Source: Prepared by the author.

\section{KPIs for countries}

As with the KPIs for IXPs, the main indicators for connecting national Internet traffic originating and terminating in a country are detailed below (see table III.A.3).

- All ISPs are interconnected so that all national communication traffic originating and terminating in the country can be sent to or from any ISP, either through one or more IXPs or through private peering. This is the main indicator of Internet connection quality, and it ensures better quality and pricing for customers. From a country's standpoint, it is the most important indicator, even if it does not guarantee the efficiency of all interconnections among IXPs. Indeed, the existence of strong IXPs meeting all of the KPIs listed above does not guarantee compliance with this indicator.

- There are regulations providing for mandatory interconnection. This is an informative indicator that is relevant when the previous condition is not met.

- There is competition among IXPs according to the criteria set forth in the country's competitiveness regulations. Competition is a strong incentive for linking IXP usage prices to opportunity costs, analogous to the typical situation of non-profit IXPs that charge in accordance with real usage costs.

- Presence of major CDNs at IXPs or in the country, with national interconnection for all ISPs. This is an indication of how important it is for a country to have an IXP system to improve Internet access quality and pricing for the members of IXPs. Hosting major providers and ensuring that the customers of 
all ISPs have access to them yields savings of $20 \%$ to $30 \%$ on international transit, taking into account the volume of content on providers such as Akamai, Google-YouTube, Microsoft, Lime Light Networks and others. As a reference, this indicator is deemed to have been met when at least two of the CDNs mentioned above are present.

- All IXPs allow bilateral agreements for regional and international transit.

Table III.A.3

KEY COUNTRY PERFORMANCE INDICATORS

Indicator

All ISPs are interconnected for handling all national communication traffic originating and terminating in the country.

There are regulations providing for mandatory interconnection. An important indicator in cases of non-compliance with indicator 1.

There is competition among IXPs.

There are major CDNs at IXPs or in the country, with national interconnection for all ISPs.

All IXPs allow bilateral agreements for regional and international transit.

Source: Prepared by the author. 

Second part

\section{Economic impact}





\section{Chapter IV \\ Broadband, digitization and development}

Raúl L. Katzi

\section{A. Broadband and economic growth}

This chapter presents the findings of a series of studies conducted since 2009 on the contribution of broadband to development in Latin America. ${ }^{2} \mathrm{~A}$ first set of results focuses on measuring the economic impact of broadband on GDP growth, job creation and increases in average household income. A second set evaluates the contribution of broadband in terms of applications, services and content by means of a digitization index that measures both technology adoption in a country and the use of services associated with it - for example, e-government, e-commerce and social networking. On the basis of these findings, policy recommendations aimed at maximizing broadband's economic impact are proposed.

Broadband, as a general purpose technology, contributes to economic growth through a number of effects (see diagram IV.1). First, the deployment of telecommunications networks yields effects similar

1 Raúl L. Katz is an adjunct professor in the Finance and Economics Division at Columbia Business School and Director of Business Strategy Research at Columbia Institute for TeleInformation. He is also president of Telecom Advisory Services, LLC.

2 The studies were conducted within the framework of research programmes undertaken for ECLAC, the International Telecommunication Union (ITU), the World Economic Forum, the Governments of Colombia and Costa Rica, and associations of telecommunications operators. 
to those generated by any infrastructure project: broadband deployment creates jobs and impacts the economy as a whole through multiplier effects. Second, broadband use has a spillover effect on the entire economic system, which is felt by both businesses and residential users. On one hand, the use of broadband by the production sector results in increased productivity, thereby helping to raise GDP. On the other, its residential adoption increases real household income, reducing poverty and contributing, in turn, to economic growth.

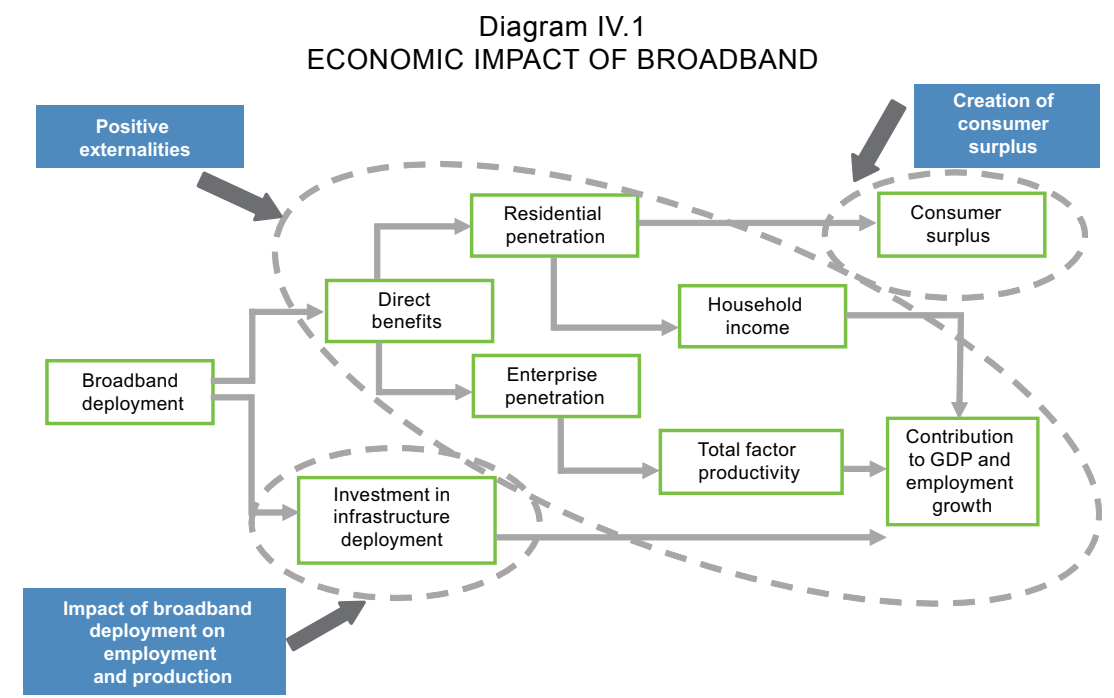

Source: Prepared by the author.

Beyond these effects, residential users who purchase broadband benefit in terms of consumer surplus, which is the difference between what consumers are willing to pay for the service and the market price. This effect, though not included in the calculation of GDP, is important because it represents an improvement in access to information, entertainment and public services.

The following three sections describe the findings of the author's studies in Latin America to date. The first presents a model for measuring the impact of broadband on GDP growth in the region as a whole, followed by disaggregated results for Colombia and Panama. The second section contains measurements of the impact of broadband on job creation in Chile, Colombia and the Dominican Republic. The last section presents the findings of studies assessing the impact of broadband on the increase in average household income in Costa Rica and Colombia. 


\section{GDP growth}

The first analysis of the economic impact of broadband in Latin America was conducted by Katz (2011a) on the basis of a cross-sample of countries. In the absence of time series, the analysis employed the ordinary least squares method, using a sample of pooled data for the years 2004 and 2009. Two methodological problems arose in this analysis. First, as panel data could not be used, it was not possible to isolate the characteristics of each country in the model results, which could have created a problem of "omitted variable". This problem was mitigated, however, by including variables such as broadband development and degree of economic openness in the model. The second problem with this type of model stems from endogeneity between growth of GDP per capita and broadband penetration. Ideally, it would be possible to build a multiplestructure model based on simultaneous equations in order to endogenize the development of broadband as a function of per capita GDP, prices, competition and degree of telecommunications industry regulation. Again, lack of data did not allow the construction of such a model at the time. The solution was to lag the variable "development of broadband" by one year. With these caveats, the model generated the results shown in table IV.1.

Table IV.1

LATIN AMERICA: CONTRIBUTION OF BROADBAND TO GDP GROWTH

\begin{tabular}{|c|c|c|c|c|c|c|}
\hline GDP growth & Coefficient & $\begin{array}{l}\text { Standard } \\
\text { error }\end{array}$ & t-statistic & $P>[t]$ & \multicolumn{2}{|c|}{$\begin{array}{l}95 \% \text { confidence } \\
\text { interval }\end{array}$} \\
\hline $\begin{array}{l}\text { Growth in broadband } \\
\text { penetration for 2001- } \\
2003 \text { and } 2004-2006\end{array}$ & 0.0158715 & 0.0080104 & 1.98 & 0.054 & -0.0002942 & 0.0320372 \\
\hline $\begin{array}{l}\text { Average investment/ } \\
\text { GDP for } 2004-006 \\
\text { and } 2007-2009\end{array}$ & -0.0471624 & 0.1689699 & -0.28 & 0.782 & -0.3881575 & 0.2938328 \\
\hline $\begin{array}{l}\text { Population growth } \\
\text { in 2004-2006 and } \\
2007-2009\end{array}$ & -0.4469177 & 1.40418 & -0.32 & 0.752 & -3.280668 & 2.386832 \\
\hline $\begin{array}{l}\text { Higher education } \\
(2002)\end{array}$ & 0.2139614 & 0.1108325 & 1.93 & 0.060 & -0.0097076 & 0.4376304 \\
\hline $\begin{array}{l}\text { Per capita GDP at } \\
\text { the start of } 2003 \text { and } \\
2006\end{array}$ & -0.0006957 & 0.0001806 & -3.85 & 0.000 & -0.0010602 & -0.0003313 \\
\hline $\begin{array}{l}\text { Average globalization } \\
\text { rate for } 2001-2003 \\
\text { and } 2004-2006\end{array}$ & -0.0653024 & 0.1929498 & -0.34 & 0.737 & -0.4546908 & 0.324086 \\
\hline Constant & 13.02883 & 12.04659 & 1.08 & 0.286 & -11.28217 & 37.33982 \\
\hline
\end{tabular}


Table IV.1 (concluded)

\begin{tabular}{lr}
\hline Number of observations & 49 \\
$\mathrm{~F}(6,42)$ & 7.18 \\
Prob>F & 0.0000 \\
$\mathrm{R}^{2}$ & 0.3814 \\
Root MSE & 7.024 \\
\hline
\end{tabular}

Source: R. Katz, "The impact of broadband on economic growth", Fast-tracking the digital revolution: Broadband for Latin America and the Caribbean (LC/R.2167), V. Jordán, H Galperin and W Peres, Santiago, Economic Commission for Latin America and the Caribbean (ECLAC), 2011.

The results show that, when controlling for education level and initial per capita GDP level, a 1\% increase in broadband penetration raises GDP by $0.0158 \%$. The broadband penetration coefficient is positive in sign and statistically significant. This finding is consistent with the result generated by Koutroumpis (2009) in a study of OECD countries, in which, using a simultaneous equations model, showed that in countries where broadband penetration averaged under $14 \%$, a $1 \%$ increase in penetration contributed $0.008 \%$ to GDP growth.

In 2011, increased availability of disaggregated data made it possible to conduct studies at the national level. The first one was carried out in Colombia with department-level data for 2006-2010 (Katz and Callorda, 2011). This study analyses the impact of fixed broadband on departmental GDP growth, controlling for initial level of economic development, population growth and human capital level (average years of education) (see table IV.2).

Table IV.2

COLOMBIA: CONTRIBUTION OF BROADBAND TO GDP GROWTH

\begin{tabular}{lrrr}
\hline & \multicolumn{1}{c}{ Total } & Low penetration & High penetration \\
\hline Growth in broadband access & $0.0036542^{* * *}$ & $0.0039548^{* * *}$ & $0.0039453^{* * *}$ \\
(percentage) & $(0.001282)$ & $(0.0014167)$ & $(0.0012952)$ \\
Population growth & 0.8734808 & -0.7848735 & $4.585921^{* *}$ \\
(percentage) & $(0.9599308)$ & $(1.019278)$ & $(1.948842)$ \\
& -3.538593 & -1.878803 & 3.668626 \\
Years of education & $(5.127222)$ & $(11.28887)$ & $(3.831199)$ \\
GDP in 2003 (millions of & 0.0056116 & -0.2697321 & $-0.0432453^{*}$ \\
pesos) & $(0.0284458)$ & $(0.3899207)$ & $(0.0360005)$ \\
Adjusted R & 0.1649 & 0.2088 & 0.2093 \\
Prob > F & 0.0103 & 0.0778 & 0.0086 \\
Number of observations & 132 & 64 & 68 \\
\hline
\end{tabular}

Source: R. Katz and F. Callorda, Medición de Impacto del Plan Vive Digital en Colombia y de la Masificación de Internet en la Estrategia de Gobierno en Línea, Bogota, Centro de Investigación de la Telecomunicaciones (CINTEL), 2011.

Note: The robustness of the model was evaluated on the basis of tests of independence between variables, normality and covariance. In addition, the analysis was extended by performing the Doornik-Hansen multivariate normality test. In all cases, the validity of the impact estimation models was found to be over $99 \%$. ${ }^{\star \star \star},{ }^{\star *}$ and ${ }^{*}$ indicate significance levels of $1 \%, 10 \%$ and $15 \%$, respectively. 
The model shows that an increase in broadband connections has a positive effect on GDP growth: if connections increased 10\%, GDP would increase $0.037 \%$. This effect is less than was found in the model for the region as a whole, mainly because the average rate of broadband penetration in Colombia is below the average for Latin America. This suggests the existence of a returns to scale effect -i.e. economic impact increases with higher levels of penetration.

Growth of broadband connections is the only independent variable that is significant in explaining the growth of GDP in all specifications, both for departments with high penetration and for departments with low penetration (columns 3 and 4). The coefficients for departments with high and low penetration are similar because in no case was penetration more than $20 \%$ (hence, by international standards, all departments have low penetration). The model explains between $15 \%$ and $20 \%$ of the variance in the dependent variable, indicating that there are other factors affecting the evolution of GDP. ${ }^{3}$ Nevertheless, the coefficient for impact of broadband growth is significant and consistent in all specifications.

For Panama, as more information was available, Katz and Koutroumpis (2012a) used a multiple-structure model originally developed by Roller and Waverman (2001) for fixed-line telephony and subsequently adapted by Koutroumpis (2009) for broadband and by Gruber and Koutroumpis (2011) for mobile telephony. The model comprises four equations: a production function, which models the aggregate operation of the economy, and demand, supply and output functions, which model the broadband market, controlling for reverse causality.

In the aggregate production function, GDP is linked to the stock of fixed capital (excluding ICT infrastructure), the supply of skilled labour and fixed broadband infrastructure, proxied by broadband penetration. The demand function links broadband penetration to the price of basic service - the number of subscribers depending on the price of broadband accessand average individual consumption estimated on the basis of GDP per capita. The supply function links aggregate broadband sales revenues to broadband price levels, GDP per capita and degree of urbanization in the country. To the extent that fixed broadband deployment is correlated with greater urban population concentration, the supply of the service should reflect this structural variable. The output equation links the annual change in fixed broadband penetration with broadband sales revenue, and this change is used as an indicator of annual capital investment in broadband. ${ }^{4}$

Lack of department-level data for these variables prevents their inclusion in the regression model.

4 This assumes a stable and constant relationship between sales and investment, which often does not occur. Information on fixed capital formation in telecommunications, which would be a more appropriate variable, was not available. 
Based on these models (see table IV.3), fixed broadband infrastructure had a significant impact on growth between 2000 and 2010. Its average annual contribution to GDP growth was estimated at $0.045 \%$ for every $1 \%$ increase in penetration.

Table IV.3

PANAMA: CONTRIBUTION OF BROADBAND TO GDP GROWTH

Aggregate production function:

$$
G D P_{i t}=a_{1} K_{i t}+a_{2} L_{i t}+a_{3} B B_{-} P e n_{i t}+\mathcal{E}_{\text {lit }}
$$

Demand function:

$$
\begin{aligned}
B B_{-} P e n_{i t}= & b_{1} B B P r_{i t}+b_{2} G D P C_{i t}+\varepsilon_{2 i t} \\
& \text { Supply function: } \\
B B_{-} \operatorname{Rev}_{i t}= & c_{1} G D P C_{i t}+c_{2} U r b_{i t}+\varepsilon_{3 i t} \\
& \text { Output function: }
\end{aligned}
$$

\begin{tabular}{|c|c|}
\hline Variables & Fixed broadband model \\
\hline \multicolumn{2}{|l|}{ Growth $\left(G P_{i t}\right)$} \\
\hline Labour force with secondary education $\left(L_{\text {it }}\right)$ & $1.148^{* * *}$ \\
\hline Fixed capital stock $\left(\mathrm{K}_{\mathrm{it}}\right)$ & $0.234^{* * *}$ \\
\hline Fixed broadband penetration $\left(B B \_P e n_{i t}\right)$ & $0.045^{* * *}$ \\
\hline Constant & - \\
\hline \multicolumn{2}{|l|}{ Demand (BB_Pen ${ }_{\text {it }}$ ) } \\
\hline Fixed broadband price $\left(\mathrm{BBPr}_{\mathrm{it}}\right)$ & $-2.121^{* * *}$ \\
\hline GDP per capita $\left(\mathrm{GDPC}_{\mathrm{it}}\right)$ & $2.443^{* * *}$ \\
\hline Constant & $-18.536^{* *}$ \\
\hline \multicolumn{2}{|l|}{ Supply (BB_Rev ${ }_{i t}$ ) } \\
\hline GDP per capita $\left(G^{2} C_{i t}\right)$ & $0.556^{* * *}$ \\
\hline Urbanization $\left(\mathrm{Urb}_{\mathrm{it}}\right)$ & $0.374^{* * *}$ \\
\hline Constant & $13.910^{* * *}$ \\
\hline \multicolumn{2}{|l|}{ Output $\left(\Delta B B \_P e n_{\text {itt }}\right)$} \\
\hline Broadband revenue $\left(B B \_\operatorname{Rev}_{i t}\right)$ & $4.606^{* * *}$ \\
\hline Constant & $-95.451^{* * *}$ \\
\hline Year effects & sí \\
\hline Observations & 40 \\
\hline \multicolumn{2}{|l|}{$\mathrm{R}^{2}$} \\
\hline Growth & 0.99 \\
\hline Demand & 0.92 \\
\hline Supply & 0.97 \\
\hline Output & 0.40 \\
\hline
\end{tabular}

$$
\triangle B B_{-} P n_{i t}=d_{I} B B_{-} \operatorname{Rev}_{i t}+\varepsilon_{4 i t}
$$

Source: R. Katz and P. Koutroumpis, The Economic Impact of Broadband: Case Studies of the Philippines and Panama, Geneva, International Telecommunication Union, 2012.

Note: The symbols ${ }^{\star \star *},{ }^{* *}$ and * indicate significance levels of $1 \%, 10 \%$ and $15 \%$, respectively. 
Comparison of the results for Colombia and Panama confirms, first, the existence of returns to scale. The economic contribution of broadband is greater in Panama, where, in 2010, fixed broadband penetration was $7.8 \%$ versus $4.8 \%$ in Colombia. Beyond this comparative result, the multiplestructure model for Panama yields other conclusions. In addition to the contribution of capital, a 1\% increase in skilled labour would increase GDP by $1.15 \%$. The model also shows the relative importance of broadband subscription rates: a $10 \%$ decrease in broadband price would increase broadband penetration by more than $21 \%$.

The interpretation of the model results suggests the existence of returns to scale from broadband. This type of effect had already been identified for other ICTs, such as telephony (Roller and Waverman, 2001). Comparison of the results of different estimates of the economic contribution of broadband as a function of penetration shows evident returns to scale (see figure IV.1). ${ }^{5}$

Figure IV.1

COMPARATIVE CONTRIBUTION OF BROADBAND TO ECONOMIC GROWTH (Percentages)

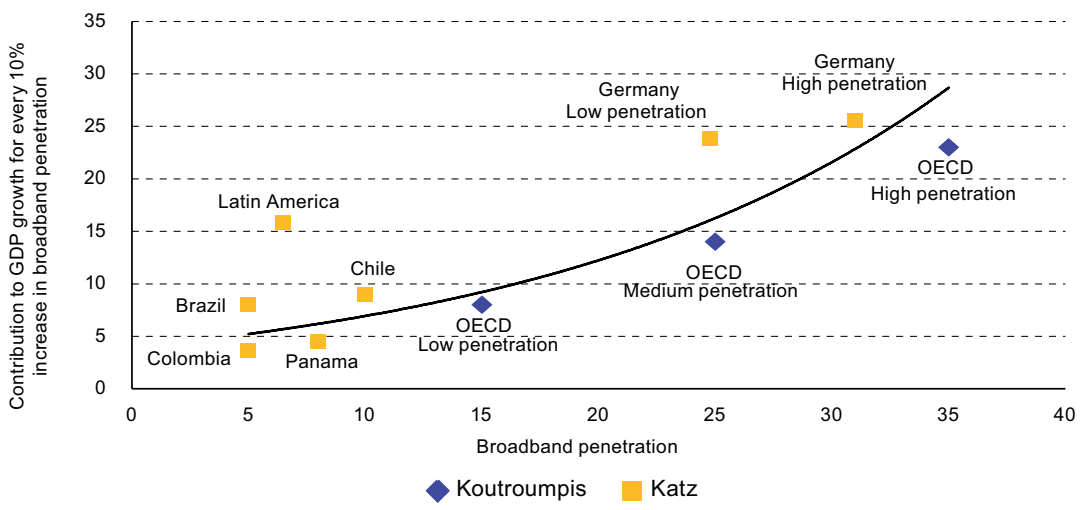

Source: R. Katz, The Impact of Broadband on the Economy: Research to Date and Policy Issues, The Impact of Broadband on the Economy Broadband Series, Geneva, International Telecommunication Union (ITU), 2012.

Note: The trend line does not reflect observations for Latin America.

In summary, although the results are based on differently specified models, the greater the broadband penetration, the greater impact its expansion will have on GDP growth. The public policy implications are clear: maximizing the economic impact of broadband is contingent on significantly increasing its penetration.

5 The significant effects in the case of Panama (not shown in this figure) are due to the importance of broadband in a service-based economy oriented mainly towards commerce and financial services. 


\section{Job creation}

In addition to its impact on economic growth, broadband contributes to job creation, although its effects in this area are more complex. First, increased broadband penetration can increase productivity, which in the short term may lead to net job loss (an effect that has been verified by the author for labour-intensive industrial sectors). Second, by incorporating new sectors of the population into the broadband market, the technology contributes to the creation of new businesses through an innovation effect, which generates new jobs. Lastly, broadband can lead to the outsourcing of certain business functions, which can create jobs as outsourcing firms are established, but it can also lead to the loss of opportunities if business functions in the country under consideration are transferred to other locations. The sum of these three effects is shown in diagram IV.2.

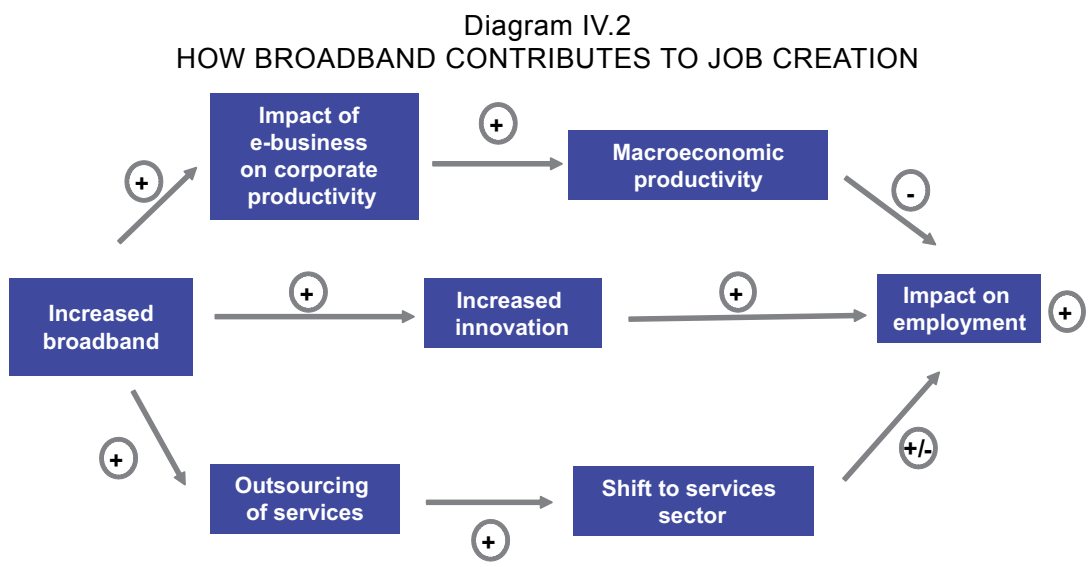

Source: Adapted by the author from a model developed by M. Fornefeld, G. Delaunay and D. Elixmann, "The impact of broadband on growth and productivity", study for the European Commission, Directorate General for Information Society and Media, 2008.

It is not possible on the basis of the available information to measure the individual impact of each of these three effects, so the analyses had to be limited to measurement of aggregate impact. The job creation potencial of broadband was estimated for Chile, Colombia and the Dominican Republic.

To estimate the impact of broadband in Chile, a study was conducted using quarterly panel data controlled for fixed effects reflecting specific features of each region of the country that have an impact on the labour market (industrial sectors, education levels). Information was compiled for 
all regions (except the Santiago metropolitan region, for which quarterly data were not available) for the period from 2001 to the fourth quarter of 2009 (see table IV.4).

Table IV.4

CHILE: IMPACT OF BROADBAND ON JOB CREATION (12 regions, 2001-2009)

\begin{tabular}{|c|c|c|c|c|c|}
\hline & Coefficient & $\begin{array}{l}\text { Standard } \\
\text { error }\end{array}$ & t-statistic & $P>|t|$ & $\begin{array}{c}95 \% \\
\text { confidence } \\
\text { interval }\end{array}$ \\
\hline $\begin{array}{l}\text { Economic activity } \\
\text { index }{ }^{a}\end{array}$ & 0.0003509 & 0.0000595 & 5.90 & 0.000 & 0.0002338 \\
\hline $\begin{array}{l}\text { Change in } \\
\text { broadband } \\
\text { penetration }\end{array}$ & 0.0018118 & 0.0004708 & 3.85 & 0.000 & 0.0008853 \\
\hline Constant & 0.8682527 & 0.0079638 & 109.03 & 0.000 & 0.85258283 \\
\hline \multicolumn{3}{|c|}{ Number of observations } & \multicolumn{3}{|c|}{324} \\
\hline \multicolumn{2}{|c|}{$F(2,310)$} & & \multicolumn{3}{|c|}{60.89} \\
\hline \multicolumn{2}{|l|}{ Prob $>F$} & & \multicolumn{3}{|c|}{0.0000} \\
\hline \multicolumn{2}{|l|}{$\mathrm{R}^{2}$} & & \multicolumn{3}{|c|}{0.2820} \\
\hline
\end{tabular}

Source: R. Katz, "The impact of broadband on economic growth", Fast-tracking the digital revolution: Broadband for Latin America and the Caribbean (LC/R.2167), V. Jordán, H Galperin and W Peres, Santiago, Economic Commission for Latin America and the Caribbean (ECLAC), 2011.

a Control variable.

The model results indicate that in Chile a $10 \%$ increase in broadband penetration would increase the employment rate by 0.018 points. The increase in broadband penetration appears to be statistically significant in explaining the employment rate trend during the period under consideration.

A similar analysis was performed for Colombia. In this case, a model was constructed at the departmental level, and the relationship between the growth of broadband connections and the rate of employment growth was analysed, controlling for population growth and initial level of economic development. The model was applied first to the country as a whole, and the information was then disaggregated by department and level of penetration (high or low).

In these models, the effect is statistically significant at the national level and for low-penetration departments; in departments with high penetration, the coefficient is significant at $24 \%$. Population growth, on the other hand, seems to have an effect only in high-penetration departments (with a positive coefficient), possibly because the innovation effect mentioned above makes it easier to enter the market in those departments. Initial GDP seems to have no effect on employment growth. 
Table IV.5

COLOMBIA: IMPACT OF BROADBAND PENETRATION GROWTH

ON EMPLOYMENT GROWTH

\begin{tabular}{|c|c|c|c|}
\hline \multicolumn{4}{|l|}{$\begin{array}{l}\text { Employment rate growth (\%) } \\
\text { Dependent variable: employment }\end{array}$} \\
\hline & Total & Low penetration & High penetration \\
\hline \multirow[t]{2}{*}{$\begin{array}{l}\text { Growth in broadband } \\
\text { connections (percentage) }\end{array}$} & $0.0003004^{* *}$ & $0.0002951^{* *}$ & 0.0006572 \\
\hline & $(0.0001359)$ & $(0.0001547)$ & $(0.0005495)$ \\
\hline \multirow[t]{2}{*}{ Population growth (percentage) } & 0.0159829 & -0.2538734 & $0.5937073^{*}$ \\
\hline & $(0.5114836)$ & $(0.7899623)$ & $(0.3761862)$ \\
\hline \multirow[t]{2}{*}{ GDP 2003 (millions of pesos) } & 0.0053431 & -0.1084577 & 0.0003309 \\
\hline & $(0.0077051)$ & $(0.1308956)$ & $(0.0090124)$ \\
\hline Adjusted $\mathrm{R}^{2}$ & 0.0110 & 0.0318 & 0.0338 \\
\hline Prob $>$ F & 0.0730 & 0.0321 & 0.4351 \\
\hline Number of observations & 132 & 64 & 68 \\
\hline
\end{tabular}

Source: R. Katz and F. Callorda, Medición de Impacto del Plan Vive Digital en Colombia y de la Masificación de Internet en la Estrategia de Gobierno en Línea, Bogota, Centro de Investigación de la Telecomunicaciones (CINTEL), 2011.

Note: The symbols ${ }^{* \star *}$, ${ }^{\star \star}$ and * indicate significance at a level of $1 \%, 10 \%$ and $15 \%$, respectively.

In the study of broadband impact on job creation in the Dominican Republic, a model was constructed using panel data for 32 provinces. Unlike the models used for Chile and Colombia, the objective was to determine the impact of broadband in reducing unemployment.

The results show the high impact of broadband (see table IV.6), with a $1 \%$ increase in penetration reducing unemployment by 0.29 percentage points. Other variables affecting the unemployment rate indirectly are, as expected, change in the number of industrial establishments between 2008 and 2009 and the importance of the construction sector in 2009. Thus, a combination of increased broadband penetration, growth in construction and an increase in the number of industrial establishments has a significant impact in reducing unemployment.

Based on the coefficients, the contribution of broadband relative to the other two variables is higher than would have been expected. Part of this effect is due to greater growth in broadband penetration in the capital, Santo Domingo, and in a resort area, Altagracia. To determine the relative contribution of broadband, it would be important to include in the model a variable reflecting the importance of this sector in each province. Such a variable is not available for all provinces, however. Hence, although the model shows that broadband plays an important role in creating jobs, it is difficult to measure its impact in relation to the development of key industrial sectors in the country. 
Table IV.6

DOMINICAN REPUBLIC: IMPACT OF INCREASED BROADBAND

PENETRATION ON EMPLOYMENT GROWTH

\begin{tabular}{lcccccc}
\hline $\begin{array}{l}\text { Growth in } \\
\text { unemployment }\end{array}$ & Coefficient & $\begin{array}{c}\text { Standard } \\
\text { error }\end{array}$ & t-statistic & $P>t$ & \multicolumn{2}{c}{$\begin{array}{c}95 \% \text { confidence } \\
\text { interval }\end{array}$} \\
\hline $\begin{array}{l}\text { Population growth } \\
\begin{array}{l}\text { Change in broadband } \\
\text { penetration }\end{array}\end{array}$ & 0.72442 & 0.24939 & 2.90 & 0.0070 & 0.21180 & 1.23704 \\
$\begin{array}{l}\text { Change in number of } \\
\text { establishments }\end{array}$ & -0.29529 & 0.13290 & -2.22 & 0.0350 & -0.56846 & -0.02211 \\
$\begin{array}{l}\text { Value of construction } \\
\text { industry 2009 }\end{array}$ & 0.69456 & 0.14588 & 4.76 & 0.0000 & 0.39469 & 0.99443 \\
$\begin{array}{l}\text { Change in construction } \\
\text { 2008-2009 }\end{array}$ & -0.64299 & 0.12787 & -5.03 & 0.0000 & -0.90583 & -0.38015 \\
Constant & 0.74317 & 0.37360 & 1.99 & 0.0570 & -0.02477 & 1.51111 \\
\hline
\end{tabular}

$\begin{array}{lr}\text { Number of observations } & 32 \\ F(5,26) & 12.70 \\ \text { Prob }>F & 0.0000 \\ R^{2} & 0.4175\end{array}$

Source: R. Katz, The Impact of Broadband on the Economy: Research to Date and Policy Issues, The Impact of Broadband on the Economy Broadband Series, Geneva, International Telecommunication Union (ITU), 2012.

\section{Growth of household income}

This third economic effect of broadband is important since an increase in the growth of average household income has an impact on poverty reduction in a country. This aspect is crucial because, although it has been shown that broadband contributes to GDP growth, it is important to ensure that this growth does not favour only the higher-income population, resulting in greater social polarization (Fernandez-Ardevol and Vázquez Grenno, 2011). Studies in Costa Rica and Colombia have looked at this question.

In a study assessing the economic impact of Costa Rica's national broadband strategy, Katz (2011) conducted an analysis based on the National Household Survey between 2005 and 2009. Panel data with random effects were used for estimates where the results by region are specific to a given period (see table IV.7). ${ }^{6}$

\footnotetext{
6 At the same time, the White method was used to correct for potential error bias and thus to increase the statistical significance of the coefficients.
} 
Table IV.7

COSTA RICA: IMPACT OF BROADBAND ON GROWTH

IN REAL HOUSEHOLD INCOME

\begin{tabular}{lrrrrrr}
\hline $\begin{array}{l}\text { Growth in } \\
\text { household income }\end{array}$ & Coefficient & $\begin{array}{c}\text { Standard } \\
\text { error }\end{array}$ & $z$ & $p>|z|$ & \multicolumn{3}{c}{$\begin{array}{c}\text { Confidence } \\
\text { interval 95\% }\end{array}$} \\
\hline Household income (-1) & -0.000337 & 0.000033 & 10.08 & 0.0000 & -0.0004 & -0.0003 \\
Broadband penetration & 2.960308 & 0.970254 & 3.05 & 0.0020 & 1.0586 & 4.8620 \\
No education & -4.603882 & 0,889184 & -5.18 & 0.0000 & -6.3437 & -2.8611 \\
$<3$ persons & 1.923927 & 0,446712 & 4.31 & 0.0000 & 1.0484 & 2.7995 \\
Manufacturing & 2.526376 & 1.017825 & 2.48 & 0.0130 & 0.5315 & 4.5213 \\
Agriculture & 0.708006 & 0.195230 & 3.63 & 0.0000 & 0.3254 & 1.0907 \\
Hotels and restaurants & 2.665666 & 0.302174 & 8.82 & 0.0000 & 2.0734 & 3.2579 \\
Exports (-1) & 0.010438 & 0.001638 & 6.37 & 0.0000 & 0.0072 & 0.0136 \\
Constant & -98.568610 & 31.663730 & -3.11 & 0.0020 & -160.6284 & -36.5088 \\
\hline
\end{tabular}

\begin{tabular}{lr}
\hline Number of observations & 24 \\
Number of groups & 6 \\
$\mathrm{R}^{2}$ within groups & 0.8029 \\
$\mathrm{R}^{2}$ between groups & 0.8119 \\
$\mathrm{R}^{2}$ total & 0.7971
\end{tabular}

Source: R. Katz, "Impacto económico de la Estrategia Nacional de Banda Ancha", Gobierno de Costa Rica, Rectoría de Telecomunicaciones, Estrategia Nacional de Banda Ancha, San José, 2011.

According to the model results, a one-percentage-point increase in regional broadband penetration raises average household income by $2.96 \%$; the rise in household income is larger if the head of household is employed in manufacturing or in the tourism sector (hotels and restaurants). Achieving broadband penetration of $10 \%$ would increase real average monthly household income in Costa Rica by the equivalent of US\$ 48. Thus, if broadband penetration reached $16 \%$, average household income would increase by US\$ 141. In turn, these increases in household income would contribute to GDP growth by boosting consumption.

For Colombia, the specified model aimed to study the impact of growth in broadband connections on the growth of real household income in 2006-2010. Following the literature, controls were included for population growth, human capital, share of output accounted for by the mining sector and initial level of wealth (as measured by the percentage of households with unmet basic needs (UBNs) in 2005). 
Table IV.8

COLOMBIA: IMPACT OF BROADBAND PENETRATION GROWTH ON REAL HOUSEHOLD INCOME GROWTH

\begin{tabular}{lrrr}
\hline \multicolumn{4}{c}{ Percentage increase in real household income, controlled for human capital } \\
\hline & \multicolumn{1}{c}{ Total } & Low penetration & High penetration \\
\hline $\begin{array}{l}\text { Growth in broadband } \\
\text { connections (percentage) }\end{array}$ & 0.0034083 & 0.0035966 & 0.0025196 \\
& $(0.0011585)$ & $(0.0013686)$ & $(0.0011616)$ \\
$\begin{array}{l}\text { Population growth } \\
\text { (percentage) }\end{array}$ & -2.533624 & -5.520381 & 1.702465 \\
& $(1.245529)$ & $(1.361513)$ & $(1.19664)$ \\
Years of education & 1.462938 & 0.4542847 & 0.1371095 \\
& $(0.7531259)$ & $(1.273384)$ & $(0.7649286)$ \\
$\begin{array}{l}\text { Mining sector output } \\
\text { (percentage) }\end{array}$ & 7.816958 & 9.122359 & 8.837977 \\
& $(4.226792)$ & $(4.701466)$ & $(8.11938)$ \\
$\begin{array}{l}\text { Households with UBNs 2005 } \\
\text { (percentage) }\end{array}$ & 19.7768 & 31.17167 & -34.74956 \\
& $(9.51923)$ & $(10.61504)$ & $(28.60452)$ \\
Adjusted $R^{2}$ & 0.1885 & 0.2986 & 0.1435 \\
$\begin{array}{l}\text { Prob > F } \\
\text { Number of observations }\end{array}$ & 0.0101 & 0.0006 & 0.0672 \\
\hline
\end{tabular}

Source: R. Katz and F. Callorda, Medición de Impacto del Plan Vive Digital en Colombia y de la Masificación de Internet en la Estrategia de Gobierno en Línea, Bogota, Centro de Investigación de la Telecomunicaciones (CINTEL), 2011.

Note: the symbols ${ }^{\star \star \star},{ }^{\star \star}$ and ${ }^{*}$ indicate significance at a level of $1 \%, 10 \%$ and $15 \%$, respectively.

a Dependent variable: growth in real household income between 2006 and 2010. Independent variables: growth in broadband connections, population growth, years of education, mining sector output and households with unmet basic needs in 2005 .

The main finding is that if the number of connections increases by $10 \%$ in a year, real household income would rise by $0.034 \%$ (see table IV.8). Growth in broadband penetration consistently explains increases in real household income in the three models (national level, departments with low penetration and departments with high penetration). The effect appears to be greater in departments with low penetration, although, except in Bogota, no department had more than $9 \%$ broadband penetration in 2010 (in other words, all departments had low penetration by international standards). Thus, it can be concluded that none of Colombia's departments had reached a sufficient level of penetration in 2010 to see returns to scale of the type that exist in OECD countries. ${ }^{7}$

In keeping with the human capital theory, a larger number of years of education results in greater growth in household income. Moreover, In accordance with the Solow growth model, there is a trend towards income convergence, as indicated by the coefficient "households with UBNs in 2005". 


\section{B. Digitization and development}

Beyond the impact of broadband access, it is important to study the combined impact of all services and applications enabled by broadband. The concept of digitization - defined as the ability to use digital technologies to generate, process and share information- was developed for that purpose (Katz and Koutroumpis, 2012b). This indicator measures not only the penetration of the technology, but also the use of applications and the consumption of content at three levels: (i) individuals, businesses and government; (ii) goods and services production processes; and (iii) provision of public services.

In order for digitization to reach its full potential, it must meet the following conditions with respect to infrastructure: affordability (prices), technological accessibility (network coverage) and technological reliability (capacity and access speed). A composite index based on the 23 indicators listed in diagram IV.3 was created in order to measure a country's level of development in terms of digitization.

The digitization index is composed not only of infrastructure indicators but also includes information regarding the adoption of applications and services transmitted by broadband - for example, use of e-commerce, mobile broadband, social networks, and e-government services. Calculations of the digitization index for a sample of 184 countries in 2011 indicated that countries pass through four stages of development (see figure IV.2).

Generally speaking, industrialized countries score above 50 on the digitization index. Countries in transition to advanced digitization have scores ranging from 35 to 50; this group includes countries in the Middle East, Eastern Europe and South-East Asia and some Latin American countries (Argentina, Brazil, Chile, Colombia, Costa Rica, Mexico, Panama and Uruguay). The majority of Latin American countries and some African and Asian countries have scores between 20 and 35, while the least developed countries score under 20. 


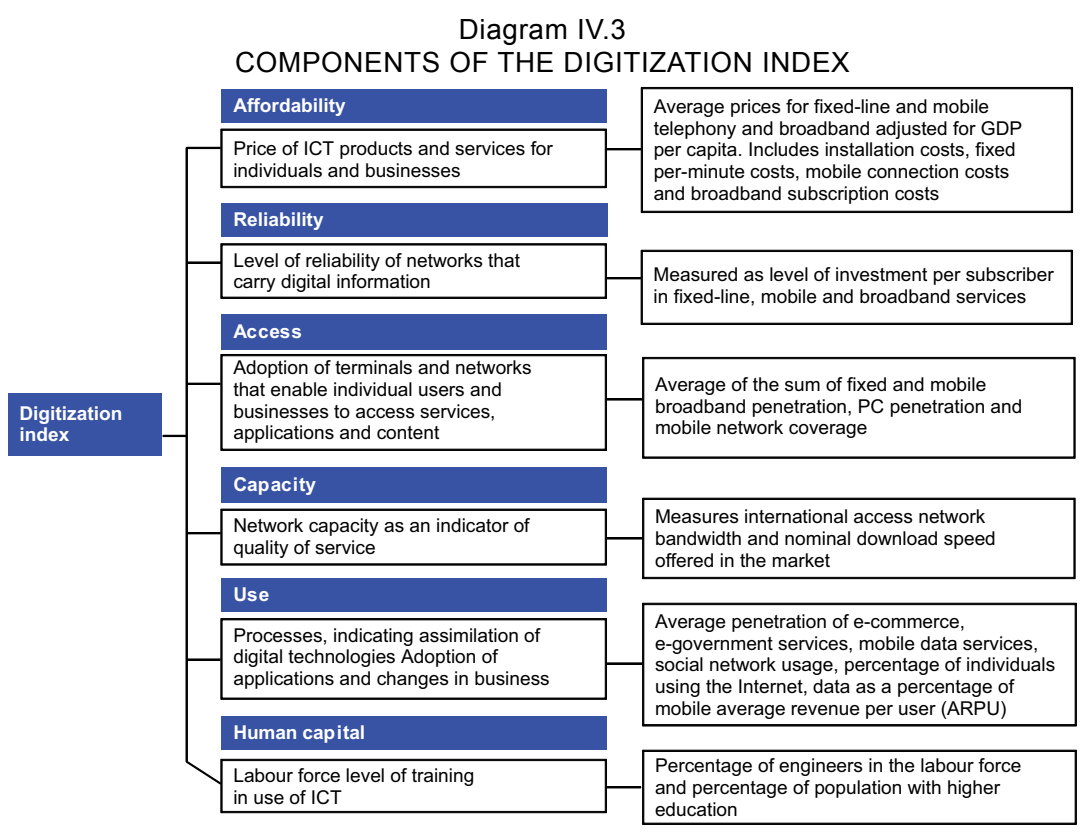

Source: R. Katz, P. Koutroumpis and F. Callorda, "The Latin American path towards digitization", Info, vol. 15, N³, 2013, pp. 6-24.

Figure IV.2

TYPOLOGY OF COUNTRIES BY STAGE OF DIGITIZATION, 2011

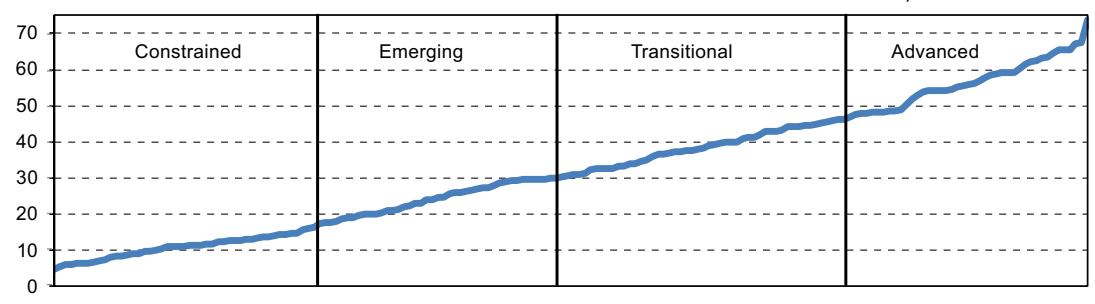

$\begin{array}{lcccc}\text { Region } & \text { Constrained } & \text { Emerging } & \text { Transitional } & \text { Advanced } \\ \text { Sub-Saharan Africa } & 35 & 6 & 1 & 0 \\ \text { South-East Asia } & 8 & 6 & 0 & 0 \\ \text { East Asia and the Pacific } & 5 & 7 & 4 & 2 \\ \text { CIS and Russian Fed. } & 3 & 3 & 7 & 2 \\ \text { Middle East and } & 4 & 9 & 13 & 0 \\ \text { Northern Africa } & & 14 & 13 & 4 \\ \text { Latin America and } & 3 & 3 & 1 & 2 \\ \text { the Caribbean } & 0 & 0 & 3 & 17 \\ \text { Eastern Europe } & 0 & 0 & & \end{array}$

Source: R. Katz, P. Koutroumpis and F. Callorda, "The Latin American path towards digitization", Info, vol. 15, N³, 2013, pp. 6-24. 
Analysis of the six sub-indices in the digitization index reveals that the biggest difference between advanced and emerging countries is not necessarily in technological infrastructure but rather in network use and capacity and in availability of the local human capital necessary to develop applications and content. Although there are large differences between developed and emerging countries in access to fixed broadband (one of the components of the index), the recent deployment of mobile broadband has done much to narrow the gaps. For all countries, then, the sub-index for use of technology never reaches the same level of development as the access sub-index, although the numerical distance between the infrastructure and use of technology sub-indices is less in advanced countries than in developing ones. Overcoming the lag in the adoption of applications and content, especially in countries at a medium stage of development, is the greatest technological challenge. In other words, the focus of a technology strategy should be more on applications and services than on infrastructure development. Models of the economic impact of digitization show that it has greater effect than broadband or mobile telephony by themselves (see figure IV.3).

Figure IV.3

DIGITIZATION AND ECONOMIC GROWTH (Percentages)

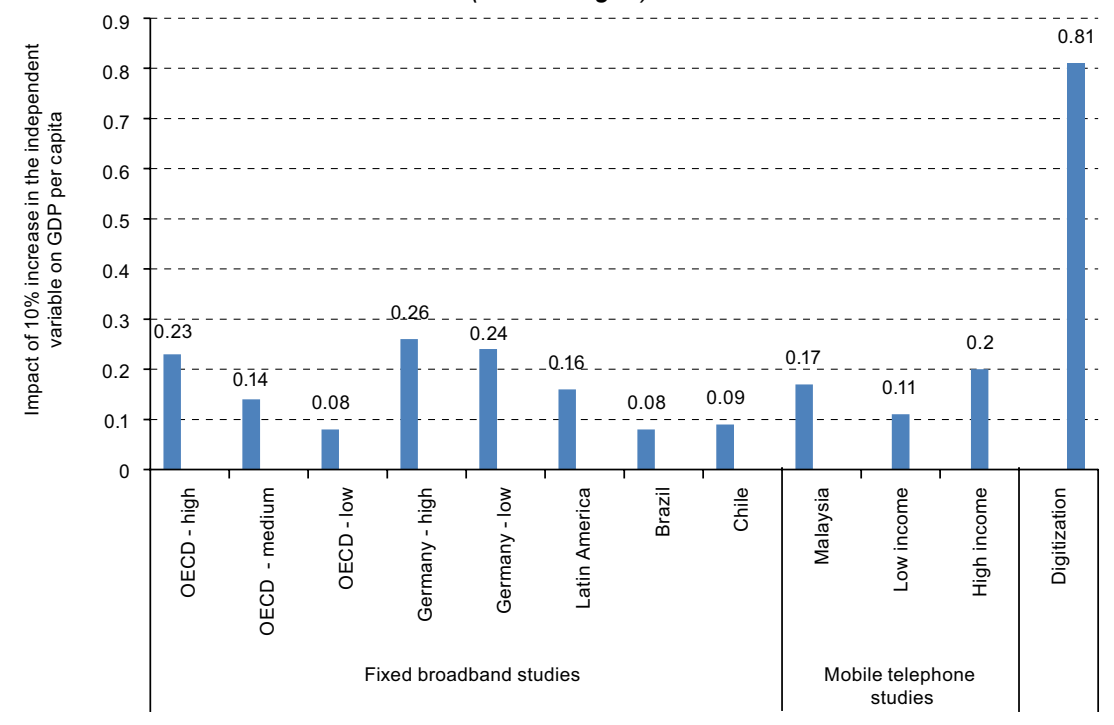

Source: R. Katz and P. Koutroumpis, "Measuring Socio-Economic Digitization: A Paradigm Shift", 2012, unpublished. 
A $10 \%$ rise in the digitization index results in a $0.81 \%$ increase in GDP per capita. This result is highly significant as it suggests that the economic impact of ICT is the result of cumulative adoption of all technologies, as well as of the assimilation of content and applications. Achieving high broadband penetration is just a telecommunications policy objective; maximizing its economic impact requires a combination of policies in the areas of telecommunications, information technology, and content and applications. In addition, disaggregating the economic impact model in order to measure the contribution of digitization by stage of digitization again reveals the existence of returns to scale (see figure IV.4).

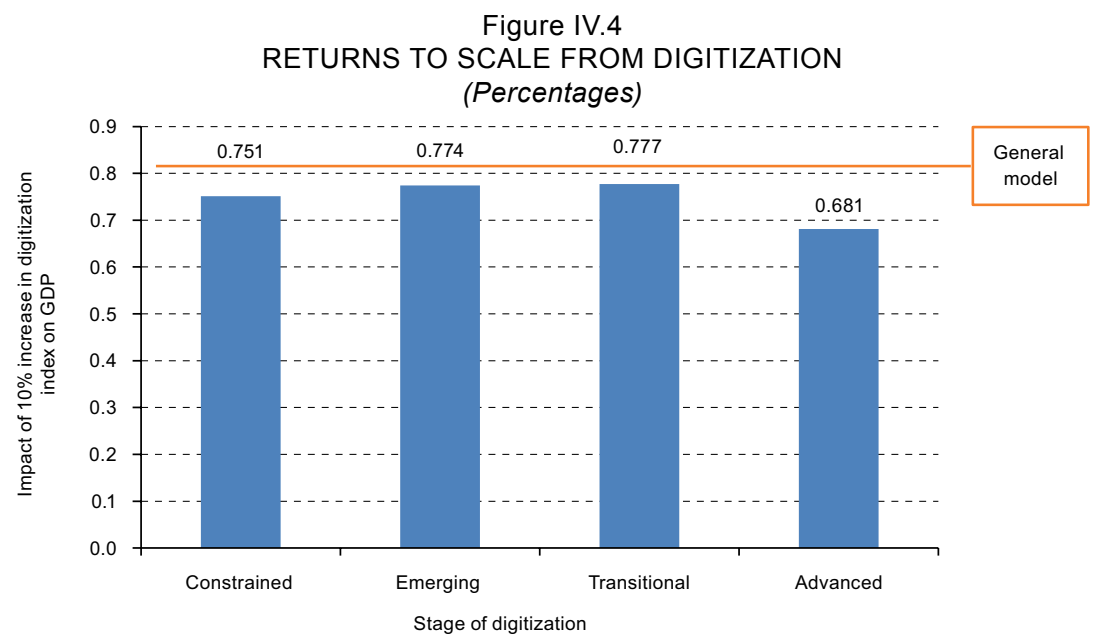

Source: R. Katz and P. Koutroumpis, "Measuring Socio-Economic Digitization: A Paradigm Shift", 2012, unpublished.

While, as shown above, the overall model indicates that a $10 \%$ increase in digitization results in a $0.81 \%$ increase in GDP per capita, for advanced-stage countries the figure is $0.681 \%$ and for countries with lower levels of digitization it is between $0.751 \%$ and $0.777 \%$. The results presented in figure IV.4 confirm the hypothesis of increasing returns, but they could also indicate that diminishing returns begin to emerge at an advanced stage of digitization. The impact is less pronounced among advanced-stage countries than among countries in the transitional and emerging stages. The latter two stages are closely linked and are in a different position in relation to countries at a constrained stage. Obviously, there is considerable heterogeneity within these categories, 
which could affect the results. However, from an aggregate perspective it is clear that there are increasing returns to scale in the process and that the benefits began to be seen at a digitization level of 30, with a saturation effect appearing at around 65.

Digitization also has a greater impact on job creation than broadband alone (see figure IV.5). A 10\% increase in the digitization index results in an increase of $0.82 \%$ in employment. This effect can, once again, be attributed to two trends. First, the deployment and assimilation of ICT contributes more to job growth in technology-intensive sectors (software development, business process outsourcing, manufacturing of equipment and parts). Second, the assimilation of ICT has a spillover effect on other sectors of the economy, especially commerce, financial services and health services.

Figure IV.5

DIGITIZATION AND EMPLOYMENT

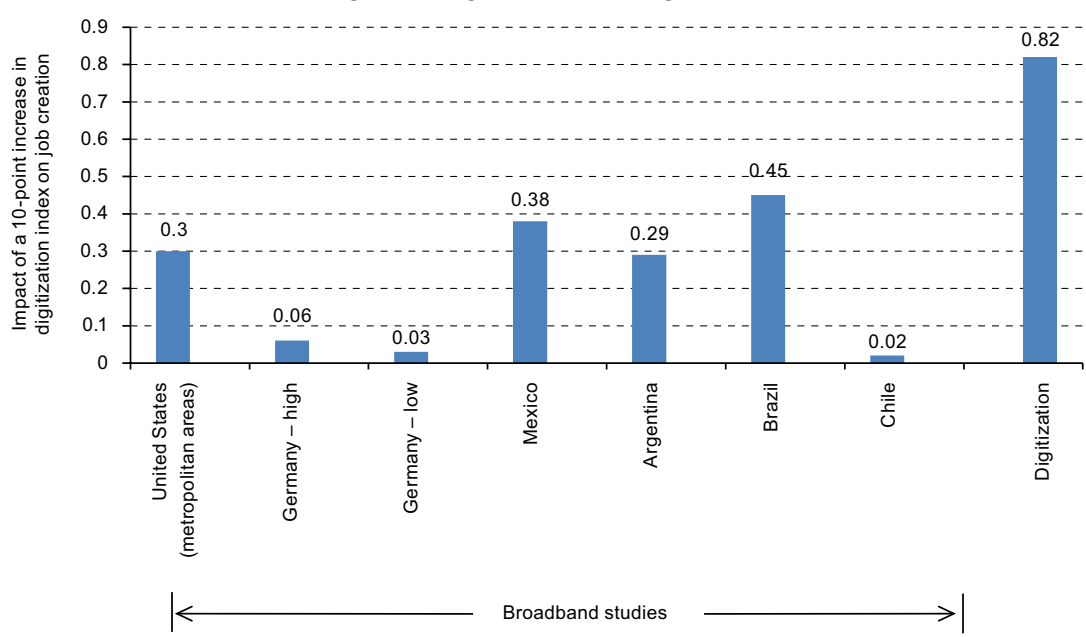

Source: R. Katz and P. Koutroumpis, "Measuring Socio-Economic Digitization: A Paradigm Shift”, 2012, unpublished.

Lastly, a country's level of digitization is closely correlated with the innovation capacity of its economy (see figure IV.6), although, as in the models presented above, it is not possible to confirm a causality relationship. The impact of digitization on innovation capacity would appear to be attributable to the capacity of the digitization environment to facilitate the creation of new products and services that add value. 
Figure IV.6

DIGITIZATION AND INNOVATION IN A SAMPLE OF 125 COUNTRIES

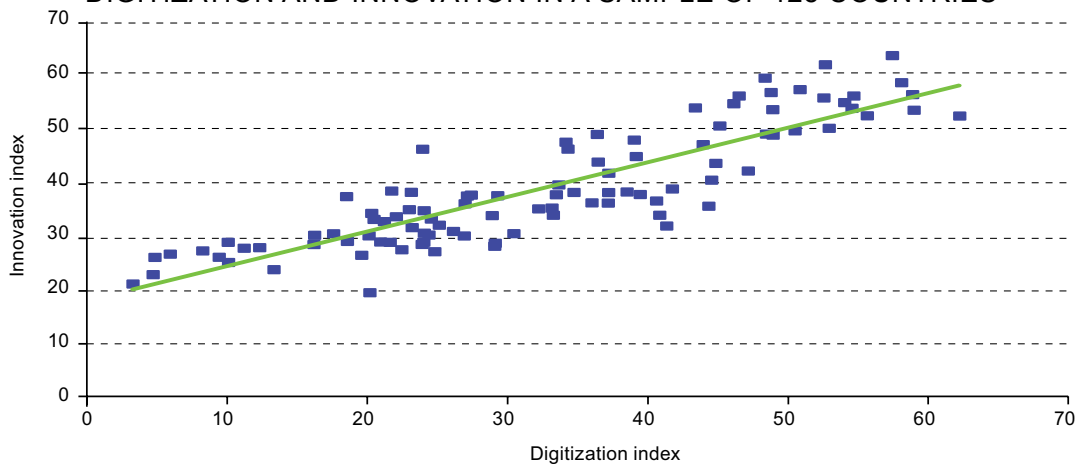

Source: R. Katz and P. Koutroumpis, "Measuring Socio-Economic Digitization: A Paradigm Shift", 2012, unpublished.

Based on the correlation coefficient, a $10 \%$ increase in digitization would result in a $6.4 \%$ increase in innovation. This boost to innovation comes from the introduction of ICT-facilitated services and applications (including new ones like telemedicine, Internet searching, e-commerce, distance education and social networks) and new forms of commerce and financial intermediation. These estimates show that the economic impact of digitization is significant (see table IV.9).

Table IV.9

LATIN AMERICA: ESTIMATED ECONOMIC IMPACT OF DIGITIZATION

\begin{tabular}{|c|c|c|c|c|c|c|}
\hline \multirow[b]{2}{*}{ Country } & \multicolumn{3}{|c|}{ Indicators (2011) } & \multicolumn{3}{|c|}{$\begin{array}{c}\text { Change as a result of } 10 \% \text { increase } \\
\text { in digitization index }{ }^{\mathrm{a}}\end{array}$} \\
\hline & $\begin{array}{l}\text { Digitization } \\
\text { index }\end{array}$ & $\begin{array}{c}\text { GDP per } \\
\text { capita }^{b} \\
\text { (dollars) }\end{array}$ & $\begin{array}{l}\text { Innovation } \\
\text { index }\end{array}$ & $\begin{array}{l}\text { Digitization } \\
\text { index }\end{array}$ & $\begin{array}{c}\text { GDP per } \\
\text { capita }^{\mathrm{b}} \\
\text { (dollars) }\end{array}$ & $\begin{array}{l}\text { Innovation } \\
\text { index }\end{array}$ \\
\hline Argentina & 41.32 & 10881 & 34.40 & 45.45 & 10969 & 36.60 \\
\hline Brazil & 36.61 & 12594 & 36.60 & 40.27 & 12696 & 38.94 \\
\hline Chile & 45.33 & 13738 & 42.70 & 49.86 & 13849 & 45.43 \\
\hline Colombia & 38.33 & 7121 & 35.50 & 42.16 & 7179 & 37.77 \\
\hline Costa Rica & 37.33 & 8644 & 36.30 & 41.06 & 8714 & 38.62 \\
\hline Ecuador & 32.75 & 4504 & 28.50 & 36.03 & 4540 & 30.32 \\
\hline El Salvador & 29.56 & 3602 & 29.50 & 32.52 & 3631 & 31.39 \\
\hline Mexico & 37.05 & 9980 & 32.90 & 40.76 & 10061 & 35.01 \\
\hline Panama & 44.29 & 8740 & 30.90 & 48.72 & 8811 & 32.88 \\
\hline Paraguay & 28.68 & 3594 & 31.60 & 31.55 & 3623 & 33.62 \\
\hline Peru & 32.20 & 5860 & 34.10 & 35.42 & 5907 & 36.28 \\
\hline Uruguay & 42.78 & 14294 & 35.10 & 47.06 & 14410 & 37.35 \\
\hline
\end{tabular}

Source: World Economic Forum, Maximizing the Impact of Digitization, Global Information Technology Report (GITR), Geneva, 2012; R. Katz and P. Koutroumpis, "Measuring Socio-Economic Digitization: A Paradigm Shift", 2012, unpublished.

a An ICT development policy results in a 10\% increase in the digitization index.

${ }^{b}$ Constant United States dollars. 
In conclusion, digitization has a positive economic impact. Every $10 \%$ rise in the digitization index increases GDP by $0.81 \%$ and decreases the unemployment rate by $0.82 \%$. In this process, there are increasing returns to scale, the benefits of which are seen mainly after the index reaches a threshold of 30 points; a saturation point is reached at around 50 points. This suggests that countries should accelerate the development of digitization, in particular for usage, applications and content, in order to maximize its impact on economic growth.

\section{Policy implications}

There is abundant empirical evidence of the economic impact of broadband and its positive externalities in innovation, productivity and business restructuring. Studies are beginning to show that these effects vary with the environment in which broadband is deployed (more or less developed regions). This highlights the need for prospective impact studies in order to target plans and investment, as well as to coordinate broadband deployment with regional economic development programmes in less developed areas. From an impact research standpoint, more work is needed on threshold and saturation levels in order to identify quantitative targets for digitization programmes. This is because the broadband demand gap is the main obstacle standing in the way of increasing the digitization index in Latin America (see table IV.10).

Table IV.10

LATIN AMERICA: BROADBAND SUPPLY AND DEMAND GAP, 2011

(Percentages)

\begin{tabular}{|c|c|c|c|c|}
\hline \multirow[b]{2}{*}{ Country } & \multicolumn{2}{|c|}{ Fixed broadband } & \multicolumn{2}{|c|}{ Mobile broadband } \\
\hline & $\begin{array}{l}\text { Supply gap } \\
\text { (network } \\
\text { coverage) }\end{array}$ & $\begin{array}{l}\text { Demand } \\
\text { gap }^{\mathrm{a}}\end{array}$ & $\begin{array}{c}\text { Supply gap } \\
\text { (network coverage) }\end{array}$ & $\begin{array}{l}\text { Demand } \\
\text { gap }\end{array}$ \\
\hline Argentina & 4 & 55 & 8 & 73 \\
\hline $\begin{array}{l}\text { Bolivia (Plurinational } \\
\text { State of) }\end{array}$ & 60 & 37 & 71 & 26 \\
\hline Brazil & 6 & 65 & 16 & 63 \\
\hline Chile & 22 & 34 & 28 & 65 \\
\hline Colombia & 19 & 54 & 4 & 87 \\
\hline Costa Rica & 5 & 63 & 7 & 82 \\
\hline Ecuador & 13 & 67 & 34 & 55 \\
\hline Mexico & 38 & 15 & 23 & 63 \\
\hline Peru & 41 & 43 & 37 & 54 \\
\hline
\end{tabular}

Source: Katz and Galperín (2013).

a The difference between the percentage of population covered and the penetration rate. 
As expected, the percentage of households that could obtain fixed broadband service but do not do so is significant. Excluding countries with low fixed-line telephony coverage (Peru and the Plurinational State of Bolivia), the demand gap ranges from $67 \%$ (Ecuador) to $15 \%$ (Mexico). The situation with respect to mobile broadband is similar: excluding countries with low mobile coverage (Plurinational State of Bolivia), the demand gap is significant, ranging from $87 \%$ (Colombia) to $54 \%$ (Peru). However, mobile broadband is still in the embryonic stages; dissemination projections indicate that the demand gap will narrow significantly in the coming years.

The demand gap is determined by generational, education and economic factors. Studies in industrialized and developing countries show that broadband adoption and Internet access are associated with younger generations. In the study of Costa Rica, over $80 \%$ of individuals accessing the Internet by means of a computer at home were between 15 and 24 years of age. The number drops substantially among age groups over 45 and is only $20 \%$ among persons aged over 55 . Just as broadband adoption is associated with younger generations, greater household Internet and computer penetration are associated with higher levels of education. In the Costa Rican study, households with lower levels of education showed considerably lower adoption rates (less than $50 \%$ in terms of service use). In contrast, more than $70 \%$ of households headed by an individual with post-secondary education used computers and broadband. In keeping with the affordability argument put forward by Galperin and Ruzzier (2010), the third explanation for the demand gap is the economic factor.

In this context, public policies aimed at addressing the demand gap should be underpinned by four fundamental principles. First, to the extent that affordability is one of the main obstacles to broadband adoption, it is important to highlight the benefits of increased competition among private operators as a factor leading to lower prices. Second, beyond the benefits of competition, the State should play a key role in promoting programmes designed to encourage broadband adoption. Areas to be prioritized include education and training programmes, deployment of e-government services that enhance the appeal of broadband service and implementation of subsidy programmes for the purchase of equipment.

Third, one of the most important factors in stimulating broadband adoption is the development of applications that meet individual needs, in both the social and the economic realms. The role of the applications and equipment ecosystem in fostering demand is critical. Lastly, public policies aimed at promoting broadband adoption should be long-range ones, since some of their results will not materialize in the short term. Accordingly, such initiatives should stem from State policies that go beyond political and electoral cycles. 
Bearing in mind these principles, four public policy areas for encouraging broadband adoption and increasing digitization can be identified. From an economic perspective, consideration should be given to eliminating sales tax on basic broadband service and on computers (especially import duties) and to offering subsidies to reduce monthly service fees for certain beneficiaries. It is also important to negotiate with broadband providers with a view to ensuring the availability of affordable broadband services.

In the area of education, ICT should figure more prominently in the curriculum. Secondary schools and specialized training institutions should be encouraged to offer short courses or university extension classes on ICT. Governments should promote digital literacy programmes targeting disadvantaged groups, older persons and persons with disabilities. They should also introduce initiatives to promote broadband adoption by small and medium-sized enterprises (SMEs). Measures to be considered include reducing taxes on the purchase of computer equipment and on broadband services, allowing accelerated depreciation of equipment and offering discounts or rewards to companies using ICT and broadband for their transactions with the government. Such economic incentives should be accompanied by training programmes for SME workers and advisory services to enable business owners to install and obtain maximum benefit from ICT.

Finally, with regard to incentives for broadband adoption arising from direct government action, it is important to develop content on portals providing information on cultural topics, preventive health care and public services. Mechanisms should also be put in place to promote e-government services such as electronic tax payment systems, e-procurement systems for use by suppliers of goods and services to the government and the development of platforms to facilitate telework. 


\section{Bibliography}

Fernández-Ardevol, M. and J. Vázquez Grenno(2011), "Estimación de la contribución de la telefonía móvil al crecimiento y reducción de la pobreza", Comunicación Móvil y Desarrollo Económico y Social en América Latina, M. Fernández-Ardevol, H. Galperin and M. Castells, Barcelona, Ariel.

Fornefeld, M., G. Delaunay and D. Elixmann (2008), "The impact of broadband on growth and productivity", study for the European Commission (DG Information Society and Media), MICUS.

Galperin, H. and C. Ruzzier (2010), "Broadband tariffs: benchmarking and analysis", Fast-tracking the digital revolution: Broadband for Latin America and the Caribbean, V. Jordán, H. Galperin and W. Peres, ECLAC-DIRSI, Santiago.

Gruber, H. and P. Koutroumpis (2011), "Mobile telecommunications and the impact on economic development", Economic Policy, vol. 67, July.

Jordana, J. (2001), “Desigualtats digitals i societat de la informació: un debat pendent", Papers de la Fundació, No. 130, Barcelona, Fundació Rafael Campalans.

Katz, R. (2009), El papel de las TIC en el desarrollo: Propuesta de América Latina a los retos económicos actuales, Colección Fundación Telefónica, Madrid, Ariel.

(2011a), "The impact of broadband on economic growth", Fast-tracking the digital revolution: Broadband for Latin America and the Caribbean (LC/R.2167), V. Jordan, H Galperin and W. Peres, ECLAC-DIRSI, Santiago.

(2011b), "Impacto económico de la Estrategia Nacional de Banda Ancha", Gobierno de Costa Rica, Rectoría de Telecomunicaciones, Estrategia Nacional de Banda Ancha, San José.

(2012), The Impact of Broadband on the Economy: Research to Date and Policy Issues, The Impact of Broadband on the Economy Broadband Series, Geneva, International Telecommunication Union (ITU).

Katz, R. and F. Callorda (2011), Medición de Impacto del Plan Vive Digital en Colombia y de la Masificación de Internet en la Estrategia de Gobierno en Línea, Bogotá, Centro de Investigación de la Telecomunicaciones (CINTEL).

Katz, R. and H. Galperin (2013), "The demand gap: drivers and public policies", H. Galperin, V. Jordán and W. Peres, Broadband in Latin America: beyond connectivity, ECLAC-DIRSI, Santiago, Chile.

Katz, R. and P. Koutroumpis (2012), The Economic Impact of Broadband: Case Studies of the Philippines and Panama, Geneva, International Telecommunication Union.

Katz, R., P. Koutroumpis and F. Callorda (2013), "The Latin American Path Towards Digitalization", Info, vol. 15, No. 3, pp. 6-24.

Koutroumpis, P. (2009), "The Economic Impact of Broadband on Growth: A Simultaneous Approach", Telecommunications Policy, No. 33.

Roller, L-H. and L. Waverman (2001), "Telecommunications Infrastructure and Economic Development: A simultaneous approach", American Economic Review, vol. 91, No. 4.

World Economic Forum (2012), Maximizing the Impact of Digitization, Global Information Technology Report (GITR), Geneva. 



\section{Chapter V \\ Mobile broadband: the urgent need for speedier roll-out}

Ernesto M. Flores-Roux ${ }^{1}$

\section{A. Introduction}

The importance of telecommunications in development has been recognized for decades. Much of the literature that has looked at this phenomenon has focused on assessing its impact on the transformation of specific social and economic groups. A pioneering study by Jensen (2007) to measure the impact of access to information and communications technologies (ICT) identified the positive effect that mobile telephony has had on fishing communities in southern India by reducing transaction costs. Several other studies have assessed the contribution of mobile telephony to growth (Waverman and others, 2005; Qiang, 2010; Katz, 2010a), employment (Katz, 2010b) and productivity (Waverman, 2009; García Zaballos, 2012, Waverman and others, 2005).

Mobile telephony is not new. The first real attempts to establish a mobile telecommunications network date back to the Second World War, ${ }^{2}$

Ernesto Flores-Roux is a professor at the Center for Economics Research and Teaching (CIDE) in Mexico City.

2 The first network came into operation in Saint Louis, Missouri, in 1946. The hands-off concept (the ability to move from one cell to another without interrupting a call) was proposed one year later by Bell Labs. 
but it was not until 1978 that Bell Labs launched the first test network in Chicago, for which AT\&T received a commercial use license in 1982. Around that same time, other countries, most with high per capita income, also installed mobile networks. ${ }^{3}$

However, early telephony was very different from today's. Due to the cost of service for users - the price of terminal equipment as well as user rates - the market was very restricted. In other words, it was a luxury service. It is worth remembering that in the early 1980s, AT\&T conducted an in-depth study of this market, seeking to estimate how many mobile telephones would be in use at the turn of the century. That study highlighted several problems with the product: the terminals were large and heavy, the batteries ran out quickly, network coverage was patchy and the price was exorbitant. Accordingly, the conclusion was that the total market would amount to approximately 900,000 terminals (The Economist, 1999). If these assumptions and the conclusion drawn from them had been accurate, the decision made by AT\&T would have been the right one: in 1984, when its local and long-distance services were split up, the company spun off its mobile operations to what would come to be known as the Baby Bells. Ten years later, when it became apparent that the mobile telephony market would be larger by several orders of magnitude than originally estimated, AT\&T returned to the market by acquiring McCaw Cellular Communications, Inc., completing the operation in 1995 and establishing AT\&T Wireless (http://www.corp.att.com/history/milestones.html).

By then, it was already clear that mobile telephony would be a market with considerable potential, but the role that it would play in making voice services universally available outside the developed world was not yet understood. Over the past 20 years, virtually every country in the world has experienced a sweeping social and economic transformation driven by mobile telecommunications. There have been several waves, from the early days when mobile telecommunications was a service for a small segment of the population, followed by the widespread roll-out of voice services, to the explosive growth of data services today.

This chapter describes some of the road traveled since mobile services began to be used on a large scale and discusses some of the causes of this phenomenon. Contrary to what was suggested in the literature in the early 1990s by authors such as Mueller (1998), the penetration of ICT, particularly mobile services, is not associated only with wealth. There is virtually no correlation between GDP per capita and time in service in Latin America: in other words, the decision to launch mobile data

The first 1G (first generation) network was launched in the Nordic countries (Sweden, Denmark, Finland and Norway) in 1981 by NMT (Nordic Mobile Telephone) and offered full roaming capabilities. 
networks does not seem to be related to income levels. This chapter argues that the launch of networks did much to speed growth of the service. An important factor behind the faster penetration rate is the amount of time that networks have been in place: an earlier network launch guarantees earlier adoption, regardless of how wealthy a country is or how developed the preceding technology was.

\section{B. Status of mobile telephony in Latin America}

As of late 1995, Latin America ${ }^{4}$ had only 3.6 million mobile terminals in operation, ${ }^{5}$ for a penetration rate of $0.77 \%$. The United States and the European Union had 33.8 million terminals (12.7\%) and 22.1 million terminals $(4.6 \%)$, respectively, with penetration rates sixteen and six times greater than in Latin America. Fifteen years later, the gap has closed. In fact, there are more mobile telephones per 100 inhabitants in Latin America than there are in the United States (see figure V.1). As may be seen in the figure, the convergence in penetration rates is a phenomenon of the past six years.

Figure V.1

MOBILE TELEPHONY PENETRATION RATE IN THE UNITED STATES AND THE EUROPEAN UNION COMPARED WITH LATIN AMERICA

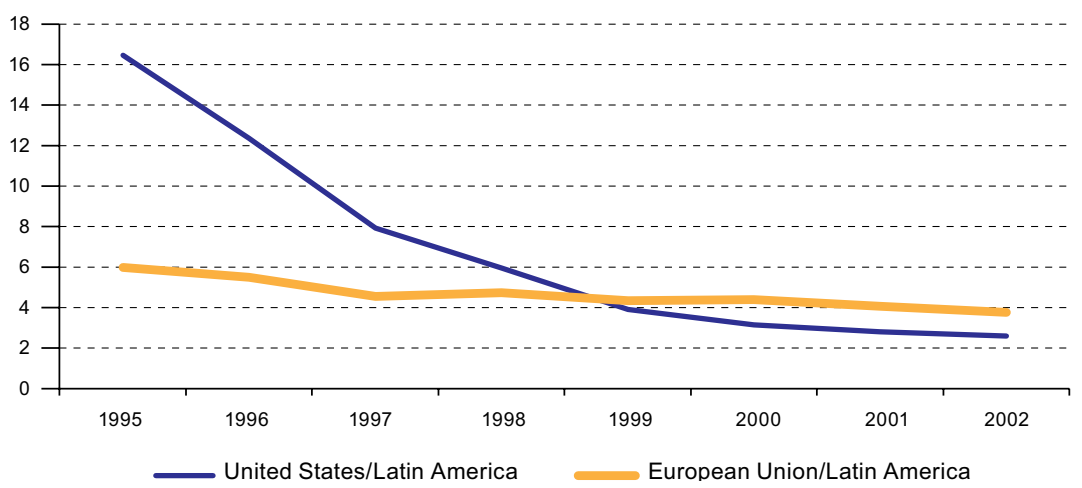

4 In this chapter, references to Latin America include Argentina, the Bolivarian Republic of Venezuela, Brazil, Chile, Colombia, Costa Rica, the Dominican Republic, Ecuador, El Salvador, Guatemala, Honduras, Mexico, Nicaragua, Panama, Paraguay, Peru, the Plurinational State of Bolivia and Uruguay. Cuba has a mobile telephony penetration rate of $14.1 \%$, with a subscriber rate of $12.7 \%$. That country's data are not included in this analysis so as to prevent findings that cannot be generalized to the region as a whole.

5 All figures on market size (penetration, access, and number of subscribers) from the year 2000 and after were taken from Wireless Intelligence. For statistics prior to that year, the figures reported by the International Telecommunication Union (ITU) were used. 
Figure V.1 (concluded)

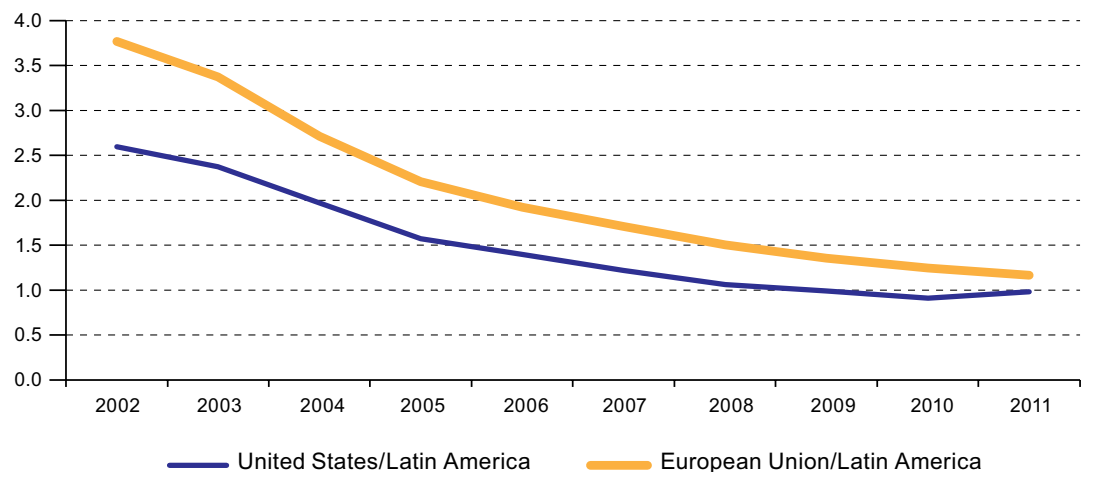

Source: ITU, Wireless Intelligence.

Penetration rates above $100 \%$ are generally interpreted to mean that mobile telephony use has become universal in a region where voice services were a luxury enjoyed by the few just over a decade ago. However, there is a problem with the traditional measure of penetration: this indicator is increasingly divergent from the real indicator of how universal access has become because it measures the total number of connections, not the number of people who own a mobile telephone (see box V.1). Today, slightly more than half of the population uses mobile services, a figure whose importance should not be played down as it indicates great progress towards achieving universal access, but it is also an indication of the work yet to be done.

Box V.1

SERVICE PENETRATION AND UNIQUE SUBSCRIBERS

Penetration, defined as the number of connections per 100 inhabitants, has been the traditional measure used to quantify the use of telecommunications services. However, it has been recognized for some time that this figure does not accurately reflect the number of people who actually subscribe to the service. Anecdotal evidence suggests that many people have more than one mobile line, a number of connections reported by firms or regulators are not active, and there are many machine-to-machine (M2M) connections, so interpreting penetration as the number of people per 100 inhabitants who have a mobile telephone overstates the real number of unique subscribers. But just how inflated is this figure? In October 2012, the association that represents the interests of mobile operators worldwide (GSMA) published a first report addressing the issue on a global scale, based on field research and statistical models (Gillet, 2012). These were the findings: in June 2012, there were 6.6 billion lines worldwide excluding M2M, but $10 \%$ of connections were not active, reducing the number to 5.9 billion. With every consumer using an average of $1.85 \mathrm{SIM}$ cards, this brings the total number of unique subscribers in the world to 3.2 billion. Accordingly, the global penetration rate was just $44 \%$, which suggests that not only is there still considerable growth potential, but also that service coverage is far from being truly universal 
Box V.1 (concluded)

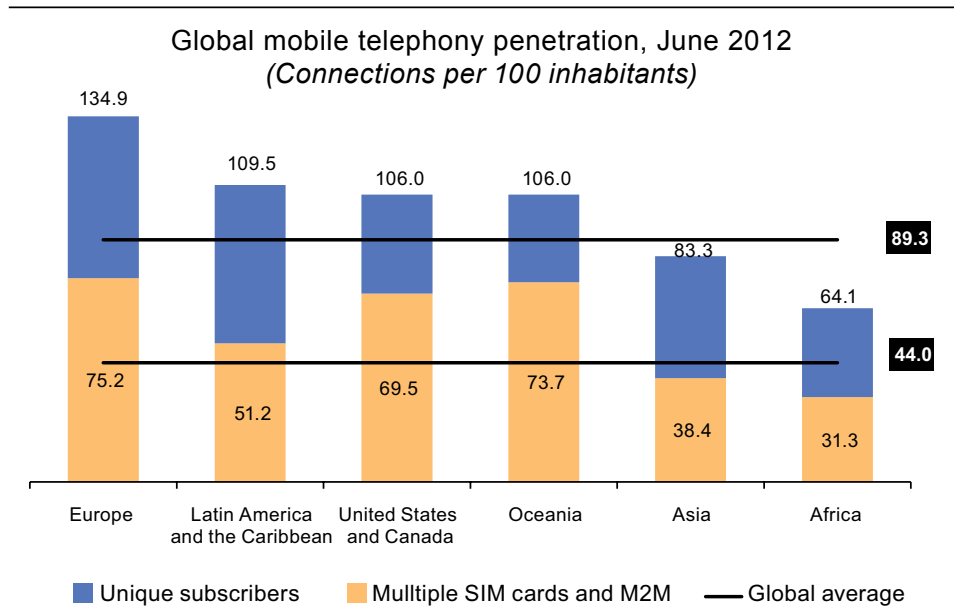

According to GSMA, as of the same date, $51.2 \%$ of the population of Latin America and the Caribbean had a mobile telephone, with the figure running as low as $37.6 \%$ in Mexico to as high as $66 \%$ in El Salvador.

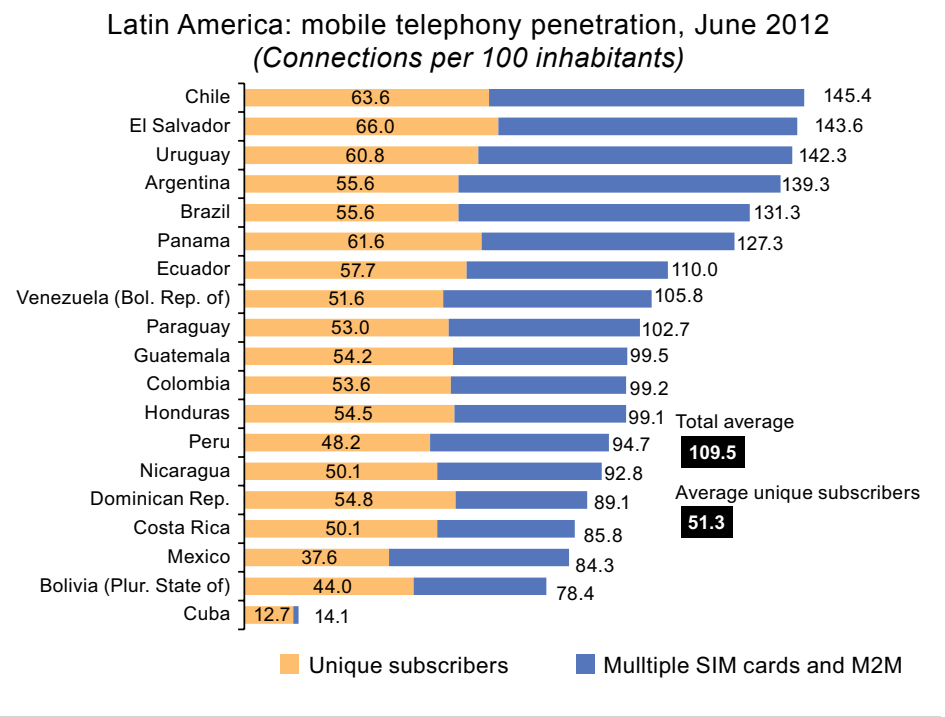

Source: GSMA, Wireless Intelligence (2012).

If mobile telephony has been the main vehicle for the spread of voice services in Latin America, it can be expected that mobile broadband will provide universal access to the global information and knowledge network. This was the assertion made by Flores-Roux and Mariscal (2010), who posited, based on preliminary data, the substitution and complementarity effects of fixed and mobile broadband. 


\section{Mobile data networks in Latin America}

The spread of mobile services is linked not only to technological progress and steadily lower service delivery costs but also to its cost structure. The marginal investment needed to add new consumers is not the main cost component, unlike in the case of fixed telecommunications, which require a single-purpose last-mile investment. Other than the sales and distribution costs and possible subsidies for terminal equipment, the cost attributable to each new user is very low. The cost incurred is associated with use -which is reflected in price structures and has made prepaid or pay-per-use services possible- not with the investment in a dedicated connection, which must be amortized.

These characteristics have enabled a steady stream of investments to be made in setting up new networks and upgrading old ones. Although in many cases the patterns of service introduction have correlated with the development level of countries, this has not been the case in Latin America. There is a strong correlation between the development of mobile telecommunications and the wealth of the region's countries, but launch patterns seem to correspond not with levels of economic development but with spectrum licensing and liberalization processes, which have stood in the way of fully capitalizing on the potential social and economic impact of mobile telecommunications.

This section analyses the relationship between service penetration and wealth creation, measured by GDP per capita, as well as the launch of mobile telecommunications networks in the region.

\section{Relationship between penetration and wealth creation}

One of the most common approaches in telecommunications sector studies is to show how penetration is dependent on per capita income, generally defined as GDP per capita in terms of purchasing power parity (PPP). However, the fact that penetration rates in Latin American countries and in regions with substantially higher GDPs have converged makes this point somewhat moot, providing as it does information that is of little consequence and in some cases irrelevant. In fact, when analysed over time, the correlation between penetration and GDP per capita gradually diminishes until virtually disappearing.

Based on the model specified as "penetration ${ }_{t}=\mathrm{k}_{0 \mathrm{t}}+\mathrm{k}_{1 \mathrm{t}} \mathrm{GDP}_{\mathrm{pct}, \mathrm{t}}$ ", where $t$ represents a moment in time, and verifying the statistical significance of the parameters $k_{0 t}$ and $k_{1 t^{\prime}}$ the wealth creation factor in Latin America was highly indicative of penetration until the middle of the last decade. However, over the past five years, as levels of access around the world began to converge, this parameter lost its explanatory power, as 
illustrated in figure V.2. The figure also shows how the significance of the constant grew, which indicates a convergence in penetration rates.

Figure V.2

STATISTICAL SIGNIFICANCE OF THE PARAMETERS, 1995-2011

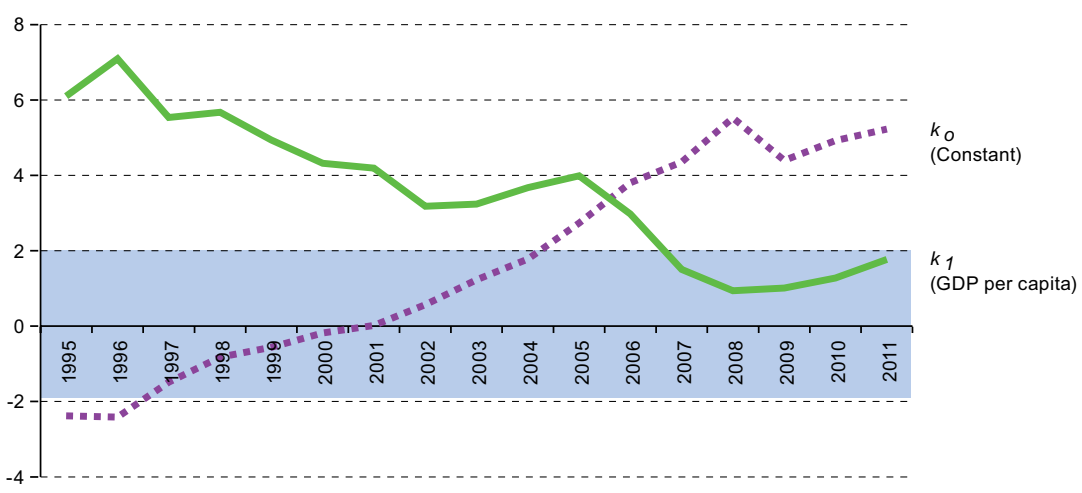

Value of $t$ where the estimated parameter is not significant

Source: Prepared by the author on the basis of data from Wireless Intelligence.

Note: Value of the statistic $t$ for the regressions "penetration $=k_{0}+k_{1} G D P_{p c}$ " from 1995 to 2011. For values of $|t|>2$, the estimate of the value of the parameter is significant at a confidence level of $95 \%$ or greater.

Beginning in 2007, the correlation between wealth and penetration is no longer statistically significant. Indeed, it falls sharply in 2004-2008, reflecting convergence towards a reasonably constant level of penetration throughout the region, regardless of wealth.

If the hypothesis that mobile platforms will bring about universal broadband service is accepted as true, a pattern of convergence similar to the one seen for voice services should be expected. If so, the relationship with income will be a time variable that will partly explain the adoption rate but will not be a determining factor in achieving near-universal levels of use. The following section further elaborates on these relationships.

\section{Introduction of mobile broadband networks in Latin America}

Although the world's first mobile broadband networks $(3 \mathrm{G})^{6}$ were installed at the beginning of the twenty-first century, the first one in Latin America 6 3G or later-generation networks are those that use one of the following technologies:
EVDO, HSDPA, HSPA+ or LTE (networks that use the latter are considered to be $4 \mathrm{G}$ ). 
did not appear until the first half of 2004, in Guatemala. ${ }^{7}$ Not many latestgeneration networks were launched in the following three years; by the first half of 2007, only six Latin American countries had these services, which were provided by a total of nine networks (see figure V.3). However, over the next two years, 3G networks came online in nearly every country in the region. By mid- 2009 there were 47 networks in 17 countries (Cuba and Costa Rica ${ }^{8}$ did not have $3 G$ services). Since that time, spectrum licensing has increased and mobile broadband networks have been set up by nearly all incumbent operators in the region, as well as some new entrants, so that every country in the region (except Cuba) now has these services, which are provided by 78 different networks. ${ }^{9}$

Figure V.3

NUMBER OF 3G NETWORKS IN OPERATION IN LATIN AMERICA

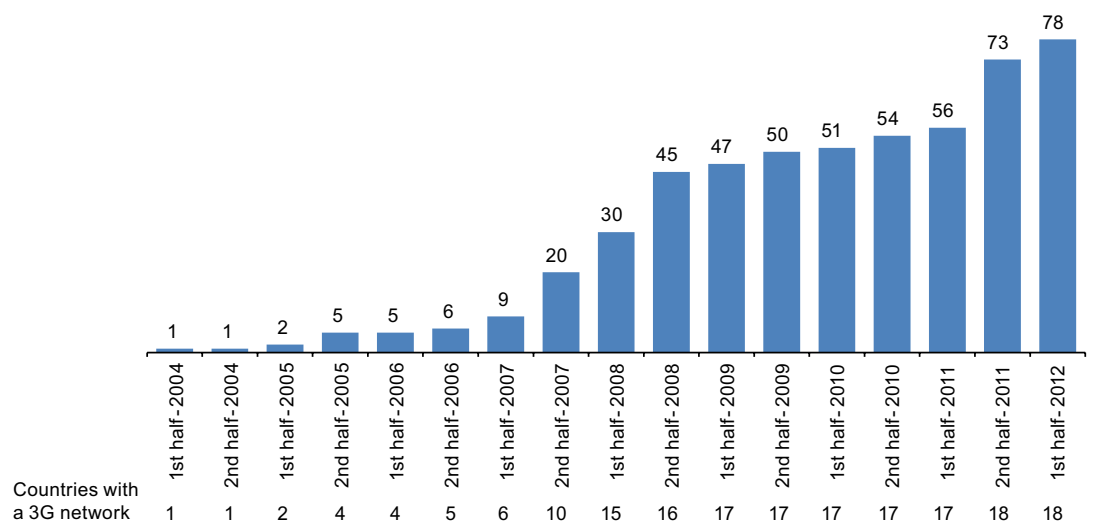

Source: Wireless Intelligence.

Note: EVDO, HSDPA, HSPA+ and LTE technologies.

There have been some technological discontinuities in mobile telephony. These have been so significant that their names have come to form part of everyday language: $1 \mathrm{G}, 2 \mathrm{G}, 3 \mathrm{G}$ and now $4 \mathrm{G}$. Mobile data became a reality with the step from $2 \mathrm{G}$ to $3 \mathrm{G}$, a process that may be compared to the transition from $1 \mathrm{G}$ to $2 \mathrm{G}$. The adoption of digital technologies (commonly

$7 \quad$ BellSouth Guatemala began to operate a CDMA2000 1xEV-DO network in May 2004. This company was subsequently acquired by Telefónica Móviles, S.A., which is now part of Telefónica S.A.

8 As will be explained later, the development of Costa Rica's telecommunications sector has been a typical of sector development in the rest of the region.

9 Different networks are defined as the networks in different countries that are run by the operators that provide services in the region, as well as when they have more than one technology deployed. 
known as $2 \mathrm{G}$ ), which replaced analog technologies, began in Latin America in the mid-1990s and accelerated dramatically with the arrival of GSM technology in the region, which replaced the technologies that had initially been deployed (TDMA and CDMA).

The time analysis shows that there do not seem to be any significant differences between the advent of $3 G$ networks in Latin America and the transition from analog $(1 \mathrm{G})$ to digital $(2 \mathrm{G})$ telephony. Mobile broadband was slightly slower to take off, but the pace at which the networks were deployed subsequently accelerated (see figure V.4). ${ }^{10}$

Figure V.4

COMPARISON BETWEEN NETWORK LAUNCHES

(Number of networks in operation)

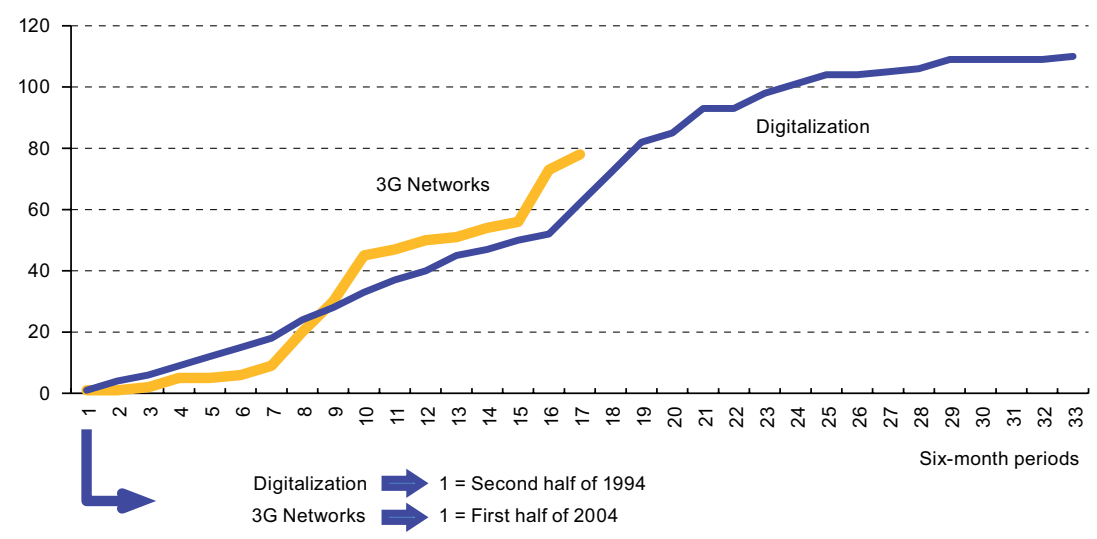

Source: Wireless Intelligence, 4G Americas, press archives.

The introduction of new networks offering Internet and other broadband services was clearly reflected in the number of users. From just 2.4 million connections ${ }^{11}$ in the region in the first half of 2007, the figure had jumped to 117 million connections in 2012. From the second half of 2009 (when the technology had already become nearly universally available) to June 2012, the annual regional growth rate was an impressive $92 \%$ (see figure V.5).

10 The figure reflects the consolidation of companies between 2000 and 2005, as well as the migration from TDMA and CDMA to GSM. There are still some companies in the region that keep more than one $2 \mathrm{G}$ or $2.5 \mathrm{G}$ network in operation, which explains why there are over 100 different networks in 19 countries.

11 This includes the total number of connections to 3G networks, regardless of whether these are users of mobile data services or just voice services delivered on this platform. 
Figure V.5

GROWTH IN THE NUMBER OF $3 G$ USERS

(Number of connections at end-quarter; in millions)

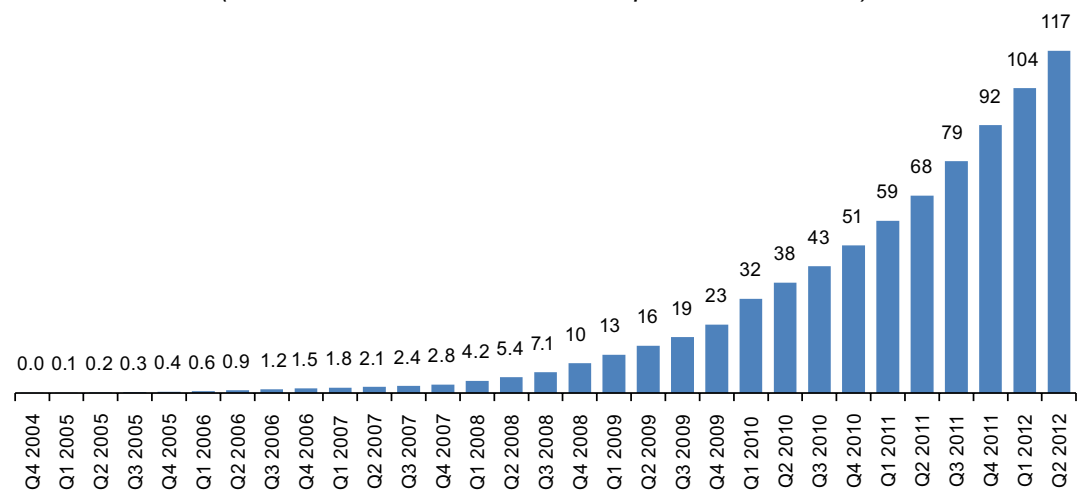

Source: Wireless Intelligence.

There are several reasons for this surge: more appropriation, lower service delivery costs (owing both to the maturation of the technology and greater network use, as well as the realization of economies of scale) and a substantial reduction in the cost of terminal equipment (which is a major entry barrier for consumers). However, the rate of adoption between the different countries is still very uneven (see figure V.6), and this should have an explanation beyond levels of wealth.

Figure V.6

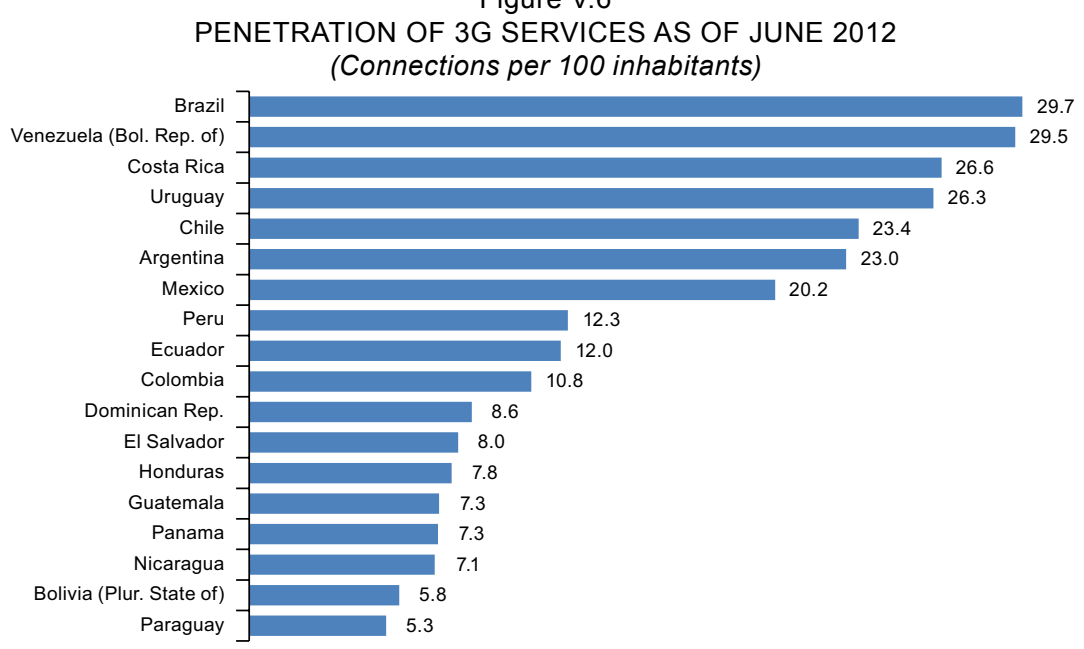

Source: Wireless Intelligence. 
The correlation between GDP per capita and penetration of 3G services has been relatively weak in Latin America. Figure V.7 tracks the correlation of penetration with both GDP per capita and the amount of time that the service has been available (measured in quarters, which is the minimum unit of time for which data are available for the entire region). As shown in the figure, it was not until late 2010 that the correlation with GDP surpassed the correlation with time in service.

In other words, at any moment $t$ after mobile data networks have been installed, the rate of adoption has been tied both to wealth and to the time in which the service has been available. Excluding Costa Rica, which has been an atypical case, ${ }^{12}$ the data point to a strong correlation between penetration and the amount of time in service.

Figure V.7

CORRELATION OF PENETRATION WITH TIME IN SERVICE AND GDP PER CAPITA (Correlation factors)

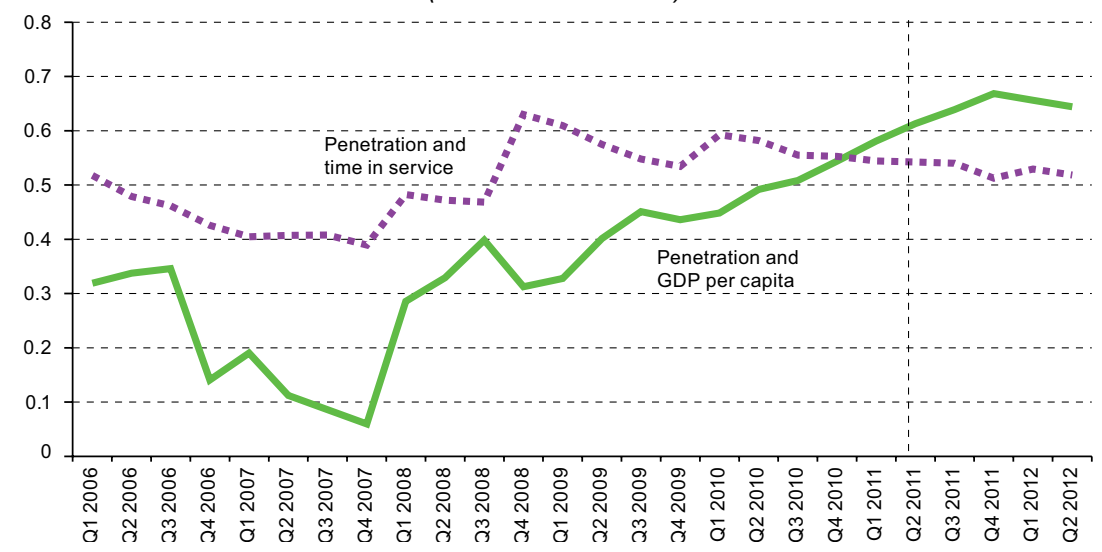

Source: Prepared by the author on the basis of data from Wireless Intelligence.

Note: For each quarter, the set of data observed at that moment for all countries in Latin America that already had $3 \mathrm{G}$ networks available was used.

To conclude the correlation analysis, it is important to note that there is virtually no correlation between GDP per capita and time in service. In other words, the decision to launch mobile data networks does not seem to be related to levels of income (see figure V.8).

12 The State-owned electricity company, ICE, had a monopoly on the delivery of mobile services -the first 3G network (WCDMA) was launched under the "Kölbi" brand in December 2009- until the arrival of Telefónica (Movistar) and América Móvil (Claro), which launched their networks in November 2011. During the two-year period in which ICE was the only provider of $3 \mathrm{G}$ services, the penetration rate climbed to just over $6 \%$. By late 2011, it had already increased to $11 \%$, rising to $26.6 \%$ just six months later. By late 2012 , it was over $35 \%$. 
Figure V.8

RELATIONSHIP BETWEEN GDP PER CAPITA AND TIME

IN SERVICE AS OF JUNE 2012

(Correlation factors)

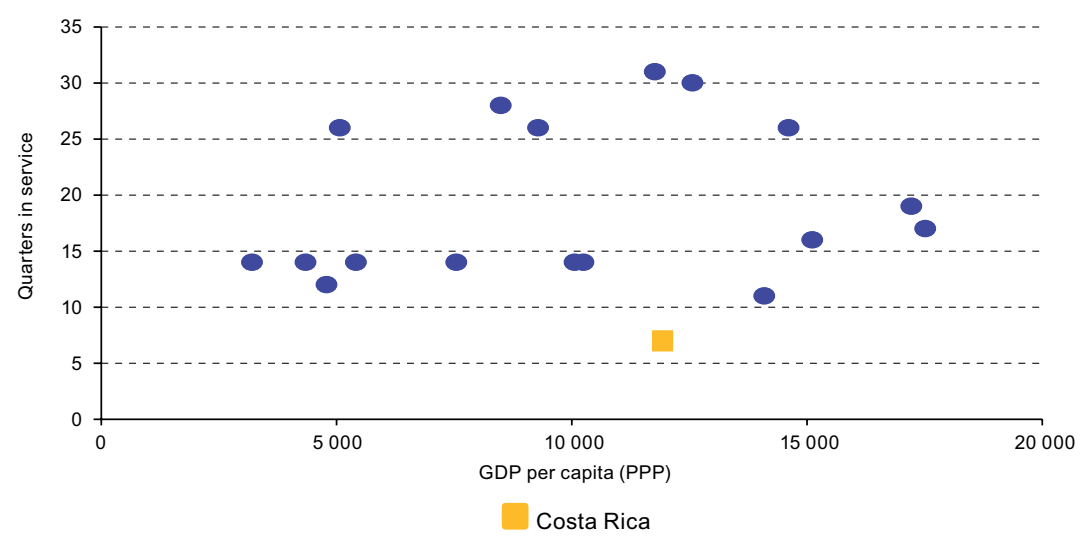

Source: Prepared by the author on the basis of data from Wireless Intelligence and the World Bank. Note: Each dot represents a country in the region as of June 2012.

Lastly, in an analysis of how penetration increases according to network age, the longer the network has been in service the more the adoption rate raises. The speed, or rate, of adoption (the number of percentage points of penetration that are added to the baseline in a given period of time) went from 0.15 percentage points of penetration per quarter initially to 0.4 percentage points in the third year. By the fifth year, the rate had climbed to over one percentage point (see figure V.9). At the end of the sixth year, the rate slows somewhat but rebounds one year later. This is largely explained by a reduction in the number of countries in the considered universe starting in the twenty-fourth quarter; by 2012, there were only three countries that had at least one $3 \mathrm{G}$ network in operation for over seven years.

Based on the foregoing, it can concluded that the growth of mobile broadband has followed a pattern similar to that of the transition from analog to digital mobile telephony. Adoption has been correlated with GDP per capita, but another important factor has been the length of time in which latest-generation networks have been available. Moreover, there has not been any correlation between the installation of networks and the wealth of individual countries in the region. 
Figure V.9

AVERAGE QUARTERLY INCREASE IN PENETRATION, BY NETWORK AGE (Percentage points)

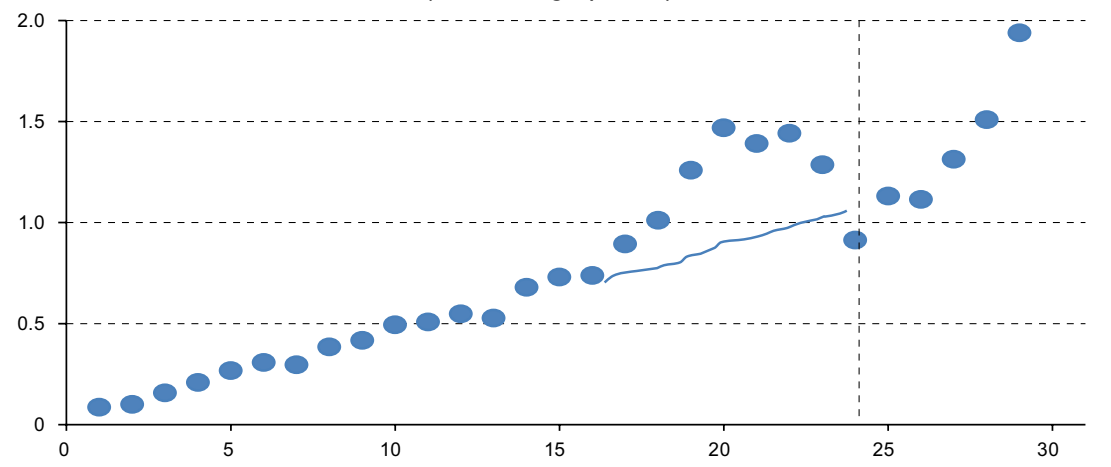

Number of quarters with $3 G$ network in operation

Source: Prepared by the author on the basis of data from Wireless Intelligence.

\section{A supporting theoretical model and its implications}

To test the hypothesis of the importance of time for penetration, a simple adjustment model was constructed for the data observed in Latin America from the fourth quarter of 2004 to June 2012. Subsequently, the model was used to estimate the average cost of a delayed roll-out of mobile broadband networks.

\section{The adjustment model}

The model that was developed seeks to explain the penetration of mobile data services in terms of GDP per capita $\left(\mathrm{GDP}_{\mathrm{pc}^{\prime}}\right.$ measured in PPP dollars per quarter) and time in service of the network $(t$, measured in quarters) (model 1). ${ }^{13}$ The fact that the rate of adoption increases over time means that the relationship between penetration and time is not linear; therefore, a quadratic model starting at the origin was used. ${ }^{14}$

13 For an explanation and rationale of the models used, see the chapter "Smoothing and extrapolation of time series" in Pindyck and Rubinfeld (1998).

14 The model can be marginally improved by using an estimate of parameters for an equation in an adoption model, which normally follows an S-curve, also described in Pindyck and Rubinfeld (1998). Given that the beginning of the adoption curve is being analysed and the turning point has not likely been reached yet, using a quadratic model as a proxy for an S-curve is acceptable. The ordinate was taken at the origin (i.e., the linear term kit was eliminated) since no shift has been observed in Latin America: in all cases, the penetration rate begins to climb in the first quarter in which the network is brought online. The data confirm this, inasmuch as the variable $t$, with the inclusion of $t^{2}$, is not statistically significant. 
Three variants of the model were considered. The first includes a country indicator as a fixed effect $\left(\mathrm{FE}_{\text {country }}\right)$ to incorporate the existence of differences among countries (model 2). The second adds the year of observation as a fixed effect, in order to incorporate fluctuations in the economy of the region (model 3). Lastly, a model was studied taking as a fixed effect the (total) mobile penetration in each country at the time of launch $\left(\mathrm{MP}_{\mathrm{t}}\right)$. Models 2 and 4 are statistically equivalent. ${ }^{15}$

$$
\begin{aligned}
& \text { penetration }=k_{0}+k_{1} G D P_{p c}+k_{2} t^{2} \\
& \text { penetration }=k_{0}+k_{1} G D P p c+k_{2} t^{2}+F E_{\text {country }} \\
& \text { penetration }=k_{0}+k_{1} G D P_{p c}+k_{2} t^{2}+F E_{\text {country }}+F E_{\text {year }} \\
& \text { penetration }=k_{0}+k_{1} G D P_{p c}+k_{2} t^{2}+M P_{t 0}
\end{aligned}
$$

The models were adjusted to the database, excluding Costa Rica (where, as previously indicated, the pattern has differed from the rest of the region). Cuba is not included either because it does not have a 3G network in operation and so cannot be represented in the model, given that $t>0$ is required.

For Latin America, 376 observations were available for different points in time from the fourth quarter of 2004 to June 2012, grouped into 17 data sets, each one representing a country. The number of observations per country varies depending on when mobile data services were launched.

Across all of the models considered, the results are consistent and demonstrate that time in service does in fact have a significant impact on penetration growth, regardless of wealth or legacy technology penetration rate. All estimated parameters are highly significant, and the critical value of the statistic $F$ is near 0 (see tables V.1 and V.2).

How can these results be interpreted? In the period encompassed by the data, the unweighted linear average of quarterly GDP per capita for all countries in Latin America was 2,160 PPP dollars, with compound annual growth of $3.4 \%$, according to data from the World Bank. Using models 2 and 3 , it can be estimated that $68 \%$ of the growth in the penetration of mobile data services as of the end of the first year came from GDP growth and the rest can reasonably be attributed to network time in service. For the second, third and fourth years, this figure drops to $35 \%, 19 \%$ and $12 \%$, inverting the ratio. In other words, in the first year, the impact of GDP is approximately double the impact of network time in service, but by the fourth year the impact of time in service is 7.5 times greater than GDP.

15 The two models are equivalent inasmuch as $\mathrm{MP}_{\mathrm{t} 0}$ ends up functioning as a fixed effect because only the value at $t_{0}$ was considered. 
Table V.1

MODEL PARAMETERS

\begin{tabular}{lcccc}
\hline & Coefficient & Standard error & T-statistic & P>lt| \\
\hline Model 1 & & & & \\
Constant & -0.031119 & 0.004668 & -6.667 & 0.00 \\
GDP $_{\mathrm{PC}}$ & 0.000017 & 0.000001 & 8.754 & 0.00 \\
$\mathrm{t}^{2}$ & 0.000202 & 0.000008 & 23.992 & 0.00 \\
Model 2 & & & & \\
Constant & -0.281923 & 0.038878 & -7.252 & 0.00 \\
GDP $_{\mathrm{PC}}$ & 0.000092 & 0.000011 & 8.223 & 0.00 \\
$\mathrm{t}^{2}$ & 0.000197 & 0.027949 & 23.539 & 0.00 \\
Model 3 & & & & \\
Constant & -0.260783 & 0.055592 & -4.691 & 0.00 \\
GDP $_{\mathrm{PC}}$ & 0.000108 & 0.000012 & 8.803 & 0.00 \\
$\mathrm{t}^{2}$ & 0.000232 & 0.000020 & 11.646 & 0.00 \\
\hline
\end{tabular}

Source: Prepared by the author.

Table V.2

REGRESSION AND VARIANCE ANALYSIS STATISTICS

\begin{tabular}{lrrr}
\hline & Model 1 & Model 2 & Model 3 \\
\hline $\mathrm{R}^{2}$ & 0.665 & 0.838 & 0.868 \\
Adjusted $\mathrm{R}^{2}$ & 0.663 & 0.829 & 0.858 \\
$\mathrm{~F}$ & 370.01 & 102.35 & 88.40 \\
$\mathrm{P}>\mathrm{F}$ & 0.00 & 0.00 & 0.00 \\
Number of groups & & 17 & 17 \\
Number of observations & & 376 & 376 \\
\hline
\end{tabular}

Source: Prepared by the author.

\section{Implications of the model}

The analysis based on the model reveals two basic points. A significant portion of growth in the penetration rate is not explained by GDP per capita, but rather by network time in service. In addition, the portion of penetration that is explained by time in service increases as the time in service lengthens, which is to be expected during the period of adoption of a technology. In other words, an earlier launch guarantees earlier and swifter adoption, regardless of how wealthy a country is or how developed the preceding technology was.

Under this assumption and given that telecommunications, as a general purpose technology, has a major spillover effect on the economy, 
the approximate cost in terms of well-being that countries incur by delaying decisions to launch telecommunications networks can be estimated. This is important because, among other reasons, Latin America is now engaged in launching new latest-generation networks (LTE), and the region's governments are making additional spectrum available to the market (primarily, the digital dividend, or frequencies in the $700 \mathrm{MHz}$ band, as well as the $2.6 \mathrm{GHZ}$ bands). Furthermore, all of the countries are transitioning to digital television and working ton the analog switch-off, which will free up more spectrum (a potential "second digital dividend" in the $600 \mathrm{MHz}$ band). Deferring or deliberately postponing these processes comes at a high cost, as will be discussed later.

Based on the literature, the most conservative estimate of the impact of broadband penetration on GDP is used in this chapter. In Katz (2010a), it was estimated that 10 points of broadband penetration adds 0.17 percentage points to GDP growth (see also the article by Raúl Katz herein). Other authors, such as Qiang (2009) and García Zaballo (2012), argue that the impact may be much greater. The former puts the impact in developing countries at 1.38 percentage points, while the latter estimates an average increase of $3.2 \%$ in GDP and an increase in productivity of 2.6 percentage points.

Using the figure published by Katz (2010a), it can be estimated that a region-wide delay of one year in the launch of mobile broadband networks represents a loss in spillover benefits for the economy equivalent to 66 billion 2012 PPP dollars in the sixth year (see figure V.10). Considering that regional GDP in 2011 was approximately US\$ 6.88 trillion, the delay in launch is equivalent to $1 \%$ of the wealth that is generated.

Figure $\mathrm{V} .10$

COST IN ECONOMIC WELL-BEING OF A ONE-YEAR DELAY IN THE LAUNCH

OF HIGH-SPEED NETWORKS

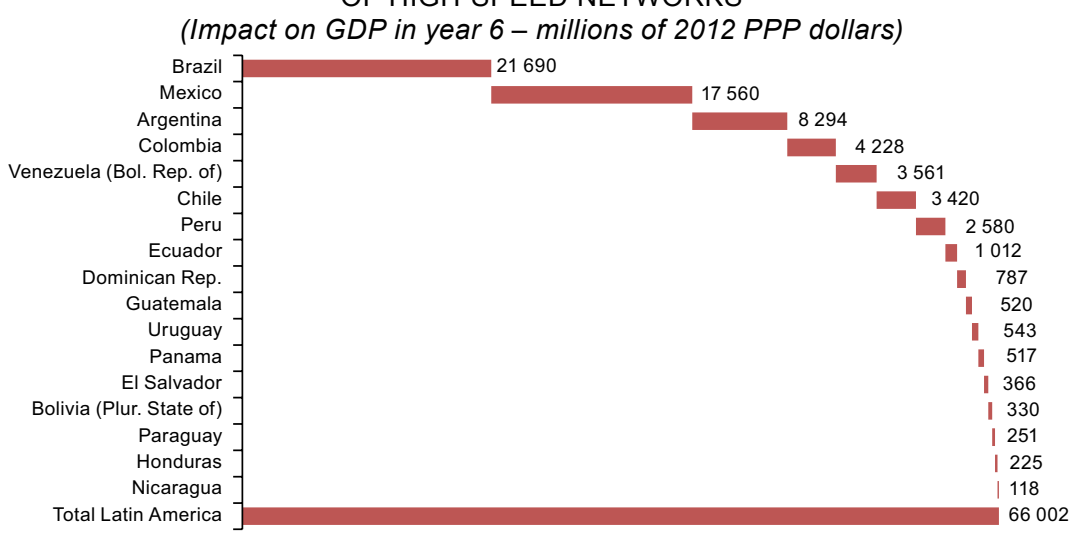

Source: Prepared by the author. 
To make it even more dramatic, the cost of delaying launch by just one quarter can be estimated. In the sixth year, regional GDP would be negatively impacted by between 0.15 percentage points and 0.26 percentage points, equivalent to an average of US\$ 27 per capita in 2012 PPP terms (see figure V.11). Regionally, the value of this unrealized spillover approaches 15 billion PPP dollars.

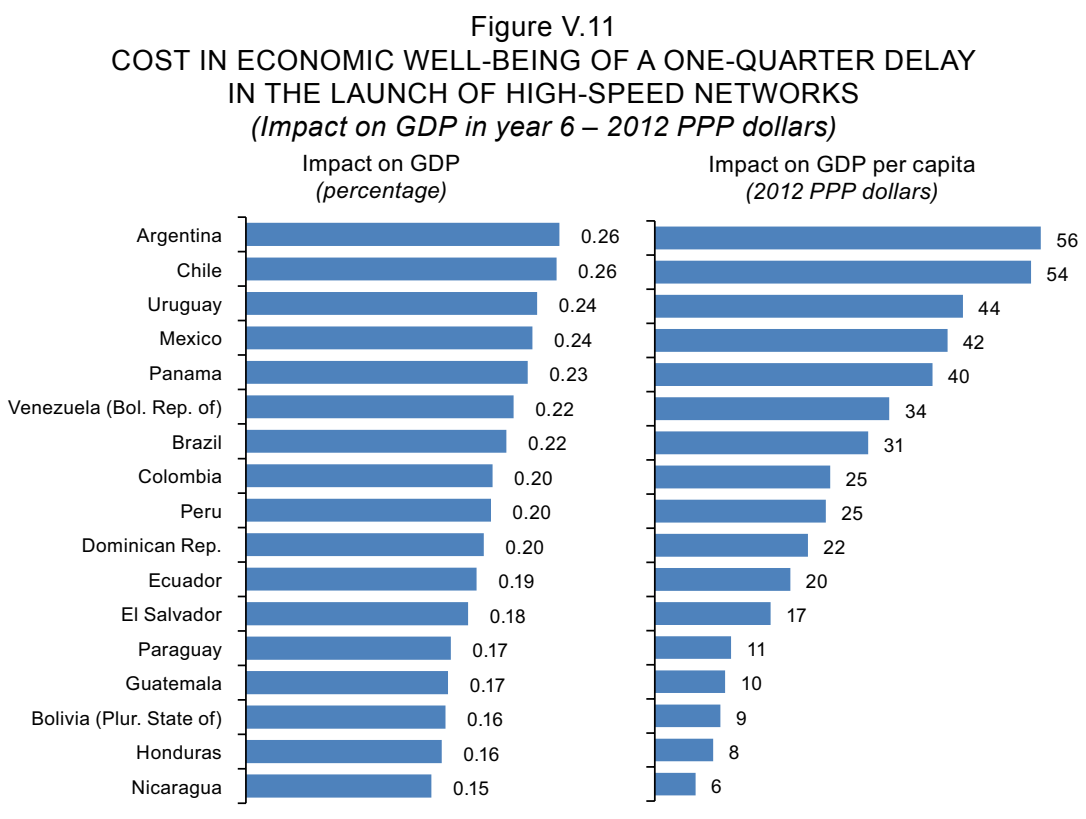

Source: Prepared by the author.

\section{E. Conclusions}

A number of conclusions with direct public policy implications can be drawn from these analyses.

(i) In the medium term, mobile broadband penetration will likely vary from country to country, as is presently the case with mobile telephony. However, per capita income will be less and less of a determining factor in penetration. Given that penetration is the principal measure of the spread of access, its evolution should be a first-order concern of public policymakers. ${ }^{16}$

16 This chapter does not address the issue of use, but it is plausible to assume that average income is directly related to intensity of use. This variable should be the second item of concern for the authorities, since spillover benefits are achieved primarily through actual use of technology, not just mere access to it (see the chapter herein by Galperín and Katz on the demand gap). 
(ii) Because penetration and the rate of adoption increase as networks mature, earlier launches make it possible to reach the saturation point sooner.

(iii) Penetration has a direct positive impact on the well-being of the population, so earlier launches translate into greater wealth creation.

In general, an early launch is associated with efforts to prevent delays, to the extent possible, in the processes that make it possible to bring networks online. The main barriers are spectrum licensing and the processing of concessions, licenses and operating permits. However, there are other barriers, including those associated with obtaining construction permits, testing and standardization, which result in delays in network roll-out and expansion. As suggested earlier, this has a substantial quantifiable impact on economic development and well-being.

Accordingly, the region's governments should focus a good part of their efforts on eliminating barriers so these services, as well as new services to be launched in the future as technology evolves, can be provided.

The possibility of applying instruments to accelerate network rollout should also be considered. There are several approaches to this, but spectrum allocation contract requirements have proven effective, as have fiscal incentives tied to investment and roll-out. Lastly, it is important to note that national broadband plans have virtually ignored mobile broadband. Inasmuch as mobile telecommunications are among the strongest drivers of the spread of broadband service, actions to promote its development should be at the core of any public policy in the sector.

The amount of time that a network has been available is a basic indicator of the total penetration achieved in a country. Any unwarranted delay comes at a real cost to the economy and to the well-being of the population. Since much of the decision to launch services is subject to government actions, the authorities control a strategic variable. There are not many variables over which the authorities do have control, but this is one and it can be used to further social and economic development. Failing to take action and allowing delays to mount will work against efforts to close the digital divide in Latin America. 


\section{Bibliography}

Flores-Roux, E. M. and J. Mariscal (2010), “Oportunidades y desafíos de la banda ancha móvil", Acelerando la revolución digital: banda ancha para América Latina y el Caribe, V. Jordán, W. Peres and H. Galperin (eds.), Santiago, Chile, Economic Commission for Latin America and the Caribbean (ECLAC).

García-Zaballos, A. and G. A. Truitt Nakata (2012), “Construyendo puentes, creando oportunidades: La banda ancha como catalizados del desarrollo económico y social en los países de América Latina y el Caribe. La visión de la industria", Washington, D.C., Inter-American Development Bank, citing A. García-Zaballos and R. López-Rivas. "Control gubernamental sobre el impacto socio-económico de la banda ancha en los países ALC", working paper.

Gillet, J. (2012), "Global mobile penetration - subscribers versus connections", Wireless Intelligence/GSMA, October.

Jensen, R. (2007), "The Digital Provide: Information (Technology), Market Performance, and Welfare in the South Indian Fisheries Sector", The Quarterly Journal of Economics, vol. 122, No. 3.

Katz, R. L. (2010a), "La contribución de la banda ancha al desarrollo económico", Acelerando la revolución digital: banda ancha para América Latina y el Caribe, V. Jordán, W. Peres and H. Galperín (eds.), Santiago, Chile, Economic Commission for Latin America and the Caribbean (ECLAC).

Katz, R. L. (2010b), "The impact of broadband on the economy; Research to date and policy issues", paper presented at the 10th Global Symposium for Regulators "Enabling Tomorrow's Digital World", Dakar, Senegal.

Mueller, M. L. (1997), Universal Service: Interconnection, Competition, and Monopoly in the Making of American Telecommunications, AEI Series on Telecommunications Deregulation, MIT Press.

Pindyck, R. S. and D. K. Rubinfeld (1998), Econometric Models and Economic Forecasts, Irwin/McGraw-Hill.

Qiang, C. Z. (2010), "Broadband infrastructure investment in stimulus packages: Relevance for developing countries", Info, vol. 12, No. 2.

Qiang, C. Z. and C. M. Rossotto (2009), "Economic impacts of broadband on growth: A simultaneous approach", Telecommunications Policy, No. 33.

The Economist (1999), "Cutting the cord", 7 October [online] http:/ / www.economist. com/node/246152.

Waverman, L., M. Meschi and M. Fuss (2005), "The impact of telecoms on economic growth in developing countries", Vodafone Policy Paper Series, No. 2, London.

Waverman, L. and others (2009). Economic Impact of Broadband: An Empirical Study, LECG, London.

Wireless Intelligence [online] www.wirelessintelligence.com.

World Bank [online] www.worldbank.org and data.worldbank.org. 



\section{Chapter VI \\ Cloud computing, structural change and job creation in SMEs}

Andrea Colciago and Federico Etro ${ }^{1}$

\section{A. Introduction}

Structural change and technology adoption are key aspects of economic development in emerging economies. This chapter studies them by looking at a particular contemporary experience: the adoption of a new IT innovation, and by focusing on the leading emerging markets of Latin America.

Cloud computing is an Internet-based general purpose technology that is spreading at the global level with an important economic impact in both developed and developing countries. Through this technology, information can be stored in servers and provided online as a service to business custumers on a pay-as-you-go basis. The provision of this technology is emerging in a rather competitive environment, with a number of leading players offering cloud solutions with aggressive pricing (Fershtman and Gandal, 2012). Its adoption allows firms to avoid large upfront costs for hardware and software and turn part of them into variable

Andrea Colciago is from the Department of Economics of the University of Milano Bicocca. Federico Etro is from the Department of Economics of the University Cà Foscari in Venice. 
costs to be optimized at the margin. As a result they will be able to adjust their demand for IT according to their needs. The reduction in required up-front investment will be crucial for business creation and for the growth of young firms which typically face stringent financial constraints and thus cannot engage in large initial investments. Moreover, the new technology is likely to promote new investment in R\&D for applications developed in the cloud (Borek and others, 2012).

Emerging countries, including Latin American ones, are expected to benefit a lot from this revolution as it could close the information and technology gap with more advanced developed countries (De Oliveira and OgasawaraIs, 2012). ${ }^{2}$

This chapter evaluates the impact of the adoption of cloud computing on output, employment and business creation, focusing on selected countries - in particular, Latin American countries- as well as the United States and European Union countries for reference purposes. The authors used a macroeconomic model with Endogenous Market Structures (EMSs) in the spirit of Etro and Colciago (2010), Colciago and Rossi (2011) and Bilbiie and others (2012). The analysis goes beyond the preliminary attempt by Etro (2009a) at estimating the impact of cloud computing in the European Union because:

(i) It employs a more advanced theoretical model augmented with a job matching model that can more realistically reproduce flows in and out of employment and with a separate (competitive) sector providing cloud services to the production sector;

(ii) It revises the calibration accordingly, focusing on a global perspective and in particular not only on the European Union but also on the United States and on selected emerging countries from Latin America, namely Brazil and Argentina; and

(iii) It provides a different conceptual experiment focused on extrapolating the medium- and long-run impact of the adoption of the new technology on aggregate variables so as to emphasize the potential net gain from the new technology.

The model is characterized by three industries: the final good one, the industry producing the physical IT stock, and the industry providing IT maintainance and development services. The final good industry features many sectors, where the dynamics of the number of market competitors is endogenous. Firms face a cost of market entry which they will decide they can afford only if it is compensated by the expectation

2 The literature on structural change and innovation has emphasized the importance of structural change toward technology-intensive industries for emerging countries (for instance, see Cimoli and others, 2011, on Brazil). 
of future profits. Firms produce final goods using labour and physical capital. The stock of capital takes the form of IT hardware which the firm has to install and maintain over time. The industry producing IT adopts physical capital as the only input, while in the industry providing IT maintainance and development services the input is labour. The fraction of workers employed in the latter industry is defined as IT employment. The labour market is characterized by frictions following the literature on job search and matching (Mortensen and Pissarides, 1994; Merz, 1995; Andolfatto, 1996; Pissarides, 2000). In the final sector, both new firms and incumbent firms need to hire workers from the pool of unemployed agents who are looking for a job and to set up a stock of IT material before starting production. Similarly, the industry providing IT services faces labour market frictions.

In line with the observations made above, the model counterpart of the introduction of cloud computing will be a reduction in the installation and maintainance cost of IT for the individual firm. IT services, hardware and software can be outsourced by the firm. In particular, they can be obtained on demand by the provider of cloud IT services. This reduces the upfront sunk entry costs, since the firm no longer needs to build up a stock of IT before starting production. Also, it reduces IT stock maintainance costs. As a result of lower entry costs, there is a stronger incentive for new firms to enter the market; this promotes investment and impacts the demand faced by incumbent producers. In turn, the creation of new firms and the growth of the existing ones promotes both competition and job creation, affecting the unemployment rate. It is important to note that, although maintainance and development costs decline for the individual firm, higher IT usage promotes a long-run increase (after some periods of reduction) in IT employment.

The quantitative results provided by the model are then translated into empirical results using data on business creation and job creation relative to Brazil, Argentina and, as a reference, the European Union (Etro, 2009a) and the United States. The empirical literature supports the view that new firms have a fundamental role for the creation of new jobs. Haltiwanger and others (2010), on the basis of United States manufacturing data between 1972 and 1986, estimate that 25\% of annual gross job creation is due to start-ups. Similarly, Jaimovich and Floetotto (2008) focus on employment data at the establishment level. They estimate that the average fraction of quarterly job gains (losses) that can be explained by the opening (closing) of establishments is about $20 \%$. Therefore, the authors' analysis of job creation derived from business creation appears well-grounded in the macroempirical literature. The simulation shows a substantial impact of the structural technological change associated with the introduction of cloud computing on business and job creation: in 
particular, the long-run estimates herein show the creation of 900,000 new jobs in Brazil and 100,000 in Agentina, which can be compared with about 3 million new jobs in both the United States and the European Union.

This chapter is organized as follows. Section B reviews the literature on the economics of cloud computing and introduces its aspects concerning Latin American countries and the European Union and the United States. Section C develops the basic DSGE model with IT investment. Section D augments it with the introduction of cloud computing. Section E calibrates the model on Brazil, Argentina and the European Union and the United States. Section F analyzes the transition to the cloud economy, performs the simulation and discusses the results. The conclusions are set out in Section G.

\section{B. What is cloud computing, and how can it affect the global economy?}

Cloud computing is defined by the United States National Institute of Standards and Technology as "a model for enabling convenient, ondemand network access to a shared pool of configurable computing resources (e.g., networks, servers, applications and services) that can be rapidly provisioned and released with minimal management effort or service provider interaction." Through cloud computing, firms will be able to rent computing power (both hardware and software) in their latest versions and storage from a service provider, and to pay on demand, as they already do for other inputs such as energy and electricity (see the chapter on the subject in this book).

A new general purpose technology such as cloud computing can exert a number of effects on the economy. First of all, cloud computing can provide cost efficiencies in the private sector; across all industries its use is directly related to lower entry costs and therefore to the creation of new businesses and the diffusion of what Lanvin and Passman (2008) call e-business skills in the managerial environment, the ability to exploit new opportunities provided by ICT and, again, to establish new businesses. The introduction of cloud computing can also create multilateral network effects between businesses and increased productivity within them, and it can promote entry and innovation in all the sectors where ICT costs are relevant and are drastically reduced by the adoption of this technology. Second, it can provide huge cost savings and more efficiency in large areas of the public sector, including hospitals and health care (especially to provide information and technologies in remote or poorer locations), education (especially for e-learning and universities) and the activity of government agencies with periodic spikes in usage. Last, beyond cost 
efficiencies, substantial positive externalities are expected from cloud computing because of energy savings: the improvement of energy efficiency may contribute to the reduction of total carbon emissions in a substantial way.

Recent research (Etro, 2009a) based on the work of Etro and Colciago (2010) has provided the first simulation in the literature of the economic impact of the diffusion of cloud computing in Europe focusing on incentives to promote business creation. The initial adoption of cloud computing solutions started in the United States, followed by the countries of the European Union, and now by some developing countries including the more advanced Asian and Latin American ones. While the initial focus in Etro (2009a) was on Europe, it is clear that similar ideas and results apply to other countries and also to developing countries, where there is equally wide attention being paid to the diffusion of this new technology. For instance, see Kuyucu (2011) on Turkey or Center of Information Development (2010) on China. ${ }^{3}$

This chapter focuses on Latin American countries such as Brazil and Argentina, where key players are already active. The first mover in the field, Amazon, has recently started operations in two data centres in São Paulo. The entry of Amazon Web Services in the Latin American cloud space is of crucial importance to the region, but other players are also building data centres or starting to plan operations in Brazil and other Latin American countries. Private clouds are already spread, and the challenge is now to move to public clouds. Local players, such as Vurbia Technologies, are already active in Argentina and elsewhere. The scenario appears quite dynamic even if it is clearly less developed compared with European and North American realities.

The key point of this research is that, somewhat surprisingly, a big portion of the benefits associated with the adoption of the new technology derives from indirect mechanisms active in non-IT sectors rather than from the direct efficiencies in the IT sector. This chapter reports on some refinements of this study which take into consideration aspects that were neglected in earlier work, namely the decomposition of the process of job creation across countries and macrosectors and between job creation and job destruction, and the role of public finances.

Starting from conservative assumptions on the cost reduction process associated with the diffusion of cloud computing, Etro (2009a)

In perspective, the Chinese market, with its wide public sector, could become a major area of development of cloud computing. According to the China Center of Information Development (2010), Chinese local governments are investing heavily in setting up data centres, and the central government has designated cloud computing as a strategic new business for the next years. 
suggested that the diffusion of cloud computing could provide a positive and substantial contribution to the annual growth rate (up to a few decimal points), helping to create several hundreds of thousands of new jobs every year through the development of a few hundred thousand new small and medium-sized enterprises (SMEs) throughout the 27 European Union member countries (EU-27). The driving mechanism behind the positive contribution works through incentives to create new firms, and in particular SMEs. One of the main obstacles to entry in new markets is the high up-front costs of entry, often associated with physical (and IT) capital spending. Cloud computing allows potential entrants to save on the fixed costs associated with hardware/software adoption and on general IT investment, and turns part of this capital expenditure into operating expenditure, that is, into variable costs. This reduces the constraints on entry and promotes business creation. The importance of such a mechanism is well known at the policy level, especially in Europe, where SMEs play a crucial role in the production structure, but it is quite relevant also in emerging economies such as those of Latin America.

To evaluate the impact of cloud computing, the authors have adopted a macroeconomic approach emphasizing the effects that this innovation has on the cost structure of firms investing in IT (and consequently the incentives to create and expand new business), on the market structure and on the level of competition in their sectors, and ultimately on the induced effects for aggregate production, employment and other macroeconomic variables. The methodology is based on a dynamic stochastic general equilibrium calibrated model augmented with endogenous market structures in line with recent developments in the macroeconomic literature.

The model follows the framework introduced by Etro and Colciago (2010) and Colciago and Etro (2010) and recently extended to include the dynamics of the labour market by Colciago and Rossi (2011), and it has been augmented with a public sector producing goods and services. The analysis goes beyond the preliminary attempt by Etro (2009a) at estimating the impact of cloud computing in the European Union because it employs a more advanced theoretical model augmented with a job matching model able to reproduce flows in and out of employment in a more realistic way and with a separate (competitive) sector providing cloud services to the production sector. It revises the calibration accordingly, focusing on a global perspective and, in particular, not only on the European Union but also on the United States and on selected emerging countries in Latin America, namely Brazil and Argentina, and it involved a different conceptual experiment focused on extrapolating the medium- and longrun impact of the adoption of the new technology on aggregate variables, so as to emphasize the potential net gain from the new technology. 
Two key factors for the impact of cloud computing are, on the one hand, the size of the cost savings in ICT spending and, on the other hand, the reduction of the fixed costs of production. On the first point, the business literature emphasizes large savings. The International Data Corporation (IDC) $(2008,2009)$ estimated a total cost reduction up to $40 \%-50 \%$ in the private sector, but a more prudential estimate in a negative scenario could go down to $10 \%$. Estimates for the public sector are more limited, ranging between a $10 \%$ reduction in total costs in a pessimistic scenario and of 30\% in an optimistic one (but West, 2010, suggests a range between $25 \%$ and $50 \%$ in successful cases). It should also be kept in mind that the portion of these potential benefits that will be translated on the private sector will also depend on the level of competition in the provision of cloud services. As noted by Fershtman and Gandal (2012), there are reasons to believe that competition in the field will be strong enough to conjecture an approximately competitive provision of cloud services and a wide translation of the cost savings. Overall, a conservative assumption would require keeping the estimated effective reduction in savings at around $10 \%$.

The estimates in Etro (2009a) suggested a permanent creation of about 400,000 new SMEs. The largest impact was expected to occur in the aggregate sectors of wholesale and retail trade and of real estate and other financial and business activities. That exercise did show a strong impact on the creation of new SMEs, on the magnitude of a few hundred thousand in the whole European Union. Incidentally, this is consistent with the conclusions of studies by IDC (2009) arguing that cloud services could add US $\$ 800$ billion in net new business revenues between 2009 and 2013. The revised exercise herein shows now a substantial impact of the technological change on business and job creation at the global level: the long-run estimates will suggest a likely creation of more than 3 million new jobs in the European Union and in the United States, and about one million in Brazil and Argentina.

\section{The theoretical model}

This section describes the main model to be used for simulations. The structure of the model is a basic DSGE model that is standard in the macroeconomic analysis (Kydland and Prescott, 1982; Christiano, Eichenbaum and Evans, 2005), augmented with endogenous market structures as opposed to perfectly competitive or monopolistically competitive markets (Colciago and Etro, 2010, and Etro and Colciago, 2010). ${ }^{4}$

See Etro (2009b) for a survey of the related literature on endogenous market structures in general equilibrium. 
The economy features a continuum of atomistic sectors, or industries, on the unit interval. Each sector is characterized by different firms producing a good in different varieties, using labour and IT material as input. In turn, the sectoral goods are imperfect substitutes for each other and are aggregated into a final good. The IT material is produced by a perfectly competitive firm using physical capital as the only input.

Households use the final good for consumption and investment purposes. Price competition and endogenous firms' entry is modelled at the sectoral level, where firms also face search and matching frictions in hiring workers, modelled in the tradition of the literature on job search (Mortensen and Pissarides, 1994; Pissarides, 2000). In the pre-cloud economy they also face IT material maintainance costs.

\section{Labour market and job matching}

The labour market is characterized by search and matching frictions, as in Andolfatto (1996) and Merz (1995). Firms producing in $t$ need to post vacancies in order to hire new workers. Unemployed workers and vacancies combine according to a CRS matching function and deliver $m_{t}$. new hires, or matches, in each period. The matching function is assumed to be a Cobb-Douglas one:

$$
m_{t}=\left(\gamma_{m}\right)\left(v_{t}^{\text {tot }}\right)^{1-\gamma} u_{t}^{\gamma}
$$

where $\gamma_{m}$ reflects the efficiency of the matching process, $v_{t}^{\text {tot }}$ is the total number of vacancies created at time $t$ and $u_{t}$ is the unemployment rate. The probability that a firm fills a vacancy is given by $q_{t}=m t / v_{t}^{t o t}$, while the probability to find a job for an unemployed worker reads as $z t=m_{t} / u_{t}$. Firms and individuals take both probabilities as given. Matches become productive in the same period in which they are formed. Each firm separates exogenously from a fraction $1-\varrho$ of existing workers each period, where $\varrho$ is the probability that a worker stays with a firm until the next period. As a result a worker may separate from a job for two reasons: either because the firm where the job is located exits from the market or because the match is destroyed. Given that population is normalized to one, the number of unemployed workers and the unemployment rate are identical. Therefore, given labour at time $t$ as $L_{t}$, the unemployment rate is:

$$
u_{t}=1-L_{t-1}
$$

and represents also the fraction of agents searching for a job.

Given this functional form, the probability of filling a vacancy can be expressed as:

$$
q_{t}=\gamma_{m}\left(\frac{v_{t}^{t o t}}{u_{t}}\right)^{-\gamma}=\gamma_{m}\left(\theta_{t}\right)^{-\gamma}
$$


where $\theta_{t}=\left(v_{t}^{\text {tot }} / u_{t}\right)$, the probability of finding a job, is defined as:

$$
z_{t}=\frac{\left(\gamma_{m}\right)\left(v_{t}^{\text {tot }}\right)^{1-\gamma} u_{t}^{\gamma}}{u_{t}}=\gamma_{m}\left(\theta_{t}\right)^{1-\gamma}
$$

and their ratio as:

$$
\frac{z_{t}}{q_{t}}=\frac{\gamma_{m}\left(\theta_{t}\right)^{1-\gamma}}{\gamma_{m}\left(\theta_{t}\right)^{-\gamma}}=\theta_{t}
$$

\section{Households}

Using the family construct of Merz (1995) a representative household can be referred to as consisting of a continuum of individuals of mass one. Members of the household insure each other against the risk of being unemployed. The representative family has lifetime utility:

$$
U=E_{0} \sum_{t=0}^{\infty} \beta^{t}\left\{\log C_{t}-\chi \mathrm{L}_{\mathrm{t}} \frac{h_{\mathrm{t}}^{1+1 / \varphi}}{1+1 / \varphi} d j\right\} \quad \chi, \varphi \geq 0
$$

where $\beta \in(0,1)$ is the discount factor, the variable $h_{t}$ represents individual hours worked and $C_{t}$ is the consumption of the final good. The family receives real labour income $w_{t} h_{t} L_{t}$, where $w_{t}$ is the real wage, and profits $\Pi_{t}$ from the ownership of firms. Unemployed individuals receive a real unemployment benefit $b$, hence the overall benefit for the household is $b\left(1-L_{t}\right)$. This is financed through lump sum taxation by the government. The households hold the stock of physical capital, $K_{t}$, which evolves according to

$$
K_{t}=\left(1-\delta^{k}\right) K_{t-1}+I_{t}^{k}
$$

where $I_{t}^{k}$ is investment in capital. The household chooses how much to save in riskless bonds, physical capital and the creation of new firms according to standard Euler and asset pricing equations. The first order condition (FOC) with respect to employment, $L_{t}$, is

$$
\Gamma_{t}=\frac{w_{t} h_{t}}{C_{t}}-\chi \frac{h_{\mathrm{t}}^{1+1 / \varphi}}{1+1 / \varphi}-\frac{b}{C_{t}}+\beta E_{\mathrm{t}}\left[(1-\delta) \rho-z_{t+1}\right] \Gamma_{t+1}
$$

here $\Gamma_{t}$ is the marginal value to the household of having one member employed rather than unemployed and $1 / C_{t}$ is the marginal utility of consumption. Equation (6) indicates that the household's shadow value of one additional employed member (the left-hand side) has four 
components: (i) the increase in utility generated by having an additional member employed, given by the real wage expressed in utils; (ii) the decrease in utility due to more hours dedicated to work, given by the marginal disutility of employment; (iii) the foregone utility value of the unemployment benefit; and (iv) the continuation utility value, given by the contribution of a current match to next period household's employment.

\section{Technology}

There are four types of firms in the economy. They are (i) the producers of intermediate goods; (ii) the final good producer; (iii) the producers of IT material; and (iv) the providers of maintanance services for IT. The final good is an aggregate of a continuum of mass one of sectoral goods defined as

$$
Y_{t}=\left[\int_{0}^{1} \ln Y_{j t}^{\frac{\omega-1}{\omega}} d j\right]^{\frac{\omega}{\omega-1}}
$$

where $Y_{j t}$ denotes output of sector $j$ and $\omega$ is the elasticity of substitution between any two different sectoral goods. The final good producers behave competitively. In each sector $j$, there are $N_{j t}>1$ firms producing differentiated goods that are aggregated into a sectoral good by a CES aggregating function defined as

$$
Y_{j t}=\left[\sum_{i=1}^{N_{j t}} y_{j t}(i)^{\frac{\varepsilon-1}{\varepsilon}}\right]^{\frac{\varepsilon}{\varepsilon-1}}
$$

where $y_{j t}(i)$ is the production of $\operatorname{good} i$ in sector $j, \varepsilon>1$ is the elasticity of substitution between sectoral goods. As in Etro and Colciago (2010), the authors assume a unit elasticity of substitution between goods belonging to different sectors. This makes it possible to realistically separate limited substitutability at the aggregated level, and high substitutability at the disaggregated level. Each firm $i$ in sector $j$ produces a (intermediate) differentiated good with the following production function

$$
y_{j t}(i)=A_{t}\left[n_{j t}(i) h_{j t}(i)\right]^{1-\alpha}\left[I T_{j t-1}(i)\right]^{\alpha}
$$

where $A_{t}$ represents technology which is common across sectors and evolves exogenously over time. The variable $n_{j t}(i)$ is firm $i$ 's time- $t$ workforce used for the production of the final good, and $h_{j t}(i)$ represents hours per employee. In the remainder, firms in tho intermediate goods sector are referred to as producers. The variable $I T_{j t}(i)$ is the amount of IT material involved in the production process. The latter is produced by 
a perfectly competitive firm which uses physical capital as the only input. In each period a flow of IT, defined as $\Delta I T_{t}$, is produced with technology

$$
\Delta I T_{t}=A_{t}^{c} K_{t-1}
$$

where $K_{t}$ is the stock of capital in the economy and $A_{t}^{c}$ is the productivity of the IT industry. Given perfect competition the price of IT material is the marginal cost of production. The latter can be obtained by profit maximization of the producer of IT services as $p_{t}^{I T}=r_{t}^{k} / A_{t}^{C}$. Period-t real profits of a producer are defined as

$$
\pi_{j t}(i)=\rho_{j t}(i) y_{j t}(i)-w_{j t} h_{t} n_{t}-p_{t}^{M} M_{j t}(i)-\kappa v_{j t}(i)-p_{t}^{I T} I_{j t}^{I T}(i)
$$

where $w_{j t}(i)$ is the real wage paid by firm $i, v_{j t}(i)$ represents the number of vacancies posted at time $t, \kappa$ is the output cost of keeping a vacancy open, $I_{j t}^{I T}(i)$ is period $t$ investment in IT and $p_{t}^{I T}$ is the price of a unit of IT in terms of the final good. Notice that $\rho_{j t}(i)$ is the real price of firm i's output.

The term $p_{t}^{M} M_{j t}(i)$ represents maintainance and development costs of the IT stock. These services are provided by a firm which operates in perfect competition with technology $M_{t}=n_{t}^{I T} h_{t}$, where $n_{t}^{I T}$ represents the number of workers employed in the industry. The provider of maintainance services also faces search costs in the labour market. It hires workers by posting vacancies at an output cost equal to $\kappa$, taking as given hours and the real wage determined in the bargaining process between workers and firms operating in the final good industry. ${ }^{5}$ Its workforce evolves according to $n_{j t}^{I T}=\varrho n_{t-1}^{I T}+v_{t}^{I T} q_{t}$. The problem faced by the provider of maintainance services can thus be written as:

$$
\max _{\left\{n_{s}^{I T}, v_{s}^{I T}\right\}_{s=t}^{\infty}} E_{t} \sum \Lambda_{t, s}\left(p_{s}^{M} M_{s}-w_{s} h_{s} n_{s}^{I T}-\kappa v_{s}^{I T}\right)
$$

s.t. $n_{s}^{I T}=\varrho n_{s-1}^{I T}+v_{s}^{I T} q_{s}$

Profit maximization requires

$$
\frac{\kappa}{q_{t}}=\left(p_{t}^{M} h_{t}-w_{t} h_{t}\right)+\varrho E_{t} \frac{\kappa}{q_{t+1}} \Lambda_{t, t+1}
$$

this condition equates the marginal cost of hiring a worker with the marginal benefit. The latter is given by a discounted stream of a firm's expected future net earnings from the marginal worker. A maintainance technology is assumed such that the final good producer must acquire $m / A_{t}^{c}$ units of maintainance services for each unit of IT owned. As a

In this case it is indifferent for a member of the household to work in the IT sector or in the final sector. 
result, the individual demand for maintanance services is $\frac{m}{A_{t}^{c}} I T_{j t-1}(i)$
and profits of the final good producer can be rewritten as $\pi_{j t}(i)=\rho_{j t}(i) y_{j t}(i)-w_{j t} h_{t} n_{t}-p_{t}^{M} \frac{m}{A_{t}^{c}} I T_{j t-1}(i)-\kappa v_{j t}(i)-p_{t}^{I T} I_{j}^{I T}(i)$

The value of a final good producer is the expected discounted value of its future profits

$$
V_{j t}(i)=E_{t} \sum_{s=t+1}^{\infty} \Lambda_{t, s} \pi_{j s}(i)^{(1-\delta)}
$$

where $\Lambda_{t, t+1}=(1-\delta) \beta\left(\frac{c_{t+1}}{c_{t}}\right)^{-1}$ is the households' stochastic discount factor which takes into account that firms' survival probability is $(1-\delta)$. Firms which do not exit from the market have a time $t$, individual workforce given by

$$
n_{j t}(i)=\varrho n_{j t-1}(i)+v_{j t}(i) q_{t}
$$

and a stock of IT equal to

$$
I T_{j t}(i)=\left(1-\delta^{I T}\right) I T_{j t-1}(i)+I_{j t}^{I T}(i)
$$

where $\delta^{I T}$ is the depreciation rate of IT material. The unit intersectoral elasticity of substitution implies that the nominal expenditure, $E X P_{t}$, is identical across sectors. Thus, the final producer's demand for each sectoral good is

$$
P_{j t} Y_{j t}=P_{t} Y_{t}=E X P_{t}
$$

where $P_{j t}$ is the price index of sector $j$ and $P_{t}$ is the price of the final good at period $t$. Denoting with $p_{j t}(l)$ the price of good $i$ in sector $j$, the demand faced by the producer of each variant is

$$
y_{j t}(i)=\left(\frac{p_{j t}}{P_{j t}}\right)^{-\varepsilon} Y_{j t}
$$

where $P_{j t}$ is defined as

$$
P_{j t}=\left[\sum_{i=1}^{N_{j t}}\left(p_{j t}(i)\right)^{1-\varepsilon}\right]^{\frac{1}{1-\varepsilon}}
$$


Using (16) and (15) the individual demand of good $i$ can be written as a function of aggregate expenditure,

$$
y_{j t}(i)=\frac{p_{j t}^{-\varepsilon}}{P_{j t}^{1-\varepsilon}} E X P_{t}
$$

\section{Entry}

At the beginning of each period $N_{j t}^{e}$ new firms enter into sector $j \in_{(0,1) \text {, }}$ while at the end of the period a fraction $\delta \varepsilon(0 ; 1)$ of market participants exits from the market for exogenous reasons. ${ }^{6}$ As a result, the number of firms in a sector $N_{j t}$, follows the equation of motion:

$$
N_{j t+1}=(1-\delta)\left(N_{j t}+N_{j t}^{e}\right)
$$

where $N_{j t}^{e}$ is the number of new entrants in sector $j$ at time $t$. Following Bilbiie and others (2012) it is assumed that new entrants at time $t$ will only start producing at time $t+1$ and that the probability of exit from the market, $\delta$, is independent of the period of entry and identical across sectors. The assumption of an exogenous constant exit rate is adopted for tractability, but it also has empirical support. Using United States annual data on manufacturing, Lee and Mukoyama (2007) find that, while the entry rate is procyclical, annual exit rates are similar across booms and recessions. The entry process and the mode of competition within each sector are described in detail below. Prior to entry, firms face a sunk entry cost $\phi_{t}^{e}$ to be paid in order to serve the market. It is made up of two components

$$
\phi_{t}^{e}=\phi_{t}^{a d}+p_{t}^{k}\left(I_{j t}^{I T}(i)\right)^{n e w}
$$

The first term $\phi_{t}^{a d}$ represents the cost associated with regulation and barriers to entry, which is common across sectors. It is exogenous and expressed in units of the final good. The second component of the entry cost reflects instead the fact that in order to start production in the next period new firms must set up a stock of IT. This requires an amount of investment in IT given by $\left(I_{i t}^{l T}(i)\right)^{\text {new }} .7$ If the firm exits from the market its IT stock is lost. Firms will enter into the market up to the point where their

As discussed in Bilbiie and others (2012), if macroeconomic shocks are small enough $N_{j t}$ is positive in every period. New entrants finance entry on the stock market.

7 The parameter $\Phi$ is an indicator variable which takes value 0 or 1 and allows to nest the post-cloud economy into the pre-cloud economy. As will be clear below, it takes value 1 before the introduction of cloud services and value 0 after the introduction of the cloud. 
value, represented by the discounted value of their future profits, equals the sunk entry $\operatorname{cost} \phi_{t}^{e}$.

\section{Imperfect competition and job creation}

Let us consider competition à la Bertrand. Each firm $i$ chooses; $p_{j t}(i) ; n_{j t}(i) ; v_{j t}(i)$ y $I T_{j t}(i)$; to maximize $\pi_{t}(i)+V_{t}(i)$, taking as given the price of the other firms in the sector. In a symmetric equilibrium optimal pricing implies that the relative price chosen by firms is

$$
\rho_{t}\left(\varepsilon, N_{t}\right)=\mu_{t} m c_{t}
$$

where $\mu_{t}$ the markup over the marginal cost is given by

$$
\mu_{t}\left(\varepsilon, N_{t}\right)=\frac{\varepsilon\left(N_{t}-1\right)+1}{(\varepsilon-1)\left(N_{t}-1\right)}
$$

The latter is decreasing in accordance with the number of firms in the sector. Further, when $N_{t} \rightarrow \infty$ the markup tends to $\varepsilon /(\varepsilon-1)$, i.e. the traditional one under monopolistic competition. The first order condition (FOC) with respect to vacancies reads as

$$
\phi_{t}=\frac{\kappa}{q_{t}}
$$

Thus, the firm sets the value of the marginal worker, $\phi_{t}$, equal to the expected cost of hiring the worker, $\frac{\kappa}{q_{t}}$. The FOC with respect to $n_{t}$
delivers

$$
\phi_{t}=\left[(1-\alpha) m c_{t} A_{t}\left(\frac{I T_{t-1}}{n_{t} h_{t}}\right)^{\alpha} h_{t}-w_{t} h_{t}\right]+\beta \rho \frac{C_{t}}{C_{t+1}} E_{t} \phi_{t+1}
$$

Combining the latter two equations delivers the following Job Creation Condition (JCC)

$$
\frac{\kappa}{q_{t}}=(1-\alpha) \frac{\rho_{t}}{\mu_{t}} A_{t}\left(\frac{I T_{t-1}}{n_{t} h_{t}}\right)^{\alpha} h_{t}-w_{t} h_{t}+\varrho E_{t} \Lambda_{t, t+1} \frac{\kappa}{q_{t+1}}
$$

where the authors used the pricing condition to substitute for $m c_{t}=\rho_{t} / \mu_{t}$. Since the ratio $\rho_{t} / \mu_{t}$ increases in the number of firms, it follows that competition leads to a rise in the marginal cost and hence in the equilibrium marginal revenue. For this reason the marginal revenue product of labour (MRP), given by $(1-\alpha) \rho_{t} / \mu_{t} A_{t}\left(I T_{t-1} / n_{t} h_{t}\right)^{\alpha} h_{t}$, also rises with competition. Thus, stronger competition promotes the creation of vacancies and employment due to its positive effect on the MRP of labour. The firm will invest in IT up to the point where 


$$
p_{t}^{l T}=\Lambda_{t, t+1}\left[\frac{\rho_{t+1}}{\mu_{t+1}} A_{t+1} \alpha\left(\frac{I T_{t}}{n_{t+1} h_{t+1}}\right)^{\alpha-1}-p_{t+1}^{M} \frac{m}{A_{t+1}^{c}}\right]+\Lambda_{t, t+1} p_{t+1}^{l T}\left(1-\delta^{I T}\right)
$$

Increasing IT by one unit today costs $p_{t}^{I T}$. The benefit associated with the marginal unit of IT is given by the discounted marginal revenue product of IT net of maintainance costs, the first term at the RHS, added to the discounted value that the additional unit of IT will have tomorrow, $\Lambda_{t, t+1} p_{t+1}^{I T}\left(1-\delta^{I T}\right)$. Since IT is a stock variable, the firm is forced to look ahead when taking decisions concerning optimal investment in IT.

\section{Bargaining over wages and hours}

As in Trigari (2009), bargaining takes place along two dimensions: the real wage and the hours of work. The authors assume Nash bargaining. That is, the firm and the worker choose the wage $w_{t}$ and the hours of work $h_{t}$ to maximize the Nash product

$$
\left(\phi_{t}\right)^{1-\eta}\left(\Gamma_{t} C_{t}\right)^{\eta}
$$

where $\phi_{t}$ is the firm value of having an additional worker, while $\Gamma_{t} C_{t}$ is the household surplus expressed in units of consumption. The parameter $\eta$ reflects the parties' relative bargaining power. The FOC with respect to the real wage is

$$
\eta \phi_{t}=(1-\eta) \Gamma_{t} C_{t}
$$

Using the definition of $\phi_{t}$ in equation (23) and that of $\Gamma_{t}$ given by equation (6), after some manipulations, yields the wage equation

$$
w_{t}=(1-\eta) \frac{b}{h_{t}}+(1-\eta) \chi C_{t} \frac{h_{t}{ }^{1 / \varphi}}{1+1 / \varphi}+\frac{\eta \kappa}{1-\delta} E_{t} \Lambda_{t, t+1} \frac{\theta_{t+1}}{h_{t}}+(1-\alpha) \eta \frac{\rho_{t}}{\mu_{t}} A_{t}\left(\frac{I T_{t-1}^{A}}{n_{t} N_{t} h_{t}}\right)^{\alpha}
$$

where $\phi_{t}=\frac{\kappa}{q_{t}}, \frac{z_{t}}{q_{t}}=\theta_{t}, I T_{t-1}^{A}=N_{t} I T_{t-1}$. The wage shares costs and benefits associated with the match according to the parameter $\eta$. The worker is rewarded for a fraction $\eta$ of the firm's revenues and savings of hiring costs and compensated for a fraction $1-\eta$ of the disutility he or she suffers from supplying labour and the foregone unemployment benefits. A distinguishing feature of this approach is that the wage depends on the degree of competition in the goods market. The direct effect of competition on the real wage is captured through the term $\eta \rho_{t} / \mu_{t}(1-\propto) A_{t}\left(I T_{t-1}^{A} / n_{t} N_{t} h_{t}\right)^{\alpha}$, which represents the share of the MRP which goes to workers. Entry leads to an increase in the ratio $\rho_{t} / \mu_{t}$ and hence in the MRP which goes to the workers. Thus, everything else being equal, stronger competition shifts the wage curve up. This result is similar to that in the static model by Blanchard and Giavazzi (2003), 
who find a positive effect of competition on the real wage. The FOC with respect to $h_{t}$ yields

$$
h_{t}=\left[\frac{(1-\alpha)^{2}}{\chi C_{t}} \frac{\rho_{t}}{\mu_{t}} A_{t}\left(\frac{I T_{t-1}^{A}}{n_{t} N_{t} h_{t}}\right)^{\alpha}\right]^{\varphi}
$$

Because the firm and the worker bargain simultaneously about wages and hours, the outcome is (privately) efficient and the wage does not play an allocational role for hours. Stronger competition leads to an increase in hours bargained between the workers and firms for the same reasons for which competition positively affects the wage schedule.

\section{Business creation, hiring and IT policies}

Let $\pi_{t}^{\text {new }}, v_{t}^{\text {new }}$ y $\left(I_{t}^{I T}\right)^{\text {new }}$ be, respectively, real profits, the number of vacancies posted by a new firm and investment in IT. Symmetrically, $\pi_{t}, v_{t}$ y $I_{t}^{I T}$ define, respectively, individual profits and vacancies posted by an incumbent producer. New firms and incumbent firms are characterized by the same size, $n_{t}$. Thus, the optimal hiring policy of new firms, which have no initial workforce, consists of posting at time $t$ as many vacancies as required to hire $n_{t}$ workers. As a result $v_{t}^{\text {new }}=n_{t} / q_{t}$. Since $n_{t}=\varrho n_{t-1}+v_{t} q_{t}$ it has to be the case that

$$
v_{t}^{\text {new }}=v_{t}+\varrho \frac{n_{t-1}}{q_{t}}
$$

Hence, a new firm posts more vacancies than an incumbent producer. For this reason, and given vacancy posting is costly, the profits of new firms are lower than those of incumbent firms, in particular

$$
\pi_{t}^{\text {new }}=\pi_{t}-k \frac{\varrho n_{t-1}}{q_{t}}
$$

Notice also that a new entrant must set up a stock of IT before starting production next period. Given the IT choice is symmetric across producers they have to invest during time $t$ as much as required to reach a stock of IT identical to that held by incumbent producers at the end of time $t$, that is $\left(I_{t}^{I T}\right)^{\text {new }}=I T_{t}$. The sunk entry cost for a new firm can thus be written as

$$
\phi_{t}^{e}=\phi^{a d}+p_{t}^{I T} I T_{t}
$$

In each period the level of entry is determined endogenously to equate the value of a new entrant, $V_{t}^{e}$, to the entry cost

$$
V_{t}^{e}=\phi_{t}^{e}
$$


Notice that prospective new entrants have lower value than producing firms because if they do not exit from the market before starting production they will have to set up a workforce in their first period of activity. The difference in the value between a firm which is already producing and a prospective entrant is, in fact, the discounted value of the higher vacancy posting cost that the latter will suffer, with respect to the former, in the first period of activity. Formally

$$
V_{t}=V_{t}^{e}+\kappa \varrho E_{t} \Lambda_{t, t+1} \frac{n_{t}}{q_{t+1}}=\phi_{t}^{e}+\kappa \varrho E_{t} \Lambda_{t, t+1} \frac{n_{t}}{q_{t+1}}
$$

where $V_{t}$ is the value of a producing firm (both new firms and incumbent firms) at time $t$.

\section{The introduction of cloud computing}

As described in the introduction, the creation of cloud facilities implies that IT services, hardware and software can be outsourced by the firm. In particular, delivery of computing and storage capacity is provided as a service that can be obtained on demand. This technological change is modelled as follows. It is assumed that after the introduction of cloud computing all producers of intermediate goods will no longer own a stock of IT but will rent it from the provider of cloud services. The existing stock of IT is transferred to the cloud-services provider. There are two main consequences spreading from this modelling device. The first one is that maintenance and depreciation costs associated with the stock of IT will be borne by the provider of IT services. The second one is that new entrants will no longer need to build up a stock of IT before starting production. As a result, up-front sunk entry costs faced by potential entrants are sharply reduced.

Production of IT services is carried out with the same production function considered earlier, namely equation (10). However, profit maximization must now take into account that the production of new IT services will no longer be sold, but rented to intermediate goods producers. The authors define $r_{t}^{I T}$ as the rental rate of IT services. As a result the IT produced at time $t, \Delta I T$ will contribute to the holdings of IT by the cloud provider. Period $t$ profits of the cloud provider are

$$
r_{t}^{I T} I T_{t-1}^{A}-p_{t}^{M} \frac{m}{A_{t}^{c}} I T_{t-1}^{A}-r_{t}^{k} K_{t-1}
$$

The cloud-provider solves the following problem

$$
\begin{aligned}
& \max _{\left\{K_{s-1}, I T_{s}\right\}_{s=t}^{\infty}} \sum_{s=t}^{\infty} \Lambda_{t, s}\left[\left(r_{s}^{I T}-p_{s}^{M} \frac{m}{A_{s}^{c}}\right) I T_{s-1}^{A}-r_{s}^{k} K_{s-1}\right] \\
& \text { s.t. } I T_{s}^{A}=\left(1-\delta^{I T}\right) I T_{s-1}^{A}+A_{s}^{c} K_{s-1}
\end{aligned}
$$


After defining as $p_{t}^{I T}$ the Lagrange multipliers on the constraint, it can be shown that the FOCs for this problem are

$$
p_{t}^{I T}=\frac{r_{t}^{k}}{A_{t}^{c}}
$$

and

$$
p_{t}^{I T}=\Lambda_{t, t+1}\left[\left(r_{t+1}^{I T}-p_{t+1}^{M} \frac{m}{A_{t+1}^{c}}\right)+\left(1-\delta^{I T}\right) p_{t+1}^{I T}\right]
$$

The first FOC implies that the provider of cloud services will rent capital up to the point where the rental rate of capital equals the marginal revenue product of capital. Combing the FOCs delivers

$$
\frac{r_{t}^{k}}{A_{t}^{c}}=\Lambda_{t, t+1}\left[\left(r_{t+1}^{I T}-p_{t+1}^{M} \frac{m}{A_{t+1}^{c}}\right)+\left(1-\delta^{I T}\right) \frac{r_{t+1}^{k}}{A_{t+1}^{c}}\right]
$$

Profit maximization requires that the marginal cost of production of an additional unit of IT at time $t, r_{t}^{k} / A_{t}^{c}$, must be identical to the marginal revenue that the firms obtain from producing the additional unit. The latter is given by the rental rate at which the additional unit will be rented out tomorrow net of the maintainance costs, plus the continuation value, $\left(1-\delta^{I T}\right)\left(r_{t}^{k} / A_{t}^{c}\right)$. The marginal revenue has to be discounted since the IT producers will be able to rent the additional unit produced in $t$ just at period $t+1$.

Sectoral goods producers will now simply demand IT up to the point where the rental cost of IT equals the marginal product of IT. Formally, the FOC with respect to $I T_{t-1}$ is no longer equation (24), but

$$
r_{t}^{I T}=\alpha \frac{\rho_{t}}{\mu_{t}} A_{t}\left(\frac{I T_{t-1}}{n_{t} h_{t}}\right)^{\alpha-1}
$$

Notice that combining equations (37) and (36) we recover equation (24). Time $t$ entrants will no longer need to face up-front entry costs in terms of IT. Once they are in the market and start production they will demand IT services up to the point where condition (37) is satisfied. As a result, firms will enter the market up to the point where

$$
\phi^{e}=\phi^{a d}
$$

This means that the IT policy of a new entrant does not differ from that of an incumbent producer. As in the pre-cloud economy, goods producing firms need to set up a workforce before starting production. For 
this reason the difference between the hiring policy of new entrants and that of incumbent producers is the same as that spelled out above.

\section{Aggregation and market clearing}

Considering that sectors are symmetric and have a unit mass, the sectoral number of firms and new entrants also represents their aggregate counterpart. Thus, the dynamics of the aggregate number of firms is

$$
N_{t}=(1-\delta)\left(N_{t}+N_{t}^{e}\right)
$$

As aggregate expenditure and sectoral expenditure are identical, it follows that $E X P_{t}=\Sigma_{i=1}^{N_{t}} p_{t} y_{t}=N_{t} p_{t} y_{t}$. Considering $\rho_{t}=p_{t} / P_{t}$ and the individual production function we obtain

$$
Y_{t}=\rho_{t} N_{t} y_{t}=\rho_{t} A_{t}\left(I T_{t-1}^{A}\right)^{\alpha}\left(N_{t} n_{t} h_{t}\right)^{1-\alpha}
$$

The aggregate production function features a form of increasing returns. In this case a productivity shock impacts directly on output, but also through the firm creation channel. Total vacancies posted at period $t$ are

$$
v_{t}^{\text {tot }}=(1-\delta) N_{t-1} v_{t}+(1-\delta) N_{t-1}^{e} v_{t-1}^{\text {new }}+v_{t}^{I T}
$$

where $(1-\delta) N_{t-1}$ is the number of incumbent producers and $N_{t-1}^{e}$ is the number of new firms. Aggregating the budget constraints of households yields the aggregate resource constraint of the economy

$$
C_{t}+\left(\phi^{a d}+p_{t}^{I T} \frac{I T_{t}}{N_{t}}\right) N_{t}^{e}+I_{t}^{k}=w_{t} h_{t} L_{t}+r_{t}^{k} K_{t-1}+\Pi_{t}
$$

which states that the sum of consumption and investment in new entrants and capital must equal the sum of labour income and aggregate profits, $\Pi_{t}$, distributed to households at time $t$. Aggregate profits are defined as ${ }^{8}$

$$
\Pi_{t}=(1-\delta) N_{t-1} \pi_{t}+(1-\delta) N_{t-1}^{e} \pi_{t}^{n e w}
$$

where

$$
\pi_{t}=\rho_{t} y_{t}-w_{t} n_{t} h_{t}-\kappa v_{t}-p_{t}^{M} \frac{m}{A_{t}^{c}} I T_{t-1}-p_{t}^{I T} I_{t}^{I T}
$$

and

$$
\pi_{t}^{n e w}=\rho_{t} y_{t}-w_{t} n_{t} h_{t}-\kappa v_{t}^{\text {new }}-p_{t}^{M} \frac{m}{A_{t}^{c}} I T_{t-1}-p_{t}^{I T} I_{t}^{I T}
$$

Since the producer of IT material and the provider of IT services operate in perfect competition, they make no profits. 
In this case

$$
\begin{aligned}
\Pi_{t}=(1-\delta) N_{t-1}\left[\rho_{t} y_{t}-w_{t} n_{t} h_{t}-\kappa v_{t}-p_{t}^{M} \frac{m}{A_{t}^{c}} I T_{t-1}-p_{t}^{I T} I_{t}^{I T}\right] \\
+(1-\delta) N_{t-1}^{e}\left[\rho_{t} y_{t}-w_{t} n_{t} h_{t}-\kappa v_{t}^{n e w}-p_{t}^{M} \frac{m}{A_{t}^{c}} I T_{t-1}-p_{t}^{I T} I_{t}^{I T}\right]
\end{aligned}
$$

Since $I T_{t-1}^{A}=N_{t} I T_{t-1}$, and defining

$$
v_{t}^{F}=(1-\delta) N_{t-1} v_{t}+(1-\delta) N_{t-1}^{e} v_{t}^{n e w}
$$

as the number of vacancies created by the producers of the final good, it follows that

$$
\Pi_{t}=Y_{t}-w_{t} N_{t} n_{t} h_{t}-p_{t}^{M} \frac{m}{A_{t}^{c}} I T_{t-1}^{A}-p_{t}^{I T} N_{t} I_{t}^{I T}-\kappa v_{t}^{F}
$$

Notice that

hence

$$
p_{t}^{M} h_{t}=\frac{\kappa}{q_{t}}-\varrho \Lambda_{t, t+1} \frac{\kappa}{q_{t+1}}+w_{t} h_{t}
$$

$$
\begin{gathered}
\Pi_{t}=Y_{t}-w_{t} N_{t} n_{t} h_{t}-w_{t}\left(\frac{m}{A_{t}^{c}} I T_{t-1}^{A}\right)+ \\
-\left(\frac{\kappa}{q_{t}}-\varrho \Lambda_{t, t+1} \frac{\kappa}{q_{t+1}}\right) \frac{1}{h_{t}}\left(\frac{m}{A_{t}^{c}} I T_{t-1}^{A}\right)-p_{t}^{I T} N_{t} I_{t}^{I T}-\kappa v_{t}^{F}
\end{gathered}
$$

Since, $\quad M_{t}=n_{t}^{I T} h_{t}=\left(m / A_{t}^{c}\right) I T_{t-1}^{A}$ aggregate profits can be expressed as

$$
\Pi_{t}=Y_{t}-w_{t} N_{t} n_{t} h_{t}-w_{t} n_{t}^{I T} h_{t}-\left(\frac{\kappa}{q_{t}}-\varrho \Lambda_{t, t+1} \frac{\kappa}{q_{t+1}}\right) n_{t}^{I T}-p_{t}^{I T} N_{t} I_{t}^{I T}-\kappa v_{t}^{F}
$$

The aggregate number of workers is $L_{t}=n_{t} N_{t}+n_{t}^{I T}$, which leads finally to

$$
\Pi_{t}=Y_{t}-w_{t} L_{t} h_{t}-\left(\frac{\kappa}{q_{t}}-\varrho \Lambda_{t, t+1} \frac{\kappa}{q_{t+1}}\right) n_{t}^{I T}-p_{t}^{I T} N_{t} I_{t}^{I T}-\kappa v_{t}^{F}
$$

As a result, the clearing of the market for the final good requires

$$
\begin{array}{r}
C_{t}+\left(\phi^{a d}+p_{t}^{I T} \frac{I T_{t}^{A}}{N_{t}}\right) N_{t}^{e}+I_{t}^{k} \\
=r_{t}^{k} K_{t-1}+Y_{t}-\left(\frac{\kappa}{q_{t}}-\varrho \Lambda_{t, t+1} \frac{\kappa}{q_{t+1}}\right) n_{t}^{I T}-p_{t}^{I T} N_{t} l_{t}^{I T}-\kappa v_{t}^{F}
\end{array}
$$




$$
\begin{gathered}
\text { or } \\
C_{t}+\phi^{a d} N_{t}^{e}+p_{t}^{I T}\left(\frac{I T_{t}^{A}}{N_{t}} N_{t}^{e}+N_{t} I_{t}^{I T}\right)+I_{t}^{k} \\
=r_{t}^{k} K_{t-1}+Y_{t}-\frac{\kappa}{q_{t}} \frac{m}{A_{t}^{c}} \frac{I T_{t-1}}{h_{t}}+\varrho \Lambda_{t, t+1} \frac{\kappa}{q_{t+1}} \frac{m}{A_{t}^{c}} \frac{I T_{t-1}}{h_{t}}-\kappa v_{t}^{F}
\end{gathered}
$$

Notice that the total IT produced at time $t$ must be equal to the sum of investment by incumbent firms and that of new entrants, that is

$$
\Delta I T_{t}^{A}=\frac{I T_{t}^{A}}{N_{t}} N_{t}^{e}+N_{t} I_{t}^{I T}
$$

thus, using $\Delta I T_{t}^{A}=A_{t}^{c} K_{t-1}$ y $p_{t}^{I T}=r_{t}^{k} / A_{t}^{c}$, it follows

$$
C_{t}+\phi^{a d} N_{t}^{e}+I_{t}^{k}=Y_{t}-\frac{\kappa}{q_{t}} \frac{m}{A_{t}^{c}} \frac{I T_{t-1}}{h_{t}}+\varrho \Lambda_{t, t+1} \frac{\kappa}{q_{t+1}} \frac{m}{A_{t}^{c}} \frac{I T_{t-1}}{h_{t}}-\kappa v_{t}^{F}
$$

and finally

$$
Y_{t}=C_{t}+\phi^{a d} N_{t}^{e}+I_{t}^{k}+\kappa v_{t}^{F}+\left(\frac{\kappa}{q_{t}}-\varrho \Lambda_{t, t+1} \frac{\kappa}{q_{t+1}}\right) \frac{m}{A_{t}^{c}} \frac{I T_{t-1}}{h_{t}}
$$

The dynamics of the aggregate stock of IT reads as follows

$$
I T_{t}^{A}=(1-\delta)\left[\left(1-\delta^{\mathrm{IT}}\right) I T_{t-1}^{A}+\Delta I T_{t}^{A}\right]
$$

\section{The equilibrium in the cloud economy}

In the cloud economy the producers of the final good rent their stock of IT from the cloud services producer. Profits of an incumbent producer are thus given by

$$
\pi_{t}=\rho_{t} y_{t}-w_{t} n_{t} h_{t}-\kappa v_{t}-r_{t}^{I T} I T_{t-1}
$$

while those of a new firm are

$$
\pi_{t}^{\text {new }}=\rho_{t} y_{t}-w_{t} n_{t} h_{t}-\kappa v_{t}^{\text {new }}-r_{t}^{I T} I T_{t-1}
$$

Aggregating as above leads to

$$
\Pi_{t}=Y_{t}-w_{t} N_{t} n_{t} h_{t}-\kappa v_{t}^{F}-r_{t}^{I T} N_{t} I T_{t-1}
$$

Given that $N_{t} I T_{t-1}=I T_{t-1}^{A}$, it follows

$$
\Pi_{t}=Y_{t}-w_{t} N_{t} n_{t} h_{t}-\kappa v_{t}^{F}-r_{t}^{I T} I T_{t-1}^{A}
$$

while the entry condition is simply $\phi^{e}=\phi^{a d}$. As a result, the market clearing condition reads as 


$$
Y_{t}=C_{t}+\phi^{a d} N_{t}^{e}+I_{t}^{k}+\kappa v_{t}^{F}-\left(r_{t}^{k} K_{t-1}-r_{t}^{I T} N_{t} I T_{t-1}\right)-w_{t} \frac{m}{A_{t}^{c}} I T_{t}^{A}
$$

where

$$
r_{t}^{I T}=\alpha \frac{\rho_{t}}{\mu_{t}} A_{t}\left(\frac{I T_{t-1}^{A}}{N_{t} n_{t} h_{t}}\right)^{\alpha-1}
$$

\section{E. Calibration}

There are relatively few analyses of labour market dynamics at a macroeconomic level in Brazil and Argentina. In the past few years, most studies of labour markets have focused on microeconomic aspects such as wage differentials, convergence and demand for skilled workers, among other themes.

Siqueira (2009) is one of the few studies that analyzes variables such as gross job creation, job destruction and job finding in Brazil. He finds that job transitions in Brazil are more frequent than in most of OECD countries where the same statistics are available. One possible explanation for this high mobility in the Brazilian labour force is the presence of informal jobs and self-employed workers, classes which are widely known to be the most flexible. As suggested by Siquieira (2009), although this feature can account for some part of the high worker mobility, it cannot account for all of it. All this implies that labour market flows in Brazil are closer to those of the dynamic United States labour market than to those of the more rigid European countries. For this reason, in the remainder of this section the authors calibrate the model, and in particular parameters relative to the labour market, following two alternative strategies. The first one is meant to mimic the United States and Latin American labour markets, characterized by high flows. The second one is instead based on the more rigid European market.

Calibration is conducted on a quarterly basis as in Shimer (2005) and Blanchard and Galì (2010) among others. Initially, the authors describe parameters which are common across calibration strategies. The discount factor, $\beta$, is set to the standard value of 0.99. Campos and Iootty (2005) report an average yearly exit rate for Brazil of $9.8 \%$, very close to the $10 \%$ reported by Bilbiie and others (2012) for the United States. For this reason the authors set $\delta=0.025$.

The baseline value for the entry cost is set such that the ratio of investment in new firms and physical capital is close to $15 \%$, as in Bilbiie 
and others (2012). The implied steady state price markup is about $35 \%$. This value is within the range estimated by Oliveira Martins and Scarpetta (1999) for a large number of United States manufacturing sectors. With no loss of generality, the value of $\chi$ is such that steady state hours equals one. In this case the Frisch elasticity of labour supply reduces to $\varphi$, to which a low value of 0.5 is assigned in line with the evidence. The authors take as the baseline value for the intersectoral elasticity of substitution $\varepsilon=6$, as estimated by Christiano, Eichenbaum and Evans (2005) using United States quarterly data between 1965 and 1995. As standard in the literature the steady state marginal productivity of labour, $A$, is set to 1 . The same value is set for the marginal productivity of capital in the IT producing sector, $A^{c}$.

The elasticity of matches to unemployment is $\gamma=1 / 2$, within the range of the plausible values of 0.5 to 0.7 reported by Petrongolo and Pissarides (2001) in their survey of the literature on the estimation of the matching function. In the baseline parameterization the authors impose symmetry in bargaining and set $\eta=1 / 2$, as in the bulk of the literature. Since the authors consider a labour-leisure choice, the overall replacement rate is given by the sum of the unemployment insurance benefit and the disutility cost of working. The authors calibrate the latter to 0.95 consistently with Hagerdon and Manovskii (2008). The cost of posting a vacancy $\kappa$ is obtained by equating the steady state version of the JCC and the steady state wage setting equation. Finally the authors set $m=0.025$ and $\delta^{I T}=0.025$. These figures imply that the maintainance cost of the IT stock is about $10 \%$ a year, and that the IT stock of a firm fully depreciates in about 10 years.

Next the authors turn to parameters that differ across calibration strategies and that characterize the flexibility of the labour market. In the flexible environment they set the separation rate $\varphi$ to 0.1 , as suggested by estimates provided by Hall (1995) and Davis and others (1996). They then set the efficiency parameter in matching, $\gamma_{m}$, and the steady state job market tightness to target an average job finding rate, $z$, equal to 0.7 and a vacancy filling rate, $q$, equal to 0.9 . The authors draw the latter value from Andolfatto (1996) and Dee Haan and others (2000), and the former from Blanchard and Galì (2010). Notice that a job finding rate equal to 0.7 corresponds, approximately, to a monthly rate of 0.3 .

The rigid market is instead characterized by a separation rate equal to 0.03 in line with the estimates from the Labour Force Survey in Bell and Smith (2002) and by a job finding rate equal to 0.25 as in Thomas and Zanetti (2009). Finally the authors set the vacancy filling rate to 0.7 in line with estimates reported by the ECB (2002). 


\section{F. Transition to the cloud economy}

This section evaluates the effect of the introduction of cloud computing. Following the strategy in Etro (2009a), we assume that IT is produced more efficiently. This is obtained featuring a $1 \%$ increase in $A^{c}$ in the long run. The authors also assume that bringing IT services on the cloud leads to a reduction in the units of maintainance services required for each single IT unit installed. This is formalized by assuming a $5 \%$ reduction in $\mathrm{m}$. Figure VI.1 displays percentage deviations from the pre-cloud steady state when all existing firms adopt the cloud technology. Solid lines refer to the case of a flexible labour market, dashed lines to that of a more rigid market. Time on the horizontal axis is in quarters.

Figure VI.1

TRANSITION OF THE MAIN MACROECONOMIC VARIABLES FROM THE STEADY STATE OF THE PRE-CLOUD ECONOMY TO THAT OF THE CLOUD ECONOMY (Percentage deviations from the pre-cloud steady state on the vertical axis, quarters on the horizontal one)

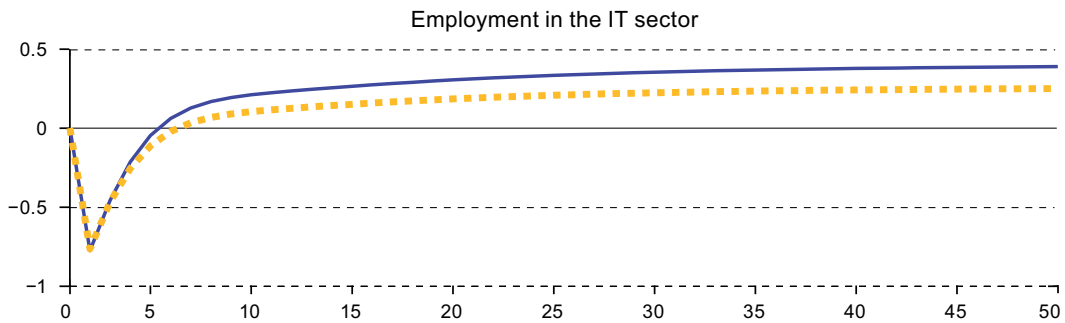

Number of firms

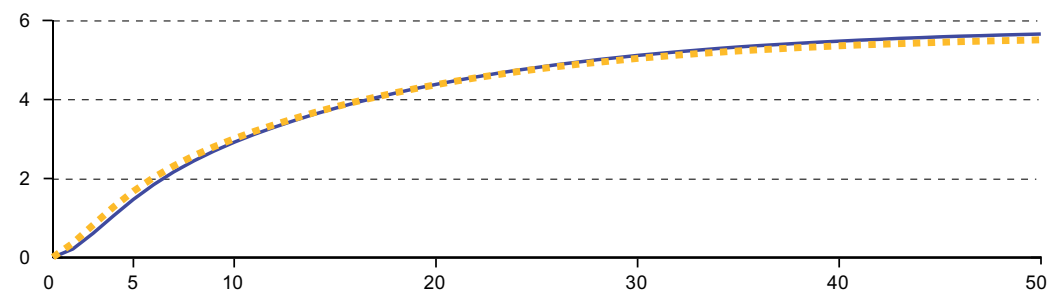

IT stock

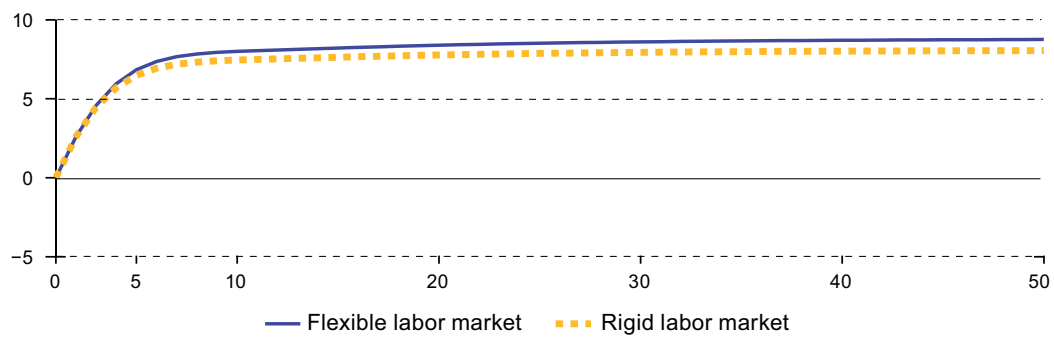


Figure VI.1 (concluded)
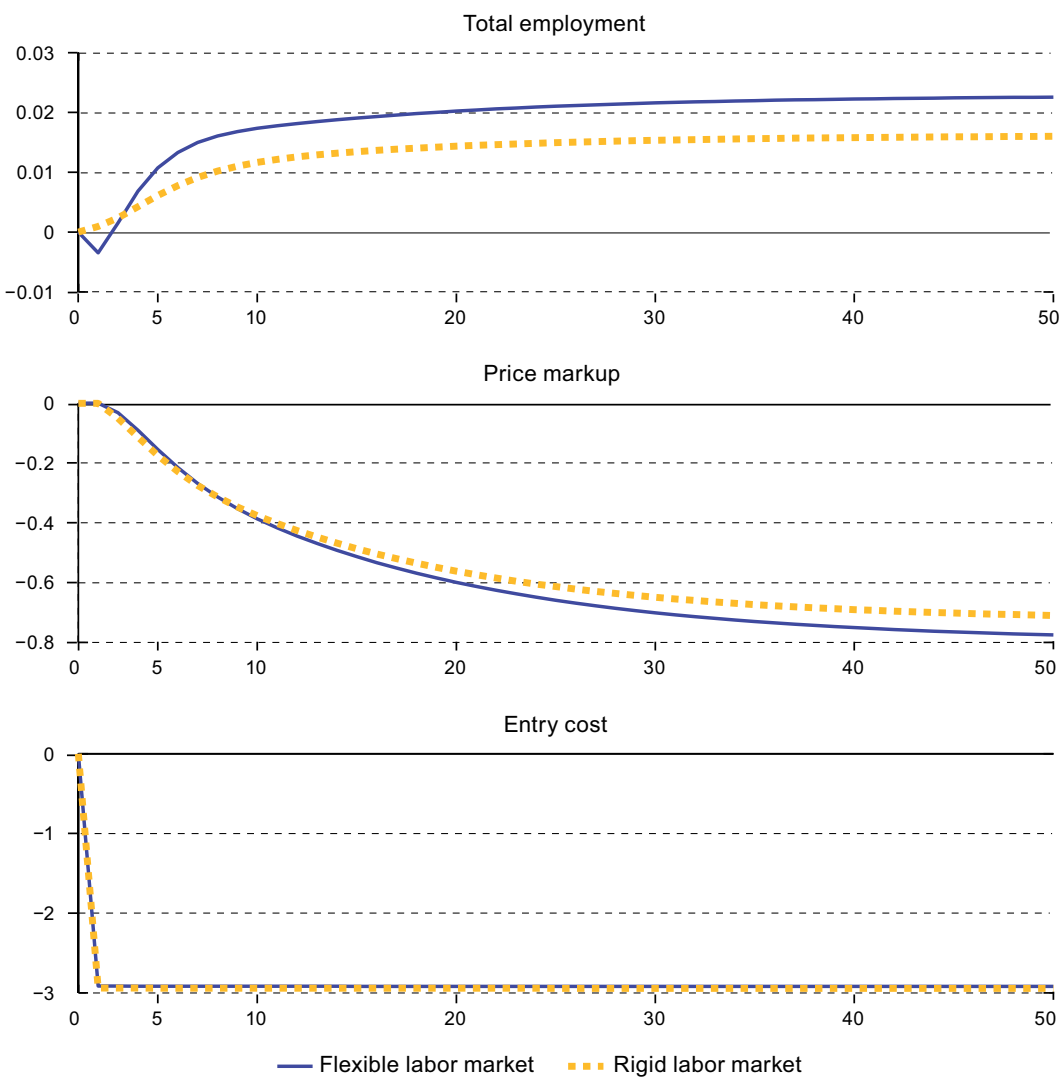

Source: Prepared by the author.

The introduction of cloud computing lowers the up-front entry costs in terms of IT. The implied reduction in the latter is about $3 \%$ with respect to that in the pre-cloud economy. This stimulates entry of new firms. Given that entry is subject to a one-period time-to-build lag, the total number of firms, $N_{t}$, does not change on impact but builds up gradually. New firms post a large amount of vacancies to reach their desired size. This results in a persistent change in aggregate employment.A larger number of firms leads to a stronger usage of IT. Higher employment together with a higher IT stock lead in turn to a sustained increase in aggregate output. Finally, the creation of new firms and the growth of the existing ones promotes competition in the final good sector which translates into a lower markup.

Notice that employment in the IT sector initially goes down, due to more efficient technology of maintainance, i.e. lower $\mathrm{m}$. However, as the stock of IT rises to its new long-run level, IT employment increases above 
its initial value. A crucial role for the increase in employment, both in the aggregate and in the IT sector, is played by the creation of new firms.

While the previous description holds for both the flexible and the rigid characterization of the labour market, the variation in employment is, as expected, more pronounced in the market characterized by more flexibility. It is interesting that this is also mirrored in the changes in the number of firms and in the price markups, which are more relevant in the market characterized by higher worker flows.

Finally, to get a sense of the implications of this analysis, the authors translate the results obtained with the model into the potential change in the number of employed persons and number of business since the introduction of cloud computuing. Argentina and Brazil are analyzed at the sectoral level, but aggregate figures for the United States and the EU-27 are also provided.

In line with the simulation above, the authors assume that the economy is currently in the steady state of the pre-cloud situation. The precloud number of firms and employed persons is obtained by averaging the number of firms and the number of workers over the past five years. Then the authors obtain the change in the employment and number of firms by applying to the averages just obtained the rates of change implied by the simulation. Data for Brazil come from the Relação Anual de Informações Sociais (RAIS) of the Brazilian Ministry of Labour, which requires by law that all formally-registered firms report information each year on each worker employed by the firm. Data relative to Argentina come instead from the Observatorio de Empleo y Dinámica Empresarial. The source of United States data is the Business Dynamics Statistics (BDS) database, while for the eurozone infomation on the number of firms and number of employed persons is from Eurostat. As specified above the authors assume that Latin America and the United States are characterized by higher labour market flexibility, while the European Union is characterized as a rigid labour market. Tables VI.1 to VI.5 show the change in the number of employed persons and the number of firms created after 5 and 10 years from the adoption of cloud computing. This makes it possible to evaluate the effects of this new technology in both the medium and the long run. The focus is on those sectors that could be affected by the introduction of cloud computing. ${ }^{9}$

As an example, the authors do not consider sectors as mining and agriculture which are characterized by aspects, such as natual capacity constraints, which are not captured by their model. 
Table VI. 1

CHANGE IN THE NUMBER OF EMPLOYED PERSONS DUE TO THE INTRODUCTION OF CLOUD COMPUTING IN ARGENTINA

\begin{tabular}{lrr}
\hline Sector & 5 years & 10 years \\
\hline Manufacturing & 25600 & 28100 \\
Utilities & 1200 & 1300 \\
Construction & 9200 & 10100 \\
Wholesail and retail trade & 22400 & 24700 \\
Hotels and restaurants & 4900 & 5400 \\
Transport & 11100 & 12200 \\
Financial services & 3200 & 3500 \\
Housing services & 17200 & 18900 \\
Education & 8500 & 9300 \\
Social services & 5600 & 6200 \\
Other services & 8400 & 9200 \\
Total & 117300 & 128900 \\
\hline
\end{tabular}

Source: Prepared by the author.

Table VI.2

BUSINESS CREATION DUE TO THE INTRODUCTION OF CLOUD COMPUTING IN ARGENTINA

(Number of new firms)

\begin{tabular}{lrr}
\hline Sector & 5 years & 10 years \\
\hline Manufacturing & 2900 & 3500 \\
Utilities & 50 & 70 \\
Construction & 1200 & 1500 \\
Wholesail and retail trade & 7900 & 9600 \\
Hotels and restaurants & 1300 & 1600 \\
Transport & 2600 & 3200 \\
Financial services & 250 & 350 \\
Housing services & 4400 & 5400 \\
Education & 400 & 480 \\
Social services & 1100 & 1400 \\
Other services & 2600 & 3200 \\
Total & 24700 & 30300 \\
\hline
\end{tabular}

Source: Prepared by the author.

Table VI.3

CHANGE IN NUMBER OF EMPLOYED PERSONS DUE TO THE INTRODUCTION OF CLOUD COMPUTING IN BRAZIL

\begin{tabular}{lrr}
\hline Sector & 5 years & 10 years \\
\hline Industry & 171000 & 188000 \\
Construction & 50700 & 56000 \\
Wholesail and retail trade & 169300 & 186000 \\
Services & 470000 & 515000 \\
Total & 861000 & 945000 \\
\hline
\end{tabular}

Source: Prepared by the author. 
Table VI.4

BUSINESS CREATION DUE TO THE INTRODUCTION

OF CLOUD COMPUTING IN BRAZIL

(Number of new firms)

\begin{tabular}{lrr}
\hline Sector & 5 years & 10 years \\
\hline Industry & 17150 & 21000 \\
Construction & 17750 & 22650 \\
Wholesail and retail trade & 131500 & 191500 \\
Services & 35700 & 167500 \\
Total & 202100 & 402650 \\
\hline
\end{tabular}

Source: Prepared by the author.

Table VI.5

JOB CREATION AND BUSINESS CREATION IN THE UNITED STATES AND

IN THE 27 EUROPEAN UNION MEMBER COUNTRIES

\begin{tabular}{lcc}
\hline Job creation & 5 years & 10 years \\
\hline United States & 2892000 & 3179000 \\
EU 27 & 3127000 & 3431000 \\
\hline Business creation & 5 years & 10 years \\
\hline United States & 1346000 & 1651000 \\
EU 27 & 369000 & 451000 \\
\hline
\end{tabular}

Source: Prepared by the author.

The authors' simulations show a substantial impact of the structural technological change associated with the introduction of cloud computing on business and employment. In particular, their long-run estimates show the creation of about 900,000 new jobs in Brazil and approximately 100,000 in Agentina. They have disaggregated the results for the two Latin American countries for the sectors on which they could have a more detailed analysis of the market structure. For reference purposes one can compare the numbers with about 3 million new jobs expected under similar assumptions in both the United States and the European Union. In light of this, the impact of the adoption of cloud computing for the Latin American countries appears quite large, especially for Brazil.

\section{G. Conclusions}

This chapter has provided a simulation of the economic impact of the diffusion of cloud computing in Latin America, the United States and the European Union. The authors evaluate the impact of the adoption of cloud computing on output, employment and business creation using a macroeconomic model characterized by endogenous market structures and job matching. This setting features an economy with many sectors, 
where the dynamics of the number of market competitors is endogenous. Firms face a cost of market entry which they will decide they can afford only if it is compensated by the expectation of future profits. In the authors' model, firms produce the final goods using labour and physical capital. The stock of capital takes the form of IT hardware which the firm has to install and maintain over time. Firms employ multiple workers, and the labour market is characterized by frictions. Both new firms and incumbent firms need to hire workers from the pool of unemployed agents who are looking for a job and to set up a stock of IT material before starting production. The simulation shows a substantial impact of a technological change such as the introduction of cloud computing in terms of business and job creation.

Contrary to the concern of many experts in the field, the authors' framework does not suggest a reduction in IT employment due to the adoption of the cloud technology, at least in the medium and long run. Part of the positive effects of cloud computing are going to be positively related to the speed of adoption of the new technology. Of course there are a number of factors that may slow down this adoption, such as a lack of understanding of the cloud on the part of firms, systemic risk, security, privacy and interoperability issues, reliability, jurisdictional complexity, data governance, loss of IT control and general status quo inertia. For this reason, the authors' research suggests that policymakers should promote as much as possible a rapid adoption of cloud computing. Concrete interventions include (beyond the expansion of the broadband capacity, of course):

(i) international agreements in favour of unrestricted flow of data across borders (since data centres are located in different countries with different privacy laws, data portability remains a key issue for the diffusion of cloud computing $)^{10}$ and to agree with industry leaders a minimum set of technological standards and process standards to be respected in the provision of cloud computing services to guarantee data security, privacy and portability, and promote a healthy diffusion of the new technology;

(ii) introduction of fiscal incentives for the adoption of cloud computing, targeting dynamic sectors (for instance, governments could finance, up to a limit, the variable costs of computing for all the domestic and foreign firms that decide to adopt a cloud computing solution) or sectors were environmental gains are likely to be larger.

10 On the security risks of cloud computing, see Ahmad (2010); on privacy issues, see Ranganathan (2010). 
(iii) introduction of government support for the reallocation of employment within the IT field (from IT departments, especially of small firm,s to different destinations in the IT sector).

These policies may be studied in such a way to optimize the process of adoption of the new technology and to strengthen the propagation of its benefits. Such a normative analysis is left for future research. 


\section{Bibliography}

Ahmad, M. (2010), Security Risks of Cloud Computing and Its Emergence as 5th Utility Service, Information Security and Assurance, Communications in Computer and Information Science, 76, 209-219.

Andolfatto, D. (1996), Business Cycles and Labor Market Search, American Economic Review, 86, 112-32.

Bell B. and J. Smith (2002), On Gross Worker Flows in the United Kingdom: Evidence from the Labour Force Survey, Bank of England WP 160, Bank of England.

Bilbiie, F., F. Ghironi and M. Melitz (2012), Endogenous Entry, Product Variety, and Business Cycles, Journal of Political Economy, 120, 2, 304-44.

Blanchard, O. and J. Galì (2010), Labor Market Frictions and Monetary Policy: A New Keynesian Model with Unemployment, American Economic Journal: Macroeconomics, 2, 2, 1-30.

Blanchard, O. and F. Giavazzi (2003), Macroeconomic Effects of Regulation and Deregulation in Goods and Labor Markets, Quarterly Journal of Economics, 118, 3, 879-907.

Borek, C. L. Christensen, P. Hess, G. Rafert and J. Lerner (2012), Lost in the Clouds: The Impact of Copyright Scope on Investment in Cloud Computing Ventures, mimeo, Harvard University.

Campos, N. and M. Iootty (2005), Firm Entry and Exit in Brazil: Cross-sectoral Evidence from Manufacturing Industry, Anais do XXXIII Encontro Nacional de Economia.

Center of Information Development (2010), Whitepaper on Cloud Industry Development in China, CCID Group, Beijing.

Cimoli, M., W. Pereira, G. Porcile and F. Scatolin (2011), Structural Change, Technology, and Economic Growth: Brazil and the CIBS in a Comparative Perspective, Economic Change and Restructuring, 44, 1, 25-47.

Christiano, L., M. Eichenbaum and C. Evans (2005), Nominal Rigidities and the Dynamic Effects of a Shock to Monetary Policy, Journal of Political Economy, 113, 1-45.

Colciago, A. and F. Etro (2010), Real Business Cycles with Cournot Competition and Endogenous Entry, Journal of Macroeconomics, 32, 4, 1101-17.

Colciago, A. and L. Rossi (2011), Endogenous Market Structures and Labor Market Dynamics, mimeo, University of Milano Bicocca.

Davis, S.J., J. C. Haltiwanger and S. Schuh, 1996, Job Creation and Job Destruction, The MIT Press, Cambridge

Den Haan, W., G. Ramey, J. Watson (2000), Job Destruction and the Propagation of Shocks, American Economic Review, 90, 482-98.

De Oliveira, D. and E. OgasawaraIs (2012), Cloud Computing the Solution for Brazilian Researchers? , International Journal of Computer Applications, 6, 8, 19-23.

ECB (2002), Labor Market Mismatches in the Euro Area Countries, European Central Bank.

Etro, F. (2009a), The Economic Impact of Cloud Computing on Business Creation, Employment and Output in the E.U., Review of Business and Economics, 54, 2, 179-208.

Etro, F. (2009b), Endogenous Market Structures and the Macroeconomy, New York and Berlin, Springer. 
Etro, F. and A. Colciago (2010), Endogenous Market Structure and the Business Cycle, The Economic Journal, 120, 549, 1201-33.

Fershtman, C. and N. Gandal (2012), Migration to the Cloud Ecosystem: Ushering in a New Generation of Platform Competition, Communications E Strategies, 85, 1, CEPR Discussion Paper 8907.

Hagedorn, M. and Manovski, J. (20080, The Cyclical Behavior of Equilibrium Unemployment and Vacancies Revisited, American Economic Review, 98, 4, 1692-706.

Hall, R. (1995), Lost Jobs, Brookings Papers on Economic Activity, Economic Studies Program, The Brookings Institution, 26, 221-74.

Haltiwanger, J. C., R. S. Jarmin and J. Miranda (2010), Who Creates Jobs? Small vs. Large vs. Young, NBER Working Paper No. 16300.

Jaimovich, N. and M. Floetotto (2008), Firm Dynamics, mark up Variations, and the Business Cycle, Journal of Monetary Economics, 55, 7, 1238-52.

International Data Corporation (2008), IT Cloud Services Forecast-2008-2012: A Key Driver for Growth, mimeo, 8 October.

International Data Corporation (2009), White Paper. Aid to Recovery, 9 October.

Kydland, F. and E. Prescott (1982), Time to Build and Aggregate Fluctuations, Econometrica, 50, 6, 1345-70.

Kuyucu, A.D.H. (2011), The playground of cloud computing in Turkey, Procedia Computer Science, 3, 459-63.

Lanvin, B. and P. Passman (2008), Building E-skills for the Information Age, Chapter 1.6, Global Information technology Report 2007-2008, WEF.

Lee, Y. and T. Mukoyama (2008), Entry, Exit, and Plant-level Dynamics over the Business Cycle, mimeo, Federal Reserve Bank of Cleveland.

Merz, M. (1995), Search in the Labor Market and the Real Business Cycle, Journal of Monetary Economics, 36, 269-300.

Mortensen, D. and C. Pissarides (1994), Job Creation and Job Destruction in the Theory of Unemployment, Review of Economic Studies, 61, 3, 397-415.

Oliveira Martins, J. and S. Scarpetta (1999), The Level and Cyclical Behavior of Mark-ups Across Countries and Market Structures, OECD Working Paper No. 213, OECD Publishing.

Petrongolo, B. and C. Pissarides (2001), Looking into the Black Box: A Survey of the Matching Function, Journal of Economic Literature, 39, 2, 390-431.

Pissarides, C. (2000), Equilibrium Unemployment Theory, Cambridge: MIT Press.

Ranganathan, V. (2010), Privacy Issues with Cloud Applications, IS Channel, 5, 1, 16-20.

Siqueira, F. (2009), The Ins and Outs of Cyclical Unemployment in Brazil - A First Assessment, mimeo, Economic School of Sao Paulo - Getulio Vargas Foundation.

Shimer, R. (2005), The Cyclical Behavior of Equilibrium Unemployment and Vacancies, American Economic Review, 95, 1, 25-49.

Thomas, C. and F. Zanetti (2009), Labor Market Reform and Price Stability: An Application to the Euro Area, Journal of Monetary Economics, 56, 6, 885-99.

Trigari, A. (2009), Equilibrium Unemployment, Job flows and Inflation Dynamics, Journal of Money, Credit and Banking, 41, 1, 1-33.

West, D. (2010), Saving Money Through Cloud Computing, mimeo, Governance Studies at Brookings, Washington, D.C. 
Third part

Public policies 



\title{
Chapter VII \\ National broadband plans
}

\author{
Hernán Galperin \\ Judith Mariscal \\ María Fernanda Viecens ${ }^{1}$
}

\section{A. Introduction}

Sizeable public investment in the deployment of new network infrastructure and ambitious government initiatives to develop broadband services are unequivocal signs of the changing role of the State in the telecommunications sector. Contrary to the consensus that prevailed until a few years ago, governments are no longer content with regulating private-sector activity and using universalization funds to correct market failures. Government financing of networks and infrastructure, State participation in operating those networks, and a proactive telecommunications industry policy stance are all back in the toolbox for telecommunications sector policymakers.

Hernán Galperin is a professor at the Universidad de San Andrés in Buenos Aires; Judith Mariscal is a professor at the Centro de Investigación y Docencia Económicas (CIDE) in Mexico City, and María Fernanda Viecens is a researcher at the Universidad de San Andrés and at the Consejo Nacional de Investigaciones Científicas y Técnicas (CONICET) in Buenos Aires. 
This change is seen in developed and developing countries alike and has been particularly evident in the proliferation of what are called 'national broadband policies.' This term encompasses the diverse set of initiatives adopted over the past five years whose core objective is to accelerate the roll-out and adoption of broadband services. The larger countries of Latin America have been particularly proactive in the design and implementation of national broadband plans, which have been accompanied by growing efforts towards regional coordination.

This changing role of the State in the telecommunications sector has raised a number of questions. To what extent does it represent a return to the days before market liberalization and privatization of Stateowned operators? What safeguards should be adopted to avoid market distortions and the crowding out of private investment? What should be the objectives of State intervention in the market for broadband services, and what are the best instruments for achieving them? How to regulate the activities of operators that receive public subsidies or are directly controlled by the State?

This chapter takes up these issues by means of a comparative analysis of the network deployment objectives, instruments and models set out by a number of countries of Latin America in their national broadband plans. One of the main objectives of this chapter is to identify similarities and differences, both among the plans put in place by countries in the region and in comparison with initiatives taken by developed countries. Another goal is to analyse these plans in the context of broader political changes in the region, especially in the wake of the international economic crisis of the late 1990s. The recommendations focus on the development of regulatory frameworks for broadband service that ensure complementarity between public-sector initiatives and the promotion of private-sector competition and investment.

This chapter is divided into five sections. The following section identifies the factors that have led the governments of the region to launch initiatives supporting the roll-out and adoption of broadband services. Section $C$ provides a snapshot of the national broadband plans of five countries (Argentina, Brazil, Chile, Colombia and Mexico), which are also outlined in the table in the annex. These countries were selected because they are useful examples and because information on implementation of the plans in question was available. Section D identifies the similarities and differences in the objectives, instruments and management of these plans, which are then compared with initiatives in developed countries. The European experience with regulatory guidelines for achieving balance between public initiatives and private investment is of particular interest. The final section discusses policy recommendations and sets out the conclusions of the study. 


\section{B. The end of a cycle: the changing role of the State in telecommunications}

In Latin America, the cycle of policies geared towards deregulating the telecommunications industry and privatizing State-owned operators began in the late 1980s and was showing the first signs of having run its course by late in the first decade of the 2000s. This waning might at first seem surprising because the cycle saw leaps in service coverage, exponential growth in investment and a virtuous process of technological innovation, new business models and new services (Estache and others, 2002; Jordán and others, 2010).

Studies of the impact of the reforms on aggregate well-being have demonstrated that the indirect effect on employment has been positive, and that the direct effect in terms of layoffs in privatized enterprises has been largely offset by the growth in total employment in the sector (McKenzie and Mookherjee, 2003). Furthermore, several studies have documented the positive or neutral distributive impact of privatizing and opening the telecommunications market, despite tariff adjustments linked to reforms in the sector (particularly in local fixed services) (Navajas, 1999; Ennis and Pinto, 2003).

So, if most of the evidence points to the success of the reform process that began in the 1990s, why are governments interested in changing it and heightening State intervention in the telecommunications sector? This chapter identifies various drivers. Some have to do with the changing economic and political context in the region; others are associated with trends within the telecommunications sector itself.

To start with the context factors, the first is what has been called the political 'left turn' taken by the governments of Latin America in the early 2000s (Castañeda, 2006; Levitsky and Roberts, 2011). This shift is relevant in that it brought with it a policy agenda calling for more State intervention in the economy and a return to the developmental and industrial policy tradition that had characterized Latin America during the greater part of the twentieth century (Corrales, 2008). Specifically, the economic crisis of 1998-2002 (when per capita output in the region contracted and poverty and inequality levels increased) penalized several of the governments associated with market reforms as public opinion shifted towards candidates with redistributive agendas calling for more State intervention in the economy (Murillo and others, 2011).

This shift has been especially noticeable in the sweeping publicopinion rejection of the privatization of public service enterprises in Latin America following the crisis. The level of support for privatization plummeted from $46 \%$ in 1998 to $19 \%$ in 2004, after which it recovered 
slightly (Latinobarómetro, 2011). Studies have identified numerous reasons for the scant support in the region for private management of public services, primary among which are lack of confidence in the capacity of governments to regulate private operators adequately (Panizza and Yañez, 2006), the continued existence of private monopolies in several sectors (Murillo and Martinez Gallardo, 2006) and the unequal distribution of the benefits of privatization (Shirley, 2004).

The second context factor is the significant improvement in the terms of trade of many countries in the region, particularly in South America. Several authors have pointed out that the combination of fiscal and external surpluses resulting from what they refer to as the 'commodity boom' not only gave governments the resources needed to invest heavily in infrastructure but also reduced the macroeconomic risk involved in State operation of public service enterprises (Weyland, 2009; Murillo and others, 2011). By enabling the rapid build-up of foreign reserves and easing the external debt burden, the macroeconomic boom cycle that began in the early 2000s increased the capacity of governments to carry out agendas providing for redistribution and State intervention in strategic industries.

This context is the inverse of the situation in the late 1980s, when the State controlled the incumbent operators but was unable to make the investments needed to modernize and expand national telecommunications network coverage while the private sector had both the resources and the know-how to do so. Two decades later, in a context of global economic uncertainty, private investors are hesitant to make large investments in network infrastructure, particularly the riskier ones with lower expected rates of return such as deploying the fibre backbone beyond the confines of large urban centres. This has encouraged the governments of the region - benefiting from favourable terms of trade - to fill the void left by the slowdown in private investment in the sector.

Focusing on the telecommunications sector, the third factor behind the public policy about-face is the growing body of evidence about the contribution that telecommunications - and broadband in particularmake to aggregate economic growth and job creation. The evidence of the importance of telecommunications for economic growth and business efficiency is nothing new and has, for fixed telephony, been available at least since the 1980s (Hardy, 1980; Leff, 1984). This contribution was subsequently confirmed by studies of mobile telephony (Roller and Waverman, 2001) and broadband services (Qiang and Rossotto, 2009; Koutrompis, 2009).

The difference lies in the role of the State in ensuring that the supply of services is enough to harness the potential of telecommunications as an engine for the other sectors of the economy. In other words, while the 
empirical evidence just shows the positive impact of network roll-out for competitiveness and employment, in the late 2000s an emerging consensus began to call for proactive public policies to speed deployment, particularly in the case of next-generation networks (NGNs) (OECD, 2009; ECLAC, 2010; ITU Broadband Commission, 2011). These policies were part of the economic stimulus packages implemented in several countries in response to the 2008 economic crisis, once the deployment of broadband had been linked to increases in competitiveness and employment (Qiang, 2010).

Just as the State played a key role in developing the electricity grid, transportation systems and the telecommunications network itself before the 1980s, the new consensus is calling for governments to take on a similar role in modernizing the telecommunications infrastructure in the twenty-first century. ${ }^{2}$

The fourth factor explaining the policy shift in the sector has to do with the limited impact of the instruments designed during the reform process in terms of mitigating geographical disparities in network deployment and access to services. Basically, the evidence points to failures in monitoring and enforcing private operators' network deployment obligations and to problems in designing and implementing universal service funds (USFs). Various studies (for example, REGULATEL, 2006) have shown that private-sector investment during the past two decades has been concentrated in urban areas with higher per capita income, perpetuating the gap in access to services between urban and rural areas and by income level (Grazzi and Vergara, 2011). The limited impact of USFs in Latin America has been widely documented as well (Stern, 2009; Barrantes, 2011). ${ }^{3}$

Towards the end of the first decade of the 2000s, the governments of Latin America reached basically the same conclusions. On the one hand, the limited penetration of high-capacity backbone networks and

\footnotetext{
Obviously, the consensus is not sweeping; Kenny (2011) has reviewed the evidence and summarized the criticisms of public investment in next-generation networks.

3 Brazil's Universal Telecommunications Service Fund (FUST) was set up in 2000 and collects approximately US $\$ 800$ million annually. But the fund has never been used, due to legal obstacles to its implementation. In Argentina, USF implementation and collection problems date back to renegotiation of contracts with fixed telephony operators after the 2011 economic crisis. Strictly speaking, Mexico does not have a USF but rather a temporary fund (the Telecommunications Social Coverage Fund) set up in 2002 to bring fixed telephony to isolated localities. Other countries, such as Colombia, Chile and Peru, have managed to achieve better results in implementing USFs. However, as pointed out by Barrantes (2011), even where USFs were more or less successfully implemented they have two basic problems. The first has to do with funding constraints and, therefore, with limited impact. The second is that by focusing on shared fixed telephony and Internet access they have lost ground to new technologies such as broadband, which require infrastructure deployment and service provision models.
} 
the lack of competition for access networks outside of large urban centres were having a negative effect on broadband service coverage, quality and price. On the other hand, the instruments for promoting infrastructure deployment and mitigating regional imbalances in access to services were insufficient for meeting the new need for connectivity in homes, businesses and public institutions. In that context, State intervention in the deployment of networks in areas with limited private return was deemed to be not only a matter of equity but also of taking the fullest advantage of the positive externalities to be derived from broadband consumption.

The final factor for understanding the shift in telecommunications sector policy focus in Latin America is the spread of broadband incentive policies implemented by the more developed countries. A few Southeast Asian countries have taken the lead in deploying next-generation networks, and their success can be seen in deployment and adoption rankings. ${ }^{4}$ The leadership of countries such as the Republic of Korea is not associated so much with successful market reforms as with proactive public policies combining private-sector incentives with significant public investment in infrastructure, training, and research and development (R\&D) (Kim and others, 2010; Choi herein). For the developing countries, the lesson to be learned from these success stories is, therefore, the need to complement private enterprise with greater State involvement in channelling investment and stimulating demand for broadband.

\section{Overview of national broadband plans}

\section{Argentina: Plan Nacional de Telecomunicaciones Argentina Conectada}

Argentina Conectada (the National Telecommunications Plan) was introduced in October 2010 to integrate ongoing initiatives in the sphere of new information and communications technologies (ICT) such as the roll-out of digital television and the introduction of notebook computers in schools, as well as to respond to uneven access to high-speed transmission networks in the region. ${ }^{5}$ The goal is to widen coverage and improve broadband Internet service access, particularly in areas that are not profitable for commercial operators (Plan Argentina Conectada, 2011).

The plan hinges on, among other things, deployment of a federal fibre-optic network extending some 58,000 kilometres, combining

\footnotetext{
4 Some of the most notable are the ICT Development Index (IDI) prepared by the International Telecommunication Union (ITU), the Network Readiness Index (NRI) designed by the World Economic Forum, and the broadband reports produced by the Organisation for Economic Cooperation and Development (OECD).

5 Argentina Conectada was passed by Presidential Decree No.1552 in October 2010.
} 
(i) the construction of a 22,000-kilometre provincial network and an 18,000-kilometre interprovincial network with (ii) the lighting of stretches of dark fibre-optic cable by the electrical company Transener (in which the State is a shareholder) and (iii) fibre exchange agreements with several private operators. This backbone network is expected to cover $97 \%$ of the population by 2015, with local operators being responsible for providing last-mile service.

The federal fibre optic network is operated by AR-SAT, a Stateowned enterprise created in 2006 to take over the assets of Nahuelsat, a privately-owned satellite operator that, unable to meet its liabilities, had agreed to transfer its assets to the recently-created State enterprise. The government plan emphasized the need to lower costs and increase competitiveness in the wholesale access market, but it did not structurally separate the new State operator and thus left the door open for AR-SAT to step into the retail side.

The plan includes initiatives that complement deployment of the fibre-optic network. For example, it promotes the creation of public access and training centres (called knowledge access hubs and digital access points) as well as digital literacy and ICT research initiatives. On the regulatory front, the plan includes initiatives to promote competition, such as a tender to award additional spectrum for mobile broadband services and reactivating the universal service fund. The plan also includes aid in the form of credit and technical assistance for cooperatives and small private broadband service operators that the plan sees as key for achieving coverage and adoption targets. Investments under the plan are expected to total 8 billion Argentine pesos (approximately US\$ 1.8 billion) over five years (2011-2015), of which 3.7 billion Argentine pesos (approximately US\$ 840 million) represents investment in the backbone fibre-optic network.

So far, tenders have been offered for the construction of 11 segments (approximately 18,700 kilometres) of the federal fibre-optic network and for 2,500 kilometres of provincial network, representing a total investment of 2.85 billion Argentine pesos (approximately US\$ 640 million). The new national data centre out of which AR-SAT will run the new network is also under construction. Laying of the fibre-optic cable across the Strait of Magellan to Tierra del Fuego island has been completed. Fifty shared access and training centres have been inaugurated in several provinces, and cooperation agreements with neighbouring countries, particularly Brazil and Uruguay, for the creation of Internet exchange points are moving forward. ${ }^{6}$

See Argentina Conectada, Informe de Gestión 2012 [online] http:/ / www.argentinaconectada. gov.ar. 


\section{Brazil: Plano Nacional de Banda Larga}

The Plano Nacional de Banda Larga (National Broadband Plan) (PNBL) was developed during 2010 under the administration of President Lula and endorsed by the administration of President Dilma Rouseff. The five broad objectives of the plan are: make it easier for the population to access broadband Internet services; speed social and economic development; promote digital inclusion; reduce social and regional inequalities; and promote job and income creation. ${ }^{7}$ The plan especially seeks to lower the cost of Internet access and increase broadband service coverage and quality. It provides for action along four fronts: regulation and infrastructure standards; tax incentives for telecommunications services; production and technology policy; and deployment of a national fibre-optic network.

The primary focus of the national fibre-optic network is deployment of a network connecting the 27 state capitals so as to meet government agency connectivity requirements, and to offer connectivity to localities where there is no private operator service or the supply is of low quality and high cost. The goal is to connect 4,278 (76\%) of the 5,564 municipalities around the country within four years (2011-2014) at a total investment cost of 5.7 billion reais (approximately US\$ 3.3 billion). The network is planned to extend over 30,000 kilometres and will include the laying of new fibre cables and making use of the idle fibre-optic capacity of State-controlled enterprises like Petrobras and Eletrobras.

Under the PNBL, Telebras will build and operate the network and the State will inject 3.2 billion reais (approximately US\$ 1.8 billion) to capitalize the company. Telebras (the incumbent State telecommunications company until its privatization in 1998) was reactivated by the government in 2010 to lead infrastructure initiatives under the plan. It will supply capacity to the wholesale market and reach the end user by means of agreements with last-mile operators. The plan requires that these agreements include an offer to supply the client with access at $1 \mathrm{Mbps}$ for 35 reais per month (about US\$20). As in Argentina, Brazil's plan provides that Telebras can, on terms set by the telecommunications sector regulator (Anatel), operate in the retail segment in localities where there are no local operators or where service is poor.

The entry of a State operator into the market has been questioned by the major private operators (Jensen, 2011). In spite of this, some of them have already signed agreements with Telebras. The smaller operators see it as an opportunity to change the conditions of a market in which five operators control more than $90 \%$ of the market (PNBL, 2010). Meanwhile, Anatel,

The Plano Nacional de Banda Larga (PNBL) was established by Presidential Decree

No. 7175 of May 2010. 
in an effort to promote competition, adopted a general competition plan that empowers it to require companies with substantial market leverage to share their infrastructure with other operators, although it declared a nineyear regulatory holiday for the deployment of fibre-optic networks.

The PNBL also envisages fiscal incentives, support for research and development, and financing for equipment using domestically-produced technology, as well as leveraging government purchasing power to promote the production of national technology. The State expects to invest some 2.5 billion reais (approximately US $\$ 1.45$ billion) in these initiatives, on top of 7.5 billion reais (US\$ 4.17 billion) in National Bank for Economic and Social Development (BNDES) credit facilities.

Telebras has already signed contracts for taking the fiber-optic backbone network to $40 \%$ of Brazil's municipalities by the end of 2012 . And this State operator has signed data capacity contracts with private operators who have committed to offer 1-Mbps connections at a cost of 35 reais per month with a guaranteed speed that cannot be lower than $20 \%$ of the advertised speed. The first of these contracts was signed in June 2011 with the company Sadnet for an area in the state of Goiás, where Telebras offers $100 \mathrm{Mbps}$ of capacity at a cost of less than 200 reais (US\$ 115) per $\mathrm{Mb}$ per month (Pena, 2012). In addition, several tender processes have been initiated for the construction of a number of segments of the new network.

\section{Chile: Plan Todo Chile Comunicado}

The Plan Todo Chile Comunicado (All Chile Connected Plan) project seeks to spur production development, education and the insertion of communities in isolated rural areas of the country by supplying them with mobile broadband coverage. Most (68\%) of these communities are small (less than 1,000 inhabitants) and are thus of little interest to private operators. The initiative has been implemented within the framework of the Telecommunications Development Fund (FDT), which was created to increase telecommunications service coverage in low-income and isolated areas and earmarks national budget funds for subsidies to encourage telecommunications enterprises to provide services to such areas.

The Plan Todo Chile Comunicado project (2010) is a public-private partnership where the government subsidizes operators to provide enduser services in predetermined areas under the conditions established in the tender specifications for the plan. The initiative was launched in 2010 with the aim of providing mobile broadband services to more than 3 million inhabitants of 1,474 isolated rural localities upon completion of its three phases by 2012. The tender was awarded to the private operator Entel and involves a total investment of approximately US\$ 110 million, of 
which US\$ 65 million will be contributed by Entel and the remainder in equal parts by the FDT and local governments.

The plan is up and running in the more than 1,000 localities where Entel offers mobile broadband Internet access services at a monthly rate of 14,220 Chilean pesos (approximately US\$ 30) with a maximum download speed of $1 \mathrm{Mbps}$. The operator also offers a daily access mode at a rate of 1,886 Chilean pesos (approximately US\$4).

\section{Colombia: Plan Vive Digital}

The Plan Vive Digital (Live Digital Plan) was launched in 2010 to deliver mass Internet access in Colombia. It sets three basic goals to be achieved within five years: triple the number of municipalities connected to the national fibre-optic network, connect $50 \%$ of micro, small and mediumsized enterprises and $50 \%$ of households to the network, and quadruple the number of Internet connections around the country-from 2.2 million connections in 2010 to 8.8 million connections in 2014. The plan seeks to take fibre-optic connectivity to $62 \%$ of the country's 1,120 municipalities (representing $90 \%$ of the population) and establish shared access centres in all localities with more than 100 inhabitants (Vive Digital, 2010).

One of the main initiatives under the plan is the National FibreOptic Project for deployment of backbone fibre-optic cable to those municipalities not connected to high-speed transmission networks under a public-private partnership model. In July 2011, the Ministry of Information and Communications Technologies (responsible for implementing the plan) published the tender conditions for the National Fibre-Optic Project. In November 2011, the project was awarded to the Colombia Provisional Fibre-Optic Union, consisting of the companies Total Play and TV Azteca, controlled by Mexico's Grupo Salinas. The government of Colombia agreed to contribute 415 billion Colombian pesos (approximately US\$237 million), which was estimated to be about one third of the total investment needed for deployment of the network. According to the Ministry, out of the four bids tendered, the project was awarded to the consortium offering coverage to the greatest number of municipalities $(1,078){ }^{8}$

According to the tender specifications, the operator must configure the fibre-optic transmission network, operate it and connect it to the target group of municipalities ensuring freedom of access, transparency, nondiscriminatory treatment, free competition, efficiency and user rights. Once the infrastructure has been deployed in the municipalities, the company shall operate and manage the network for 15 years pursuant to

See [online] www.mintic.gov.co/index.php/fibra-inicio/53-sitio-fibra-optica/sitio-fibranoticias/542-20111104licitacionfibra.. 
the tender specifications, which include considerations such as free Internet broadband access for the 2,000 public institutions in the municipalities connected to the network. At the end of this period, ownership of the infrastructure will pass to the tender awardee and come under the standard regulations governing the rest of the private operators. There are no structural separation requirements, so the fibre-optic network operator may provide access services to the end user.

Other initiatives under the plan include establishing a legal and regulatory framework for convergence, efficient infrastructure utilization and incentives for the software and digital content industries. (In July 2011 the withholding tax on software development firms in Colombia was reduced from $11 \%$ to $3.5 \%$.) For e-government services, the plan calls for $100 \%$ of national entities and $50 \%$ of territorial entities to provide government services online by 2014. In addition, import tariffs on Internet access terminals such as computers, tablets and smartphones were eliminated in the second half of 2011. The plan also provides for designing ICT capacity-building programmes for segments of the population with lower resources and the removal of the value-added tax on broadband services to those population segments.

\section{México: Agenda Digital.mx}

During the administration of President Calderon (2006-2012) measures were taken to promote Internet deployment and use. In the first quarter of 2012, these ongoing initiatives were grouped into two broadband development programmes: Acciones para el Fortalecimiento de la Banda Ancha y las Tecnologías de la Comunicación y la Información (Actions for Strengthening Broadband and Information and Communications Technologies) and Agenda Digital.mx (Digital Agenda.mx). The first programme focuses on boosting the supply of telecommunications services by encouraging private investment in infrastructure and government investment. The second centres on developing demand for services by promoting the adoption and use of ICT and developing the market for telecommunications-based content and applications. The four goals are: promote investment in the infrastructure needed for providing broadband services nationwide; reduce the cost of broadband services; increase digital literacy; and encourage uptake of Internet services.

One of the initiatives in place by 2011 was for operationalizing the fibre-optic backbone network of the Federal Electricity Commission (CFE), a public corporation and the main electricity provider in Mexico. This network extends over 34,000 kilometres and has 36 fibre-optic cables, of which CFE uses only six (Mariscal and Flores-Roux, 2009). In 2010, the Communications and Transport Secretariat (SCT) auctioned 
off a couple of dark fibre cables from the CFE network on three routes totalling 19,500 kilometres for a period of 20 years, during which time the operator agreed to make complementary investments aimed at boosting network coverage and capacity. A consortium made up of the Spanish company Telefónica and Mexico's Televisa won the tender with a bid of approximately US\$ 70 million that included a commitment to invest another US\$ 103 million in extending the network by 1,700 kilometres. The new operator can offer intercity data-transfer services under nondiscriminatory conditions with the proviso that third parties be allowed to use the dark fibre in those parts of the network not being used by the consortium (SCT, 2012).

Another infrastructure development initiative is the 'Fibre-tothe-Node' programme. It is being funded by the National Infrastructure Fund (FONADIN), which can provide non-reimbursable subsidies for private operators to deploy fibre-optic cable "in localities with insufficient coverage or where there is market failure" (SCT, 2012). More than 400 municipalities have been identified as meeting these requirements, and interested parties have been invited to bid for the first stage in the state of Guanajuato. Under the public-private partnership planned for this initiative, the licensee will be required to share the infrastructure and comply with non-discriminatory rules of access. These projects, because of their nature, will be subject to asymmetric rate regulation.

The e-Mexico programme, renamed Coordinación de la Sociedad de la Información y el Conocimiento (Information and Knowledge Society Coordinating Office) (CSIC), has relaunched its digital literacy strategy with the Campaña Nacional por la Inclusión Digital de los Adultos, geared towards digital literacy for persons aged 25 to 54 . Partnering with the Instituto Nacional para la Educación de los Adultos (INEA), has enabled the campaign to train between 300,000 and 500,000 persons per year during the past five years. The government, in order to promote access for low-resource segments of the population, is seeking to increase the number of Digital Community Centres from 6,788 to 24,000 by the end of 2012. This will be achieved mainly by increasing satellite connectivity capacity. CSIC will also launch a social network called Digital Club to build technological capacities and encourage technological entrepreneurship among young people. Thirty-seven Digital Clubs are planned at Mexican Youth Institute facilities and some secondary schools. 


\section{National broadband plans: different strategies, same goal}

The broadband plans rolled out in Latin America have much in common with initiatives launched by the governments of many countries. This section identifies the similarities and differences between initiatives put in place by the countries of the region and compares them with those undertaken by more developed countries.

\section{Analysis and objectives}

A comparative analysis of the plans implemented in Latin America with those undertaken in developed countries reveals, first of all, important differences as to the diagnosis of the situation. In the wealthy countries, the main issue is incomplete deployment of high-speed access networks (especially fibre-to-the-home); in the countries of Latin America, the issue is a lack of interurban backbone network capacity. That is why the developed countries seek to encourage deployment of high-speed access networks (usually in excess of $30 \mathrm{Mbps}$ ) while the countries of Latin America are focusing more on correcting regional imbalances in the supply of firstgeneration broadband services with more modest target access speeds (usually around $1 \mathrm{Mbps}$ ). In other words, for the more developed countries the priority is to improve service quality, while the rationale for initiatives in the region is to expand geographical coverage and increase the number of connections.

Initiatives in Latin America are focused almost exclusively on increasing coverage and encouraging competition on the wholesalebackbone-segments of the network, particularly in areas where there are few or no private operators. This reduces (but does not eliminate) the problem of market distortions and displacement of private investment that public investment in network infrastructure could generate because the focus is on areas not covered by fibre optic networks (as in Colombia and Mexico) or on areas with a single incumbent provider (characteristic of the plans of Argentina, Brazil and, to a certain extent, Mexico). This strategy stands in contrast to those being followed by some developed countries, such as Australia, New Zealand and Singapore, whose plans have no specific geographical focus. 


\section{Investment and funding}

A comparison of the estimated investment costs and sources of funding for the national broadband plans of Latin American countries yields several interesting results. Public investment in the deployment of network infrastructure in the region ranges from US\$2.60 per capita in Chile to US\$ 21 per capita in Argentina (see annex). These differences are due in part, to differences in length and the segments of the planned network that are already built. Compared with more ambitious initiatives, such as in Australia and New Zealand (Given, 2010), where public investment per capita is US\$ 845 and US\$245, respectively, the levels of investment planned by the countries of Latin America are low. The comparison is, however, qualified by the fact that Australia's and New Zealand's plans include fibre-optic services to households with access speeds of up to 100 Mbps, while the plans implemented in Latin America have much more modest objectives.

Taking into consideration those objectives, the geographical conditions, and the network architecture, it would seem more appropriate to compare Latin American broadband plans with initiatives in the United States of America and Canada, where per-capita public investment in network infrastructure amounts to US\$ 8 and US\$ 5, respectively (Qiang, 2010). ${ }^{9}$ This comparison shows how sizeable the investment commitment is in the case of Argentina (US\$ 21 per capita) and, to a lesser degree, Brazil (US\$ 9.2 per capita), particularly when the per capita GDP of the United States is almost three times that of Argentina and four times that of Brazil. The opposite applies to Chile, which, with a GDP per capita similar to that of Argentina, plans to invest ten times less.

As for funding, the region's national broadband plans are not well coordinated with existing supplier subsidy schemes, such as USFs. The fact that funding from national broadband plans is not earmarked and is therefore subject to fiscal budget variations and macroeconomic cycles poses a significant challenge for these initiatives in the medium term. This affects Argentina and Brazil, in particular, where new State-owned operators have to find the delicate balance between financial sustainability and achieving their objectives of serving the least profitable segments of the market.

\section{Deployment models}

A comparison of the national plans implemented by the countries of the region reveals many similarities in terms of their analysis of the situation

The figure for the United States includes only the US $\$ 2.5$ billion to be spent under the Broadband Initiatives Program (BIP) for network infrastructure deployment. 
and their rationale and goals. But differences arise when it comes to the policy instruments the governments have chosen, especially for deployment of national fibre-optic backbone networks. There are two approaches: the one taken by Argentina and Brazil, where backbone network deployment and operation is assigned to a State-controlled company, and the public-private partnership (PPP) model adopted in Colombia, Mexico and Chile. Each model has different implications regarding the role of the State in the sector.

One of the most significant aspects refers to the level of financial commitment by the State in each model. In the State-operator model, the government is responsible for the investment cost of laying the entire backbone network, with the private sector covering the last-mile investment (in both cases, there are provisions for soft loans to small local operators). There is, therefore, an implicit connection between public and private investment, although how they are linked is not spelled out in the plans. By contrast, under the PPP model the split between public and private investment is defined, thus reducing the State's initial investment commitment as well as its future commitments for maintaining and operating the network. In the cases examined, public funding ranges from $38 \%$ of the estimated total investment in Colombia to $45 \%$ in Chile.

In the State-operator model the level of public investment is higher because the government must cover $100 \%$ of the investment in new network infrastructure (capital expenditure, or CAPEX) as well as the longterm cost of operating the network (operating expenditure, or OPEX). But it should be borne in mind that in such cases the investment is in assets of which the State retains ownership whereas in Chile's and Colombia's PPP models the State subsidizes deployment of the network that, after a certain period, is handed over to the private operator.

The PPP model adopted by Chile is closely related to the marketreform paradigm for the sector. In this model, a private operator provides services in unprofitable areas in exchange for a subsidy whose amount is established by tender. A well-designed scheme of this kind optimizes the use of public funds and minimizes the displacement of private investment (Wallsten, 2009). In Colombia, the tender process has also been used to determine the final amount of the State subsidy, with 15-year agreements providing for set contributions by the State. In cases such as these, the implementation mechanism seeks to promote market competition in areas where there is little potential for private return. In contrast, the strategy in Argentina and Brazil, and to a certain extent in Mexico, is to promote market competition by creating a new backbone network operator that would put pressure on the incumbent operators and drive down the price of access. 
The PPP scheme adopted by Mexico differs in that the State auctions the use of existing but underutilized infrastructure (the fibre network owned by the State-owned electrical company, the Federal Electricity Commission, CFE). Despite some of the aforementioned weaknesses in the design of the tender, such approaches usually allow full advantage to be taken of the combination of State-owned assets and the financial and management capacity of the private sector. Although the scheme depends on the availability of this kind of infrastructure, there are usually many State-owned assets that could leverage private investment in new network infrastructure (such as dark fibre, ducts and associated rights of way, poles and towers for wireless network equipment, and so on). ${ }^{10}$

\section{Regulation and coordination with the private sector}

Another feature of broadband plans in Latin America is that they combine public investment in backbone network infrastructure with last-mile services provided by the private sector. Both in Argentina and in Brazil, the plans promote small- and medium-sized local access operators by means of soft loans, technical training and facilities for interconnection at local Internet exchange points. In these countries, the entry of the State operator in the retail market segment is seen as a strategy of last resort, although the plans do not set out the criteria for such intervention. However, unlike initiatives in some developed countries (such as Australia and New Zealand) that include the creation of a State-controlled backbone network operator, Argentina, Brazil and Colombia have no provisions for the structural or functional separation of operators (AR-SAT, Telebras and the Colombian Provisional Fibre Optic Union, respectively). However, Mexico and Colombia have set up safeguards in the tender contracts that bar discrimination in access by the new network operator.

In Argentina and Brazil, the regulatory framework and the authority responsible for monitoring the conduct of the State operator are still under discussion. Both theoretical arguments and international experience suggest the need for State operators to be held to the same regulatory standards as other operators in the market. If State operators provide services and develop infrastructure in areas that are not profitable, subsidies should be awarded transparently via mechanisms that optimize public investment. Such safeguards turn out to be particularly important when the plans do not provide for long-term financing mechanisms for the State operator.

10 See ITU (2008) for a discussion of the subject. 
Europe has experience in setting rules for State aid for nextgeneration network projects. These rules seek to avoid displacing private investment and to create a lasting balance between public and private initiatives. They were created in September 2009 by the European Commission in response to the wave of broadband initiatives implemented by European Community member governments. Known as the Broadband Guidelines (European Commission, 2009), these directives define and guide the actions of European governments in the deployment of telecommunications infrastructure and refer specifically to the application of the principles on State aid for the establishment of broadband networks. ${ }^{11}$ This is the reason why the directives seek to establish clear rules governing where, and how, public funds may be used for the deployment of broadband networks.

The Guidelines are based on the distinction between competitive areas (the 'black areas'), in which State aid is not allowed, and areas that are unprofitable or unserved (the 'white' and 'grey' areas, respectively) in which State aid might be justifiable under certain conditions. The areas are defined in the following manner: (i) white areas: broadband services are not currently available, nor are they likely to be deployed by private investors in the near future (which is understood to be within the next three years); (ii) black areas: there are at least two broadband network providers, and broadband services are supplied under competitive conditions (competition understood as based on broadband infrastructure) and (iii) grey areas: there is only one network supplier operating under monopolistic conditions; in this situation, the Commission requires a detailed analysis and evaluation before State aid can be authorized.

Since the directives were published, the Commission has heard approximately 50 cases of State aid for the roll-out of next-generation access networks. ${ }^{12}$ Most of the projects presented by European governments have involved broadband deployment in rural areas not covered by the private sector (white areas) and have been authorized without objection by the Commission..$^{13} \mathrm{~A}$ few cases have required a more detailed examination of

11 European Community competition policy prohibits unjustified State aid that could distort competition.

12 For example, during 2010 projects amounting to some 1.8 billion euros were approved. See "State Aid: Commission approves record amount of State aid for the deployment of broadband networks in 2010", Press Release (IP/11/54), 20 January 2011.

13 Some examples of projects authorized by the Commission are Broadband support in rural areas of Germany, National broadband plan for rural areas in Italy, Highspeed construction aid in sparsely-populated areas in Finland, and RAIN (Rural Area Information Technology Network) in Lithuania. 
the non-white areas impacted by the projects..$^{14}$ In general, the directives have helped to minimize the crowding out of private investment, establishing conditions for complementarity between public and private sector investment in the deployment of next-generation networks.

\section{E. Conclusions}

During the past decade, the role of the State in the telecommunications industry in the countries of Latin America has changed significantly. At first glance, this change seems paradoxical in view of the evidence concerning the success of market reforms in the sector. Part of this paradox is explained by rapid technological change, and particularly by the growing importance of broadband Internet services in the economic and social fabric. Even though private investment has generated exponential growth in the levels of access to basic telephony services, an examination of the main countries in the region reveals the insufficient development of both fibre backbone networks and the capacity of households, firms and the State itself to absorb the new services associated with the Internet. However, the success that some countries leading the way in the adoption of broadband services (the Republic of Korea, in particular) have had with proactive public policies has drawn the attention of countries in the region.

This chapter puts forth that the national broadband plans adopted in Latin America in recent years were shaped by factors in the political and economic context of the early twenty-first century and the development of the sector itself. However, these plans do not represent a wholesale return to the State-owned operator model of the period prior to the market reforms in the sector. As has been seen, the new State-owned operators created in the framework of the national broadband plans are mandated above all to operate in the wholesale access market in areas where private investment has been insufficient or non-existent, coordinating with private last-mile operators under non-discriminatory conditions. Other countries have adopted several different public-private partnership models which

14 This has been the case with the Xarxa Oberta project in Cataluña, Spain. This project involved the deployment of a fibre optic network that would connect all the public facilities (schools, health centres, police stations, courts of justice, and so on) in the region. This aspect of the project did not, in itself, trigger an examination because selfprovision by the State is not considered State aid. However, the project also allowed the network service provider to use any surplus network to provide wholesale broadband access to third-party operators. It was considered that this aspect of the project could distort competition by allowing an operator receiving State funding to enter the private broadband market as a wholesale provider. The Commission then resolved that providing wholesale broadband access should be restricted to the white areas of Cataluña and be barred in the big cities in the region (Ganuza and Viecens, 2011). 
ensure complementarity between public funding and private operation of the new network (Falch and Henten, 2010).

All in all, there have been no rigid dichotomies between State operators and competition between private actors, but rather a range of policies seeking complementarities to promote the development of the sector. The new role of the State is a mixed model in which the State and the private sector partner in the deployment of a general-purpose technology (broadband Internet access) with many economic and social externalities. The specific circumstances facing the telecommunications sector call for close cooperation between the State and private actors in order to maximize the contribution of the sector to the economic and social development goals of the region.

It is still too soon to assess the impact of national broadband plans in Latin America. However, some issues are bound to arise in the immediate future. First, as noted above, State-run telecommunications companies bring to mind the multiple difficulties that the old State-owned telephone companies used to face. Operating these enterprises efficiently and transparently is the core challenge of national broadband plans. To this end, emulating the instruments of State intervention that have been successful in other countries must be considered in the institutional context of each country. The capacity of the State to manage a complex infrastructure network when technology and patterns of demand are changing rapidly must be evaluated carefully by each government. Moreover, the international economic context is cyclical in nature, enabling governments to take on major network infrastructure investments with relative ease today but requiring sustainable models for funding new networks over the medium term.

Second, complementarity between the public and private sectors will work as long as the mechanisms safeguarding competition and promoting private investment are not weakened. This chapter has pointed out the many challenges that setting transparent rules for State-owned or Statesubsidized operators presents. This is a long-standing debate in countries (such as Uruguay and Costa Rica) where the State has maintained a significant holding in the incumbent operator, and it is surfacing in many other countries in the region. It is important to take advantage of successful mixed-management experiences in the telecommunications industry and learn from the experiences of other regions in regulatory matters, such as the case of the European Union, discussed earlier.

Finally, to return to the question of the role of the State in the sector, there is consensus as to the need for policies that address market failures in the provision of services, particularly those that have a strong impact on social and economic well-being. This need is less apparent in 
areas supplied by a single operator, usually the historical incumbent. Is the duplication of publicly funded network segments the most efficient tool for ensuring competitive access prices? Obviously, there are other tools (such as regulating the cost of broadband access and unbundling network components that cannot be replicated) that the countries of the region should not overlook. This will require continuing to strengthen the technical expertise of industry regulators and building up institutions that enable these regulators to implement rules adapted to the new context of the sector. 


\section{Bibliography}

Barrantes, R. (2011), “Uso de los fondos de acceso universal de telecomunicaciones en países de América Latina y el Caribe", Project Documents, No.429 (LC/W.429) Santiago, Chile, Economic Commission for Latin America and the Caribbean (ECLAC).

Castañeda, J. (2006), “Latin America's left turn”, Foreign Affairs, vol. 85, No. 3.

Corrales, J. (2008), "The Backlash against Market Reforms", Constructing Democratic Governance in Latin America, J.I. Domínguez. y M. Shifter (eds.), Baltimore, Johns Hopkins University Press.

ECLAC (Economic Commission for Latin America and the Caribbean) (2010), Banda ancha: Una urgencia para América Latina y el Caribe (LC/R.2158), Santiago, Chile.Ennis, H. and S. Pinto (2003), "Privatization and income distribution in Argentina", unpublished.Estache, A., M. Manacorda and T. Valletti (2002), "Telecommunications reforms, access regulation, and Internet adoption in Latin America", Economica, No. 2.

European Commission (2009), "Guidelines for the application of state aid rules in relation to the rapid deployment of broadband networks" [online] http:/ / eur-lex.europa.eu/LexUriServ/LexUriServ.do?uri=OJ:C:2013:025:000 1:0026:EN:PDF.

Falch, M. y A. Henten (2010), "Public private partnerships as a tool for stimulating investments in broadband", Telecommunications Policy, vol. 34.

Ganuza, J.J. y M.F. Viecens (2011), "Deployment of high-speed broadband infrastructures during the economic crisis. The case of Xarxa Oberta ", Telecommunications Policy, vol. 35.

Given, J. (2010), "Take your partners: Public private interplay in Australian and New Zealand plans for next generation broadband", Telecommunications Policy, vol. 34, No. 9.

Grazzi, M. and S. Vergara (2011), "Determinants of ICT Access", ICT in Latin America: A Microdata Analysis, S. Vergara, S. Rovira and M. Balboni (eds.), Santiago, Chile, Economic Commission for Latin America and the Caribbean (ECLAC).

Hardy, A. (1980), "The role of the telephone in economic development", Telecommunications Policy, No. 4.

ITU (International Telecommunication Union) (2008), Trends in Telecommunication Reform: Six Degrees of Sharing, Geneva.

ITU Broadband Commission (2011), Broadband: A platform for progress, Geneva, ITU / UNESCO.

Jensen, M. (2011), Broadband in Brazil: A Multipronged Public Sector Approach to Digital Inclusion, Washington, D.C., infoDev/World Bank.

Jordán, V., H. Galperín and W. Peres (2010), Acelerando la revolución digital: Banda ancha para América Latina y el Caribe (LC/R.2167), Santiago, Chile, Economic Commission for Latin America and the Caribbean (ECLAC).

Kim, Y., T. Kelly and S. Raja (2010), Building Broadband: Strategies and Policies for the Developing World, Washington, D.C., World Bank.

Kenny, C. (2011), Overselling Broadband: a critique of the recommendations of the Broadband Commission for Digital Development, Center for Global Development.

Koutrompis, P. (2009), "The economic impact of broadband on growth: a simultaneous approach", Telecommunications Policy, vol. 33. 
Latinbarómetro (2011), Latinobarómetro 2011 Report, Santiago, Chile.

Leff, N. (1984), "Externalities, information costs, and social benefit-cost analysis for economic development: An example from telecommunications", Economic Development and Cultural Change, vol. 32, No. 2.

Levitsky, S. and K. Roberts (2011), The Resurgence of the Latin American Left, John Hopkins Press.

Mariscal, J. and E. Flores-Roux (2009), "Propuesta de licitación de la fibra oscura propiedad de la CFE. Solución que genera escasez artificial, tanto presente como futura", Regional Dialogue on the Information Society (DIRSI).

McKenzie, D. and D. Mookherjee (2003), "The distributive impact of privatization in Latin America: evidence from four countries", Economía, Latin American and Caribbean Economic Association (LACEA).

Murillo, M. V. and C. Martínez Gallardo (2006), "Political competition and policy adoption: market reforms in Latin American public utilities", American Journal of Political Science, vol. 51, No. 1.

Murillo, M. V., V. Oliveros and M. Vaishnav (2011), "Voting for the Left or governing on the Left?", Latin America's Left Turn, S. Levitsky and R. Kenneth (eds.), Cambridge University Press.

Navajas, F. (1999), Structural Reforms and the Distributional Effects of Price Changes in Argentina, Buenos Aires, FIEL.

OECD (Organisation for Economic Cooperation and Development) (2009), The Role of Communication Infrastructure Investment in Economic Recovery, Paris.

Panizza, U. and M. Yañez (2006), "Why are Latin Americans so unhappy about reforms", Working Paper, No. 567, Washington, D.C., Inter-American Development Bank.

Pena, A. (2012), "A Banda Larga e o Cenário de Telecomunicações Brasileiro", Revista de Direito, Estado e Telecomunicações, vol. 3, No. 1.

Plan Argentina Conectada (2011), Plan de Acción del Plan Nacional de Telecomunicaciones "Argentina Conectada", Ministerio de Planificación Federal, Inversión Pública y Servicios [online] http:/ / www.argentinaconectada. gob.ar//adjuntos/139/documentos/000/025/0000025555.pdf.

PNBL (Programa Nacional de Banda Larga) (2010), “Brasil Conectado. Programa Nacional de Banda Larga. Documento base do Programa Nacional de Banda Larga", Publicação da Secretaria-Executiva do Comitê Gestor do Programa de Inclusão Digital [en línea] www.planalto.gov.br/brasilconectado.

Proyecto Todo Chile Comunicado (2010), Proyecto Bicentenario "Red de Internet Rural: Todo Chile Comunicado", Ministerio de Transportes y Telecomunicaciones, Subsecretaría de Telecomunicaciones [online] http:/ / www. subtel.gob.cl/prontus_subtel/site/artic/20100819/asocfile/20100819103226/ ppt_bicentenario_fdt_red_internet_rural.pdf.

Qiang, C. (2010), Broadband Infrastructure in Stimulus Packages: Relevance for Developing Countries, World Bank.

Qiang, C. and C. Rossotto (2009), "Economic impacts of broadband", Information and Communications for Development, World Bank.

Regulatel (Latin American Telecommunications Regulators Forum) (2006), Nuevos modelos para el acceso universal de los servicios de telecomunicaciones en América Latina.

Roller, L. and L. Waverman (2001), "Telecommunications infrastructure and economic development: a simultaneous approach", American Economic Review, No. 4. 
SCT (Communications and Transport Secretariat) (2012), Acciones para el fortalecimiento de la banda ancha y las tecnologías de información y comunicación, Mexico City.

Shirley, M. (2004), "Why is sector reform so unpopular in Latin America", Roland Coase Institute Working Paper Series, No. 4.

Stern, P. (2009), "Objetivos y obligaciones de acceso universal en el sector de las telecomunicaciones en América Latina", Más allá del mercado: las políticas de servicio universal en América Latina, J. Caldaza, A. Costas and J. Jordana (eds.), Fundación CIDOB.

Vive Digital (2011), Ministerio de Tecnologías de la Información y Comunicaciones, República de Colombia [online] http://www.vivedigital.gov.co/files/Vivo_ Vive_Digital.pdf.

Wallsten, S. (2009). Reverse Auctions and Universal Telecommunications Service: Lessons from Global Experience. Federal Communications Law Journal 61(2): 373-394.

Weyland, K. (2009) The Rise of Latin America's Two Lefts: Insights from Rentier State Theory, Comparative Politics 41(2):145-164.

Wallsten, S. (2009), "Reverse auctions and universal telecommunications service: lessons from global experience", Federal Communications Law Journal, vol. 61, No. 2.

Weyland, K. (2009), "The rise of Latin America's two Lefts: insights from Rentier State Theory", Comparative Politics, vol. 41, No. 2. 


\section{Annexes}

\section{Annex VII.1 \\ Main elements of broadband plans in selected countries}

Table VII.A.1

\begin{tabular}{|c|c|c|c|c|c|}
\hline & Argentina & Brazil & Chile & Colombia & Mexico \\
\hline Population & 40738000 & 195498000 & 17133000 & 46299000 & 110675000 \\
\hline Lan area $\left(\mathrm{km}^{2}\right)$ & 2780400 & 8514877 & 756102 & 2070408 & 1972550 \\
\hline $\begin{array}{l}\text { Name of the } \\
\text { initiative }\end{array}$ & $\begin{array}{l}\text { Plan Argentina } \\
\text { Conectada }\end{array}$ & $\begin{array}{l}\text { Plano } \\
\text { Nacional de } \\
\text { Banda Larga } \\
\text { (PNBL) }\end{array}$ & $\begin{array}{l}\text { Plan todo Chile } \\
\text { Comunicado }\end{array}$ & Plan Vive Digital & $\begin{array}{l}\text { Agenda Digital } \\
\mathrm{mx}\end{array}$ \\
\hline $\begin{array}{l}\text { Implementation } \\
\text { period }\end{array}$ & 2011-2015 & $2010-2014$ & $2010-2012$ & $2010-2014$ & $2012-2015$ \\
\hline $\begin{array}{l}\text { Population } \\
\text { objective }\end{array}$ & $\begin{array}{l}97 \% \text { of the total } \\
\text { population }\end{array}$ & $\begin{array}{l}89 \% \text { of } \\
\text { the total } \\
\text { population }\end{array}$ & $\begin{array}{l}90 \% \text { of the rural } \\
\text { population ( } 3 \text { million) }\end{array}$ & $90 \%$ & Not specified \\
\hline $\begin{array}{l}\text { Geographical } \\
\text { objective }\end{array}$ & $\begin{array}{l}100 \% \text { de of } \\
\text { localities } \\
(9,400 \\
\text { localities })\end{array}$ & $\begin{array}{l}76 \% \text { of } \\
\text { municipalities }\end{array}$ & 1474 rural localities & $\begin{array}{l}62 \% \text { of } \\
\text { municipalities }\end{array}$ & Not specified \\
\hline $\begin{array}{l}\text { State and } \\
\text { small- and } \\
\text { medium-sized } \\
\text { enterprise } \\
\text { connectivity } \\
\text { objectives }\end{array}$ & $\begin{array}{l}100 \% \text { of public } \\
\text { schools and } \\
\text { government } \\
\text { offices } \\
\text { connected. }\end{array}$ & $\begin{array}{l}100 \% \text { of } \\
\text { schools, } \\
\text { health-care } \\
\text { centres, } \\
\text { libraries } \\
\text { and local } \\
\text { governments } \\
\text { connected }\end{array}$ & $\begin{array}{l}2133 \text { schools, } 1108 \\
\text { day-care centres, } \\
534 \text { health-care } \\
\text { centres connected }\end{array}$ & $\begin{array}{l}100 \% \text { of health- } \\
\text { care centres and } \\
\text { public schools } \\
\text { connected; } 50 \% \\
\text { of small and } \\
\text { medium-sized } \\
\text { enterprises } \\
\text { covered }\end{array}$ & $\begin{array}{l}100 \% \text { of } \\
\text { schools, public } \\
\text { libraries and } \\
\text { health-care } \\
\text { centres and } \\
\text { offices of the } \\
\text { three levels of } \\
\text { government }\end{array}$ \\
\hline $\begin{array}{l}\text { Price and/ } \\
\text { or quality } \\
\text { objectives }\end{array}$ & 10Mbps. & $\begin{array}{l}1 \text { Mbps at } \\
\text { US\$ } 20 \text { per } \\
\text { month. }\end{array}$ & $\begin{array}{l}1 \mathrm{Mbps} \text { at US\$ } 30 \\
\text { per month }\end{array}$ & $1 \mathrm{Mbps}$ & Not specified \\
\hline $\begin{array}{l}\text { Fiscal } \\
\text { incentives }\end{array}$ & $\begin{array}{l}\text { Incentives for } \\
\text { local Internet } \\
\text { service } \\
\text { providers as } \\
\text { yet unspecified }\end{array}$ & $\begin{array}{l}\text { No Universal } \\
\text { Service Fund } \\
\text { obligations } \\
\text { for small/ } \\
\text { medium- } \\
\text { sized Internet } \\
\text { service } \\
\text { providers }\end{array}$ & Not included & $\begin{array}{l}\text { Reductions } \\
\text { in tariffs on } \\
\text { imported } \\
\text { equipment, } \\
\text { VAT exemption } \\
\text { on broadband } \\
\text { services for } \\
\text { low-income } \\
\text { population } \\
\text { segments }\end{array}$ & Not included \\
\hline $\begin{array}{l}\text { Total public } \\
\text { investment }\end{array}$ & US $\$ 1.8$ billion & $\begin{array}{l}\text { US } \$ 3.25 \\
\text { billion }\end{array}$ & US\$ 45 million & US\$ 225 billion & Not specified \\
\hline $\begin{array}{l}\text { Total } \\
\text { investment per } \\
\text { capita }\end{array}$ & US $\$ 44.2$ & US\$ 16.6 & US\$ 2.6 & US $\$ 48.6$ & Not specified \\
\hline
\end{tabular}


Table VII.A.1 (concluded)

\begin{tabular}{|c|c|c|c|c|c|}
\hline & Argentina & Brazil & Chile & Colombia & Mexico \\
\hline $\begin{array}{l}\text { Source of } \\
\text { public funding }\end{array}$ & $\begin{array}{l}\text { General } \\
\text { national } \\
\text { government } \\
\text { funds }\end{array}$ & $\begin{array}{l}\text { General } \\
\text { national } \\
\text { government } \\
\text { funds }\end{array}$ & $\begin{array}{l}50 \% \text { regional } \\
\text { governments, } 50 \% \\
\text { Telecommunications } \\
\text { Development Fund } \\
\text { (FDT), private sector. }\end{array}$ & $\begin{array}{l}\text { General national } \\
\text { government } \\
\text { funds }\end{array}$ & $\begin{array}{l}\text { General } \\
\text { national } \\
\text { government } \\
\text { funds, private } \\
\text { sector }\end{array}$ \\
\hline $\begin{array}{l}\text { Public } \\
\text { investment } \\
\text { in network } \\
\text { infrastructure }\end{array}$ & $\begin{array}{l}\text { US\$ } 840 \\
\text { million }\end{array}$ & US $\$ 1.8$ billion & $\begin{array}{l}\text { US } \$ 45 \text { million (Entel } \\
\text { to contribute about } \\
\text { another US } \$ 55 \\
\text { million). }\end{array}$ & $\begin{array}{l}\text { US } \$ 230 \text { million } \\
\text { (Colombia } \\
\text { Provisional Fibre } \\
\text { Optic Union to } \\
\text { contribute about } \\
\text { another US\$ } 370 \\
\text { million). }\end{array}$ & Not specified \\
\hline $\begin{array}{l}\text { Per capita } \\
\text { public } \\
\text { investment } \\
\text { in network } \\
\text { infrastructure }\end{array}$ & US\$ 21 & US\$ 9.2 & US\$ 2.6 & US\$ 5 & Not specified \\
\hline $\begin{array}{l}\text { Network } \\
\text { characteristics }\end{array}$ & $\begin{array}{l}58000 \mathrm{~km} \\
\text { of national/ } \\
\text { provincial fibre } \\
\text { optic network. }\end{array}$ & $\begin{array}{l}35000 \mathrm{~km} \\
\text { of national/ } \\
\text { provincial } \\
\text { fibre optic } \\
\text { network }\end{array}$ & $\begin{array}{l}12 \text { optical nodes and } \\
\text { mobile broadband for } \\
\text { the last mile }\end{array}$ & $\begin{array}{l}17000 \mathrm{~km} \\
\text { of national/ } \\
\text { provincial fibre } \\
\text { optic network }\end{array}$ & $\begin{array}{l}22000 \mathrm{~km} \\
\text { of national/ } \\
\text { provincial fibre } \\
\text { optic network }\end{array}$ \\
\hline $\begin{array}{l}\text { Ownership and } \\
\text { management } \\
\text { of the network }\end{array}$ & $\begin{array}{l}\text { AR-SAT (public } \\
\text { operator) }\end{array}$ & $\begin{array}{l}\text { Telebras } \\
\text { (public } \\
\text { operator) }\end{array}$ & $\begin{array}{l}\text { Entel (private } \\
\text { operator). }\end{array}$ & $\begin{array}{l}\text { Colombia } \\
\text { Provisional } \\
\text { Fibre Optic } \\
\text { Union (private } \\
\text { operator). }\end{array}$ & $\begin{array}{l}\text { Telefónica/ } \\
\text { Televisa } \\
\text { consortium } \\
\text { (private } \\
\text { operator). }\end{array}$ \\
\hline
\end{tabular}

Source: Argentina Conectada (2011), Colombia Plan Vive Digital (2011), Plano Nacional de Banda Larga (PNBL) (2010), Todo Chile Conectado (2010), Agenda Digital.mx (2012). 



\section{Chapter VIII \\ Broadband and industrial policy: the Korean experience}

Daewon Choi ${ }^{1}$

\section{A. Broadband industrial policy: definition and scope}

The industrial policy debate has advanced considerably in recent years. The focus has been on the dilemma between accepting horizontal policies based on World Trade Organization (WTO) rules and regulatory framework, and the possibility of developing a space for sectoral policies. This discussion is inseparable from another debate unfolding at the same time on policy instruments and how effective they are.

Experts do not agree on the costs and benefits of industrial policy. At the national level, some hold that the newly industrialized economies used industrial policy effectively in the early phases of industrialization from 1960 to 1980. Others argue that these instruments, including direct subsidies, have undermined the general efficiency of the economy. Similarly, there are those who hold that during the liberalization and privatization process of the 1980s and 1990s, Latin America eliminated the policy instruments that caused distortions in industrialization

Consultant to the Economic Commission for Latin America and the Caribbean (ECLAC) and Vice President of the Korean Association of Trade and Industry Studies. 
through import substitution; others contend that the structural barriers to industrial development in the region have not been lowered.

The conventional debate on industrial policy came to a head in the mid-1990s. With the establishment of the WTO in 1995, the multilateral trading system reached an agreement prohibiting the use of direct subsidies as an industrial policy tool. This was a decisive moment for the global industrial policy framework in that it created a system based on guidelines that included a dispute settlement mechanism for regulating the principles of most-favoured-nation and national treatment. Since then, government intervention by means of financial support to promote export competitiveness at the sectoral level has been subject to close multilateral examination under the WTO Agreement on Subsidies and Countervailing Measures and other standards.

While this institutionalized horizontal industrial policies, it did not completely mark the end of sector-based industrial policy. In particular, academic circles in favour of trade policy must still answer the following questions. What industrial policy instruments are available following the establishment of a system based on the WTO rules and regulatory framework? Is a targeted policy actionable under the WTO Agreement on Subsidies and Countervailing Measures? Is there room for industrial policy over and above the approved instruments, such as support for technological research and development $(R \& D)$ or regional development?

Experts are divided with regard to how much the horizontal approach determines industrial policy space in the framework of the system based on WTO rules. While some hold that the multilateral trade system has created a global environment with equal conditions favouring horizontal policies, others argue that compliance with WTO rules does not preclude a policy space in which national economic policy can effectively give rise to targeted industrial policy.

This context has informed most of the academic debate on industrial policy in the trade policy arena, constraining the various currents of thought and their contributions over the past decade. While this trade policy context will most likely continue to frame the industrial policy debate in the immediate future, globalization is now being driven by revolutionary advances in information and communications technologies (ICTs). The WTO multilateral trading system was conceived during the Uruguay Round (from the mid-1980s to the mid-1990s), when the Internet had not yet emerged as a trade tool.

Consequently, the WTO agreements - the General Agreement on Tariffs and Trade (GATT), the General Agreement on Trade in Services (GATS) and the Agreement on Trade-Related Aspects of Intellectual 
Property Rights (TRIPS) - were drafted without taking into account the trade environment that the Internet would later create. As a result, the Basic Telecommunications Agreement and the Information Technology Agreement (ITA), two important WTO guidelines on ICTs, were addressed only as a postscript. In subsequent decades, especially in the 2000s, the impact of the Internet increased so much that devices based on Internet protocol (IP) now outnumber the world population. In the 2010s, IP-based ICTs have become one of the main channels of trade activity around the world.

This has created a vacuum in the debate on industrial policy in the digital era, which translates into the following questions. Can the territory-based trade policy system, tariffs and technical barriers to trade be effectively applied to the new industrial and technological policy framework that is taking shape? Are the devices, platforms, contents and interconnected networks blurring the harmonized classification systems for goods and services? Will this new hyperconnected world ushered in by broadband respond consistently to the conventional trade policy regime of the past decade? Will IP-based broadband services, operating at speeds of gigabits per second (Gbps) or terabits per second (Tbps), displace the dispute settlement model that depends on rules of origin for digital goods, providing faster resolution? If a set of digital goods and broadband services (such as geolocation services) account for more than $30 \%$ of the value of an automobile, can a code against unfair competition and the WTO Agreement on Subsidies and Countervailing Measures effectively safeguard equal conditions in the multilateral trade system?

This chapter makes a contribution to the debate on industrial policy from the perspective of the development of broadband and the industrial policy associated with that development. It moves the debate rooted in conventional trade policy towards one on the new industrial policy taking into account the various factors outlined below.

First, while the dichotomy between horizontal and sectoral industrial policies is theoretically valid, there is an increasingly fuzzy area of industrial policy that is so broad that it is hard to define as either horizontal or sectoral. For example, the development of broadband networks serves as a horizontal cornerstone for the economy, but the rules, standards, and regulations are based on a sectoral focus that cannot be classified as horizontal.

Second, there is an area of industrial policy for broadband development that could be defined as a cutting-edge in terms of institutional arrangements and instruments. Through a combination of legal and technical barriers, among others, it is possible to promote the development of the cutting edge of a given industry without using direct 
subsidies or choosing winners. For example, an R\&D subsidy to achieve fourth-generation (4G) standards is permissible at the horizontal level, while the creation of a specific long-term evolution (LTE) standard for commercialization is clearly sectoral but nevertheless compatible with the WTO Agreement on Technical Barriers to Trade (TBT).

Third, areas with an R\&D-based industrial policy show a strong correlation between the targeted support of these activities in priority sectors and the type of instrument used. For example, the choice of highpriority sectors to receive government support through administrative and regulatory incentives can make for more efficient $R \& D$ resource allocation in the pre-commercialization phase. This was the case with code division multiple access (CDMA) technology in the Republic of Korea, and the process is being replicated in China, for example, with time-division longterm evolution (TD-LTE) technology.

Fourth, there is an increasing convergence in production, services and consumption that transcends any single sector, industry or firm, making a definitive classification irrelevant in terms of sanctions based on price distortions in the multilateral trade system. Many products comprising platform devices for broadband development cannot be classified exclusively as goods or services, because they can serve as components but function as services. For example, customs duties on the cross-border movement of a DVD as a physical unit can be uniform or nonexistent, due to an exemption in accordance with the WTO Information Technology Agreement (ITA), but in cyberspace the tax rate would depend on the value generated in the downloaded content. Another example is a cross-subsidy for broadband infrastructure and related devices, which can reduce the cost of using convergent services for businesses with an eye to increasing the competitiveness of digital services exports.

Finally, because the level of national production is increasingly tied to the global production supply chains, it can be hard to define the boundary between rules of origin and product value. SMS messages and voice transmissions may have little commercial value, but when gigabytes and terabytes of data are involved there can be difficulties in managing large volumes of data and cloud computing as part of industrial policy. This often happens with Internet protocol, which obstructs national jurisdiction for maintaining a protection system. The case of Google in China, which involves a certain degree of broadband-based industrial policy, is a good example. At the same time, it is difficult to configure the IP ecosystem within the set of products governed at the national level, given that global interoperability is critical for hyperconnectivity in the future.

For these reasons, it is urgent to review the role of broadbandrelated services and products in industrial and technological development, 
outside conventional trade policy. This is particularly necessary at a time when global actors in the field of networks, devices, platforms and content are moving to a new generation of regulatory policies and infrastructure. In a highly connective digital world, the difference between the flow of Kbps and gigabyte storage may be only a technical issue, but in the physical world of convergence, the flow of gigadata and terabyte cloud storage can give rise to a different ecosystem affecting all the modules along the production and distribution chain.

In this chapter, broadband and hyperconnectivity are considered essential to the new industrial policy, termed broadband industrial policy, insofar as they can represent different facets of trade policy. The following typology is useful for analysing broadband industrial policy in the context of the WTO-based multilateral trade system: sectoral industrial policy in the period before the WTO (pre-1995: first generation-1G); horizontal industrial policy in the WTO (1995-2005: second generation-2G); targeted cutting-edge policy in the WTO (2005-2010: third generation-3G); and generative convergence policy in the WTO (2010-2020: fourth and fifth generations-4G-5G). Diagram VIII.1 illustrates the analytical framework for broadband industrial policy.

The transition from the first to the second generation took almost a decade, but the transition to the third generation took just five years. The OECD economies are expected to move from a $3 \mathrm{G}$ environment to a $4 \mathrm{G}$ era in just a few years, which will accelerate both hyperconnectivity and the corresponding digital divide with developing countries.

\section{Diagram VIII.1}

ANALYTICAL FRAMEWORK FOR BROADBAND INDUSTRIAL POLICY

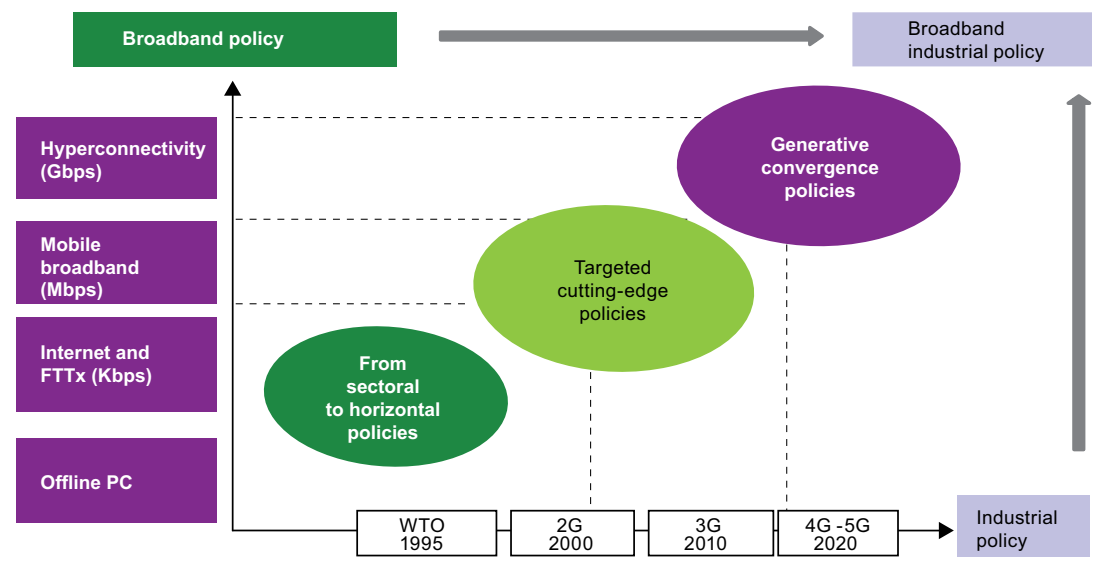

Source: Prepared by the author. 


\section{Sectoral industrial policy in the period before the WTO (pre-1995: 1G)}

Before the establishment of the WTO, many countries (most notably the newly industrialized economies) implemented sectoral industrial policies often based on targeted subsidies. This coincided with the first generation of ICTs, in which most communications went through fixedline telephones and the commercialization of mobile technology was still in its infancy. It was in this period that the Republic of Korea laid the groundwork for the development of CDMA technology based on government support for R\&D. The government, research centres and businesses worked together to commercialize this technology in the period before the WTO.

\section{Horizontal industrial policy in the WTO (1995-2005: 2G)}

With the creation of the WTO in 1995, especially in the context of the Agreement on Subsidies and Countervailing Measures, direct financial subsidies to selected industries and firms were prohibited. Violation of this rule was subject to WTO regulations in the framework of the dispute settlement mechanism. This provision led member countries to use subsidies less frequently and more indirectly. In this second-generation phase, CDMA technology became commercially viable even without government subsidies, and an alliance was forged between the R\&D centres and the private sector responsible for commercialization. Early 2G$3 \mathrm{G}$ was based on the standardization of mobile CDMA technology.

\section{Targeted cutting-edge policy in the WTO (2005-2010: 3G)}

Restrictions on the use of subsidies left governments with few industrial policy instruments during this phase. Nevertheless, a few countries somewhat selectively promoted national industrial development so as to foster key cutting-edge technologies. Instead of subsidies, the Korean government implemented a major policy for deployment of high-speed landline broadband and the standardization of wireless broadband (WiBro) for 3G-3.5G mobile technology. While the development of high-speed broadband was undeniably successful, the promotion of 3.5G WiBro mobile technology did not produce the desired results in the national and international markets. The government's targeted cutting-edge approach pushed the limits of innovation to a new level at a time when only a few countries had reached the third-generation technological frontier. 


\section{Generative convergence policy in the WTO (2010-2020: 4G-5G)}

During this period, government policy for industrial and technological development began to converge towards an intensive use of digital data and ICTs to produce a hybrid industry with embedded data capacity, which in turn produces a new form of connection with nearby industries. This period saw the global financial crisis and the stalling of the WTO Doha Round; this created a new policy space for industrial development, especially in the BRIC countries (Brazil, Russia, India and China). The main features of this period would be, on the one hand, the use of government support to protect domestic industry and, on the other, a convergent policy approach for the main industries - including automobiles, biotechnology, mechatronics, shipbuilding and petrochemicals - to build a new platform for big-data industry, which in turn feeds back into these activities. Since many countries are loath to undo the achievements of the WTO, the new protectionist policy will increasingly be channelled through a new generative industrial policy in order to avoid a deadlock in the multilateral world trading system. In this sense, two of the main components of industrial policy will be, first, large-scale deployment of ultra-fast broadband and giga-level mobile broadband such as LTE and, second, an industrial policy based on renewable energies to establish an emissions trading scheme. Cloud computing technology will take the world trading system to a new frontier, which will begin with $4 \mathrm{G}-5 \mathrm{G}$ mobile technologies. This period corresponds to broadband industrial policy.

Unlike the debate on conventional industrial policy, broadband industrial policy moves away from the dichotomy between horizontal policy and targeted policy and is more aligned with a cutting-edge policy. In addition, when targeted R\&D support is combined with technical standards, regulations and systems integration for production, distribution and consumption, it becomes a facet of industrial policy. For example, while a cloud-computing-based service with a direct link to smart devices can produce significant value, the rules of origin on value production might not be the same as the distinction between onshore and offshore production of physical goods.

To clarify the discussion of broadband industrial policy, the following assumptions shall be used for analytical purposes. First, this policy differs from conventional industrial policy in that it exists in a connected world. Some analysts predict that by 2030 the number of connected devices and artefacts will be three times the world population, which underscores the impact of the connected world on the global economy. According to this position, broadband infrastructure in not 
just a functional tool for connectivity but also a means of applying a new industrial policy.

Second, broadband industrial policy differs from conventional industrial policy in that the generalized effect of the convergence of peopleto-people or peer-to-peer (P2P) connections, machine-to-machine (M2M) connections and people-to-machine (P2M) connections will create new economic opportunities in which the promotion of a unique device and an exclusive platform may not guarantee national industry competitiveness.

Third, unlike technical trade barriers aimed at boosting national competitiveness, the hyperconnected world requires a totally new ecosystem in which the de facto standards coexist with de jure ones and where the national standard in a large market can lay the groundwork for a de facto one, as in the case of the TD-LTE standard in China, contrary to conventional industrial policy.

Fourth, the growing importance of the electronic commerce system will require a complementary platform for interoperability with the multilateral trading system. For example, the WTO General Agreement on Trade in Services seeks to reflect an age of electronic data exchange in which large volumes of data and cloud computing, among other developments, are changing the concept of service delivery and could require a different industrial policy instrument. Just as the spread of mobile 2G services led to the Basic Telecommunications Agreement and the spread of the Internet resulted in the Information Technology Agreement within the framework of the WTO, the consolidation of the connected world could create the need for a different global agreement to address emerging industrial policy issues.

Finally, the digital divide will, in the future, open a broadband industrial policy gap that will cause countries lacking such a policy to lag behind in terms of economic development and growth opportunities. The conventional analysis of industrial policy in Latin America and East Asia in 1960-1980 centred on the difference between import-substitution industrialization and export-oriented industrialization. Since 1990 the major difference has been the scope of the industrial policy space. Similarly, the decisive difference in the coming decade will revolve around economic development grounded in the existence - or lack thereof- of a broadband industrial policy.

This chapter analyses broadband development in the Republic of Korea from the perspective of broadband industrial policy. Following this introduction, section $\mathrm{B}$ describes the dynamics and structure of the broadband market. Section $C$ tracks the industrial policy space in the 1990s and 2000s in the context of broadband industrial policy. 
Section D examines the challenges presented by the development of hyperconnectivity and outlines the Giga Korea Plan 2020 for facing these challenges by fine-tuning broadband industrial policy. The final section sets out conclusions and useful lessons for Latin America.

\section{B. Broadband structure and dynamics}

\section{Expansion and mass adoption}

This is one of the main requirements for developing markets, attracting investment, adopting new technologies and ensuring pluralism in services and content. This section provides statistical data on broadband development trends in the Republic of Korea. This country ranks fifth among the OECD economies in fixed-line broadband subscriptions (wired) per 100 inhabitants, with $35 \%$ of the population connected to broadband services (see figure VIII.1). By type of technology, fibre optic cable and local area network (LAN) connectivity top the list, with $20 \%$ of the population connected - five to ten times more than the OECD average. The fact that fibre optic connectivity in the Republic of Korea is double that of Sweden means that the former leads the world in terms of broadband connection speed.

Figure VIII.1

OECD: FIXED-LINE BROADBAND SUBSCRIPTIONS (WIRED) PER 100 INHABITANTS, BY TECHNOLOGY, DECEMBER 2011

(Percentages)

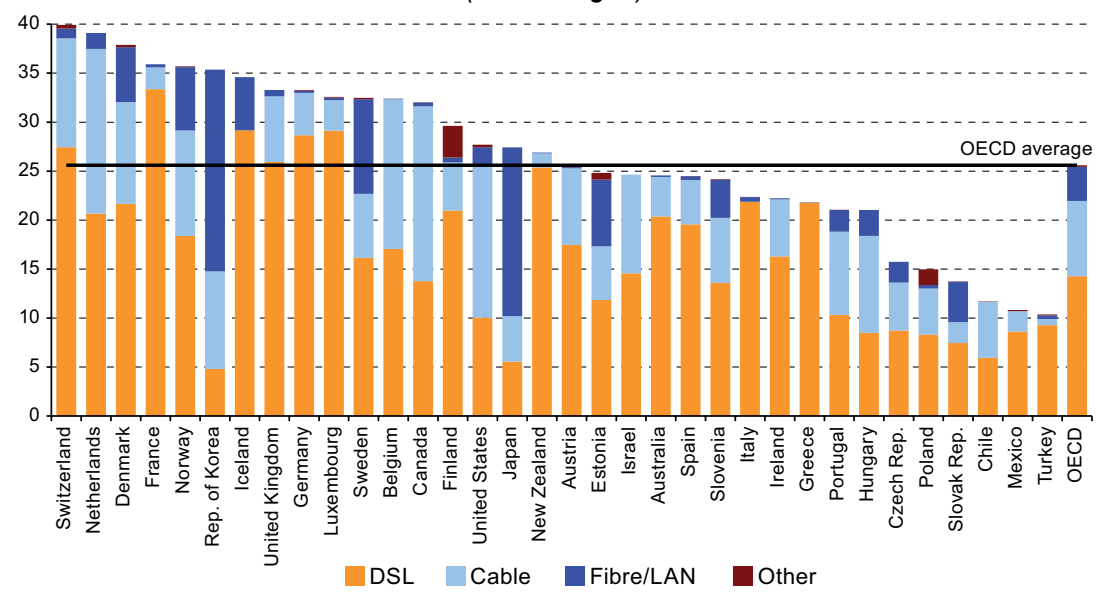

Source: Organisation for Economic Cooperation and Development (OECD). 
Another important factor is that high-speed broadband in the Republic of Korea began in the pioneering phase of broadband deployment in the early 2000s. Figure VIII.2 shows how far in the lead the Republic of Korea was in disseminating broadband between 2001 and 2005. In that period, its broadband policy differed from the OECD norm: whereas average broadband connectivity in the OECD was largely market-driven, in the Republic of Korea it was driven by government policy. Case studies of the Korean experience need to take this factor into account.

Figure VIII.2

SELECTED OECD COUNTRIES: FIXED BROADBAND PENETRATION (Percentages)

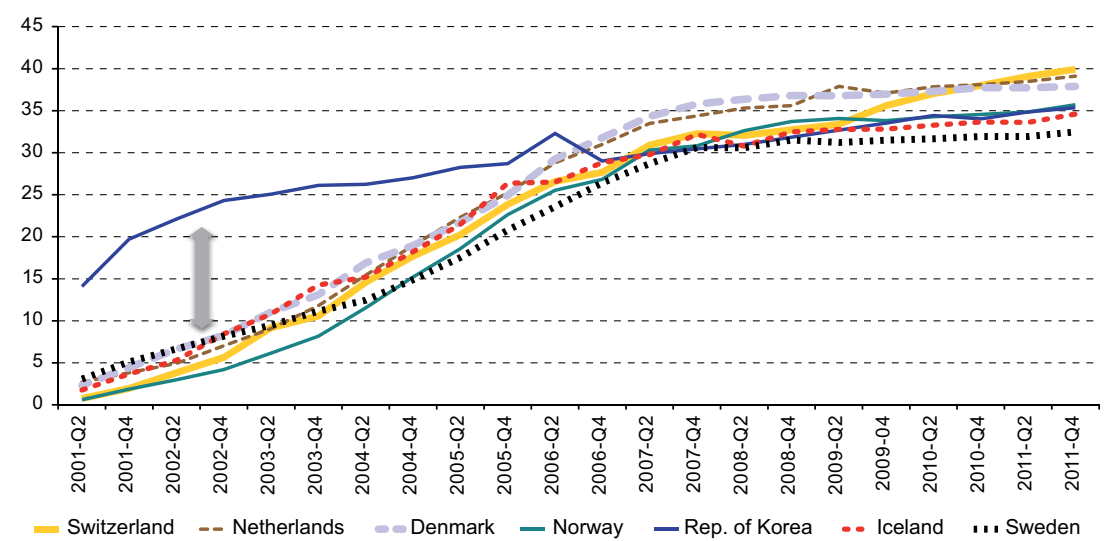

Source: Organisation for Economic Cooperation and Development (OECD).

The extraordinary development of broadband in the Republic of Korea is also reflected in the ratio between the penetration rate (per 100 inhabitants) and GDP per capita (in PPP dollars). There is a marked correlation (on the order of $65 \%$ ) between these variables in the OECD economies. As shown in figure VIII.3, which gives the ratio between the two variables for 2011, the Republic of Korea is clearly in the lead and only Estonia is close behind.

With regard to relative connection cost and quality, figure VIII.4 shows that the Republic of Korea offers the most affordable broadband services in the world, at a minimum price of 0.21 PPP dollars per Mbps and a maximum price of 1.93 PPP dollars per Mbps in September 2011. In other countries such as Germany and Chile, the same service costs 2 to 20 times more. Sweden offers a more affordable service at one extreme, but the maximum rate is at least ten times greater. The ramifications for industrial policy are substantial given the impact of broadband on growth, employment and productivity (see the chapter by Raúl Katz herein). 
Figure VIII.3

OECD: RATIO BETWEEN BROADBAND PENETRATION PER 100 INHABITANTS AND GDP PER CAPITA IN PPP DOLLARS, 2011

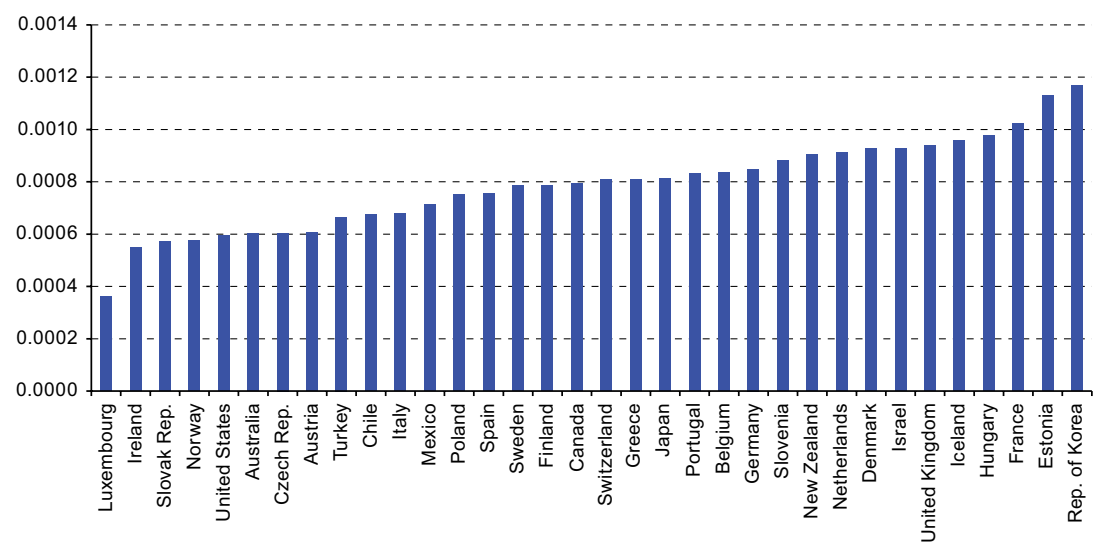

Source: Organisation for Economic Cooperation and Development (OECD).

Note: The simple correlation between the variables is 0.65 . The penetration rate is for December 2011.

Figure VIII.4

BROADBAND RATES PER MBPS OF ADVERTISED SPEED, SEPTEMBER 2011

(PPP dollars)

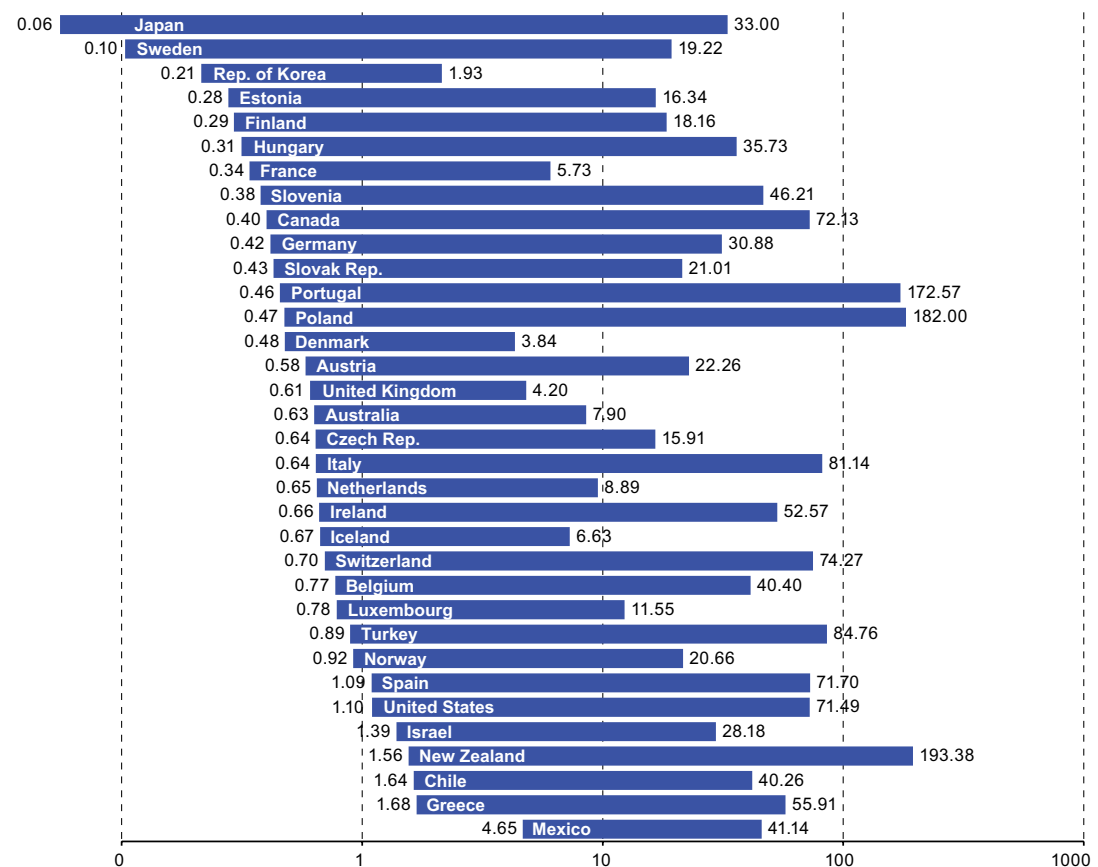

Source: Organisation for Economic Cooperation and Development (OECD). 
The Republic of Korea ranks first in the world in broadband use by the private sector and service companies: almost 100\% use IP services for management and transaction purposes (see figure VIII.5). This is an advantage that is recognized and valued by businesses and helps build support for industrial policy in favour of broadband-based products and services.

\section{Figure VIII.5}

BUSINESS ADOPTION OF BROADBAND, 2010 OR LATEST AVAILABLE YEAR (Percentage of firms with 10 employees or more)

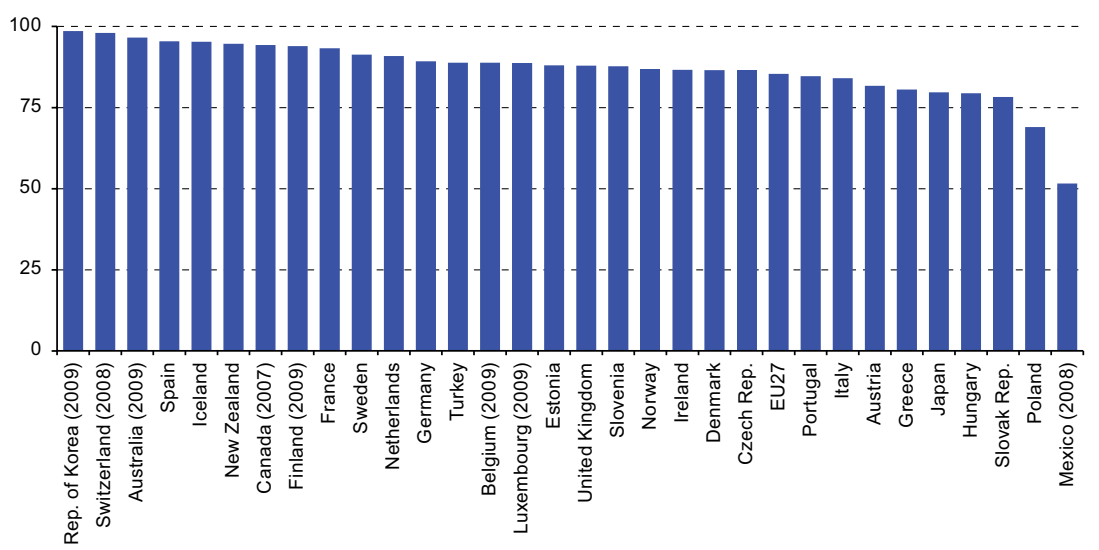

Source: Organisation for Economic Cooperation and Development (OECD).

Note: For Japan, firms with 100 employees or more. For Mexico, firms with 20 employees or more. For New Zealand, firms with 6 employees or more and sales in excess of US\$30,000. For Switzerland, firms with 5 employees or more and a connection speed of 144 Kilobits per second or faster (mobile and fixed).

\section{Drivers of mass penetration}

Several studies explore the drivers of high-speed broadband infrastructure penetration. The following analysis focuses on studies covering 20 to 25 OECD countries because these countries account for most of the broadband deployed in the world. These studies, however, do not capture the factors driving broadband penetration in the BRICs, which will be equally important in the future due to the size of their digital economies.

The main factors explaining the degree of high-speed broadband deployment include price of service, transmission speed, population density (urban areas), GDP per capita, average user age, competition among platforms, unbundling regulations, other government regulations and social and cultural factors.

The factors behind successful high-speed broadband infrastructure deployment are the same in most OECD economies. In table VIII.1, this 
is illustrated with the blue circle around price of service, transmission speed and GDP per capita, among other variables. These cost factors are positively correlated (or negatively correlated in the case of price) with broadband development.

Table VIII.1

DRIVERS OF BROADBAND DEVELOPMENT IN THE OECD AND THE REPUBLIC OF KOREA

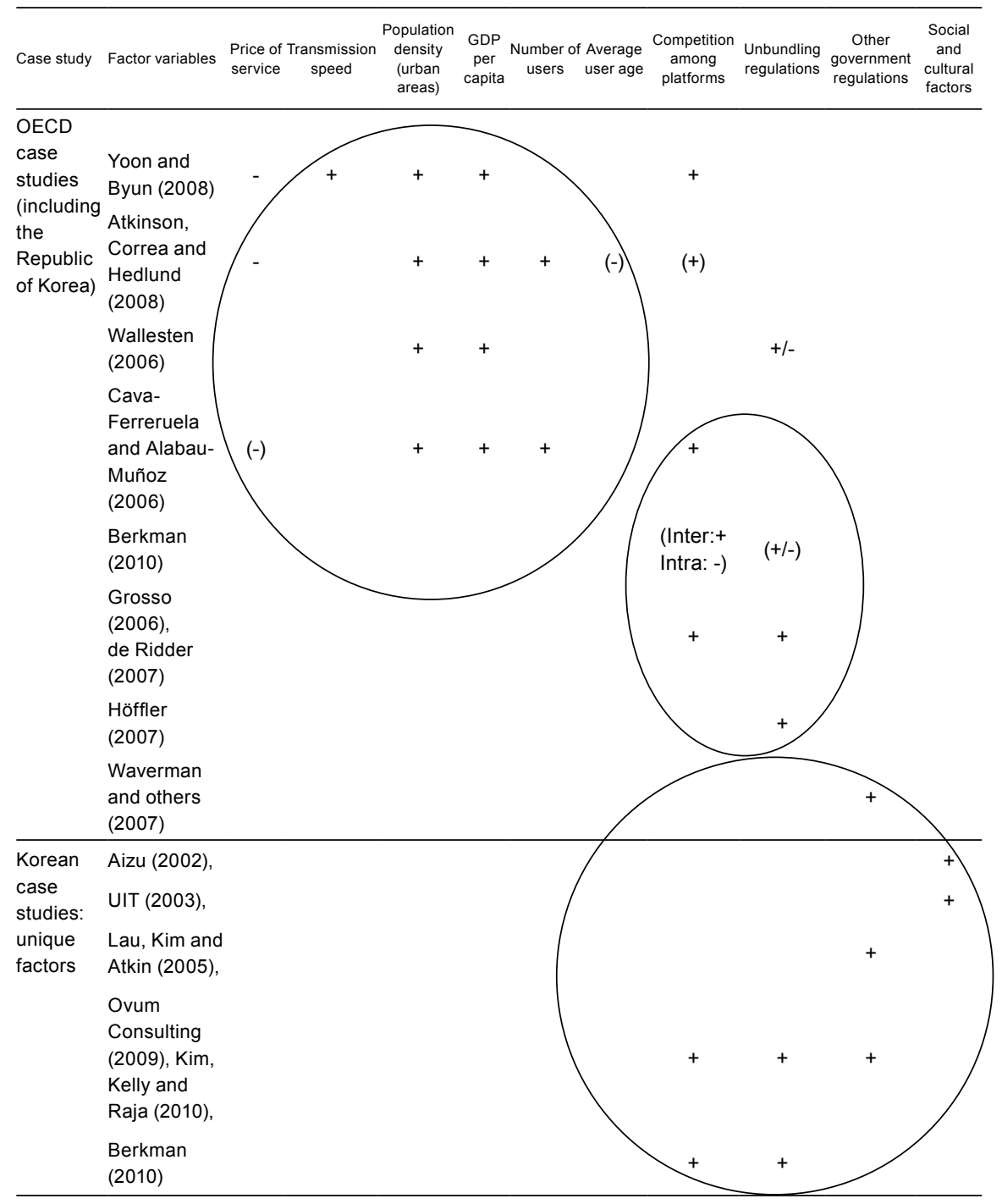

Source: Prepared by the author. 
The cost factor is largely related to competition policy: the degree of competition that it spurs depends on government regulations and policy. Therefore, the government plays a key role in establishing an appropriate regulatory environment that leads to healthy competition. This is illustrated by the green circle in table VIII.1. In the Republic of Korea, the government initially used competition among platforms to speed broadband deployment after communication services were liberalized in the mid-1990s. On achieving this objective in the 2000s, the government shifted its position to service-based competition in order to improve service quality. The authors of a number of studies agree that the government's regulatory framework is fundamental for increasing competition and managing market efficiency. Most studies find that competition among platforms is positively correlated with broadband use, while analysts such as Berkman (2010) warn of an inverse correlation with excessive competition within platforms.

In addition to these variables, several studies explore factors that can explain high-speed broadband penetration in the Republic of Korea but are not present in other countries. These studies emphasize two key factors: the government's strategic policy with a flexible regulatory framework, and the sociocultural factor. These are shown in the red circle in table VIII.1.

Most OECD governments have institutionalized broadband strategies and policies, but the speed and regularity with which the Korean government has revised its stance by designing new regulatory frameworks to respond to technological and market innovation are fairly unusual, if not unique.

ICT laws have enjoyed bipartisan support, and the quick succession of laws and regulations helped the government respond quickly to market requirements. For example, Lau, Kim and Atkin (2005) and Ovum Consulting (2009) argue that in addition to competition among platforms and services, the government has used population dynamics and tastes and the construction industry (buildings, apartments and offices) as part of the broadband infrastructure. The certification mechanism for buildings equipped with high-speed Internet attracted new residents, served as a guarantee of quality and provided an incentive for residential and business rentals. The certification system worked very well; almost all buildings now display the "broadband certification mark" in order to attract clients.

Atkinson, Correa and Hedlund (2008) and Kim, Kelly and Raja (2010) agree that the Korean government's strategic conception and regulatory framework have been excellent. Not only has it maintained a consistent leadership position over the years, but it has applied its policy instruments flexibly. Since 1995, the government has systematically designed strategic frameworks every two years, changing its policy instruments in accordance with the prevailing demands of technological innovation and the market environment. 


\section{Market structure}

To analyse the structure of the broadband-based services market, this section describes the government policy that led to the transition from a monopoly to a duopoly, from a duopoly to three-way competition and finally to broad-based competition, including mobile virtual network operators (MVNOs).

The government encouraged competition in fixed-line telephony services in the early 2000s, which resulted in three-way competition between KT, SK and LGU+. The near-monopolistic position of KT as the incumbent supplier of fixed-line services fell from $90 \%$ in 2007 to $83 \%$ in 2011 (see figure VIII.6). Despite the policy for demonopolizing fixedline services, other private actors were not much interested in offering this class of services because most of the value added is generated in the mobile sector. According to 2012 data, the joint market share of the other two suppliers of fixed-line services was less than $15 \%$.

Figure VIII.6

FIXED-LINE TELEPHONE SUBSCRIBERS BY SERVICE PROVIDER (Per 10,000 people and in percentages)
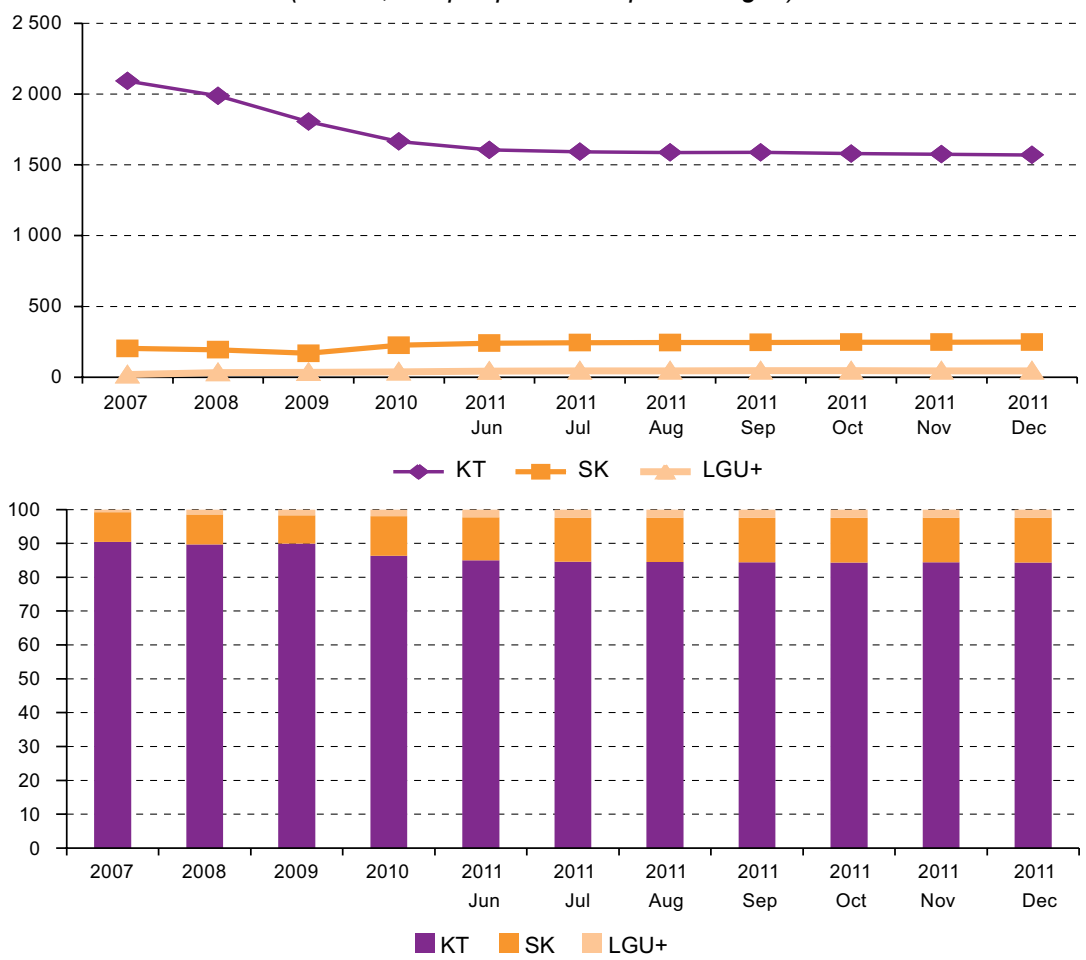

Source: Korea Information Society Development Institute (KISDI) (2012). 
Figure VIII.7 reveals an uptrend in IP-based services, with an increase in broadband that offsets the drop in fixed lines. With regard to the number of mobile service subscribers, coverage approached $100 \%$ in 2010 and exceeded $110 \%$ en 2012, with more than 30 million people using smartphone services. This means that there are three mobile phone users for every fixed-line user and that smartphones have become the cornerstone of mobile connectivity. All mobile service users are expected to be using smartphones by 2015 . Because the mobile virtual network operators currently offer VoIP free of charge, consumers have an incentive to adopt smartphone services.

Figure VIII.7

NUMBER OF SUBSCRIBERS BY SERVICE AND MOBILE TECHNOLOGY (10,000 people)
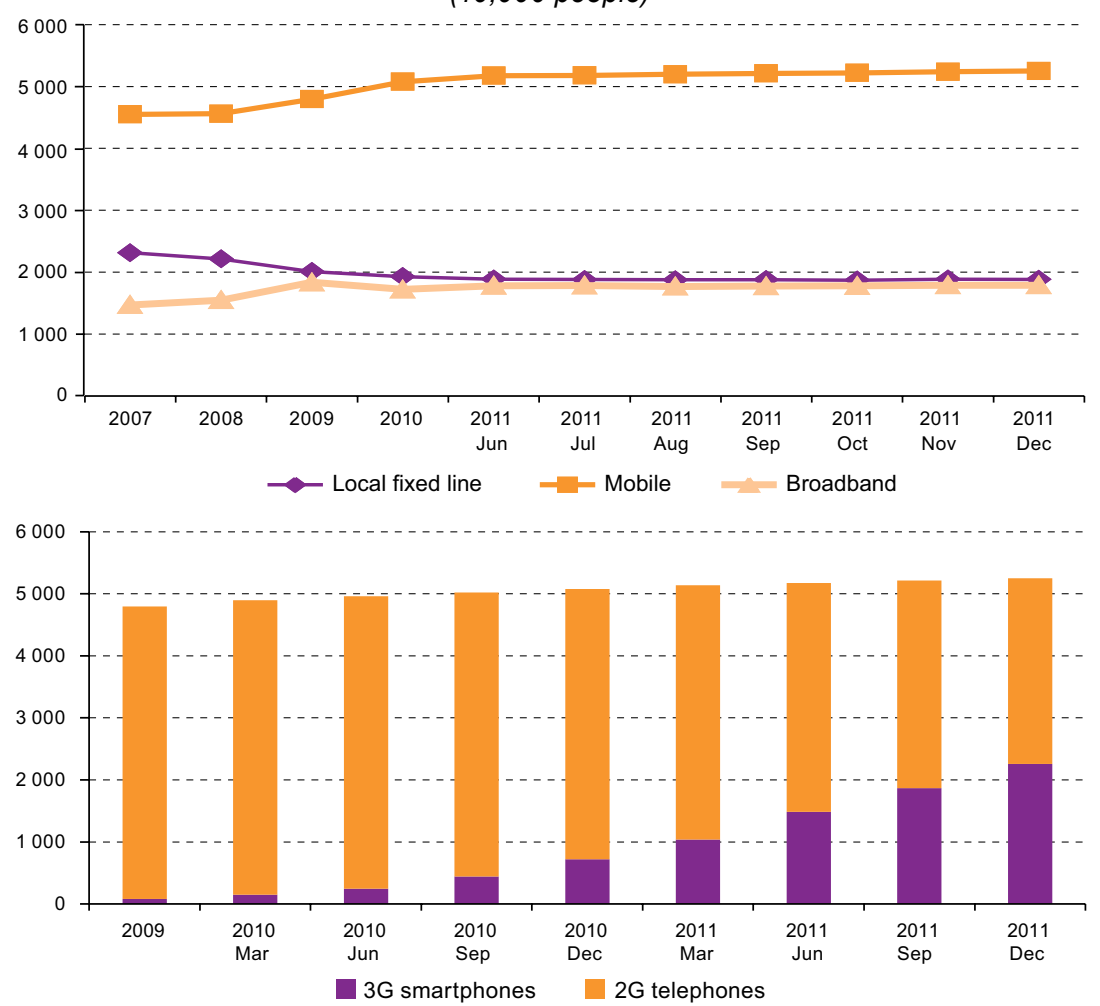

Source: Korea Information Society Development Institute (KISDI) (2012).

Among mobile service providers, SK has the largest market share, with around 27 million customers, followed by KT, with about 17 million, and LGU+, with less than 10 million (see figure VIII.8). More than half of 
all mobile service users are with SK; the rest are divided between $\mathrm{KT}$ and LGU+. LGU+ first promoted LTE-based 4G services in early 2012; SK and KT followed suit immediately. By late 2012, there was a massive transition to this type of technology. Another interesting aspect of $4 \mathrm{G}$ services is the upsurge in mobile virtual network operators, who lease the network from the incumbent provider and offer profitable, value-added services, often at a lower rate.

The hypermarket chain HomePlus, an affiliate of the British company Tesco, entered into negotiations with KT for the provision of mobile virtual network operator services, including near-field communication and automatic payment services. It is expected that within a few years, several value-added service providers will have a considerable share of the mobile virtual network operator market, with a variety of services targeting specific clients that use high-speed $4 \mathrm{G}$ connectivity.

Figure VIII.8

MOBILE SERVICE PROVIDERS: NUMBER OF SUBSCRIBERS AND MARKET SHARE (Per 10,000 people and in percentages)
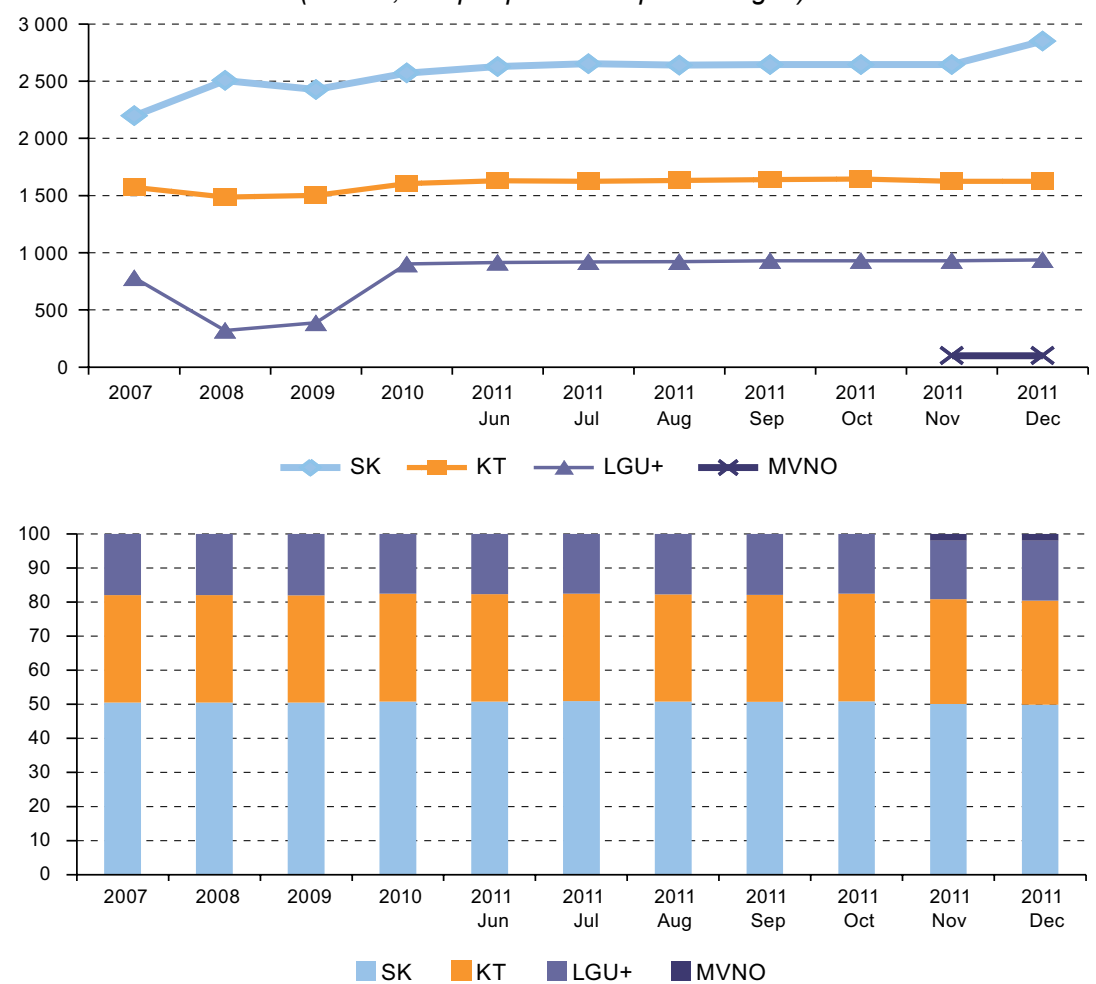

Source: Korea Information Society Development Institute (KISDI) (2012). 
In addition to mobile virtual network operators, there is a growing share of high-speed broadband connection providers (see figure VIII.9). The proportion of medium-sized broadband service providers is growing; they have overtaken SK and LGU+. In 2011, they ranked second among highspeed broadband providers and accounted for more than $20 \%$ of the market.

Figure VIII.9

HIGH-SPEED BROADBAND PROVIDERS: NUMBER OF SUBSCRIPTIONS AND MARKET SHARE

(Per 10,000 people and in percentages)
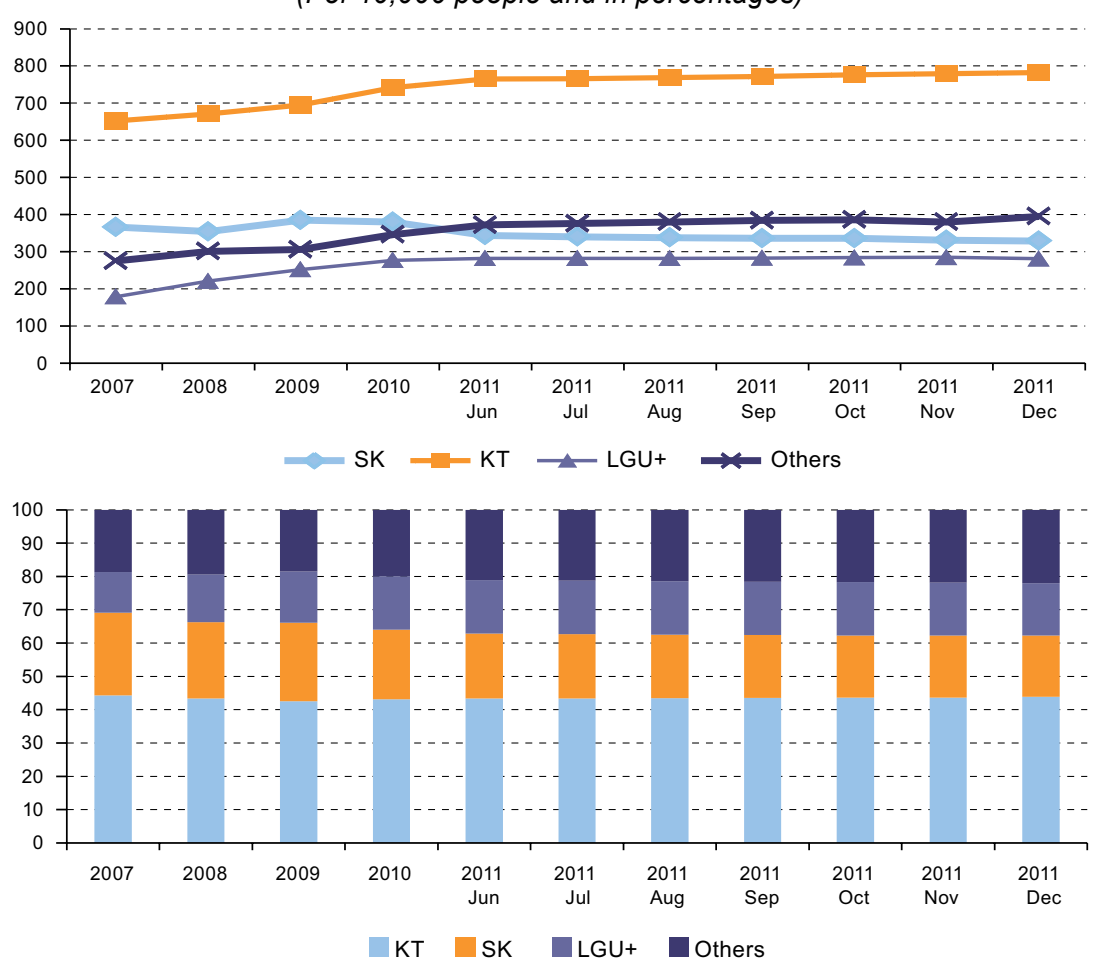

Source: Korea Information Society Development Institute (KISDI) (2012).

Since 2012, LAN services have become the primary broadband service line, followed by hybrid fibre coaxial (HFC) networks and fibre-tothe-home (FTTH). Since 2010, LAN and FTTH connections have reached a turning point in broadband development and, together with HFC networks, represent over $80 \%$ of the connection technologies in use. By contrast, the share of connections via digital subscriber lines (xDSL) has fallen to a secondary level (see figure VIII.10). By 2015, LAN and FTTH are expected to account for over $90 \%$ of broadband connectivity, keeping the country at the forefront of world high-speed broadband development. 
Figure VIII.10

HIGH-SPEED BROADBAND COVERAGE SUBSCRIBERS BY TECHNOLOGY

(Per 10,000 people and in percentages)
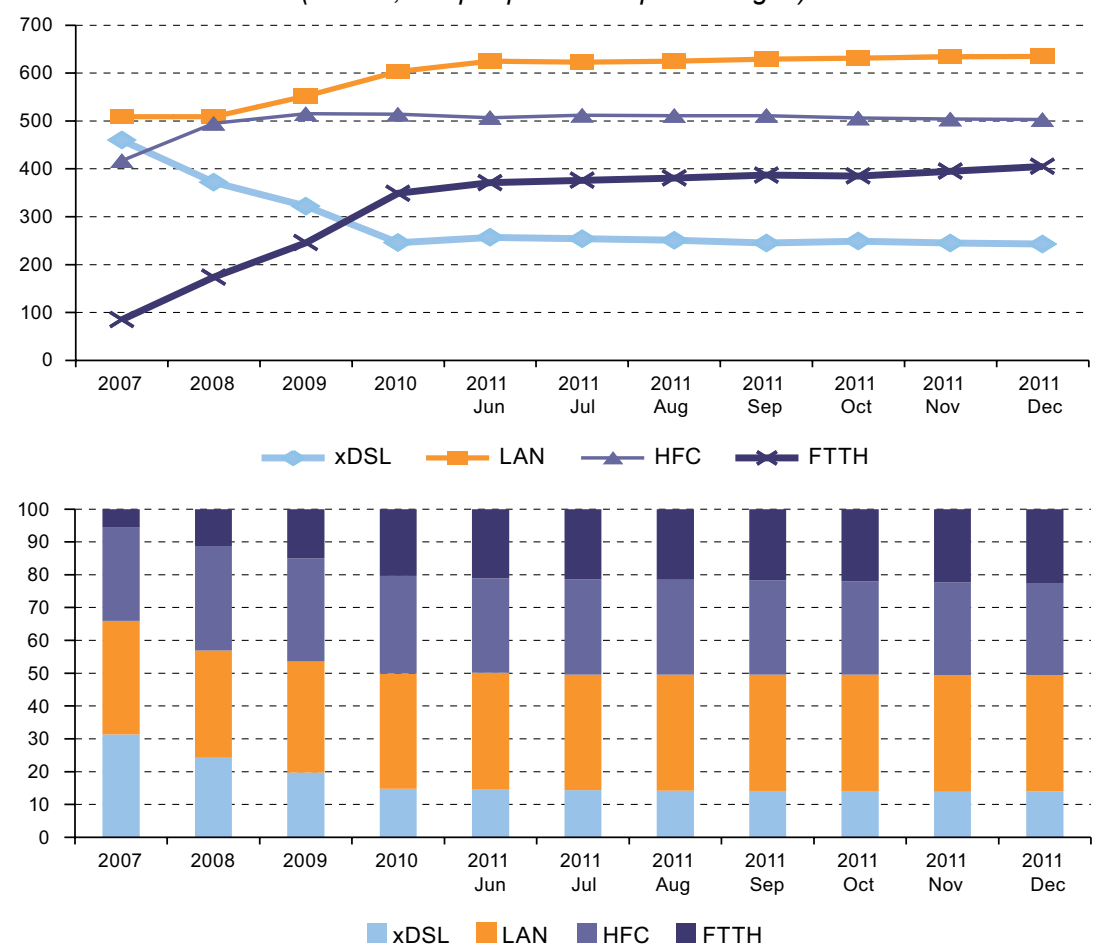

Source: Korea Information Society Development Institute (KISDI) (2012).

\section{ICT goods production and foreign trade}

There is a strong correlation between broadband development and the ICT industry in the Republic of Korea. This was deliberately fostered by government policy in order to take full advantage of the broadband infrastructure so as to create a market for the new ICTs. In general, the Korean ICT industry surged in 2005-2011, growing by $11.7 \%$ in $2005,8.7 \%$ in 2007 and $17.7 \%$ in 2011. This latter figure shows that the industry was not long affected by the 2008 global recession. The growth pattern for the ICT sector also stands in contrast to other sectors, which grew at annual rates of less than $4 \%$ in $2005-2011$.

The ICT industry's share in GDP reached $11.4 \%$ in 2011, versus $8.6 \%$ in 2005 and 9.5\% in 2007. During implementation of the e-Korea Plan (2005), ICT production was less than US\$ 33.0 billion; it surged to US $\$ 49.7$ billion under the Smart-Korea Plan (2011). According to a study of 500 companies in the sector, in the period comprising the u-Korea Plan (2007) and the 
Smart-Korea Plan (2011), income increased 49\%, the workforce grew 18\% and R\&D spending on ICT convergence rose $72 \%$. The global market share of smartphones produced in the Republic of Korea grew tenfold in just a few years, from a mere $2 \%$ in 2007 to $24 \%$ in 2011. That same year, Korea's Samsung and LG held a $57.8 \%$ share of the smartphone market in the United States. Worldwide, Samsung (21.6\%) and LG (3.4\%) led the mobile phone market in 2012, followed by Nokia (19.9\%), Apple (6.9\%) and the Chinese firms ZTE (4,3\%), Huawei (2.6\%) and TCL (2.2\%) (Chosun Daily, 21 August 2012, B3). If this trend continues, the Republic of Korea and China will account for half of all smartphone production and sales in the world in 2015.

With regard to trade, the Korean ICT industry exports US\$ 15.0 billion a month, on average, and imports US\$ 7.0 billion, maintaining a favourable trade balance of between US\$ 70.0 billion and US $\$ 80.0$ billion a year. As shown in table VIII.2, the ICT sector trade surplus was over US\$ 35.0 billion in the first half of 2010 and 2011 and stood at some US\$ 70.0 billion at the end of each year. This demonstrates the sector's solid export performance, which has contributed to a favourable trade balance in the past few decades.

Table VIII.2

ICT SECTOR TRADE BALANCE, 2010-2011

(Millions of dollars and growth rates)

\begin{tabular}{llrr}
\hline & & First half 2010 & First half 2011 \\
\hline Exports & All industries & 275340 & 221320 \\
& & $(24.4 \%)$ & $(34.3 \%)$ \\
& ICT industry & 77370 & 72810 \\
Imports & & $(6.3 \%)$ & $(38.4 \%)$ \\
& All industries & 257970 & 203790 \\
& & $(26.6 \%)$ & $(40.2 \%)$ \\
Trade balance & ICT industry & 40580 & 35290 \\
& & $(15 \%)$ & $(25.6 \%)$ \\
& All industries & 17370 & 17540 \\
\hline
\end{tabular}

Source: Ministry of Knowledge Economy (MKE) (2012).

Notes: Data for 2011 are estimates. Growth rates are in parentheses.

The main export products of the Korean ICT industry include semiconductors, display panels, cellular phones (including smartphones), television sets, computers and computer parts and home devices. In recent years, smartphone exports have posted double-digit growth. They were followed by computers and related devices (such as solid-state drives), which rivalled other major traditional export products such as 
semiconductors and computer devices. Foreign sales of memory chips contracted $15.8 \%$ in 2011; systems-on-chip (SoC) exports increased $14.8 \%$, to US\$ 1.52 billion.

In August 2012, executives at Samsung decided to convert their main semiconductor factory in the United States into a dedicated production line for systems on chips, mainly semiconductors for smartphone chips. This reflects a shift from an industrial policy based on PCs to one based on broadband. In anticipation of IP-based digital television services, 3D and smart television exports have increased, while television component exports have fallen considerably in recent years. With the slowdown of the world economy, exports of display panels also decreased by $8.2 \%$.

In recent years, the structure of the country's trading partners in the ICT sector has changed substantially. The United States still represents a large share of the market (27.4\% of exports of home devices), but sales to that country have fallen. By contrast, trade with China has expanded, and it is now twice the level of trade with the United States and Japan combined. Sales of home devices to other emerging economies grew $14 \%$, with an increase in exports to Eastern Europe (91.4\%) and Latin America (52.1\%) due to the rising demand for ICT products and related components. As part of a shared production strategy at the world level and to avoid protectionist trade barriers such as the tax on industrialized products in Brazil, some Korean companies are moving their production base to Latin America. In 2011, Brazil received its first Korean investment for the production of semiconductors, which heralds a new era of ICT production in that country and could be a first step towards overcoming the past decade's lag in attracting foreign direct investment in the sector. More foreign direct investment is expected to flow into Latin America to tap the dynamic ICT market, opening space for intra-industry trade policies with supplier countries like China, the Republic of Korea and Japan, as well as the current partners: Europe and the United States.

\section{Policy convergence}

This section describes the Republic of Korea's broadband industrial policy. It suggests that the conventional broadband development policy commonly recommended by the OECD and case studies of Korea based on conventional factors such as population density, gross domestic product (GDP) per capita and cultural trends might be insufficient for explaining the driving factors behind Korea's policy on ultra-broadband development. This study focuses instead on government measures for implementing an industrial policy aimed at using broadband not only as a consumer good but also as a means of achieving a higher standard of industrial and technological development. 
From a trade policy perspective, broadband development should be a natural outcome of market-driven competition, privatization and liberalization, which would translate into an appropriate price. This has, in fact, been the case with value-added services in second-generation mobile connectivity, which has provided connectivity access for more than half the world population. From the perspective of industrial policy, however, broadband development has been used as an intensive government policy geared towards encouraging technological innovation in order to lead the competition and adjust prices.

This section demonstrates the limits of conventional studies on broadband development, explaining why the conventional wisdom behind Korea's "broadband magic" has not been replicated in other developing countries with similar conditions in terms of population density (for example, Bangladesh), GDP per capita (Portugal or Spain), local loop unbundling (LLU) (most OECD countries), video game addiction (Brazil), digital literacy (the Netherlands) and addiction to speed (almost all countries), among other factors.

In terms of key variables, conventional studies on broadband development emphasize the trade policy perspective, whereas this study stresses the industrial policy viewpoint. This is shown in the following equation.

Box VIII.1

BROADBAND INDUSTRIAL POLICY APPROACHES

A. Broadband development policy (BDP) approach:
$\mathrm{BDP}=\mathrm{f}$ (trade policy based on connectivity, passive policy on
technological innovation, little convergence between broadband and
industry, user-based education)
$\mathrm{B}$. Broadband industrial policy (BIP) approach:
$\mathrm{BIP}=\mathrm{f}$ (industrial policy based on value added, active policy on
technological innovation, substantial convergence between broadband and
industry, producer-based education)
$\mathrm{C}$ Synthetic proposition (SP):
$\mathrm{SP}=\mathrm{f}(\mathrm{BDP}+\mathrm{BIP})$

Source: Prepared by the author.

While most of the factors considered decisive for the successful launching of world-class broadband infrastructure are well-founded, this chapter addresses a dimension of broadband-based economic industrial policy that acted as both a driving force and a drag on use of the network for deployment of new classes of industrial products and digital services. Broadband industrial policy does not necessarily generate 
the best infrastructure for the economy, so this causality should be closely examined. Nonetheless, it is proposed herein that in the case of the Republic of Korea, there is, at a minimum, a strong correlation between broadband development policy and broadband industrial policy. To support this argument, the next section reviews the literature on broadband development in the OECD countries, including the Republic of Korea.

\section{Broadband development policy}

As seen above, broadband development in the Republic of Korea was intentionally and aggressively driven by government policy. Among the key elements of that policy, the government provided a vision, a strategy and, in particular, the following master plans: the National Strategic Plan on Broadband Infrastructure (1995); the Cyber Korea 21 Plan (2000); the e-Korea Vision (2005); the u-Korea Plan (2006); and the Giga Korea Plan (2011). Table VIII.3 summarizes these plans as well as the strategic framework for promoting broadband development between 1995 and 2012.

Table VIII.3

REPUBLIC OF KOREA: MASTER PLANS AND STRATEGIC FRAMEWORKS FOR BROADBAND DEVELOPMENT

\begin{tabular}{|c|c|c|c|}
\hline Year & Strategy and main instruments & $\begin{array}{l}\text { Underlying } \\
\text { technologies }\end{array}$ & $\begin{array}{l}\text { Broadband } \\
\text { speed objective }\end{array}$ \\
\hline 1995 & $\begin{array}{l}\text { National strategic plan on } \\
\text { broadband infrastructure }\end{array}$ & $\begin{array}{l}\text { ATM, ADSL, cable } \\
\text { modem }\end{array}$ & $1 \mathrm{Mbps}$ \\
\hline 1999 & $\begin{array}{l}\text { Certification of buildings } \\
\text { equipped with broadband }\end{array}$ & & \\
\hline 1999-2002 & Cyber Korea 21 & $\begin{array}{l}\text { 2G: VDSL, FTTH, } \\
\text { FTTB, W-CDMA }\end{array}$ & $10 \mathrm{Mbps}$ \\
\hline 2001-2005 & $\begin{array}{l}\text { Third revision of the strategic } \\
\text { plan on broadband infrastructure }\end{array}$ & & \\
\hline $2002-2006$ & e-Korea Vision 2006 & $\begin{array}{l}\text { 3G: WiBro, HSDPA, } \\
\text { FTTH, FTTB }\end{array}$ & $50 \mathrm{Mbps}$ \\
\hline 2003-2007 & Broadband IT Korea Vision 2007 & & \\
\hline $2004-2010$ & u-Sensor Network (USN) Plan & & \\
\hline $2004-2010$ & $\begin{array}{l}\text { Broadband Convergence } \\
\text { Network (BcN) Plan }\end{array}$ & & \\
\hline 2006 & u-Korea Plan & $\begin{array}{l}\text { FTTH, FTTB, WiBro, } \\
\text { W-CDMA, HSDPA }\end{array}$ & $100 \mathrm{Mbps}$ \\
\hline 2008 & $\begin{array}{l}\text { Basic plan for national } \\
\text { informatization }\end{array}$ & & \\
\hline 2011-2020 & Giga Korea Plan & 4G: LTE (TD-LTE) & 1 Gbps \\
\hline
\end{tabular}

Source: Prepared by the author, on the basis of data from the Korea National Computerization Agency (master plans highlighted in colour). 
The World Bank (2009) stresses that, in addition to promotion policy, the Republic of Korea's oversight laws and regulations (which could be emulated in developing countries to accelerate broadband penetration) have played an important role. These regulatory and legal frameworks for oversight include the Telecommunications Framework Law, the Telecommunications Trade Law, the Regulatory Law on Fair and Equitable Trade Practices, regulation of network access, regulation of Internet service provider (ISP) peering, local loop unbundling, regulation of significant market power, number portability for voice over Internet protocol (VoIP), digital rights management, regulation of cybersecurity and digital crimes, and the ethical use of information.

The government was also active in terms of policies to promote universal broadband access, including the following: master plans for closing the digital divide; rural connectivity strategy; low-interest loans for rural development; subsidized services for citizens living in poverty, older adults and persons with disabilities; free Internet access centres in rural and remote areas; and broadband access in all schools, even in rural areas.

Some authors hold that the users' cultural milieu could have contributed to the fast deployment of broadband, underscoring their willingness to accept new technologies. According to the International Telecommunication Union (2003), the youngest generations of Koreans are very connected to the communications media culture, movies, online games, music and digital entertainment; this makes for a favourable environment for the fast deployment of high-speed Internet. According to Lau, Kim and Atkin (2005), the Internet has brought the stock market into homes and turned online home banking and home trading systems (HTS) into an instrument for personal asset management. Since the early 2000 s, $67 \%$ of stock market transactions in the country are carried out online, which illustrates the large demand for this type of application that is contributing to the fast growth of the broadband network.

\section{Competition and regulation}

One of the key factors in the development of a world-class broadband system in the Republic of Korea is the flexible use of regulatory policies to adapt to changing technology and market trends. After the liberalization conducted at the urging of the WTO, the government effectively used competition policy as part of its carefully planned and structured incentives for broadband development. Table VIII.4 summarizes the main competition policy instruments for broadband development, from breaking up the telecommunications service monopoly to the policy on competition among platforms and, subsequently, on service-based competition. 
Table VIII.4

BROADBAND REGULATORY POLICIES

\begin{tabular}{|c|c|c|}
\hline Year & Policies and regulations & $\begin{array}{l}\text { Infrastructure } \\
\text { vs. services }\end{array}$ \\
\hline $\begin{array}{l}\text { Before } \\
1982\end{array}$ & $\begin{array}{l}\text { Telecommunications services provided by MPT } \\
\text { Telecommunications monopoly }\end{array}$ & \multirow[t]{7}{*}{ Monopoly } \\
\hline 1982 & KT founded as a public corporation & \\
\hline 1984 & $\begin{array}{l}\text { Dacom founded; } \\
\text { KT launches analogue mobile services }\end{array}$ & \\
\hline 1988 & KMT spun off of KT & \\
\hline 1991 & $\begin{array}{l}\text { Promotion of competition in value-added services; } \\
\text { Dacom enters international market }\end{array}$ & \\
\hline 1992 & Competition in localization services & \\
\hline 1994 & $\begin{array}{l}\text { Second cellular licence issued (Sinsegi Telecom); } \\
\text { Order issued on accounting separation }\end{array}$ & \\
\hline 1995 & $\begin{array}{l}\text { Competition in the long-distance market (Dacom); } \\
\text { Launch of cable television services, with KEPCO and KT as } \\
\text { operators; } \\
\text { Establishment of the WTO; } \\
\text { Managed competition between infrastructures launched }\end{array}$ & \multirow[t]{6}{*}{$\begin{array}{l}\text { Platform-based } \\
\text { broadband } \\
\text { development } \\
\text { policy }\end{array}$} \\
\hline 1996 & $\begin{array}{l}27 \text { new licences granted; } 3 \text { personal communications services; } \\
6 \text { trunking radio systems; } 1 \mathrm{Cd}-2 \text { second-generation wireless } \\
\text { telephone; } \\
2 \text { dedicated lines; } 1 \text { localization; third international operator (Onse); } \\
3 \text { wireless data transmissions }\end{array}$ & \\
\hline 1997 & $\begin{array}{l}10 \text { new licences granted; one local operator, one long-distance } \\
\text { operator, six TRS, one localization; } \\
\text { The WTO Basic Telecommunications Agreement enters into effect; } \\
\text { Introduction of resale-based competition }\end{array}$ & \\
\hline 1999 & $\begin{array}{l}\text { Hanaro starts bulding telephone and local broadband Internet } \\
\text { services; } \\
\text { Universal service regulation; } \\
\text { KT launches broadband Internet service }\end{array}$ & \\
\hline 2001 & $\begin{array}{l}\text { Launch of DBS (Skylife); } \\
\text { Regulation of local loop unbundling; } \\
\text { Rebalancing of KT's local tariff }\end{array}$ & \\
\hline 2003 & Regulation of interconnection & \\
\hline 2004 & $\begin{array}{l}\text { Revision of the regulations on competition among infrastructures } \\
\text { and the move to service-based competition; } \\
\text { Broadband Internet redefined as basic service; } \\
\text { Introduction of number portability }\end{array}$ & \multirow[t]{5}{*}{$\begin{array}{l}\text { Service-based } \\
\text { broadband } \\
\text { development } \\
\text { policy }\end{array}$} \\
\hline 2005 & Two-year prohibition of the mobile telephone subsidy & \\
\hline 2006 & $\begin{array}{l}\text { Launch of WiBro and high-speed downlink packet access (HSDPA) } \\
\text { services; } \\
\text { Establishment of KCC (Korea Communications); }\end{array}$ & \\
\hline 2007 & $\begin{array}{l}\text { Authorization of bundling services by the main operators; } \\
\text { Temporary regulation on the elimination of the mobile telephone } \\
\text { subsidy }\end{array}$ & \\
\hline 2008 & Regulation of number portability for VolP & \\
\hline 2010 & $\begin{array}{l}\text { Regulation on new lease service providers for mobile virtual } \\
\text { network operators (MVNO) }\end{array}$ & \multirow{2}{*}{$\begin{array}{l}\text { Convergence- } \\
\text { based } \\
\text { broadband } \\
\text { development } \\
\text { policy }\end{array}$} \\
\hline 2012 & Launch of Giga Korea Plan & \\
\hline
\end{tabular}

Source: Prepared by the author, on the basis of Korea Information Society Development Institute (KISDI) (2012). 
Three main characteristics emerge. First, the government effectively used competition in the private sector for granting licences, following an approach geared towards improving services through facilities for accessing new infrastructure. Second, the government did not rely solely on private-sector leadership to create a world-class broadband infrastructure, because the private sector has always tended to seek returns without making new investments in higher-level infrastructure. The authorities managed to compel the private sector to invest in the next generation of broadband services. Third, the government utilized the broadband infrastructure to boost production in the ICT industries -including IPbased devices such as headphones, displays, digital television, radiofrequency identification (RFID), near field communication (NFC) and so on- within a broader industrial policy scheme.

\section{Broadband industrial policy}

The Republic of Korea is unique in its transition from conventional industrial policy to broadband-based industrial policy. The development of the chemical and heavy manufacturing industries in the 1970s and 1980 s is a classic example of "getting the price wrong" in line with Amsden (1995), with a set of policies and instruments aimed at selectively protecting domestic industry.

In the mid-1990s, the Republic of Korea joined the OECD in the area of capital account convertibility. It later came into compliance with WTO regulations prohibiting the use of direct subsidies in the framework of the Agreement on Subsidies and Countervailing Measures. With the end of the controlled financial system era, the influx of short-term capital along with current account deficits triggered the financial crisis of 1997.

The industrial policy model has been under review since the creation of the WTO in the mid-1990s. In this process, industrial policy for information technologies was combined with communications policy to take full advantage of its potential. This was achieved through measures to increase Internet use as a fundamental tool in the promotion of four major components of broadband-based development: communication networks, device industry, platform technologies and content (see diagram VIII.2).

These four components have made up broadband industrial policy since the advent of commercial Internet in the mid-1990s. This policy has gone through two phases of development; the third phase has only just begun. The first began with CDMA technology in the early 1990s, just before the WTO agreement entered into effect. The successful development of this technology and the commercialization of the CDMA standard contributed a good deal to the dissemination of mobile broadband and 
related devices. The CDMA initiative was under the direct supervision of the Electronics and Telecommunications Research Institute (ETRI), a government research agency, with the collaboration of the private sector and other major research centres.

\section{Diagram VIII.2}

MAIN AREAS OF BROADBAND INDUSTRIAL POLICY
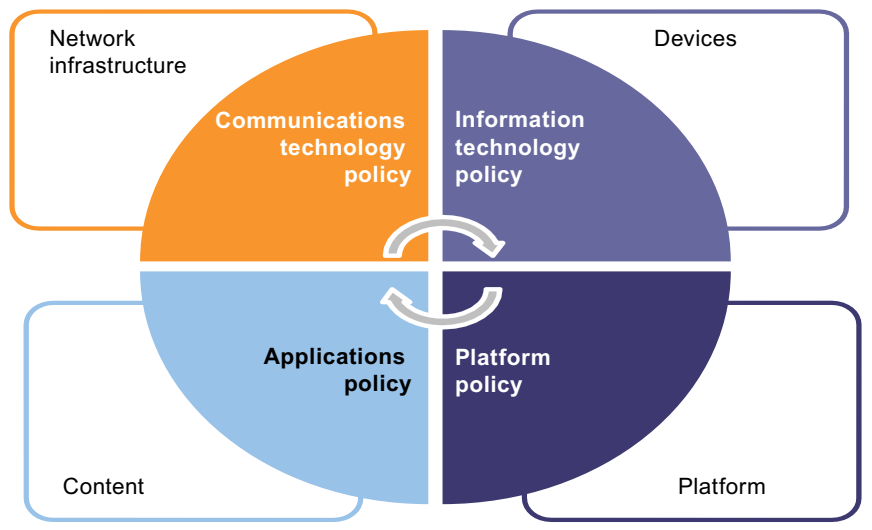

Source: Prepared by the author.

An important advance in the second phase was the launch of WiBro mobile broadband technology (a counterpart of WiMAX technology) in the 2000s. The effective use of the mobile standard with the first commercialization of CDMA gave the industry a lot of room for promoting technological innovations. It also provided justification for the development of broadband trunking networks such as FTTH and FTTx. From this perspective, the concentration of world-class broadband infrastructure in the Republic of Korea cannot simply be attributed to network development policy. As illustrated by the case of CDMA and WiBro technologies, broadband deployment is closely tied to industrial policy.

The transition to $4 \mathrm{G}$ in the early 2010s marks the beginning of the third phase of broadband industrial policy, when both CDMA and WiBro saw decreasing returns to scale because of the slow rate of adoption, the lack of commercial viability and the emergence of new technical standards.

As was the case with CDMA, the advantage of being the forerunner in technological standards was considerably smaller in the second phase, for three reasons. First, CDMA lost technical superiority over time and LTE became the pioneer. Second, 4G technology, such as TD-LTE, has emerged as the de jure ITU standard and the de facto standard of the 
major companies. Third, the development and adoption of TD-LTE as the $4 \mathrm{G}$ standard in China give China a great advantage because its internal market for $4 \mathrm{G}$ is potentially larger than the world market. In the face of these challenges, the Korean authorities launched the Giga Korea Plan in 2011 and announced the corresponding action plan in 2012.

\section{Technological development policy}

The Technological Development Promotion Law was enacted in April 2009 to develop the national economy by increasing international competitiveness through the creation and dissemination of new technologies. ${ }^{2}$ The law targets three areas for promotion: technological development, adaptation of foreign technology and new technologies.

Technological development aims to create new methods applicable to materials, manufactured products, processes and equipment systems, among others, through industrial technology research and its outcomes, including prototypes and pilot tests. Adapting and upgrading existing technology involves activities to create new technologies by analysing, complementing and improving on technologies in place in other countries. New technologies include greenfield technological development carried out in the country and the assimilation and updating of imported technology, certified by the Ministry of Knowledge Economy.

Within the framework of this law, specific $R \& D$ projects can be designed to develop key industrial technologies, choose research tasks annually and assign research programmes to institutions and organizations. The next section discusses the Giga Korea Plan as an example of broadband industrial policy in the context of technological development promotion policy.

\section{The Giga Korea Plan 2020}

As mentioned earlier, broadband industrial policy has gone through three phases: (i) CDMA-based mobile broadband policy in the 1990s; (ii) WiBro-based 3G mobile broadband policy in the 2000s; and (iii) the Giga Korea Plan based on 4G broadband industrial policy in the 2010s. The combination of broadband development policy and broadband industrial policy has exhibited a growing synergy, with revolutionary technological advances and development opportunities impacting society as a whole. ${ }^{3}$

2 See the technological development promotion law of the Republic of Korea (No. 9630) enacted in April 2009.

3 Machina Research's Mobile Broadband Global Forecast \& Analysis 2010-20 report offers a full and detailed analysis of global opportunities for mobile broadband services. The report includes the following key findings. First, mobile broadband connections for personal and 
In 2011 the government established the National Committee on the Giga Korea Plan, made up of the ministries of education and science, knowledge economy, security and public administration, culture, and defence, as well as the diffusion and communication commission and the national computerization commission. The Electronics and Telecommunications Research Institute (ETRI) provided support in terms of internal coordination. An inter-ministerial work division was established to avoid unnecessary overlapping of tasks in the various ministries, while taking into account that synergies depend on working together.

The government plans to establish an ICT hub for four sectors: networks, devices, platforms and content. The goal is for there to be 50 national software companies by 2020. In the same period, the government expects that the development of essential mobile broadband technology for processing large volumes of data will generate revenue the order of US\$ 100 billion and create 700,000 jobs (Korea IT Times, 2012).

One of the goals of the Giga plan is to build a Gbps broadband infrastructure before 2020 through fixed and wireless network convergence. With this type of network, it will be possible to download a 3D movie in less than three minutes, versus a current download time of three hours. The plan also calls for development of a 32Tbps flexible five-stage WDM optical transmission system by 2020 and the production of holographic devices and mobile 16-core 3D devices with speeds of 2.5 Ghz, which will allow a virtual reality generation interface capable of processing hundreds of terabytes with minimal energy consumption.

A key element of the Giga plan is the development of ultra-fast multiple cloud computing with holographic media processing that requires a capacity equivalent to 10 million PCs, or double-digit Tbps, for multiple heterogeneous platform services based on simultaneous data transmission. Table VIII.5 summarizes the Giga Korea Plan 2020.

laptop computers (through USB modems, embedded modules and so forth) will increase from 140 million at year-end 2010 to 1.5 billion in 2020, as a result of lower prices, increased coverage and capacity and the lack of fixed alternatives for broadband provision in many emerging markets. Second, mobile broadband will be increasingly data-capable. The number of $3 \mathrm{G}+$ and $4 \mathrm{G}$ connections will grow from 1.5 billion to 7.3 billion in 2020. The use of e-book readers and tablets with wireless wide area network (WWAN) capability will increase steadily in the mobile broadband environment, growing from 20 million in 2010 to 230 million in 2020. By 2020 the vast majority of these will be 4G+. Third, mobile data traffic will increase from 2.3 exabytes in 2010 to 41 exabytes in 2020 (a 17-fold jump). Finally, total revenue from WWAN data services for mobile telephones, PCs and laptop computers and tablets is expected to approach US\$ 400 billion in 2020, versus US\$ 100 billion in 2010. In contrast to the trend for traffic, and due to the fact that the prices per $\mathrm{Mb}$ are generally higher, this increased income will largely come from mobile telephone services. This will create a large number of mobile network operators in the $4 \mathrm{G}$ era (http://www.machinaresearch.com/mobilebroadband2020.html). 
Table VIII.5

THE GIGA KOREA PLAN 2020

\begin{tabular}{|c|c|c|c|c|}
\hline Classification & Stages & $\begin{array}{l}\text { Preliminary stage } \\
\text { (pre-2012) }\end{array}$ & $\begin{array}{l}\text { Stages I and II } \\
(2013-2017)\end{array}$ & $\begin{array}{l}\text { Stage III } \\
(2018-2020)\end{array}$ \\
\hline \multirow[t]{3}{*}{ Networks } & $\begin{array}{l}\text { General } \\
\text { objective }\end{array}$ & $\begin{array}{l}\text { Mbps wireless } \\
\text { network }\end{array}$ & $\begin{array}{l}500 \mathrm{Mbps} \\
\text { fixed-wireless } \\
\text { convergence } \\
\text { network }\end{array}$ & $\begin{array}{l}1 \text { Gbps fixed- } \\
\text { wireless } \\
\text { convergence } \\
\text { network }\end{array}$ \\
\hline & $\begin{array}{l}\text { Example: } \\
\text { download a 3D } \\
\text { movie (25GB) }\end{array}$ & 3 hours & 7 minutes & 3 minutes \\
\hline & $\begin{array}{l}\text { Main network } \\
\text { access node }\end{array}$ & $\begin{array}{l}\text { Optical packet } \\
\text { switching with } \\
\text { hundreds of Gbps }\end{array}$ & $\begin{array}{l}\text { 4Tbps flexible } \\
\text { three-stage WDM } \\
\text { optical transmission } \\
\text { system }\end{array}$ & $\begin{array}{l}\text { 32Tbps flexible five- } \\
\text { stage WDM optical } \\
\text { transmission system }\end{array}$ \\
\hline \multirow[t]{4}{*}{ Devices } & $\begin{array}{l}\text { General } \\
\text { objective }\end{array}$ & $\begin{array}{l}\text { 2K-level mobile } \\
\text { devices }\end{array}$ & $\begin{array}{l}4 \mathrm{~K} 3 \mathrm{D} \text { non-glass } \\
\text { mobile devices }\end{array}$ & $\begin{array}{l}\text { 8K 3D holographic } \\
\text { mobile devices }\end{array}$ \\
\hline & $\begin{array}{l}\text { Data } \\
\text { processing } \\
\text { capacity }\end{array}$ & $\begin{array}{l}\text { 4Core@1.5GHz } \\
\text { Mobile Core }\end{array}$ & $\begin{array}{l}\text { 8Core@1.5GHz } \\
\text { Mobile Core }\end{array}$ & $\begin{array}{l}\text { 16Core@1.5GHz } \\
\text { Mobile Core }\end{array}$ \\
\hline & Interface & Multi-touch inputs & $\begin{array}{l}\text { Biodata recognition } \\
\text { interface technology }\end{array}$ & $\begin{array}{l}\text { Virtual reality } \\
\text { generation interface }\end{array}$ \\
\hline & Data storage & $\begin{array}{l}\text { Hundreds of } \\
\text { gigabytes with } \\
\text { low power } \\
\text { consumption }\end{array}$ & $\begin{array}{l}\text { Several Tbytes } \\
\text { with low power } \\
\text { consumption }\end{array}$ & $\begin{array}{l}\text { Hundreds of Tbytes } \\
\text { with low power } \\
\text { consumption }\end{array}$ \\
\hline \multirow[t]{3}{*}{ Platforms } & $\begin{array}{l}\text { General } \\
\text { objective }\end{array}$ & $\begin{array}{l}\mathrm{T}(1012) \mathrm{IT} \\
\text { platform } \\
(=1,000 \mathrm{PCs})\end{array}$ & $\begin{array}{l}\text { Multiple UHD cloud } \\
\text { computing } \\
\text { (= } 100,000 \text { PCs) }\end{array}$ & $\begin{array}{l}\text { Holographic media } \\
\text { processing } \\
\text { (2-digit Tbps) }\end{array}$ \\
\hline & IT platform & $\begin{array}{l}\text { HD media } \\
\text { processing } \\
\text { (2-digit Gbps) }\end{array}$ & $\begin{array}{l}\text { UHD media } \\
\text { processing } \\
\text { (3-digit Gbps) }\end{array}$ & $\begin{array}{l}\text { Multiple ultra-fast } \\
\text { cloud computing } \\
\text { (=10 million PCs) }\end{array}$ \\
\hline & $\begin{array}{l}\text { Cloud } \\
\text { computing } \\
\text { service }\end{array}$ & $\begin{array}{l}\text { Mono platform- } \\
\text { as-a-service } \\
\text { cloud computing }\end{array}$ & $\begin{array}{l}\text { Multiple platform- } \\
\text { as-a-service cloud } \\
\text { computing }\end{array}$ & $\begin{array}{l}\text { Multiple } \\
\text { heterogeneous } \\
\text { platform-as-a- } \\
\text { service cloud } \\
\text { computing }\end{array}$ \\
\hline \multirow[t]{3}{*}{ Content } & $\begin{array}{l}\text { General } \\
\text { objective }\end{array}$ & $\begin{array}{l}3 \mathrm{D} \text { content } \\
\text { processing }\end{array}$ & $\begin{array}{l}\text { Biorecognition } \\
\text { content processing }\end{array}$ & $\begin{array}{l}\text { Holographic content } \\
\text { processing }\end{array}$ \\
\hline & Display & $\begin{array}{l}\text { Glass-based 3D } \\
\text { HD }\end{array}$ & $4 \mathrm{~K}$ non-glass UHD & $\begin{array}{l}\text { 8K/3D digital } \\
\text { hologram UHD }\end{array}$ \\
\hline & Virtual reality & $\begin{array}{l}\text { CAVE-type virtual } \\
\text { reality }\end{array}$ & $\begin{array}{l}\text { Interaction-based } \\
\text { virtual reality }\end{array}$ & $\begin{array}{l}\text { Auto-progressive } \\
\text { virtual reality }\end{array}$ \\
\hline
\end{tabular}

Source: Prepared by the author, on the basis of data from the Ministry of Knowledge Economy (MKE) and official documents. 


\section{E. Conclusions}

This chapter has explored Korean broadband industrial policy as an example of the creation of a national broadband infrastructure combined with broadband-based industrial development. Previous studies by the World Bank, the OECD and the ITU focused on broadband development from the network perspective, without looking in depth at the development of the ICT industry. This approach arises from seeing the ICT industry from a horizontal perspective and considering broadband development as a function of market-driven deregulation, privatization, competition and network neutrality policies and policies targeting demand for applications such as e-government and e-business.

While this approach is useful for many developing countries and emerging economies that lack a strong ICT industry, other countries have room for revising their broadband development policy from the perspective of industrial policy. The case of the Republic of Korea shows that the provision of networks is only one of the core elements of broadband industrial policy, which also encompasses devices, platforms and content.

Latin America missed out on the opportunity to take advantage of the first wave of broadband industrial policy. ${ }^{4}$ This was mainly due to the prevalence of integrated horizontal polices in the economic model in the period following the debt crisis of the 1980s and the liberalization process of the 1990s. Although the countries of Latin America are now joining the second wave of broadband development, the link between broadband development and industrial policy is a weak one in many countries in the region.

This stands in sharp contrast to the Republic of Korea, where space was made for targeted cutting-edge policies within the WTO regulations. ${ }^{5}$ This chapter has examined the case of CDMA technology as an example of broadband industrial policy, WiBro technology as another example of 3G mobile broadband industrial policy and the Giga Korea Plan as a fresh initiative for $4 \mathrm{G}$ super-broadband industrial policy.

At the dawn of a new 4G era, action under the Giga Korea Plan has turned to reducing reliance on CDMA and WiBro as technology continues to advance. This third stage of broadband development, called the era

4 The governments of the countries of Latin America did not take full advantage of the opportunities. There is some outsourcing of the assembly of PCs and components, mainly in Mexico and Costa Rica, and some production for the domestic market in Brazil, but their aggregate impact was modest. The lack of a broadband-based industrial policy is a constraint, from the perspective of both industrial production and technological development.

5 For more information on targeted cutting-edge policies, see Peres and Primi (2009). 
of hyperconnectivity, offers emerging economies a new opportunity for addressing the fundamentals of broadband industrial policy.

In the global context, China is on track to lead 4G broadband development, on the strength of the sheer number of its mobile smartphone users. Although it remains to be seen whether China can lead the hyperconnected world in the next decade, its broadband development policies will undoubtedly have repercussions far beyond a policy based solely on network deployment. China, the Republic of Korea and Japan are moving into a new stage of broadband industrial development, with synergies between industrial development and technological development. The Association of Southeast Asian Nations (ASEAN) will also take part in the division of labour for giga broadband industrial development. This will mirror the earlier "flying geese" model of the Asian division of labour, which was led by Japan following the Plaza Accord in the 1980s. This time, the group could be led by China, the Republic of Korea and Japan, under a new model that might be called the "smart dragon", in which the regional economy will grow rapidly with hyperconnected ICTs, led by China.

If Latin America participates in this process, there should be a reasonable window of opportunity for a new wave of industrial development over the next decade. Otherwise, the region's economies could lose another decade of ICT development if their policy focus is penetration rate and network speed with no significant impact on industrial development. The third stage of broadband industrial development in the 2010s will undoubtedly be different from the first. In addition to building on the first stage, it will usher in unprecedented developments such as the convergence of information, communications and environmental technologies related to lifestyles and climate change, establishing a new platform for technological and industrial development.

In sum, the Korean case displays a classic combination of broadband development and the simultaneous development of networks, devices and, to a lesser extent, platforms and content as part of broaderbased industrial development policy. Table VIII.6 compares the trajectories of horizontal industrial policies and the cutting-edge policies of the 1990s and 2000s and sets forth a new scope for a convergence policy that could change the outlook for the industrial competitiveness of Latin America in general. 
Table VIII.6

INDUSTRIAL AND TECHNOLOGICAL DEVELOPMENT MODEL IN LATIN AMERICA AND THE REPUBLIC OF KOREA, 1960-2020

\begin{tabular}{|c|c|c|c|c|}
\hline $\begin{array}{l}\text { Industrial policy } \\
\text { period }\end{array}$ & & $1960-1995$ & $1995-2010$ & $2010-2020$ \\
\hline Global framework & & GATT & WTO & $\begin{array}{l}\text { Post-Doha } \\
\text { WTO }\end{array}$ \\
\hline $\begin{array}{l}\text { Broadband } \\
\text { infrastructure }\end{array}$ & & $1 \mathrm{G}$ & $2 G-3 G$ & $4 G-5 G$ \\
\hline \multirow{4}{*}{$\begin{array}{l}\text { Industrial policy } \\
\text { path in } \\
\text { Latin America }\end{array}$} & & Sectoral policy & $\begin{array}{l}\text { Horizontal } \\
\text { policy }\end{array}$ & $\begin{array}{l}\text { Convergence } \\
\text { policy }\end{array}$ \\
\hline & $\begin{array}{l}\text { Policy } \\
\text { instruments }\end{array}$ & $\begin{array}{l}\text { Import- } \\
\text { substitution } \\
\text { industrialization }\end{array}$ & Various & Various \\
\hline & $\begin{array}{l}\text { Endogenous } \\
\text { development }\end{array}$ & Strong & Weak & Medium \\
\hline & $\begin{array}{l}\text { Global supply } \\
\text { chain }\end{array}$ & Weak & Medium & Strong \\
\hline \multirow[t]{4}{*}{$\begin{array}{l}\text { Industrial policy } \\
\text { path in the Republic } \\
\text { of Korea }\end{array}$} & & Sectoral policy & $\begin{array}{l}\text { Targeted, } \\
\text { cutting-edge } \\
\text { policy }\end{array}$ & $\begin{array}{l}\text { Generative } \\
\text { convergence } \\
\text { policy }\end{array}$ \\
\hline & $\begin{array}{l}\text { Policy } \\
\text { instruments }\end{array}$ & $\begin{array}{l}\text { Import- } \\
\text { substitution } \\
\text { industrialization } \\
+ \text { export- } \\
\text { oriented } \\
\text { industrialization }\end{array}$ & $\begin{array}{l}\text { Research and } \\
\text { development, } \\
\text { standards, } \\
\text { broadband }\end{array}$ & $\begin{array}{l}\text { Research and } \\
\text { development, } \\
\text { standards, } \\
\text { broadband- } \\
\text { based } \\
\text { convergence }\end{array}$ \\
\hline & $\begin{array}{l}\text { Endogenous } \\
\text { development }\end{array}$ & Strong & Strong & Strong \\
\hline & $\begin{array}{l}\text { Global supply } \\
\text { chain }\end{array}$ & Strong & Strong & Strong \\
\hline
\end{tabular}

Source: Prepared by the author.

This chapter concludes with some recommendations on broadband development and industrial development aimed at policymakers in Latin America.

(i) Shift the focus of broadband development policy from a network-based approach to an industrial development approach. The latter cannot be achieved without the former, but the focus has to change in order to achieve the best outcomes in the coming decade.

(ii) Establish a national giga plan for the next decade, with four components: networks, devices, platforms and content. Each area should take into account the ways and means of inserting 
the national economy into the global economy through an appropriate division of labour in production and distribution.

(iii) Design a demand-driven giga broadband policy, harnessing government promotion policy and market forces in order to develop e-government, e-business, e-learning, e-health and other application platforms.

(iv) Draw up a universal service plan to bring mobile broadband to rural communities and other areas with poor coverage. Governments can promote public-private partnerships, which assume a division of labour between the two sectors; the former would be responsible for the national fibre optic network, while the latter would invest in alternative mobile technologies such as WiMAX and HSDPA where the private sector can respond more quickly to fast-changing technologies.

(v) Closely study the development of the 4G standard in China, such as TD-LTE, to assess the effects of a new standard on national, regional and global mobile broadband markets. Brazil has begun working on TD-LTE for the development of 4G broadband. Although this process involves multiple actors, China's move towards $4 \mathrm{G}$ could have substantial repercussions on broadband industrial development in Latin America.

(vi) Gradually change the traditional curriculum approach to one based on smart learning, given the predictions that the next decade will open up an enormous gap in the region in terms of human resource development in the hyperconnected world. This requires universal literacy, to the extent possible, because as Amsden (1995) points out, the leap forward in the Republic of Korea was only possible after the attainment of universal education in the 1960s.

(vii) Attract foreign direct investment for $4 \mathrm{G}$ development and deployment. This requires a proactive broadband industrial policy to create synergies between network deployment and industrial development.

(viii) Develop intra-industry trade with the suppliers of manufactured broadband products as part of the new trade policy. At present, some countries in the region have a good pool of skilled labour, which can contribute to the adaptation and development of new technologies if the technology transfer channels are secured. Together with foreign direct investment, intra-industry trade can pave the way. 
(ix) Draw up a national policy for the endogenization of foreign and new technologies. The Giga Korea Plan could have policy spillover effects for in Latin America. The 4G and 5G stages could be a major turning point for endogenization because-even for the developed economies-many parts and components are new-generation. This could provide an untapped opportunity to harness the potential of ICTs and smart technologies in Latin America. The economic development policy behind the 4G5G stage needs to be reverse engineered so as to increasingly orient industrial policy towards the convergence of traditional industries with ICTs, based on the analysis of big data, cloud computing and memory applications. The region has the potential to catch up with the latest trends through a new industrial policy based on the adaptation and endogenization of technological innovations.

(x) Draft a master plan for internationalization and globalization in the hyperconnected economy. In some cases, trade policy needs to be redefined in accordance with the new geography of industrial development. As mentioned above, "smart dragon" is a new industrial and technological development model in Asia encompassing two thirds of the world population of smart mobile technology users. The global economic shift to the east in the $4 \mathrm{G}$ and $5 \mathrm{G}$ era requires a broadband approach to trade and industrial policy in Latin America (instead of the narrowband approach to trade policy), in order to boost inter-institutional cooperation and industrial and technological development. To paraphrase Fernando Fajnzylber in ECLAC (1990), the main task for the region consists of establishing a new framework for the development of a broadband industrial policy for "smart" production transformation with equity. 


\section{Bibliography}

Aizu, I. (2002), "A comparative study of broadband in Asia", Asia Network Research Discussion Paper.

Amsden, A. (1995), Getting the Price Wrong: The Case of Korea, MIT.

Atkinson, R. D. (2009), "The role of competition in a national broadband policy, Journal on Telecommunications \& High Technology, vol.7.

Atkinson, R.D., D. K. Correa and J.A. Hedlund (2008), “Explaining International Broadband Leadership", Social Science Research Network [online] http:/ / papers.ssrn.com/sol3/papers.cfm?abstract_id=1128203.

Berkman Centre for Internet and Society (2010), Roadmap for Open ICT Ecosystems, Harvard Law School.

Cava-Ferreruela, I. and A. Alabau-Muñoz (2006), "Broadband policy assessment: A cross-national empirical analysis", Telecommunications Policy, vol. 30, No. 8.

De Ridder, J. (2007), "Catching-up in Broadband - What Will it Take?", Paris, Organisation for Economic Cooperation and Development (OECD), July.

ECLAC (Economic Commission for Latin America and the Caribbean) (1990), Changing Production Patterns with Social Equity (LC/G.1601-P), Santiago, Chile.

Government of Korea (2009), Technology Development Promotion Act of Korea (No. 9630), April. (2011), Giga Korea Plan 2020, Seoul.

Grosso, M. (2006), "Determinants of Broadband Penetration in OECD Nations", Working Paper, Regulatory Development Branch, Australian Competition and Consumer Commission.

Höffler, F. (2007), "Cost and benefits from infrastructure competition: estimating welfare effects from broadband access competition", Telecommunications Policy, vol. 31, No. 6-7.

ITU (International Telecommunication Union) (2003-12), ITU Annual Report (2003-12); Measuring the Information Society 2012 [online] http://www.itu. int/net/pressoffice/press_releases/2012/70.aspx.

Kim, Y., T. Kelly and S. Raja (2010), “Building broadband: Strategies and policies for the developing world", GICT Publication by KISDI.

Korea Information Society Development Institute (KISDI) (2012), 2012 ICT Inductry Outlook of Korea, Seoul.

Korea IT Times (2012), [online] http:/ / www.koreaittimes.com/story/21141/visionit-powered-korea-future, 25 April.

Lau, T.Y., S.W. Kim and D. Atkin (2005), "An examination of factors contributing to South Korea's global leadership in broadband adoption", Telematics and Informatics, No. 22.

Machina Research (2012), Mobile Broadband Global Forecast E Analysis 2011-20, Sector Report, Machina Research.

Ministry of Knowledge Economy (2012), San Ueop Baek Seo 2011, Republic of Korea.

Ovum Consulting (2009), Broadband Policy Development in the Republic of Korea, A Report for the Global Information and Communications Technologies Department, World Bank.

Peres, W. and A. Primi (2009), Theory and Practice of Industrial Policy: Evidence from the Latin American Experience, Santiago, Chile, Economic Commission for Latin America and the Caribbean (ECLAC). 
Wallesten, S. (2006), "Broadband and Unbundling Regulations in OECD Countries", AEI-Brookings Joint Centre Working Paper, No. 06-16, Technology Policy Institute.

Waverman, L., M. Meschi, B. Reillier and K. Dasgupta (2007), Access Regulation and Infraestructure Investment in the Telecommunications Sector: An Empirical Investigation. With the support of ETNO, London, UK.

World Bank (2009), Broadband Policy Development in the Republic of Korea. A Report for the Global Information and Communications Technologies Department, October.

WTO (World Trade Organization) (1995), Agreement on Subsides and Countervailing Measures, Geneva. 



\section{Chapter IX \\ Net neutrality: debate and policies}

René Bustillo

\section{A. Introduction}

The issues surrounding net neutrality (broadly defined as the principle that all Internet traffic should be treated without discrimination) are changing the broadband industry all over the world through regulatory and market forces. Many regulatory bodies are trying to adopt strict network regulations, changing the way that telecommunications service providers operate. From a market perspective, consumer demand for variety and greater bandwidth for Internet-based services is constantly growing. This can cause network congestion, which not only affects Internet use but also the viability of other services often offered by providers, particularly voice services. And so the way in which the broadband industry deals with these challenges will depend largely on how regulatory bodies address the issue.

Although discussions on net neutrality often turn into an ethical, political and social debate, the challenge is above all a technical one. Network congestion has become the focal point of discussions on net neutrality. Service providers claim that because the number of broadband subscribers and high bandwidth consumption applications has risen, their networks will very soon be unable to offer the speed and service quality expected by users. The key to understanding net neutrality and its effect 
on telecommunications policy and industry lies in grasping the technical issues behind Internet gridlock and the mitigation technologies and practices used and adapted to tackle the problem since the Internet began.

\section{B. What is net neutrality?}

There are several definitions of "net neutrality", but they basically refer to the same thing: allowing the unrestricted flow of all information over the Internet. But such unrestricted freedom would have far-reaching technological, economic, regulatory, legal, social and other consequences.

The very fact that the idea behind the Internet was nondiscrimination in carrying information means that limiting what can and cannot flow through it would come across as artificial or even pointless. But structure of the networks and services that make up the Internet is so complex that absolutes do not apply in the case of net neutrality. Some knowledge of networks and topologies can be useful for understanding the underlying problem of providing unrestricted access to Internet resources.

One of the most controversial statements about neutrality was made several years ago: "In a world of dumb terminals, networks had to be smart. But in a world of smart terminals, networks have to be dumb" (Gilder, 1992). The idea was that telex and telephone networks should be smart enough to route communications and compensate for the fact that the devices themselves were not smart at all and were unable to make decisions relating to rerouting communications or managing congestion. Computer networks were still in the early stages of development, but it was thought that with smart terminals at each end the network would be nothing more than a "bit pipe". In other words, the network would not have to make decisions on communication traffic or destination. It just had to send the information.

An absolutely neutral or "dumb" network is not technically feasible, especially in such a complicated system as the Internet. The task of ensuring data exchange on a global scale and, especially, attempts to improve service quality have forced Internet engineers to make networks smart by adding "smart" routers and gateways. However, as the Internet begins to play an increasingly important role in the economy and the technical ability to identify certain packets and treat them differently grows, new criteria for discriminating against certain types of traffic are put forth (Bocache, Mikheyev and Paque, 2007).

Information technology experts -even those who advocate net neutrality- agree that, strictly speaking, the Internet was never 100\% neutral (Wu, 2005). For example, the Transmission Control Protocol/ 
Internet Protocol (TCP/IP) network distinguishes between different classes of traffic and indirectly gives some priority over others.

The Internet was designed to work differently from traditional telephone networks. Since it is based on the principle of packet switching instead of circuit switching, the Internet is more flexible (when a circuit is unavailable, the packets can take another route) and, in theory, less reliable (transmission quality varies because packets are not routed through a dedicated circuit). The Internet is therefore seen as smart at the ends: at the devices connected to it.

In the early days, most Internet traffic was largely composed of data files and messages that were not delay-sensitive. Today, it carries all kinds of traffic that can be classified as delay-sensitive or non-delay-sensitive, or high- or low-bandwidth-consumption. Table IX.1 classes Internet services according to their delay-sensitivity, bandwidth consumption and economic value perceived by users.

Table IX.1

INTERNET SERVICES ACCORDING TO DELAY SENSITIVITY, BANDWIDTH CONSUMPTION AND ECONOMIC VALUE

\begin{tabular}{lclc}
\hline Service & Delay sensitivity & Bandwidth consumption & Value / willingness to pay \\
\hline P2P file sharing & Low & Very high (no limit) & Low \\
YouTube & Low (buffered) & Medium (320-600 Kbps) & Low \\
NetFlix streaming & Low (buffered) & High (up to 4 Mbps) & Low \\
E-mail & Low & Very low & Low \\
VolP & Medium - high & Low (30-80 Kbps) & Medium \\
Online gaming & High & Low (30-80 Kbps) & Medium \\
Videoconferences & High & medium & High \\
Telemedicine & High & High (up to 8 Mbps) & High \\
\hline
\end{tabular}

Source: G. Pehnelt, "The economics of net neutrality revisited", Jena Economic Research Papers, 27 October 2008.

The table shows, first, that combining the different kinds of traffic makes for a mix that would be difficult for any network to manage unless its resources were unlimited. Data networks are usually made up of access points (physical or wireless), a core network and, lastly, connections to other networks. Constraints at any part of the network could lead to packet loss and lower quality that some applications would tolerate better than others. However, since TCP/IP networks operating under normal conditions do not distinguish between traffic according to delay-sensitive, application packets with high bandwidth consumption and low delay-sensitive flood the network to the detriment of those carrying data applications, such as VoIP and videoconferencing, that do have lag issues. 
The conclusion is that under normal traffic conditions, delaysensitive applications and services cannot maintain the same standard of quality as applications which are not affected by expected data network delay. The situation grows more complicated when there is traffic overload, because services that cannot tolerate lag are the first to suffer the consequences of equal treatment of all data packets.

\section{The non-discrimination principle}

Non-discrimination is a core principle of ICT regulation. Broadly, it should be understood as barring service providers from giving different treatment to users and other providers operating under the same conditions. Discrimination can be found in pricing (two users who are charged different rates for the same service) or in facilities (different access quality or features for different users). Discrimination in net neutrality can take many shapes: charging users differently according to the type of traffic they use the most (like web pages with or without high multimedia download content), blocking certain applications or lowering service quality (as is the case of T-Mobile 3G and Skype in Germany).

According to some authors, the underlying principle of network nondiscrimination is to give users the right to use devices and applications that are not harmful to the network while giving innovators the freedom to provide them $(\mathrm{Wu}, 2005)$. However, providers tend to be against this principle, claiming that, in the long run, unrestricted freedom impairs network and service quality and requires investments that revenue from services provided does not cover. The classic example is VoIP over data networks and the Internet, which voice providers (fixed and mobile) oppose and block when it starts to eat into their revenue.

Peha (2006) analyses the benefits and risks of mandating net neutrality and suggests a policy designed to protect the beneficial uses of discrimination which might allow the network operators to:

- Provide different quality of service to different classes of traffic, using explicit prioritization or other techniques. These techniques can be used to favor traffic with stricter quality of service requirements, and/or traffic sent using a higher-priced service.

- Charge a different price for different classes of traffic. The higher price would be justified because the traffic requires superior quality of service, consumes more of a limited resource, has a greater adverse effect on other traffic, or is otherwise linked to cost (or opportunity cost).

- Block traffic that poses a threat to security.

- Charge the senders of information, recipients, or both. 
- Offer proprietary content or unique services to their customers (without using their dominant control over the last-mile connection to favour their own content or service).

- Block traffic originating from an attached device that might reasonably be believed to be harmful to the network or its users, such as one that does not follow prescribed protocols and algorithms.

- Use any form of discrimination they wish, if the broadband market becomes truly competitive.

\section{The growth of traffic and net neutrality}

One of the most important considerations for any analysis of net neutrality is the fact that Internet traffic has been soaring. Projections are that IP traffic in petabytes (PB) per month will increase four-fold between 2010 and 2015 (see table IX.2). The situation is particularly concerning in Latin America since growth will mean a seven-fold increase in traffic. As a result, service providers will have to adapt the networks to these levels of data traffic while ensuring the viability of the business model.

Table IX.2

GLOBAL IP TRAFFIC PROJECTIONS, 2010-2015

(Petabytes per month and percentages)

\begin{tabular}{|c|c|c|c|c|c|c|c|}
\hline & 2010 & 2011 & 2012 & 2013 & 2014 & 2015 & $\begin{array}{c}\text { CAGR } \\
2010-2015\end{array}$ \\
\hline \multicolumn{8}{|l|}{ By type } \\
\hline Fixed Internet & 14955 & 20650 & 27434 & 35879 & 46290 & 59354 & 32 \\
\hline Managed IP & 4989 & 6839 & 9014 & 11352 & 13189 & 14848 & 24 \\
\hline Mobile data & 237 & 546 & 1163 & 2198 & 3806 & 6254 & 92 \\
\hline \multicolumn{8}{|l|}{ By segment } \\
\hline Consumer & 16221 & 23130 & 31592 & 42063 & 54270 & 70045 & 34 \\
\hline Business & 3930 & 4894 & 6011 & 7357 & 8997 & 10410 & 22 \\
\hline \multicolumn{8}{|l|}{ By location } \\
\hline North America & 6998 & 9947 & 12978 & 16116 & 18848 & 22274 & 26 \\
\hline Western Europe & 4776 & 6496 & 8819 & 11774 & 15187 & 18858 & 32 \\
\hline Asia-Pacific & 5368 & 7317 & 9847 & 13341 & 18060 & 24150 & 35 \\
\hline Japan & 1414 & 1923 & 2540 & 3283 & 4019 & 4762 & 27 \\
\hline Latin America & 665 & 993 & 1465 & 2158 & 3238 & 4681 & 48 \\
\hline $\begin{array}{l}\text { Central and Eastern } \\
\text { Europe }\end{array}$ & 708 & 1004 & 1413 & 1955 & 2700 & 3713 & 39 \\
\hline Middle East and Africa & 253 & 366 & 550 & 802 & 1235 & 2019 & 52 \\
\hline Total IP traffic & 20151 & 28023 & 37603 & 49420 & 63267 & 80456 & 32 \\
\hline
\end{tabular}

Source: Cisco Systems, "Cisco Visual Networking Index”, 2011. 
The service providers' main argument against net neutrality is that with the expected growth in traffic, being unable to select or prioritize data packets will make it difficult to maintain the performance level required to carry all of the traffic. This is even more difficult in wireless broadband networks, since problems setting up base stations and spectrum availability constraints prevent access networks from growing as quickly as required.

Another equally worrying aspect of IP traffic growth is global consumer traffic, which encompasses any traffic that is not confined to a single service provider's network. In other words, it is any traffic which crosses from one network to another, as is the case for most traffic generated by web browsing. Table IX.3 shows the projected growth of this traffic to 2015, disaggregated by network and subsegment.

Table IX.3

GLOBAL CONSUMER INTERNET TRAFFIC, 2010-2015

(Petabytes per month and percentages)

\begin{tabular}{lrrrrrrrr}
\hline & 2010 & 2011 & 2012 & 2013 & 2014 & 2015 & $\begin{array}{c}\text { CAGR } \\
\text { 2010-2015 }\end{array}$ \\
\hline By network & 12355 & 17467 & 23618 & 31318 & 40842 & 53282 & 34 \\
$\quad$ Fixed & 174 & 399 & 858 & 1654 & 2930 & 4931 & 95 \\
$\quad$ Mobile & & & & & & & \\
By subsegment & 4968 & 6017 & 7277 & 8867 & 11040 & 13797 & 23 \\
$\quad$ File sharing & 4672 & 8079 & 12146 & 17583 & 24357 & 33620 & 48 \\
Internet video & 2393 & 3113 & 4146 & 5325 & 6769 & 8592 & 29 \\
Web, e-mail and data & 308 & 442 & 659 & 905 & 1251 & 1736 & 41 \\
Video calling & 49 & 68 & 95 & 133 & 187 & 290 & 43 \\
Online gaming & 138 & 147 & 153 & 157 & 160 & 168 & 4 \\
Voice over IP (VolP) & 0 & 1 & 1 & 3 & 8 & 11 & 132 \\
Others & & & & & & & \\
By location & 3301 & 5000 & 6579 & 8306 & 10012 & 12537 & 31 \\
$\quad$ North America & 3147 & 4360 & 6075 & 8224 & 10841 & 13896 & 35 \\
Western Europe & 4403 & 6006 & 8142 & 11129 & 15249 & 20758 & 36 \\
Asia-Pacific & 638 & 932 & 1317 & 1807 & 2344 & 2968 & 36 \\
Japan & 482 & 735 & 1106 & 1667 & 2577 & 3850 & 52 \\
Latin America & 454 & 667 & 971 & 1381 & 1963 & 2805 & 44 \\
Central and Eastern Europe & 103 & 166 & 286 & 459 & 784 & 1399 & 68 \\
Middle East and Africa & 12528 & 17866 & 24476 & 32973 & 43771 & 58214 & 36 \\
Global consumer traffic & 1258 &
\end{tabular}

Source: Cisco Systems, "Cisco Visual Networking Index", 2011.

As can be seen, mobile Internet traffic growth is soaring (28-fold) and far outpacing fixed networks. Internet video traffic (one of the most popular applications at present) is growing disproportionately. Although IP television (IPTV) traffic does not fall into this category, projected growth will also impact service provider access networks. In view of the above, 
providers have adopted a radical stance on net neutrality, saying that if they cannot differentiate the traffic on their networks the business model will become unsustainable in a few years.

\section{The situation in Europe, the United States and Asia-Pacific}

Net neutrality is an issue in many places worldwide, particularly in the European Union countries and the United States. It has been addressed from different angles, because measures to ensure absolute neutrality would have major implications for network operability.

To identify the best international practices, net neutrality was examined in several regions of the world. For Latin America, there are useful lessons to be learned from the experience of Europe and the United States regardless of any differences in degree of development of electronic communications. The methods used in Asia-Pacific could also be a source of useful models for looking at the issue from different perspectives.

\section{Europe and the United States}

Broadband development has taken different paths in Europe and the United States. ADSL, which is the primary means of fixed broadband access in Europe, is not as prominent in the United States, where cable Internet access is the most common (see figure IX.1). This is mainly for historical and geographical reasons that made cable providers more likely to provide broadband access than was the case in most of the countries of Europe. In addition, the broadband regulatory framework is much less interventionist in Europe than in the United States, where it is tightly regulated at the federal and state levels.

Figure IX.1

FIXED BROADBAND ACCESS, BY TECHNOLOGY, 2011

(Percentages)

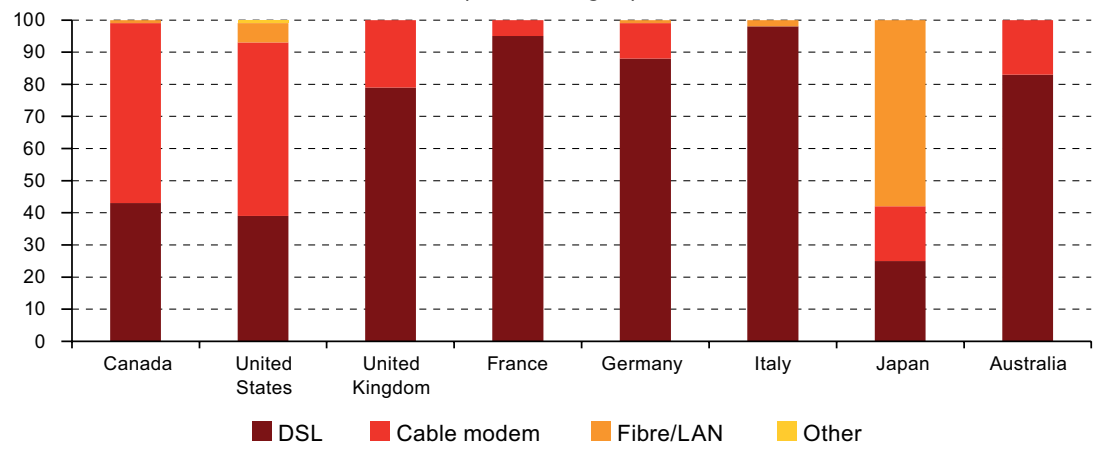

Source: Canadian Radio-television and Telecommunications Commission, CRTC Communications Monitoring Report, 2011. 


\section{a) European Union}

The European Union (EU) is made up of 27 States that are subject to community law. All of the European countries examined herein (with the exception of Norway) fall within the scope of European regulations and must adapt their national regulations to the provisions of net neutrality directives.

The regulatory framework for electronic communications networks and services (the "Regulatory Framework") is the basis for all national telecommunications laws in the EU Member States. The Regulatory Framework provides general and technology neutral rules applying to all electronic communications networks and services covering fixed and wireless telecommunications, data transmission and broadcasting transmission. It contains provisions for the structure and functioning of national telecommunications providers, and the framework for both general rules applying to all providers of electronic communications networks and services and particular rules which may only be imposed by national regulatory authorities (NRA) on operators with significant market power (SMP). The Regulatory Framework only relates to the provision of electronic communications networks and services, and does not cover the content of these services.

One of the main objectives of the Regulatory Framework is to align sectoral regulation of the electronic communications market with general competition principles. As a consequence, the Regulatory Framework adopts the principle that ex ante regulation should only be imposed where there is ineffective competition, for example, in markets where there are one or more undertakings with SMP and where competition law remedies are not sufficient to address the problem (Enaux and Escribano, 2011).

The Commission attaches high importance to preserving the open and neutral character of the Internet, taking full account of the will of the co-legislators now to enshrine net neutrality as a policy objective and regulatory principle to be promoted by national regulatory authorities, alongside the strengthening of related transparency requirements and the creation of safeguard powers for national regulatory authorities to prevent the degradation of services and the hindering or slowing down of traffic over public networks. The Commission will monitor closely the implementation of these provisions in the Member States, introducing a particular focus on how the 'net freedoms' of European citizens are being safeguarded in its annual Progress Report to the European Parliament and the Council. In the meantime, the Commission will monitor the impact of market and technological developments on 'net freedoms' reporting to the European Parliament and Council on whether additional guidance is required, and will invoke its existing competition law powers to deal 
with any anti-competitive practices that may emerge (Official Journal of the European Union, L 337, 18 December 2009). This declaration is the starting point for regulating net neutrality because it refers to preserving the open and neutral character of the Internet. However, the term "Internet neutrality" has a different nuance from "net neutrality". Internet neutrality refers to all of the elements which make up the public network, which in many cases does not include the access network or sections of the network which belong to a particular provider. Net neutrality is much more general and includes all of the elements and applications required for users to connect with each other or other devices connected to the "network of networks". Although the terms are used without distinction, they differ in scope.

Although the declaration states that Member States must report to the European Parliament on measures taken to protect Internet freedoms, there is no consensus with respect to what these freedoms encompass. Nor is the declaration in and of itself enough to guarantee user rights against, for example, content blocking or filtering.

The third European Union Telecom package (A6-0272/2009) refers to the Council common position for adopting the European Parliament and Council directive amending Directive 2002/21/EC on a common regulatory framework for electronic communications networks and services, Directive 2002/19/EC on access to, and interconnection of, electronic communications networks and associated facilities, and Directive 2002/20/EC on the authorization of electronic communications networks and services. The Telecom package sets out three sets of measures that pertain to neutrality. They are:

- To enshrine the principle of neutrality as a regulatory objective, both in its economic aspect (fostering true competition between Internet access providers and content providers for the benefit of the consumer, "including for the transmission of content") and in its social aspect (favouring end-user access to information and preserving their ability to disseminate and use the applications of their choice).

- To impose transparency obligations on operators for managing traffic and network access restrictions so as to ensure the protection of the principle of neutrality via competition (new compulsory information included in electronic communications service agreements must appear clearly and in detail and be easily accessible: traffic management procedures, restrictions on access to certain services or equipment, measures to ensure the network's security and integrity, among others). 
- To grant new powers to the regulators to prevent violations of the principle of neutrality (power to define minimum requirements in terms of quality of service; dispute resolution powers extended to disputes over the transmission of traffic between operators and other companies, including content providers).

The third Telecom package contains specific provisions on actions that can be taken by the regulator to ensure that users' rights are not violated. The measures focus on competition and information transparency, making it clear that the policy focus is on protecting user rights via a healthy, undistorted market.

\section{b) United States}

In March 2010 the Federal Communications Commission (FCC), the communications regulatory body for the United States, presented the first National Broadband Plan and set the country on a new telecommunications path that is very pro-consumer, pro-privacy and procompetition. The plan also proposes significant changes to access regimes, wholesale facilities and competition in both the telecommunications and the broadcasting markets.

Communications policy in the United States is jointly regulated by federal and state governments. At the federal level, the Communications Act of 1934, amended by the Telecommunications Act of 1996 (together, the "Act"), established a national policy geared towards widespread, rapid and efficient communication services that are universally available at affordable rates in a competitive market. The Act tasks the Commission with implementing a regulation which promotes these policies in a way that is consistent with "public interest, convenience, and necessity". Each State's Public Services Commission controls the rates and sets the obligations of fixed telephony operators. Although the United States made the transition from a monopolistic to a competitive communications market in 1996, the industry continues to be subject to oversight by the FCC and the states.

In 2005, the FCC issued a unanimous policy statement spelling out four fundamental rights of Internet users. Users are entitled to (i) access the lawful Internet content of their choice; (ii) run applications and use services of their choice, subject to the needs of law enforcement; (iii) connect their choice of legal devices that do not harm the network; and (iv) competition among network providers, application and service providers, and content providers. After further discussion, in December 2010 the FCC decided to impose two even tighter regulations on Internet access providers: no 
blocking and no unreasonable discrimination in transmitting traffic (Federal Communications Commission, 2011).

In short, the first requirement is transparency. Fixed and mobile broadband providers must disclose the network management practices, performance features, and terms and conditions of their broadband services. Secondly, there must be no blocking: fixed broadband providers may not block lawful content, applications, services, or non-harmful devices; mobile broadband providers may not block lawful websites or block applications that compete with their voice or video telephony services. Thirdly, there must be no unreasonable discrimination: fixed broadband providers may not unreasonably discriminate in transmitting lawful network traffic.

These rules, applied with the complementary principle of reasonable network management, will ensure the continued freedom and openness that have enabled the development of the Internet. This framework provides greater clarity and certainty for consumers, innovators, investors and broadband providers, as well as the flexibility that providers must have to efficiently manage their networks. It enables a virtuous circle of innovation and investment in which new uses of the network-including new content, applications, services and devices-lead to increased end-user demand for broadband, driving network improvements that in turn lead to more innovative uses.

In 2011 two bills were proposed, one by the Senate (Preventing Real Online Threats to Economic Creativity and Theft of Intellectual Property Act, or PIPA) and another by the House of Representatives (Stop Online Piracy Act, or SOPA). Both bills are based on similar principles and essentially propose the same thing: to combat piracy of United States copyright-protected products, the law should require that content providers and Internet access providers block access to websites which infringe these provisions. These regulations have caused a stir in the United States and other countries amid claims that they violate the principles of freedom of expression and presumption of innocence and that, if adopted, the effects will be similar to the "Great Firewall of China". The difference between PIPA and SOPA is that while the former aims to block domains, the latter also aims to block IP addresses. These bills are still being debated in the United States Congress. If they are approved, websites that breach United States copyright laws would be blocked within five days and then the owners would be prosecuted under criminal law (United States Senate, 2011; United States House of Representatives, 2011). 


\section{Asia-Pacific}

\section{a) Republic of Korea}

The Republic of Korea is one of the most advanced broadband markets in the world and a global leader in the deployment of FTTx. This is partly because it implemented a sound national broadband development strategy that received wide political support. The government adopted an initiative known as the Korea Information Infrastructure (KII) Plan, which aimed to connect $84 \%$ of households to broadband services with speeds of up to $1 \mathrm{Mbps}$ by 2005 . Its next major objective was to deploy $1 \mathrm{Gbps}$ broadband services by 2012 .

The government adopted two development programmes: the Broadband Convergence Network $(\mathrm{BcN})$ and IT839. Their aim was to create a widespread network enabling customers to communicate at any time using a number of devices, such as fixed and mobile telephones, personal computers and home networks. In 2004, the government selected three consortia led by Korea Telecom (KT), DACOM and South Korea Telecom (SKT) to develop self-financed $\mathrm{BcN}$ prototypes. The objective was to create the best $\mathrm{BcNs}$ in the world, which would be able to provide up to 100 million households with fixed multimedia broadband and 100 million users with wireless services. This programme was followed by an UltraBroadband Convergence Network $(\mathrm{UBcN})$ programme running from 2009 to 2013 and focused on developing 1Gbps broadband services.

A comparative study of 16 countries carried out at the start of 2011 ranked the Republic of Korea as the most advanced country in terms of government planning for broadband development. Surprisingly, the government plans to spend less than $1 \%$ of its budget on the plan and aims to fund it by promoting private investment (Point Topic, 2011).

Although the Republic of Korea is one of the leading countries in broadband development worldwide, net neutrality policy and regulation is still embryonic. While the Telecommunications Business Act does not specifically mention net neutrality and the Korean Communications Commission (KCC) has not issued an official policy, there was a case in which a broadband operator was sanctioned for blocking one provider's VOD service. The KCC found that this blocking was a prohibited activity under the law. The dispute was settled by the VOD services provider agreeing to pay the broadband company a fee for using the network. Since Internet traffic is constantly rising, it is hoped that net neutrality will move higher up the agenda. 


\section{b) Japan}

Japan was relatively late in joining the broadband revolution but started experiencing rapid growth in the service in 2001. A major reason for the lag was the slow liberalization of the telecommunications market, which allowed the incumbent Nippon Telegraph and Telephone (NTT) to control the market in many ways. Despite this, liberalization started in 1999 when NTT was divided into a holding company with five major subsidiaries: NTT East, NTT West (local telephone companies), NTT Communications (long distance), NTT Docomo (mobile) and NTT Data (information services). Following liberalization, the broadband market grew quickly; by the end of 2009 Japan had the third largest in the world, after the United States and China.

In September 2007, the Ministry of Internal Affairs and Communications of Japan (MIAC) published the "Report on network neutrality", which identified two basic issues: fair distribution of network development costs and fair access to the telecommunications operators' network, including content providers. It discusses who should bear the development costs and whether telecommunications operators can participate in packet shaping (or blocking traffic) to guarantee network service quality. It focuses on whether major consumers should be required to pay additional charges depending on their use of packets and whether mass content distributors should pay additional charges to Internet service providers (ISP). Since there is no specific law prohibiting such charges, the report concludes that these matters should be left up to the telecommunications market (Ministry of Internal Affairs and Communications, 2007).

As for traffic management, four telecommunications operator consortia published a guide in May 2008 which is in line with the discussion in the "Report on network neutrality". It states that packet shaping could violate the Telecommunications Business Law (TBL) because telecommunications secrecy is protected by this law. However, packet shaping may be permitted under exceptional circumstances, such as when users have difficulties accessing a network because of major users' traffic or a specific application that overloads the network. The guide also states that telecommunications operators must inform users of rates and any traffic shaping, and how and when it will take place.

The Ministry of Information and Communications (MIC) set up the Study Group on a Framework for Competition Rules to Address the Transition to IP Based Networks in 2005. On 19 September 2007, the Group 
determined that there is net neutrality when the following three conditions are met: consumers are entitled to (i) use IP-based networks flexibly and access the content/application layer freely; (ii) connect to IP-based networks freely through terminals that comply with technical standards provided by laws and regulations and these devices may connect to each other flexibly; and (iii) use the communication layer and the platform layer free from discrimination at a reasonable price.

In line with the MIC initiative on reasonable traffic management, the associations of Internet providers, telecommunications operators and cable companies created the "Guide for Traffic Management" in 2010. According to this guide:

- The principal means of dealing with the rise in traffic include investing in the network and increasing its capacity; traffic management should be used only in exceptional circumstances.

- Traffic management must be designed to deal with network congestion (there must be official data to prove there is congestion). However, it is not a legitimate means for dealing with copyright infringement or data security issues.

- In order not to endanger the secrecy of any means of communication (article 21 of the Constitution of Japan), the ISPs must obtain individual and explicit consent from the users unless the act performed is in the pursuit of lawful business (article 35 of the Criminal Code).

- To ensure fairness in use (article 6 of TBL), traffic management shall be appropriate and non-discriminatory unless there are reasons to justify unfair treatment. Since ISPs and others are expanding the content business, such acts (discriminatory treatment) would hinder efforts to ensure fair competition.

- ISP must disclose their traffic management data in advance and in accordance with the revised telecommunications guidelines of the Consumer Protection Act. Since the configuration packet of an ISP may affect the broadband ecosystem, all parties concerned, including Internet providers and mobile virtual network operators (MVNO) must be informed.

\section{Situation and outlook in Latin America}

Few countries of the region have legislation or regulations on net neutrality. For most of them this is a new issue that has not been fully addressed, even though national regulations governing the sector spell out principles 
which enshrine users' right to free access. All of the countries, with the exception of Chile and, to a certain extent, Brazil, have only recently started to discuss net neutrality; any experience they have in implementing the corresponding legal and regulatory framework is minimal.

\section{Chile}

In August 2010, Chile became the first country in the world to adopt a net neutrality law. It bars telecommunications operators and Internet service providers from arbitrarily blocking, interfering with, discriminating, hindering or restricting an Internet user's right to use, send, receive or offer any lawful content, application, service or any other type of lawful activity or use through the Internet.

This law focuses on how access providers should calculate and publish Internet access service quality indicators, and it identifies some of the statistical measures that should be calculated and reported. It also states that access providers may only block services, content and applications at a user's request. In terms of the use of devices, it states that users may connect to the network using any lawful device which does not harm the security or quality of a service provided to others.

The regulatory decree of 18 March 2011 covers and elaborates on all of the aspects set out in the law, focusing on user rights and how users may exercise them when faced with an unfavourable situation. The decree establishes up front the information that Internet access providers should provide, such as the characteristics of the services offered to the users, quality indicators and traffic management measures. It also sets a time limit for access providers to provide this information upon user request. Under the provisions of this regulation, any action preventing or hampering a user from exercising the right to access information on the features of the access services offered is regarded as a practice restricting freedom of content, applications and services.

\section{Brazil}

Although there is no specific legislation on neutrality in Brazil, there are some references to it in the General Telecommunications Law. Article 3 grants all users of telecommunication services the right to nondiscrimination in conditions for access and use. On these legal grounds, the regulatory body (ANATEL) seeks to regulate net neutrality by drawing up specific rules for the Multimedia Communications Services Regulation, which is currently being updated.

Despite regulatory advances, net neutrality is a more general concept in Brazil and is not limited to Internet services. The rules to be implemented 
by ANATEL will bar all network and service providers, without exception, from blocking or discriminating against any type of traffic, regardless of content (voice, data, video) or technology used on the network.

Exceptions may be made to these provisions if they are required to ensure service and network stability, provided that the privacy of users and communications is respected and competition is not affected.

\section{E. Criteria for developing a national policy}

In view of the above, a number of considerations should be taken into account with respect to net neutrality.

Free choice. When developing a national policy on net neutrality, priority should be given to the user's right to freely use, send, receive and offer any lawful content, application or service through the Internet, unless they are prohibited under statutory provisions. The user must also be able to freely use any lawful instrument, device or apparatus on the Internet which does not harm service security or quality. No characteristic of the network should prevent or hamper a user from exercising the right to free choice. The only condition should be lawful use of the Internet, since combating cybercrime takes priority over individual rights.

Non-discrimination. Network and telecommunications services providers which provide Internet access must always treat content, applications and services equally, without discriminating against source or ownership. Network and telecommunications services providers which offer Internet access can make offers based on market segment needs or use and consumption by users; this should not be taken as discrimination.

Transparency. Network and telecommunications services providers offering Internet access must disclose their network management policies to users and other providers that have access to their network, such as content or applications providers. Transparency is essential for users to know the conditions of the services they are offered. Net neutrality policymakers must bear in mind that users have the right to be informed about the conditions under which they will be provided Internet access and whether traffic management practices will be used which may affect their privacy and the quality of the service they will receive.

Right to information. Network and telecommunications services providers offering Internet access should provide users with complete information on service terms and conditions, including speed, quality 
and traffic management practices for each plan offered by the provider or hired by the user. This principle is closely related to and complements information transparency in that information targets each user as an individual client.

The Internet as basic infrastructure. The Internet is essential infrastructure, both for the flow of economic activity and as an input for many other services of great social value, such as access to educational information and the dissemination and discussion of political views. The economic value of reliable Internet access should not be left out of the debate on net neutrality which will inevitably take place between access providers and governments. After all, the access providers' business model is based on the idea not only that their investments will be recouped from users but, in addition, service providers and applications must contribute through what are known as bilateral markets. In any event, those agreements must be left to free competition and negotiation between parties.

"Neutral" Internet. One of the most hotly debated issues is whether net neutrality and Internet neutrality are synonymous. Net neutrality is the principle that all Internet traffic generated within the network should be treated equally regardless of factors such as content, access type or user characteristics. Internet neutrality, however, is a much more complex concept which deals with issues such as whether the information within the network of networks is being intentionally altered or blocked because the availability of network resources is limited at the source. Obviously, things like cybercrime often justify not only blocking the website involved in criminal activities but also prosecuting those responsible. In any event, it should be understood that the Internet will never be absolutely neutral and that a poorly implemented net neutrality principle is no reason for allowing websites, for example, to publish child pornography or copyrightinfringed material or, quite simply, threaten the future of the web.

The Chilean law on net neutrality, which is the most advanced in the region, explicitly excludes unlawful content, applications and services. Therefore, there is no reason to bar (without a court order) filtering of unlawful content, applications or services provided that the filter does not affect lawful content that may be hosted on the same website or operate with the same IP address as unlawful content. It does refer to protection against malicious acts by blocking (without waiting for a court order) outgoing and incoming traffic from anyone who has been identified as a hacker on the grounds that they are attacking the provider's or third party's equipment through the Internet. 


\section{Bibliography}

Bocache, Romina, Andrei Mikheyev and Virginia Paque (2007), The Net Neutrality Debate and Development, March.

Cisco Systems Inc. (2011), Cisco Visual Networking Index: Forecast and Methodology, 2010-2015, 1 June.

CRTC (Canadian Radio-television and Telecommunications Commission) (2011), CRTC Communications Monitoring Report 2011 [online] http:/ /www.crtc. gc.ca/eng/publications/reports/PolicyMonitoring/2011/cmr6.htm.

Enaux, Christoph and Blanca Escribano (2011), "An Overview of the EU Regulatory Framework", The International Comparative Legal Guide to: Telecommunication Laws and Regulations, Olswang LLP, 2012.

FCC (Federal Communications Commission) (2011), "Preserving the Open Internet"; [GN Docket No. 09-191; WC Docket No. 07-52; FCC 10-201]; Federal Register / Vol. 76, No. 185 / Friday, 23 September / Rules and Regulations.

Gilder, George (1992), "La llegada de la fibroesfera", Forbes ASAP, 7 de diciembre.

MIAC (Ministry of Internal Affairs and Communications of Japan) (2007), Report on Net Neutrality. Working Group on Net Neutrality, September.

Peha, Jon M. (2006), “The Benefits and Risks of Mandating Net neutrality, and the Quest for a Balanced Policy", paper presented at the 34th Telecommunications Policy Research Conference, Carnegie Mellon University, September.

Pehnelt, Gernot (2008), "The economics of net neutrality revisited", Jena Economic Research Papers, 27 October.

Point Topic (2011), "South Korea Broadband Overview, 16 September [online] http:/ / point-topic.com/content/operatorSource/profiles2/south-koreabroadband-overview.htm.

United States House of Representatives (2011) "Stop Online Piracy Act", 112th Congress, 1st Session; House Judiciary Committee; 26 October [online] http:/ /judiciary.house.gov/hearings/pdf/112\%20HR\%203261.pdf.

United States Senate (2011), Federal Communications Commission (FCC), "Preserving the Open Internet" [GN Docket No. 09-191; WC Docket No. 07-52; FCC 10-201]; Federal Register, vol. 76, No. 185, 23 September/ Rules and Regulations [online] http://judiciary.house.gov/hearings/pdf/112\%20HR\%203261.pdf.

$\mathrm{Wu}$, Tim (2005), "Net neutrality, broadband discrimination", Journal of Telecommunications and High Technology Law. 
Fourth part

The future of the ecosystem 



\section{Chapter X \\ The advance of cloud computing}

René Bustillo

\section{A. Introduction}

A topic of growing importance in the information technologies (IT) field is cloud computing also known as cloud services, "the cloud", computational cloud or cloud concepts. Like all new trends, cloud computing has sparked different opinions. There are those who see in it many benefits and others who claim it is nothing new or who view it as a passing fad. What is clear is that cloud computing in Latin America, both in government offices and in private firms, continues to grow rapidly. The adoption of cloud computing services is expanding primarily because their architecture offers the benefits of shared services over isolated products. Shared services help an organization focus on its core business and enable its departments to reduce the gap between available computing capacity (which is frequently oversized) and systems demand (generally low-volume, with occasional peaks). This results in a much more efficient usage-based model.

Cloud computing is not one single technology but rather a combination of many technologies. Its elements may look like those from the earlier days of computing, but advances in virtualization, storage, connectivity and processing capacity have, together, created a new technical ecosystem. The result is a fundamentally different and attractive phenomenon. 


\section{B. What is cloud computing?}

Cloud computing is a model for enabling convenient, on-demand network access to a shared pool of configurable computing resources (for example networks, servers, storage, applications and services) that can be rapidly provisioned and released with minimal management effort or service provider interaction. This model fosters availability and has five essential characteristics (on-demand self-service, broad network access, resource pooling, rapid elasticity, and measured service), three service models (Software as a Service, or SaaS; Platform as a Service, or PaaS; and Infrastructure as a Service, or IaaS), and four deployment models (private cloud, community cloud, public cloud and hybrid cloud). The key enabling technologies are fast wide-area networks (WAN); powerful and inexpensive server computers; and virtualization for high-performance commodity hardware. Diagram X.1 shows how these elements are interrelated and the degree of development of each one.

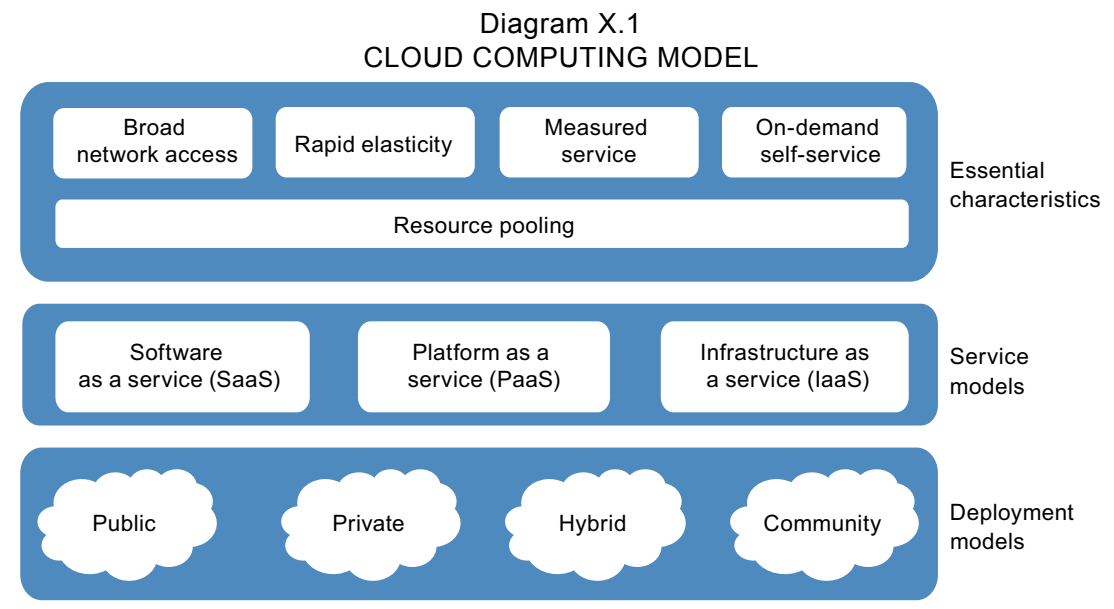

Source: National Institute of Standards and Technology (NIST).

The cloud computing model offers the promise of massive cost savings combined with greater flexibility. In developed countries, it is increasingly seen as crucial that government and industry speed uptake of this technology in response to economic constraints. But there is opposition to this technology because it challenges traditional approaches to datacentre and business applications design and management and poses unresolved issues of security, interoperability and portability. 


\section{Essential characteristics}

The definition provided by the United States National Institute of Standards and Technology (NIST) includes the five essential characteristics described below.

\section{a) On-demand self-service}

This allows for use of cloud computing resources as needed, without human interaction between the user and the service provider. With ondemand self-service, a consumer can programme the use of services in the cloud, such as computing and storage, as needed, in addition to the management and implementation of these services. In order to be effective and acceptable to the consumer, the self-service interface must be easy to use and must provide efficient means for managing the services offered. Ease-of-use and elimination of human interaction boost efficiency and cost savings for the user and the service provider.

\section{b) Broad network access}

If this technology is to be an effective alternative to in-house datacentres, large bandwith communication links need to be available for connecting to cloud services. One of the main economic justifications for cloud computing is that the reduced cost of communication with the broadband network in the cloud provides access to a larger amounts IT resources, which in turn can lead to a high degree of utilization. Many organizations are using a three-tier architecture to connect a wide variety of computer platforms, such as laptop computers, printers, mobile telephones and PDA, to the wide area network. This three-tier architecture includes access switches that connect desktop devices to aggregation switches, which in turn control the flow, and routers and switches that provide connection to the WAN and traffic management. ${ }^{1}$

\section{c) Resource pooling}

The cloud must have a large and flexible pool of resources to satisfy consumer needs, generate economies of scale, and meet level-of-service requirements. Applications need resources for running them, and these resources must be efficiently allocated for optimal performance. Resources may physically reside in many different geographic locations and be

\footnotetext{
The result of this approach is latency times of 50 microseconds or more, which causes lags in cloud computing. To ensure good performance, the switching environment must have a latency time of 10 microseconds or less. A two-tiered approach that eliminates the aggregation layer can fulfill this requirement, using 10 GB (10 Gigabits/second) Ethernet switches and the next 100 GB Ethernet switches.
} 
allocated as virtual computing components as needed. As the NIST puts it, "[t]here is a sense of location independence in that the customer generally has no control or knowledge over the exact location of the provided resources but may be able to specify location at a higher level of abstraction (e.g., country, state, or datacenter)."

\section{d) Rapid elasticity}

Rapid elasticity refers to the cloud's capacity to expand or reduce the allocated resources promptly and efficiently in order to meet the requirements of the self-service characteristic. This allocation can be done automatically, and the consumer will have the impression of an unlimited quantity of dynamic resources that can be purchased as and when needed. One of the characteristics of elasticity is that it allows rapid development and implementation of loosely coupled services that can be adjusted independently of other services and do not depend on their elasticity. Diagram X.2 shows how IT platforms have evolved over time, beginning with local memory caches in the server, moving on through distributed memory caches and elastic caching platforms and, finally, elastic application platforms in the era of cloud computing,. This is a key consideration with respect to the ease and attractiveness of cloud computing systems, because the possibility of expanding computing capacity according to need can only be achieved in traditional servers at the cost of steep investments in hardware that would stand idle most of the time.

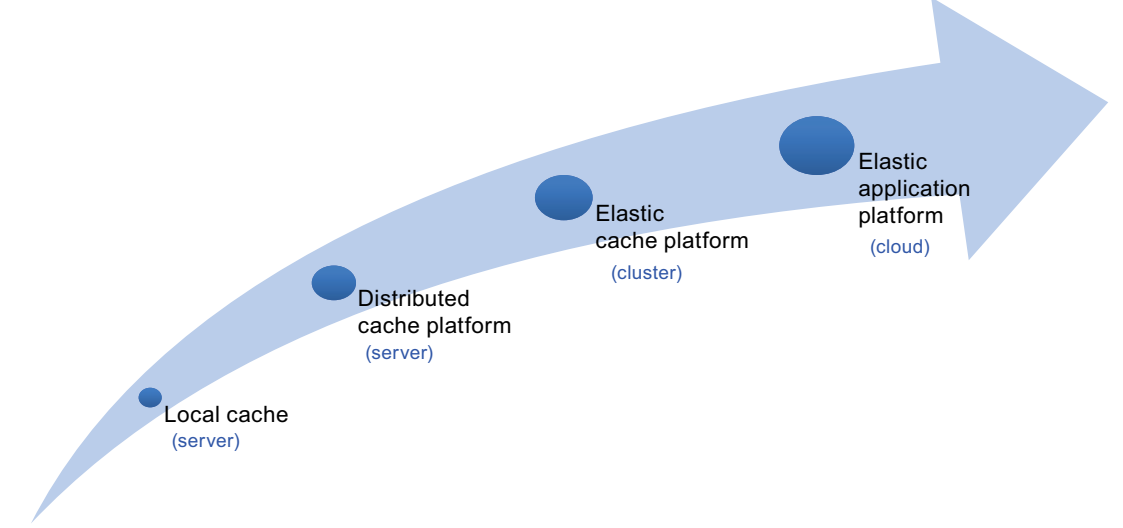

Source: Prepared by the author. 


\section{e) Measured service}

Given the characteristics of service-oriented cloud computing, the quantity of cloud resources that a consumer uses can be dynamically and automatically assigned and monitored. Customers can then be billed only for their actual use of the resources assigned to them for a particular session. The NIST describes measured service as follows: "[c]loud systems automatically control and optimize resource use by leveraging a metering capability at some level of abstraction appropriate to the type of service (e.g., storage, processing, bandwidth, and active user accounts). Resource usage can be monitored, controlled, and reported, providing transparency for both the provider and consumer of the utilized service" (Mell and Grance, 2011). The concept of measured service is closely related to that of on-demand self-service. However, the innovation is that the user is billed only for what is used and does not have to purchase costly hardware and software which, in some cases, will represent a very high fixed cost and poses a barrier to market entry. The other advantage is that if at some point the user decides to change to a different commercial activity, it does not have to modify or dispose of the IT platforms, which generally are not its property, since it merely has a service contract with the service provider.

\section{Service models}

The generally accepted classification scheme for cloud computing involves the software platform infrastructure (SPI) model, which includes three principal services provided via the cloud (SaaS, PaaS and IaaS). Although there are other concepts that suggest variations of this scheme, the SPI framework is currently the most widely accepted classification of cloud computing. The NIST uses this framework, and most cloud service providers support the concept.

Diagram X.3 shows the development path of cloud computing and the SPI model, and how service providers have adopted the various service models that the cloud offers. Cloud computing is a new concept, but the technologies that came before it and have contributed to the development of the cloud services that are commercially available today have been around for decades. Supercomputing and cluster computing existed 20 years ago, and grid computing was based on these platforms.

Although there are many similarities between utility computing and cloud computing, the former includes information processing as yet another service, like water or electricity. The similarity breaks down at this point, as cloud computing includes more elements within the service than utility computing does. Table X.1 shows the features of cloud computing 
in relation to other technologies. Because it developed from other IT architectures, cloud computing is much more comprehensive than its predecessors and encompasses their features.

Diagram X.3

DEVELOPMENT OF CLOUD COMPUTING AND SOFTWARE PLATFORM INFRASTRUCTURE (SPI)
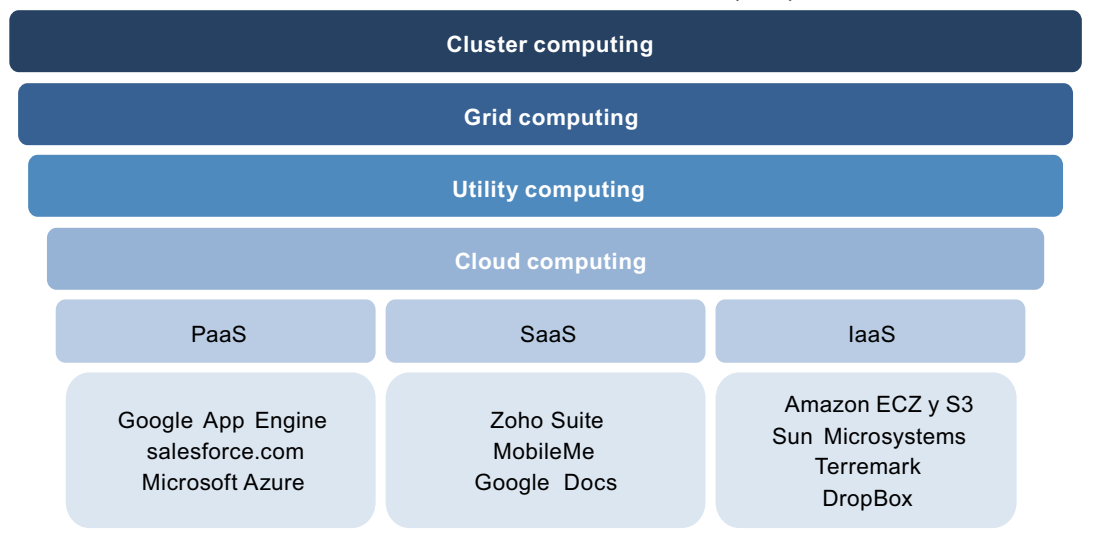

Source: D. Baran, "Cloud Computing Basics", WEBGUILD, July 2008 [online] http://www.webguild. org/20080729/cloud-computing-basics.

Table X.1

CHARACTERISTICS OF CLOUD COMPUTING

\begin{tabular}{lccc}
\hline IT architectures & Metered use & Web-based costumer & Distributed processing \\
\hline Cloud computing & $\mathrm{X}$ & $\mathrm{X}$ & $\mathrm{X}$ \\
Utility computing & $\mathrm{X}$ & & $\mathrm{X}$ \\
Grid computing & & & \\
$\begin{array}{l}\text { Virtualization } \\
\text { technology }\end{array}$ & $\mathrm{X}$ & \\
\hline
\end{tabular}

Source: F. Belfort, "Panorama do mercado brasileiro de Cloud Computing", presentation at the Cloud Conference 2012, Frost \& Sullivan, August 2012.

\section{a) Software as a cloud service}

The NIST defines SaaS as follows: "The capability provided to the consumer is to use the provider's applications running on a cloud infrastructure. The applications are accessible from various client devices through either a thin client interface, such as a web browser (e.g., webbased email). The consumer does not manage or control the underlying cloud infrastructure including network, servers, operating systems, storage, or even individual application capabilities, with the possible 
exception of limited user-specific application configuration settings" (Mell and Grance, 2011).

At a high level, SaaS offers various benefits throughout the organizational structure. First, it enables an organization to outsource application hosting to an independent software vendor or other software service provider. This nearly always reduces the cost of licenses, hardware, management and other resources needed for internally hosting the application. SaaS also benefits the application provider by increasing its control over the use of the software, limiting the distribution of unlicensed copies and allowing the software vendor to exert greater upgrade and patch management control. SaaS also enables the provider to create and control multiple revenue streams with a one-to-many model, reducing duplication of software packages and overhead. Moreover, end users in remote or branch offices can access the application more readily through a browser, and start-up is enormously simplified. Apart from modifications to peripheral devices (such as firewalls) to allow specialized ports references, the end-user's hardware requirements are also minimal.

\section{b) Platform as a cloud service}

The NIST defines PaaS as follows: "The capability provided to the consumer is to deploy onto the cloud infrastructure consumer-created or acquired applications created using programming languages, libraries, services, and tools supported by the provider. The consumer does not manage or control the underlying cloud infrastructure including network, servers, operating systems, or storage, but has control over the deployed applications and possibly configuration settings for the applicationhosting environment."

The PaaS model offers lower entry costs for application designers and distributors, supporting the complete development of the web application software lifecycle and eliminating the need to acquire hardware and software resources. A PaaS solution can include a complete end-to-end application solution for the development, testing and deployment of an application or it can be smaller and more specialized, focusing on a specific area such as content management. If a software development platform is to be considered as a PaaS solution it must have the following elements: (i) baseline supervision of applications must be used in order to improve the processing platform; (ii) the solution must offer perfect integration with other cloud resources, such as databases and other web-based infrastructure components and services; (iii) dynamic multi-tenancy must be achievable, and collaboration via the cloud between developers, customers and users over the entire lifecycle of the software must be readily achievable; (iv) security, privacy and confidentiality must be maintained as a basic service; and (v) the development platform must be browser-based. 


\section{c) Infrastructure as a cloud service}

The IaaS model is the one that most clearly demonstrates the difference between traditional IT infrastructure and cloud-based infrastructure services. The NIST definition for IaaS is as follows: "The capability provided to the consumer is to provision processing, storage, networks, and other fundamental computing resources where the consumer is able to deploy and run arbitrary software, which can include operating systems and applications. The consumer does not manage or control the underlying cloud infrastructure but has control over operating systems, storage, and deployed applications; and possibly limited control of select networking components (e.g., host firewalls)."

The benefits of IaaS are similar to those of other *aaS models. Smaller firms have access to a much greater range of IT solutions and technology, and dynamic infrastructure scalability allows IaaS consumers to adapt their needs at a more detailed level. The costs of organizing computing systems infrastructure have traditionally made up a large portion of business expenses. Leasing or buying dedicated hardware and software and engaging in-house experts or consultants consume a significant portion of any firm's resources. Using the IaaS model (often in combination with the SaaS or PaaS model) offers a level of scalability that can swiftly respond to demand in a way that conventional acquisition, deployment and maintenance of IT infrastructure cannot.

\section{Enabling technologies}

The essential enabling technologies for cloud computing include fast widearea networks, powerful and inexpensive computer servers, and virtualization for high-performance commodity hardware, as described below.

\section{a) Fast wide-area networks}

An important requirement for cloud computing is the existence of high-speed networks, more specifically wide-area networks (WAN) that allow access to remote servers at high speeds in the order of gigabits per second (or even faster in the future). The evolution of WANs has allowed the development of very high-speed connections worldwide, an aspect that facilitates the transfer of enormous volumes of information in very short times. Map X.1 shows average Internet access speed worldwide; many regions, particularly North America, Asia-Pacific and Europe, have high averages.

Much of Latin America still has relatively low average Internet access speeds, reflecting the fact that the region lacks widespread deployment of 
physical networks and that deployment of fibre-optic backbone networks is still limited. The challenge facing cloud service providers in Latin America is to ensure that their customers have access to sufficient speed and, even more important, that the WANs have enough capacity and speed to provide reliable and secure services.

Map X.1

AVERAGE INTERNET CONNECTION SPEED AROUND THE WORLD

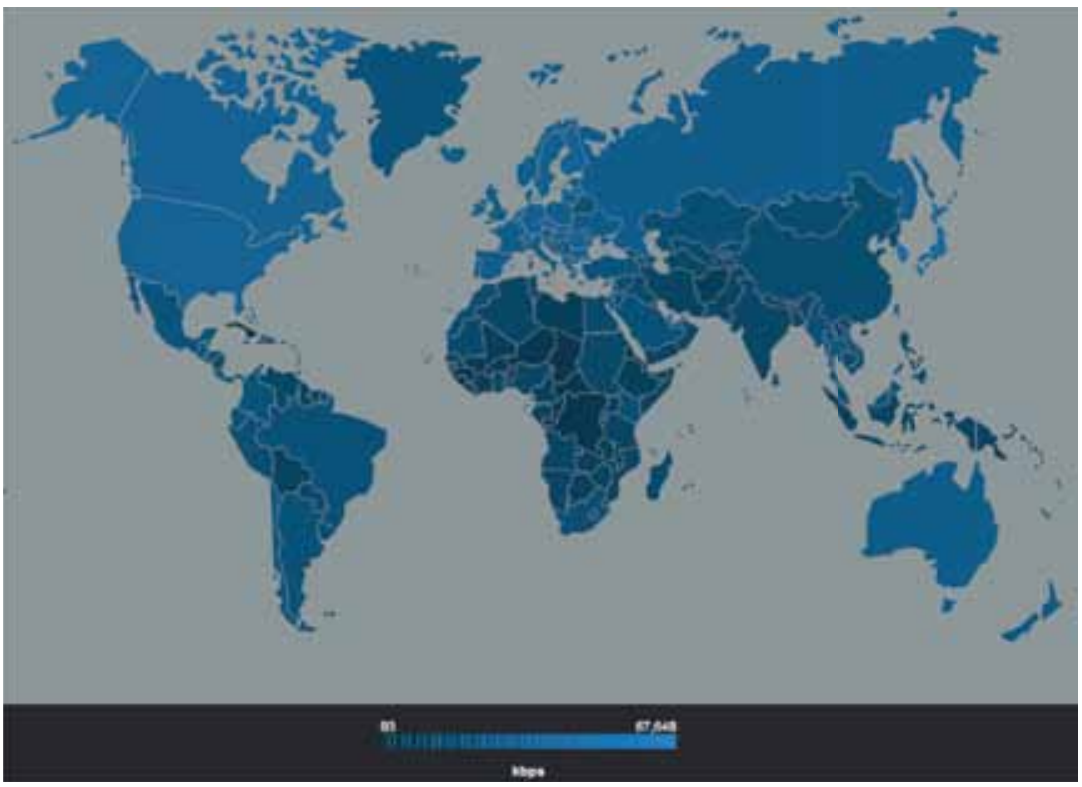

Source: Akamai, State of the Internet Report, second quarter 2012.

Note: The boundaries and names shown on this map do not imply official endorsement or acceptance by the United Nations.

\section{b) Powerful, low-cost computer servers}

Another important enabling technology is very high-speed, lowcost servers capable of handling clients' processes in the cloud in costefficient way. Moore's law, which holds that the number of transistors in an integrated circuit will double approximately every 18 months, allows these objectives to be achieved. The direct consequence of Moore's Law is that prices fall as performance rises: a computer that is today worth US $\$ 3,000$ will cost half that amount next year, and will be obsolete in two years. In 26 years the number of transistors in an integrated circuit will have increased 3,200 times. This empirical law is one of the main reasons why server equipment can be expected to fall in price and increase in speed; in other words, servers will be even more powerful and less expensive. 


\section{c) Virtualization for high-performance commodity hardware}

An indirect consequence of Moore's Law is that high-performance hardware can be found on the market at prices that render them an undifferentiated product (a commodity). Such equipment can be offered by cloud service providers in an almost generic manner, so that it makes sense to offer them in virtual form. The need for specialized equipment is receding constantly, and firms' IT requirements can be covered by generic systems.

\section{Deployment models}

In each of the three service models described there are multiple deployment models. For example, an SaaS delivery model can be presented to users in one of many deployment models, such as a private or a public cloud. These deployment models are not technically or functionally related to any delivery model. Any one of them can exist in any of the deployment scenarios, although a given service/deployment pairing model may be more common than others (for example, SaaS/public cloud).

Depending on an organization's use of the cloud and its relationship with the enterprise as a whole, these deployment models may make use of either external or internal clouds. Each of these models must share the following basic principles: (i) each deployment model uses devices connected to the Internet; (ii) each model offers dynamic scaling of virtual resources; and (iii) the users of each model normally have no control over the technology that is used.

The cloud computing deployment models are:

- Private cloud. The cloud infrastructure is operated for exclusive use by a single organization. It may be managed by the organization or a third party, and it may exist on or off premises.

- Community cloud. The cloud infrastructure is shared by various organizations and is compatible with a specific community that has shared concerns (e.g., mission, security requirements, policy, and compliance considerations). It may be managed by the organization or a third party, and it may exist on or off premises.

- Public cloud. The cloud infrastructure is provisioned for open use by the general public or a large number of enterprises and is owned by a service vendor.

- Hybrid cloud. The cloud infrastructure is a composition of two or more distinct cloud infrastructures (private, community, or public) that remain unique entities but are bound together by standardized or proprietary technology that enables data and application portability ("cloud bursting" is an example). 
An organization may deploy one or several models, depending on which offers the best solution. For example, a critical application that has compliance or some other type of security specifications may need a hybrid or private cloud model. On the other hand, a general application needed for a temporary project could better lend itself to a public cloud. In none of these four models is the physical location of the infrastructure or the application specified. A co-location facility may host both public and private clouds.

\section{Service layers}

The provisioning of cloud services can be more readily understood when analysed from the viewpoint of the architecture's component layers. Craig-Wood (2010) offers an analysis of the layers that make up the typical structure of networked computing and provides a visual diagram with examples for each layer. Diagram X.4 shows the service layers and the levels at which the different services are located within this structure.

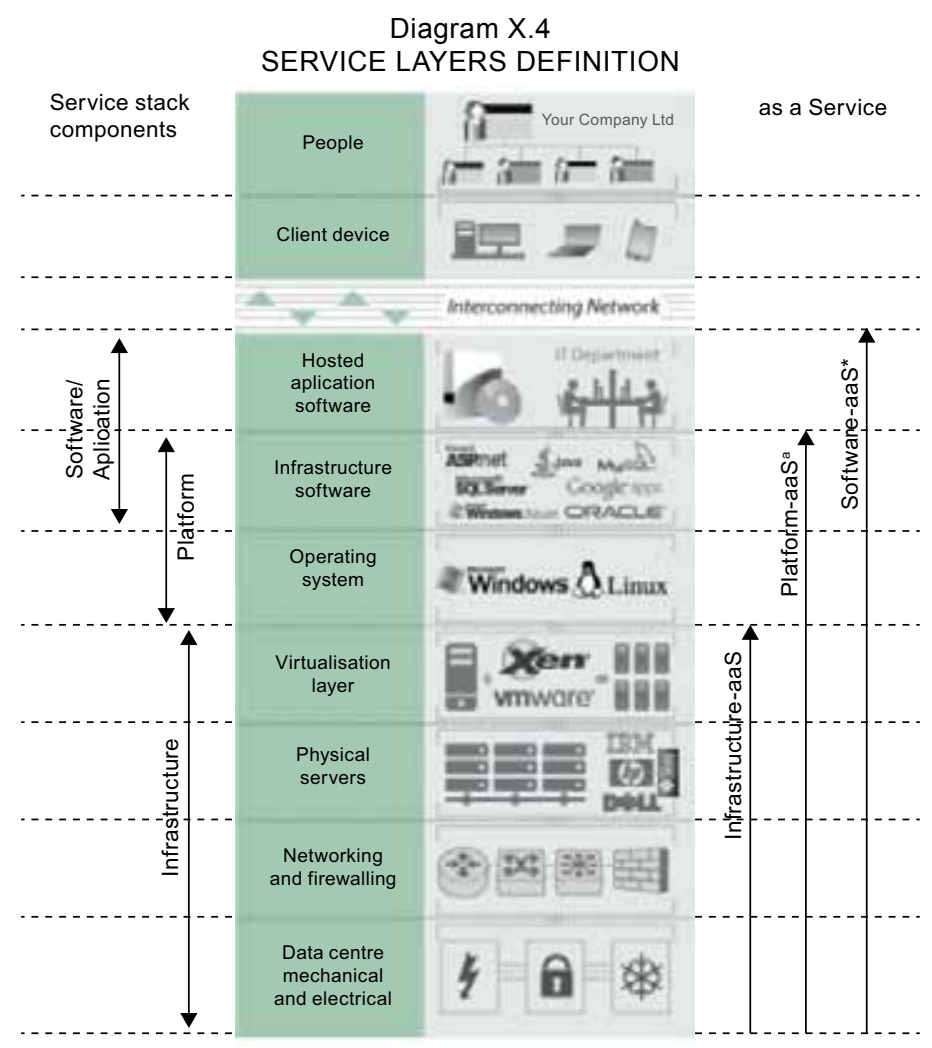

Source: Craig-Wood (2010).

Note: Brand names for illustrative/example purposes, only and examples are not exhaustive.

a Assumed to incorporate subordinate layers. 
In the first place, this structure of layers bears a great similarity to the seven-layer ISO/OSI (International Standards Organization's Open System Interconnect) structure. The four bottom layers include most of the hardware used for data communication and processing. These four layers are the ones that an IaaS provider would offer to its clients, as indicated in the right-hand portion of the diagram. Platform refers to the next two higher layers (operating system and infrastructure software), which are offered by PaaS providers in addition to the underlying infrastructure. It is at this level that applications are developed and where cloud computing has a specific market of application developers. Finally, the software and the applications are located in the two top layers, with the next-to-top coinciding with the platform. This is where SaaS, the most common cloud service, is offered.

\section{Problems and challenges}

Cloud computing, like any paradigm shift, presents problems and challenges when it is used in IT environments that usually kept everything "under control". The typical IT department today consists of personnel devoted exclusively to developing computer networks and equipment and keeping them running. These tasks take a great deal of time and much of a firm's resources. While there are a number of challenges to be addressed in adopting cloud computing, the main ones are described below.

\section{Security and privacy}

Many potential users say that concerns about data privacy and confidentiality make them less willing to use cloud computing services for sensitive data. In the cloud, data is stored on remote machines that are shared with other users. This makes many users concerned about the potential for business competitors or government authorities to access their data in the cloud without their knowledge or consent.

Governments would like to mandate and apply national legal requirements for data stored in the cloud, and many have done so. Given the cross-border nature of the cloud, though, national measures to protect data privacy and confidentiality have only limited capacity to reassure users. There is a desire for greater global consistency in data privacy requirements applying to the cloud, but government actors point out that fundamental differences in their approaches make comprehensive international agreements on this issue unlikely. For example, the United States has a stricter regulatory regime for specific sectors, such as health care, where privacy and confidentiality issues are especially sensitive. The European Union has blanket data privacy laws.

Given these regulatory challenges, users concerned about data privacy and confidentiality will ultimately have to rely on market 
mechanisms to assess provider reliability. Nonetheless, there is no guarantee that appropriate market mechanisms will emerge in a timely fashion (World Economic Forum, 2011).

Users are concerned that data in the cloud are more susceptible to cyberattacks, because aggregating multiple users' data and services on a single platform makes them a more attractive target. Providers point out that no security mechanisms are infallible and all come with trade-offs. Encryption can be expensive, and using hypervisors to virtually isolate a user's applications and data can still leave vulnerabilities. More broadly, industry and governments alike express concern that technical security mechanisms such as encryption could give users a false sense of security. Encryption is only as effective as the user's control of who has the key, and it does not solve the problem of a malicious insider or of users being manipulated into giving access. These concerns are bound up with wider questions of how to manage and verify identities.

When users store their data on their premises, it is clear who is accountable if the data is corrupted, lost or temporarily inaccessible. This is not necessarily the case when the data is stored in the cloud. When it is unclear whether a problem lies with the cloud provider or with the networks the user is using to access the cloud, users are concerned that they will be unable to establish who is accountable and to seek redress.

Many users' data may be shared on one machine, so users are concerned about the potential for problems with one user's services affecting another's. Government actors express concern about the resilience of cloud providers to distributed denial-of-service (DDoS) attacks and note there is a disincentive for providers to report breaches and problems. Some industry stakeholders, however, believe they are already being transparent enough, especially given that most client agreements require the service provider to notify the client of any data leakage or loss.

With all its benefits, cloud computing also brings with it concerns about information security and privacy, as a result of its size, structure and geographic dispersal. Krutz and Dean Vines (2010) identify the following problems:

- Leakage and unauthorized data access among virtual machines running on the same server.

- Failure of a provider to handle and protect sensitive information properly.

- Release of critical or sensitive data to law enforcement or government agencies without client's knowledge and approval.

- Inability to follow compliance and regulatory requirements.

- System crashes or failures that make service unavailable for extended periods of time. 
- Hacker invasions to obtain and distribute sensitive information from client applications.

- Provider's lack of robust security protection.

- Low interoperability of the kind that that would allow a client to easily move applications among different cloud providers and avoid lock-in.

Cloud users also worry whether their data will be continuously available over long periods of time, and whether the cloud provider might surreptitiously exploit sensitive data for its own purposes.

\section{Reliable network access}

Reliable network access includes many aspects, some of which have been covered above in relation to data protection measures. However, reliable network access includes a technical component that, while implicit in the issues discussed, is not very carefully analysed. That component is reliable access to the network.

Reliable network access implies a level of quality that allows data to be transferred as required, with confidence that communications will always be available when needed. Although this aspect does not create major problems in countries with highly developed networks, in many Latin American countries there are still problems with the lack of availability of networks and their reliability.

In the case of cloud computing, communication services are generally outsourced to specialized firms ("telcos"). Proper provision of services usually requires an above-average level of service and availability, and this must be spelled out in the service agreements. If the networks are proprietary, there must be assurance that individual failures will not compromise the functioning of the communications systems as a whole. In other words, there must be enough alternative communication routes to cope with interruptions (planned or not) and to foresee situations such as a mass cut-off of communications because of a submarine cable break. This is particularly important when it comes to storing data in various locales in different countries or regions.

\section{Legal and regulatory aspects}

It is not surprising that the nascent cloud service industry finds government regulations to be complex and contradictory. There is little agreement on the kind of regulation necessary in general or internationally. For example, one European Union regulator does not believe that data privacy 
regulations should be updated for cloud computing, a viewpoint quite different from that of the industry (World Economic Forum, 2010).

The World Economic Forum suggests that governments adapt and harmonize regulations for the cloud in order to improve their enforceability and reduce divergence across jurisdictions, while considering the maturity of the industry. There is widespread frustration among market stakeholders with the regulatory framework for cloud computing, especially in the areas of data privacy and security. Regulations are often inconsistent, conflicting and difficult to comply with for users and providers operating globally. This holds back users from moving to the cloud, as they fear regulatory provisions are insufficient to protect their data from being unduly accessed by law enforcement or retained by providers. And when regulations effectively force data to remain within national borders (either directly by restricting data transfers outside the jurisdiction, or indirectly through a lack of cross-jurisdictional alignment) they hold back cloud providers from making improvements that would create economies of scale by using multiple storage locations.

As a long-term goal, governments may wish to explore a macroregulatory framework that will be more flexible and keep pace with rapid technological change. Options include co-regulation, whereby industry takes the lead in identifying necessary provisions and governments take a policy and oversight role. This would mean a harmonized approach to the underlying principles that guide regulation, which currently differ across jurisdictions: the sectoral approach to data privacy regulation taken by the United States stands in particular contrast to the European Union's more universal one. Minimum regulatory standards are not a solution; they are often not enough to reduce complexity because they do not stop countries from introducing additional provisions.

As a step in this direction, governments should continue the dialogue with providers to better understand the impact of regulations. Data protection authorities can play an important role in interpreting and harmonizing legal frameworks to more effectively meet user and provider needs. They can also provide understandable and authoritative guidance about respective responsibilities and protections, and the recourse available in the event of breaches.

\section{Resistance to change}

One final factor, which is not related to technology but rather to human behaviour, is resistance to change. This is a very natural human trait that comes to the fore when traditional ways of doing things are confronted with new ones. Table X.2 shows the differences between the conventional IT model and the models associated with cloud computing. 
Table X.2

COMPARISON BETWEEN CONVENTIONAL MODELS AND CLOUD COMPUTING

\begin{tabular}{lll}
\hline & Conventional model & Cloud computing \\
\hline Purchase model & $\begin{array}{l}\text { Buy assets and build a } \\
\text { technological architecture }\end{array}$ & Lease services \\
Business model & $\begin{array}{l}\text { Pay for fixed and administrative } \\
\text { assets }\end{array}$ & Monthly payment \\
Access model & $\begin{array}{l}\text { From the internal network to the } \\
\text { corporate desktop }\end{array}$ & $\begin{array}{l}\text { Via Internet, to any device } \\
\text { (telework) }\end{array}$ \\
Marketing model & Face-to-face sales & $\begin{array}{l}\text { Scalable, flexible, dynamic, } \\
\text { multiuser }\end{array}$ \\
Service model & Call centre - service points & $\begin{array}{l}\text { Online sales } \\
\text { Contact centre - Anywhere }\end{array}$ \\
\hline
\end{tabular}

Source: Chamber of Commerce of Medellín, Computación en la Nube. 2011.

For one, a firm's IT personnel, after years of buying assets and building systems, are now faced with the challenge of leasing those same services. This can generate resistance among IT department staff who will feel that their main responsibilities are being outsourced. The business model changes, and instead of paying for hardware and software at unplanned intervals the firm now makes monthly service payments to the cloud provider.

The virtualization of activities is another aspect that can readily create resistance, as now, instead of single-point access, systems can be used from anywhere. Concerns associated with lack of control over data in the system are frequently reported as a potential problem by IT staff and managers. Yet perhaps the most alarming aspect for those responsible for systems is that the servers that used to be next to their offices will disappear and be replaced by servers in locations over which they have no control. These aspects relating to the new cloud working environment, together with the uncomfortable feeling that what were considered routine activities (like server maintenance and software updates) are no longer required and their time must be devoted to development work, tend to spark unease and resistance among IT personnel.

\section{Migration to cloud computing}

Migration to cloud computing occurs for many reasons, the most frequent being to reduce the costs of operating in-house computer infrastructure. But there are also other reasons why a user may decide to migrate, and when: these will depend on various aspects relating to how a business is structured. Those in the best position to analyse migration possibilities are likely to be users who have not yet begun operations, as they do not need 
to consider what they will do with an existing computer system. Those who have the greatest difficulties are likely to be users who have invested heavily in equipment and software.

\section{Reasons for migrating}

An analysis of the reasons that an enterprise may have for migrating its IT operations to cloud computing shows that all kinds of considerations come into play. Lockheed Martin Corporation (2011) conducted a survey of firms that adopted cloud computing for their IT activities; responses to the question as to why they chose this technology are set out in figure X.1.

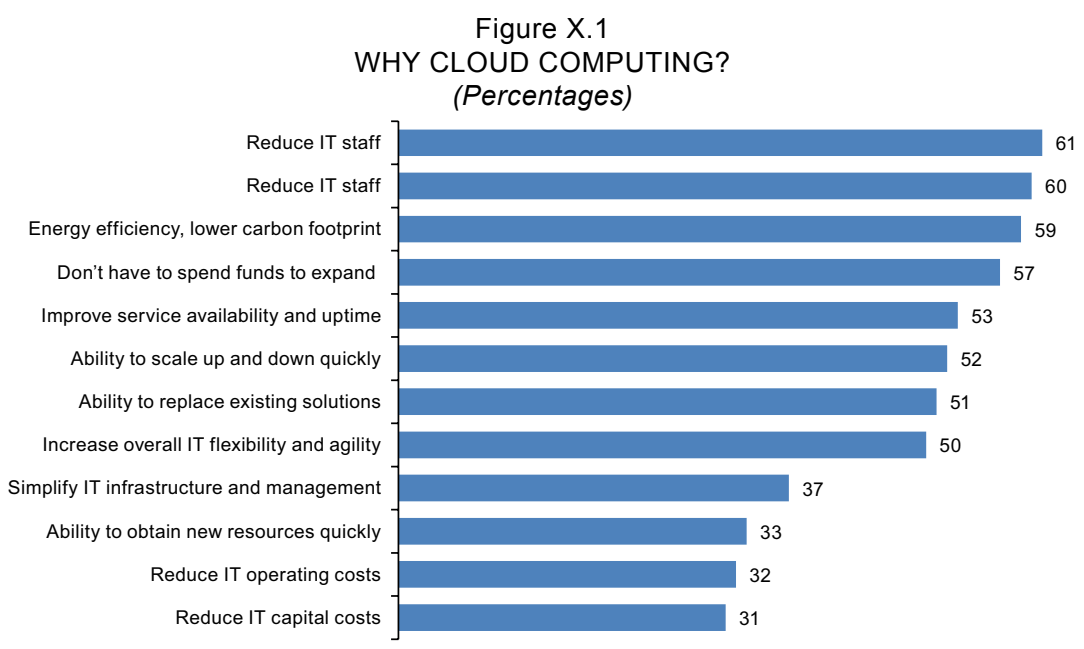

Source: Lockheed Martin Corporation, When the cloud makes sense, The Download - Cloud Computing Research Study, 2011.

The first reason is savings, both on licenses and on service management and equipment. If an infrastructure is 100\% cloud-based there is no need to install any kind of hardware beyond the terminals. It is this simplicity for the user and the fact that a much smaller investment is required to begin work that is the real strength of this technology.

There are also savings on hardware: there is no need to choose between a laptop or a desktop computer, or to determine which is cheaper and, often, faster. In the world of cloud computing, the user can buy an inexpensive thin client laptop that can be connected to a screen and a keyboard. Then, all that is needed is to connect to a provider and have all the performance and memory desired. Next, when the user would normally have to replace an obsolete laptop, it can still use its thin client, because the provider, and not the equipment itself, supplies the performance. 
Fast, low-risk deployment is another benefit. With cloud computing infrastructure, work can start very quickly. There is no need to spend a lot of time and money up front before launching a session in a new solution. Applications based on this technology will be available in a matter of a few weeks, and they will be highly customized.

Automatic upgrades are still another incentive, as the cloud computing model has no adverse impact on IT resources. When upgrading to the latest version of the application, the new technology does not force the user to decide between upgrading or keeping its work, because customizing and add-ons are automatically saved during the upgrade.

Information portability is a further attraction. Initially, most providers geared their services to corporate users, but with the passage of time private users have begun to make massive use of this concept, almost unknowingly, through the use of mobile telephone services, in particular smartphones and tablet PCs.

The cloud model is also more environmentally friendly. Desktop computers use about 150 watts each; with cloud computing there is no need for machines that consume more than 10 watts. Of course, to this must be added the power consumed by data centres. But these serve a great number of terminals, so the cloud offers substantial overall savings in energy.

Another benefit has to do with the content industry. In the past, various methods were used to prevent illegal copying of music and films, but each method had its problems. Some CD players couldn't read protected copies of CDs. DRM7 technology is yet another effort by some companies to protect their contents, sparking debate about its implementation and the design of methods for evading it. However, the cloud will provide another digital rights management (DRM) benefit for content producers offering films, games or music directly to the consumer. Content will be designed to be run on a cloud computing system and it will take more time and effort to make illegal copies of films and music distributed by this medium. The benefit also extends to consumers: the cost of videos and games will fall because users will pay only for what they use during the time requested.

\section{Assessing the benefits of cloud computing}

Assessing the benefits of cloud computing is complicated because it can impact different sectors of the economy in different ways. The United Kingdom's Centre for Economics and Business Research evaluated the impact of adopting this technology in France, Germany, Italy, Spain and the United Kingdom: the findings are shown in figure X.2 (Centre for Economics and Business Research, 2010). 
Figure X.2

BENEFITS OF CLOUD COMPUTING IN FIVE EUROPEAN COUNTRIES

(Percentages)

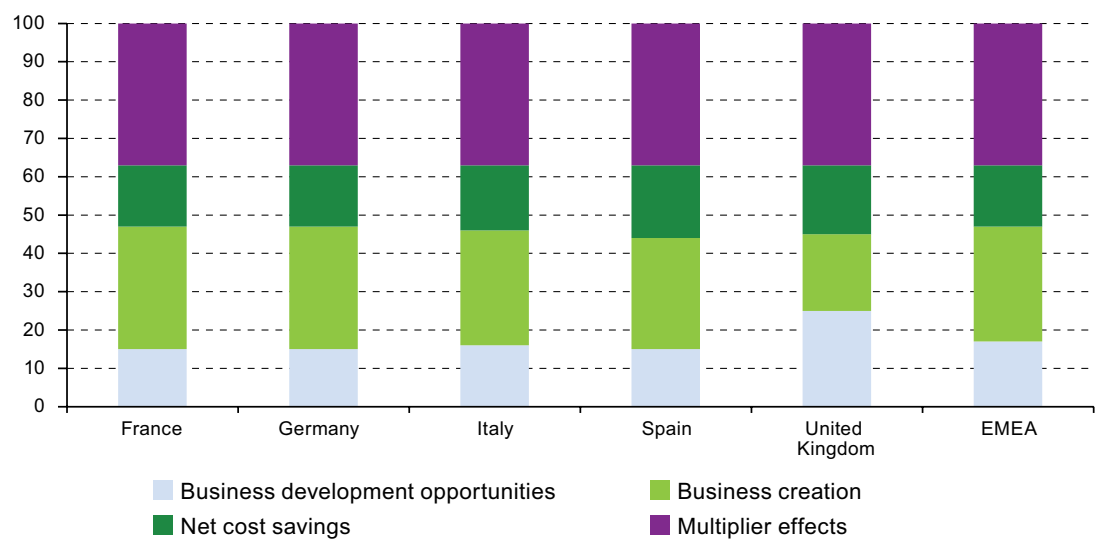

Source: Centre for Economics and Business Research, 2010.

Quantifying the economic benefits of cloud computing involved aggregating the individual benefits identified and quantified, taking into account the macroeconomic outlook for each of the five countries, and assumed rates of adoption for each aggregate industry sector in each country. Business development opportunities are cited in the report as one of the economic benefits obtained, but in most of the countries analysed (except for the United Kingdom) they do not exceed $15 \%$ of the total. A much greater economic impact comes from business creation, which in France exceeds 30\% of the total. Net IT operating cost savings (the difference between IT expenses before and after introduction of the technology) are shown in red. The economic benefits on this score vary between 15 and $20 \%$ of the total.

The last item analysed, accounting for $37 \%$ of the economic benefits, is the multiplier effects on the economy. This item is generally complicated to evaluate, as it requires a detailed analysis of the collateral benefits of using the technologies and the positive impact on other related segments of the economy. What is undeniable is how vast the multiplier effects of cloud computing can be in an industrialized society.

Cloud computing technologies result in business IT budget cost savings which, in turn, boost profitability. There are three ways for firms to cut costs. These are:

- Capital expenditure: by eliminating server and storage costs and replacing these with pay-as-you go cloud computing capabilities, firms can reduce their net IT capital cost. 
- Labour costs: by outsourcing IT services, firms can reduce their IT headcount and/or redeploy staff into more productive areas of IT departments such as application development.

- Power and cooling costs: by eliminating the need to power and cool server and data centres, firms can save a substantial amount on energy bills.

But adopting cloud computing technology will involve new expenses, particularly when using hybrid and public cloud computing models. The cost reduction from use of this technology in the five countries analysed is shown in figure X.3.

Figure X.3

SAVINGS FROM CLOUD COMPUTING

(Percentages of spending on information technologies)

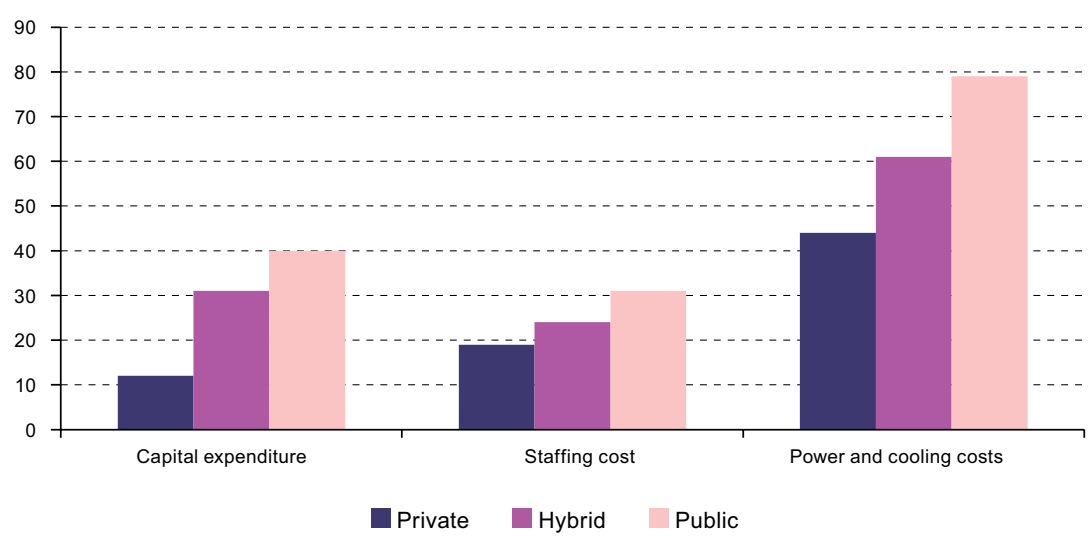

Source: Centre for Economics and Business Research (2010).

\section{Considerations for successful migration}

There are many advantages to adopting cloud computing. As indicated above, many benefits can be reaped from its implementation (IT Industry Innovation Council, 2011). They are:

(i) Simplicity: The cloud reduces to almost negligible the technical knowledge a business owner needs. The technical side of setting up, operating and maintaining any part of the ICT process is taken care of by the cloud provider, enabling firms to focus on their business. 
(ii) Accessibility: Cloud accessibility makes information available to small businesses irrespective of where it is stored, through a multitude of devices and limited only by Internet access.

(iii) Flexibility: In many respects, cloud technology offers a greater value proposition to small businesses than to larger enterprises when it comes to flexibility. Given the speed with which the business and technology landscape changes, small businesses need to be responsive, nimble and equipped to adapt their operations quickly. With cloud-based services priced per user or per subscription, small businesses can grow their technology capability in parallel with their business requirements and growth. Rather than depending on potentially risky forecasts and predictions, with cloud-based solutions they can adapt and expand IT capability on an ad hoc, as-needed basis. And given the cyclical nature of business, they can increase and reduce additional resource capability in line with actual business fluctuations. They also have flexibility in terms of how much cloud resources they use. While on the one hand they can base their entire IT systems in the cloud with negligible IT hardware requirements onsite, on the other they can select only those components that suit them and their business (e-mail hosting, databases or storage).

(iv) Affordability: Enterprise business applications such as customer relationship management (CRM) programmes and enterprise resource programmes (ERP) are typically expensive to acquire, install and maintain. In a cloud computing model, these sorts of applications become much more affordable and thus accessible to SMEs. Capital investment in infrastructure, including servers, storage and software, is avoided. Hardware and software upgrades and software version control become unnecessary, with responsibility falling instead to the cloud service provider.

(v) Improved productivity: With routine IT and network management tasks performed by the cloud service provider, SMEs can avoid the need to dedicate or redirect resources to maintain the systems they rely on to run their business. This directly improves productivity and enables SMEs to focus on issues relevant to growing and improving the business and staying competitive.

One of the first considerations when migrating to cloud computing is to decide which services to outsource. This depends on such aspects as the desired level of security, the need to develop proprietary applications and legal or contractual requirements with respect to maintaining control over information. 
In the conventional service provision model, the firm or organization hosts both the infrastructure and the platform and applications on its premises. A migration to IaaS means leasing all the infrastructure from the service provider, so that the application development platforms and the applications themselves, as well as the software, remain under the control of the organization. A more advanced level involves migrating the layers corresponding to the applications development platform to the cloud, outsourcing the development platform services under the PaaS scheme while retaining the applications and the software in the firm. Finally, when all the layers are placed in the cloud, SaaS is contracted from the provider and very little remains housed within the organization.

If there is a dedicated IT department structure, phasing in is probably the least traumatic approach for gradual migration. Nevertheless, many firms opt to migrate all the services and infrastructure directly and to contract SaaS from the provider at the outset, especially in the case of SMEs with little in-house infrastructure and variable IT needs.

When it comes to data centres, it is useful to examine their value chain. Diagram X.5 illustrates this chain and the service providers involved at each step.

Diagram X.5

THE EXTENDED DATA CENTRE VALUE CHAIN

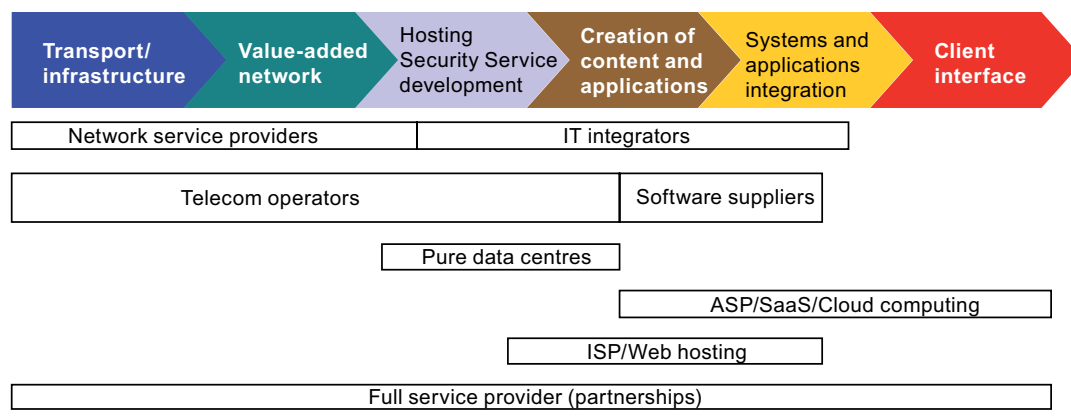

Source: CloudConf LATAM, 2012.

The first two elements of the chain comprise the services of network providers, which include transport and infrastructure as well as valueadded networks. In addition to networks, many telecommunications operators offer hosting, security and service development, tasks typical of a conventional pure data centre. The creation of content and applications is normally in the hands of the software suppliers, but various other service providers such as IT integrators and ASP, SaaS and ISP providers that host webpages can also offer them. Systems or applications integration and 
client interface (through CRMs, for example) can be handled by the SaaS provider, but there are also other possibilities.

The choice of outsourcing arrangements will depend to a large extent on the availability of services in the country or region. Ideally, it is best to maintain a contractual relationship with a single provider. However, it is rare to find providers that are involved in the entire value chain and can offer all the services.

\section{E. The situation in Latin America}

The current situation in Latin America with respect to cloud computing is difficult to assess because such services have been available in the region for only a short time. "Cloud adoption is increasing but is still not at US levels... lots of evaluations and planning but not too many implementations. Current implementations are mostly private and in multinationals following headquarters guidelines. The main beneficiaries of the increase in cloud adoption (besides the companies that actually implement it) are storage, virtualization, networking and security vendors" (Grava, 2012).

One of the main concerns in Latin America is about moving information outside of national boundaries, which makes it difficult to adopt shared environments in the United States or Europe.

\section{Legal and regulatory environment}

Latin America is making progress with legislation for the comprehensive governance of business relations in cloud computing. There is much debate in Colombia over the controversial Lleras Law that will regulate a series of aspects relating to information and could grant Internet providers tight control over data, something that could affect cloud computing either positively or negatively, depending on how it is applied. In Chile, work has started on a draft data protection law. Argentina has some regulations in this area, such as Law 25.326 on the protection of personal data, but stakeholders agree that it needs to be updated promptly because it has shortcomings similar to those found in the rest of the region.

Business Software Alliance (2011) examined preparedness for cloud computing in 24 countries (see figure X.4), including 3 in Latin America (Mexico, Argentina and Brazil).

Mexico and Argentina earn a total score of more than $50 \%$, while Brazil ranks last in the list of countries selected. The findings show convincingly that, in a region with an enormous potential for the growth of cloud computing, the regulatory and legal framework is in its infancy and, in the few cases where it exists, inadequate. 
Figure X.4

CLOUD COMPUTING REGULATION PREPAREDNESS SCORECARD

(Percentages)

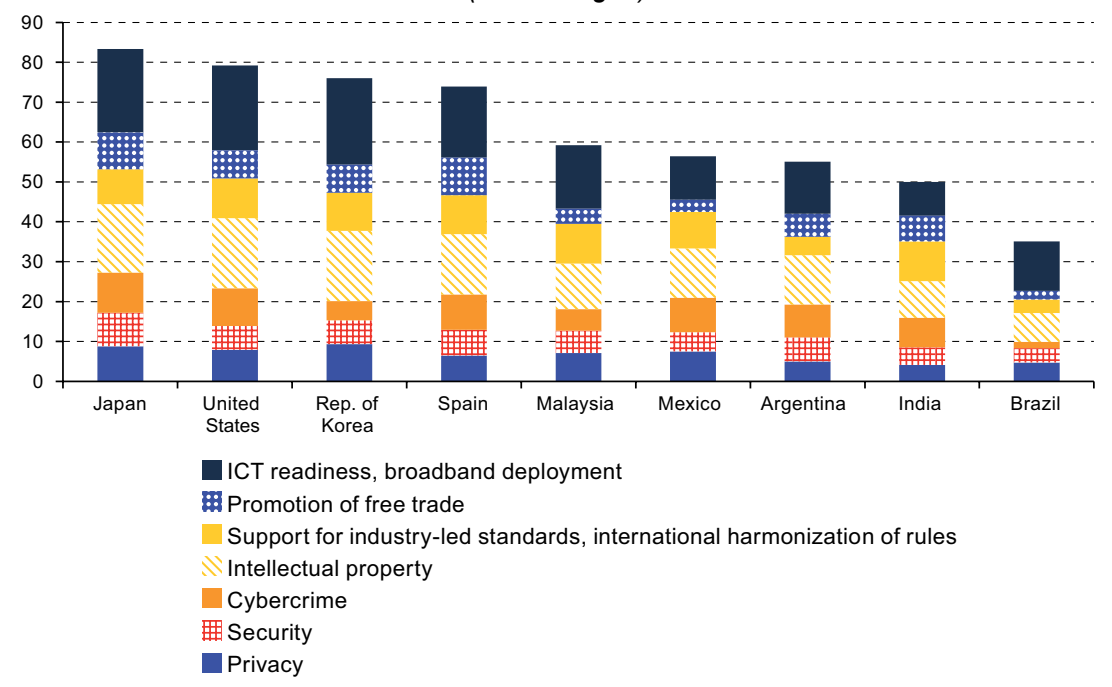

Source: Business Software Alliance, BSA Global Cloud Computing Scorecard - A Blueprint for economic opportunity, 2011.

The only Latin American country certified for international data transfer is Argentina, with Uruguay and Mexico on its heels (Martinez Fazzalari, 2011). The Argentine law follows the European approach, in the sense that it prohibits the transfer of personal data to any country that does not offer adequate protection. Mexico was the first country in the region to adopt a regulation on cloud computing, as part of its federal law on protection of personal data held by private parties. "What is noteworthy is that Mexico has and enforces explicit conditions for the contracts signed, for example, by a firm with a third-party cloud service provider, as well as technical requirements and information requirements for guaranteeing that when the information is sent to the cloud there is no risk to the rights of personal data owners" (Commission on Transparency and Access to Information of the State of Nuevo León, 2012). Chile has developed a number of legal instruments in this area; they are listed in table X.3.

In conclusion, legal and regulatory provisions in Latin American countries with the greatest degree of cloud computing use are still in their infancy and, in many respects, inadequate to the task. More coordination at the regional level is needed to establish a uniform legal and regulatory framework for the free transfer of data between countries and to ensure security for users of this technology. 
Table X.3

CHILEAN REGULATION OF CLOUD COMPUTING

\begin{tabular}{|c|c|c|}
\hline $\begin{array}{l}\text { Law/ } \\
\text { regulation }\end{array}$ & Date & Description \\
\hline Law 19,799 & 2002 & $\begin{array}{l}\text { Electronic documents and electronic signature, including certification } \\
\text { (Ministry of Economy, Development and Reconstruction) }\end{array}$ \\
\hline DS/181 & 2002 & $\begin{array}{l}\text { Regulations to Law } 19.799 \text { on electronic documents and electronic } \\
\text { signature, including certification (Ministry of Economy, Development } \\
\text { and Reconstruction) }\end{array}$ \\
\hline $\mathrm{DS} / 81$ & 2004 & $\begin{array}{l}\text { Technical standards for central government entities on interoperability } \\
\text { of electronic documents (General Secretariat of the Office of the } \\
\text { President) }\end{array}$ \\
\hline DS/83 & 2004 & $\begin{array}{l}\text { Minimum security standards for the use, storage, access and } \\
\text { distribution of electronic documents. Also regulates the electronic } \\
\text { relationship between the Government and the citizens (General } \\
\text { Secretariat of the Office of the President) }\end{array}$ \\
\hline $\mathrm{DS} / 93$ & 2006 & $\begin{array}{l}\text { Standards for proper handling of electronic messages, in particular } \\
\text { spam (General Secretariat of the Office of the President) }\end{array}$ \\
\hline DS/100 & 2006 & $\begin{array}{l}\text { Minimum standards for government websites (General Secretariat of } \\
\text { the Office } \\
\text { of the President) }\end{array}$ \\
\hline DS/158 & 2007 & $\begin{array}{l}\text { Amends DS/81 of } 2004 \text {. Approves technical standards for central } \\
\text { government entities on interoperability of electronic documents } \\
\text { (General Secretariat of the Office of } \\
\text { the President) }\end{array}$ \\
\hline $\mathrm{DS} / 271$ & 2008 & $\begin{array}{l}\text { Regulates the registration of document systems in the archives of the } \\
\text { Administrator of Systems and Metadata for central government entities } \\
\text { (Ministry of Economy, Development and Reconstruction) }\end{array}$ \\
\hline $\begin{array}{l}\text { Guía Web } \\
\text { V2.0 }\end{array}$ & 2008 & $\begin{array}{l}\text { Guidelines for design and development of government entities' web } \\
\text { platforms (Ministry of Economy, Development and Reconstruction) }\end{array}$ \\
\hline
\end{tabular}

Source: Prepared by the author on the basis of official documents.

\section{Degree of adoption in the region}

One of the first problems in addressing this issue is the lack of information and data, as there are not many specialized firms producing studies of this kind in Latin America. There are recent data available for Brazil, which hosted CloudConf LATAM 2012; for other countries, a few private or academic entities have produced studies on the adoption of technology, based primarily on surveys.

IDC Worldwide IT Public Cloud Services Forecast (2010) estimates that cloud-based services will increase by $61 \%$ in Latin America between 2010 and 2014, with especially strong growth in the areas of storage, servers and applications. This probably reflects the fact that Latin America is at an early stage of development in the use of cloud computing and that, for this reason, fast growth rates are due to initial mass adoption of the technology. Figure X.5 shows the degree of adoption of this technology 
around the world, highlighting the position of Brazil over the coming two years. The growth of non-critical applications is relatively high, reflecting perhaps the proliferation of applications such as social networks. Figure X.6 shows growth by level of processing in Brazil. Although it has no proper legislation for the development of cloud computing, Brazil is setting the pace for the region.

Figure X.5

ADOPTION OF CLOUD COMPUTING AROUND THE WORLD (Percentages)
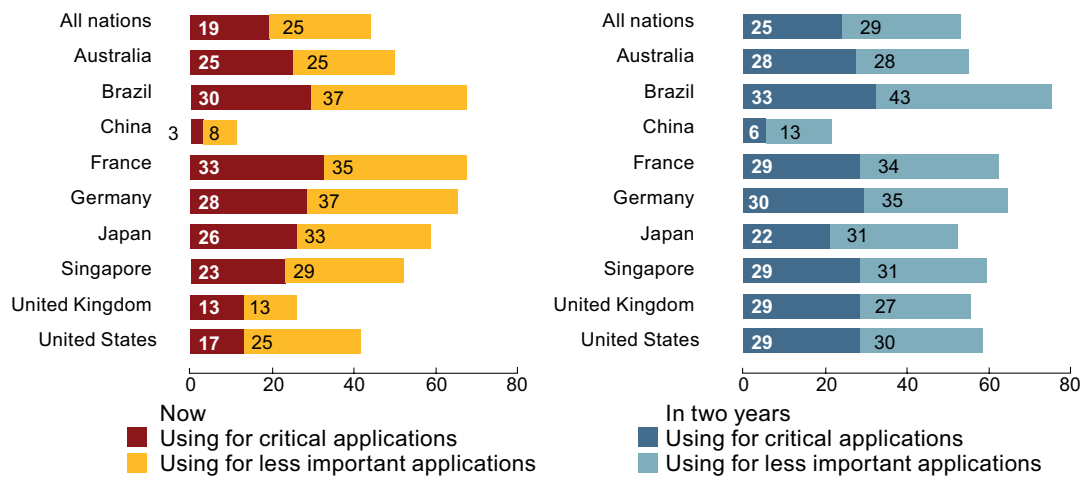

Source: Accenture Institute for High Performance.

Figure X.6

GROWTH OF CLOUD COMPUTING IN BRAZIL BY LEVEL OF PROCESSING (Percentages)

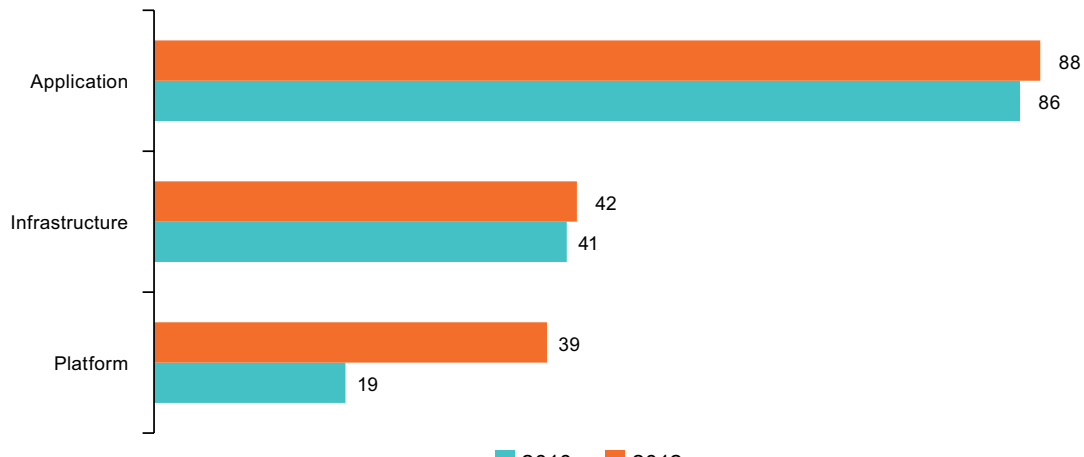

$2010 \quad 2012$

Source: F. Belfort, "Panorama do mercado brasileiro de Cloud Computing", presentation at the Cloud Conference 2012, Frost \& Sullivan, August 2012.

Colombia is another country that is promoting the use of cloud technologies: an independent evaluation found that nearly $50 \%$ of firms adopting cloud services do so through SaaS (see figure X.7). 
Data centres are an important aspect of cloud computing, as the provision of mass storage and offshore processing requires relatively large spaces in different countries. Figure X.8 is a projection by McKinsey of the data centre landscape in five countries of Latin America (Moreira, 2012). It shows that by 2014 Brazil will have the most room for the growth of cloud computing data centres. Mexico and Argentina will also be developing greater capacities for offering storage and data processing technologies.

Figure X.7

CLOUD SERVICES USED IN COLOMBIA

(Percentages)

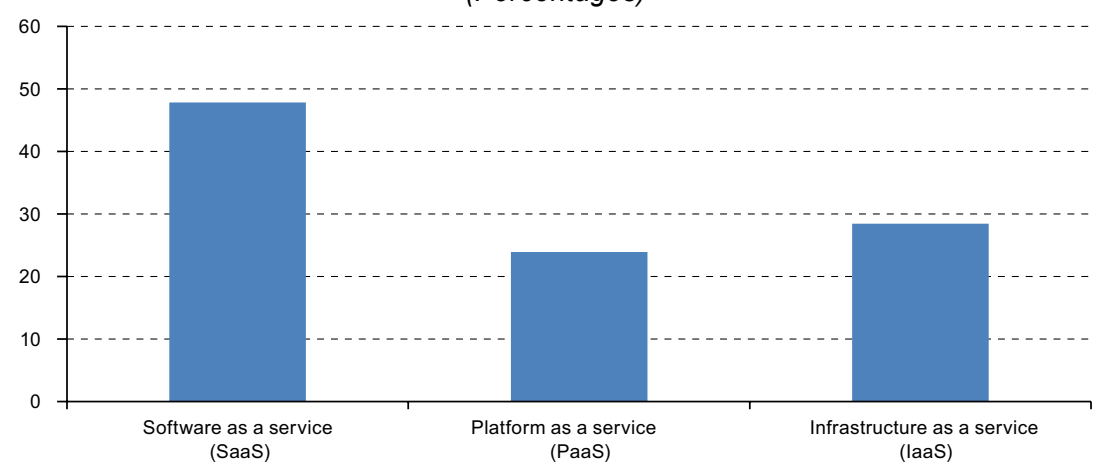

Source: F. Rueda, El uso de la computación en la nube (Cloud Computing), Departamento de Ingeniería de Sistemas y Computación, Universidad de Los Andes, Colombia, 2012.

Figure X.8

OUTLOOK FOR DATA CENTRE GROWTH IN LATIN AMERICA

(Thousands of square meters)

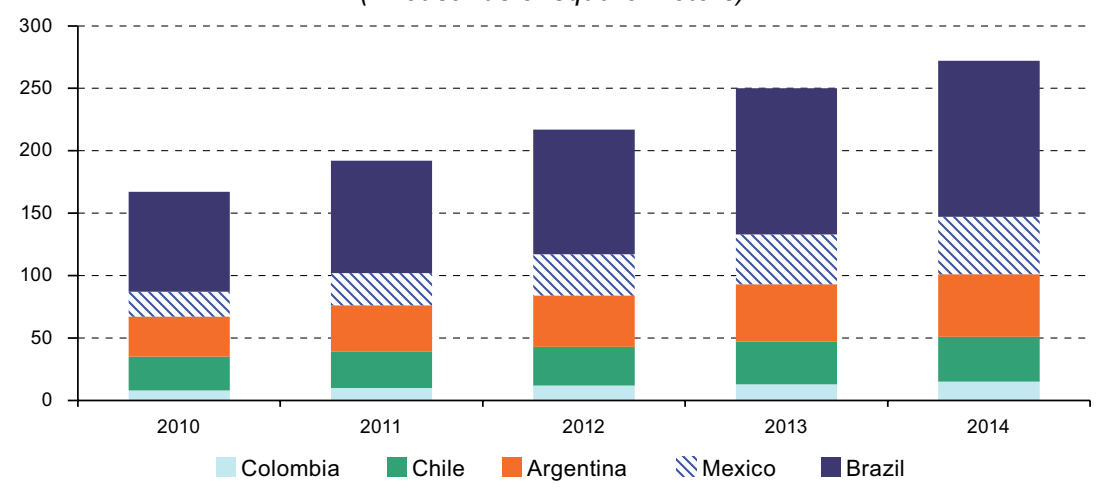

Source: R. Moreira, "IT and Cloud Computing in Brazil: Public Policies", CloudConf LATAM 2012, August, São Paulo, Brazil, 2012, based on McKinsey projections. 


\section{F. Mobile cloud computing}

Uptake of cloud computing has been expanding worldwide since 2007, as has the use of smartphones that connect to the Internet thanks to the rapid growth of wireless network technology. Mobility and ubiquity are both important features of the new-generation networks that offer a range of customized services through various kinds of terminals and access modes. The combination of a ubiquitous mobile network and cloud computing has generated a new modality: mobile cloud computing (MCC).

The Mobile Cloud Computing Forum defines MCC as follows: "Mobile Cloud Computing at its simplest refers to an infrastructure where both the data storage and the data processing happen outside of the mobile device. Mobile cloud applications move the computing power and data storage away from mobile phones and into the cloud, bringing applications and mobile computing to not just smartphone users but a much broader range of mobile subscribers" (Aepona, 2010).

\section{The structure of mobile cloud computing}

The basic structure of mobile cloud computing relies on the fusion of two technologies: mobile data access and cloud computing. It leverages both technologies to provide the user with tools for on-demand access to powerful computing capacity, free of the constraints of a physical connection. Diagram X.6 shows the typical architecture of a mobile cloud computing system.

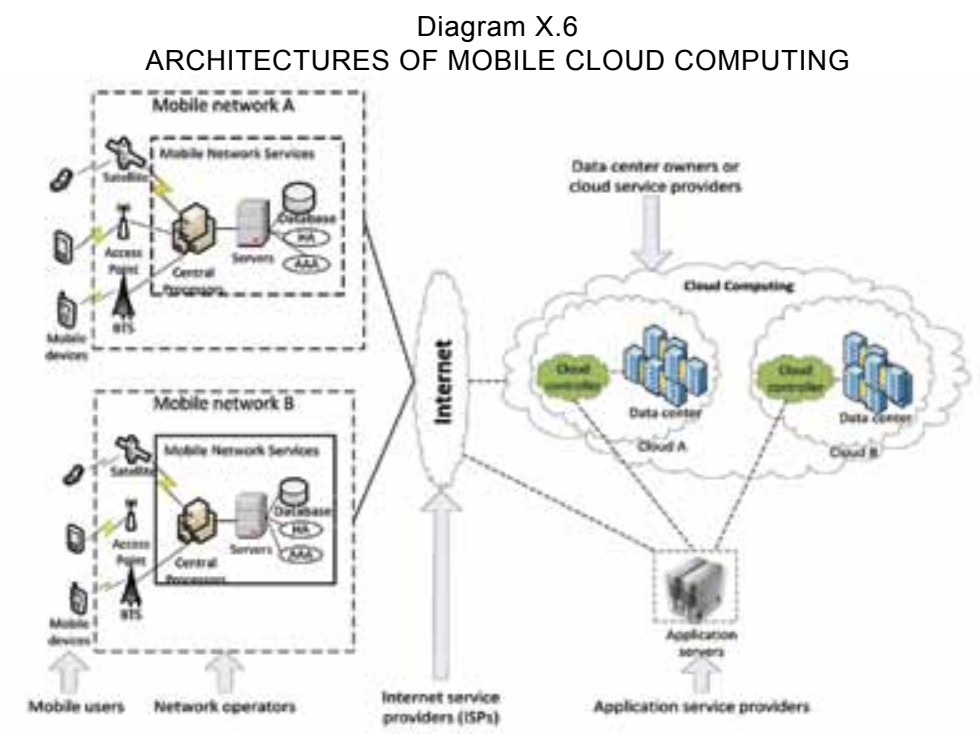

Source: Dinh, Lee, Niyato and Wang (2012). 
In MCC, the mobile devices are connected to the mobile networks via base transceiver stations (BTS), access points or satellites that establish and control the connections (wireless links) and functional interfaces between the networks and mobile devices. Mobile users' requests and information (e.g., ID and location) are transmitted to the central processors that are connected to servers providing mobile network services. Here, mobile network operators can provide mobile users with services such as AAA (authentication, authorization, and accounting) based on the home agent (HA) and subscribers' data stored in databases. After that, the subscribers' requests are delivered to a cloud through the Internet. In the cloud, cloud controllers process the requests to provide mobile users with the corresponding cloud services.

The great advantage of this architecture is that the user can use a mobile device to draw on powerful computing facilities that overcome intrinsic limitations (storage, computing capacity) and work from any location where an untethered connection is available. In theory, a mobile device with fairly simple computing capacities and memory could provide a user with the same facilities as a sophisticated computer, provided there is reliable, high-speed communication and bandwidth available. In a sense, this is a return to the 1980s concept of powerful mainframe computers and a set of access devices known as "dumb terminals". In this case the mainframe computer is replaced by the cloud, the wiring and communications by the Internet, and the terminals by mobile devices. The advantages for the mobile user are:

- Extended battery life. This is one of the main concerns of a mobile user, and offloading to the cloud the running of applications that consume CPU time can provide energy savings of up to $45 \%$.

- Improved data storage capacity and processing power. Memory capacity is a constraint with mobile devices, and the ability to store information in the cloud allows significant savings of this resource. Similarly, applications that demand substantial processing power can be offloaded to the cloud with considerably improved processing times.

- Reliability. Storing data or running applications in clouds is an efficient way to boost reliability, as various computers in the network keep backup copies or interim results.

Nevertheless, there are many challenges to be overcome in deploying MCC, as examined in the following subsection.

\section{Challenges}

Mobile devices (like smartphones and tablet PCs) are increasingly becoming an essential part of life as the most effective, convenient and, 
above all, ubiquitous communication tools. Mobile users have at their disposal a wide array of services ranging from mobile applications (such as iPhone apps and Google Apps) that run on the devices or on remote servers via wireless networks. The rapid progress of mobile computing is driving the development of IT technology as well as the fields of commerce and industry. However, the mobile devices face many challenges in terms of resources (e.g., battery life, storage, and bandwidth) and communications (like mobility and security). These resource constraints are holding back the improvement of service quality. Table X.4 lists the challenges that MCC must address, and some possible solutions.

Table X.4

MOBILE CLOUD COMPUTING CHALLENGES AND SOLUTIONS

\begin{tabular}{ll}
\hline Challenges & Solutions \\
\hline Limitations of mobile devices & $\begin{array}{l}\text { Virtualization and image management } \\
\text { Task migration }\end{array}$ \\
Quality of communications & Bandwidth upgrading \\
& Reducing data delivery time \\
Division of applications services & Elastic application division mechanism \\
\hline
\end{tabular}

Source: H. Qi and A. Gani, Research on Mobile Cloud Computing: Review, Trend and Perspectives, Faculty of Computer Science and Information Technology, Kuala Lumpur, University of Malaya, 2011.

\section{a) Limitations of mobile devices}

In examining the use of mobile devices in the cloud the first thing that stands out is resource constraint. Although smartphones have been much improved in aspects such as CPU and memory capacity, storage, screen size, wireless communication, geolocation technology and operating systems, they still have serious limitations such as insufficient computing capability and power for running complicated applications. In comparison with PCs and laptops in a given situation, smartphones have 3 times less processing capacity, 8 times less memory, 5 to 10 times less storage capacity and 10 times less network bandwidth (Qi and Gani, 2011).

Normally, a smartphone needs to be charged every day as battery power is depleted by dialling calls, sending messages, surfing the Internet, accessing social networks, and other Internet applications. According to current trends, increased mobile computing capacity and rapid development of screen technology will lead to ever more complicated applications running on smartphones. If battery technology cannot be improved apace, then saving battery power will become an increasingly important issue. 
The processing capacity, storage, battery life, and communication capabilities of smartphones will improve as mobile computing develops. However, their limitations will remain one of major challenges in mobile cloud computing. The challenges and solutions for tablet PCs are similar.

\section{b) Communication quality}

Unlike fixed networks (copper or fibre) where the physical connection ensures bandwidth consistency, the data transfer rate in a mobile cloud computing environment is constantly changing and the connection is discontinuous due to unequal network coverage and handoff. Furthermore, data centres in large companies and service provider Internet resources are usually far from end-users, especially mobile device users. In a wireless network, network latency delay may be as much as $200 \mathrm{~ms}$ in the last mile while it is only $50 \mathrm{~ms}$ in a wired network. Other variables such as changes in application throughput, user mobility, and even the weather can lead to changes in bandwidth and network coverage. Therefore, handover delay in a mobile network is greater than in a wired network. Figure X.9 shows average access speed as a function of the ratio of mobile to fixed broadband connections in Latin America.

Figure X.9

ACCESS SPEED BY TYPE OF CONNECTION IN THE REGION

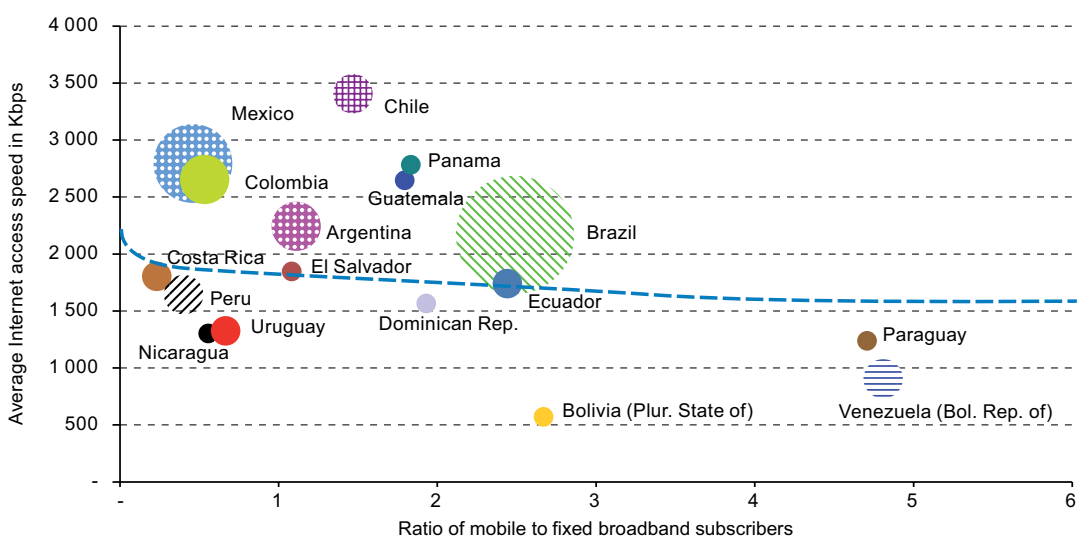

Source: Prepared by the author on the basis of data from ITU and Akamai Note: The size of the circle is proportionate to the number of Internet users.

As the ratio of mobile to fixed broadband connections rises, average access speed declines. Nevertheless, many countries with a high mobileto-fixed broadband ratio do not have a good correlation with the dotted line, which is an adjustment curve for data on Latin America. In other 
words, countries below the dotted line have a below-average connection speed and are likely to have mobile bandwidth performance that is more marginal the further they are from the curve.

\section{c) Partitioning application services}

In a mobile cloud computing environment, resource constraints mean that some computing-intensive and data-intensive applications cannot be run on mobile devices because they can be a substantial power drain. Therefore, applications and use of cloud computing capacity must be split to achieve those purposes. The core computing tasks are processed in the cloud, and the mobile devices are responsible only for some simple tasks. In this process, the major issues affecting the performance of mobile cloud computing are data processing in data centres and the mobile device, network handover delay, and data delivery time.

For a given standard, providing a guaranteed quality of cloud service means considering the following: (i) optimal application split between cloud and mobile device; (ii) interaction between low latency and code offload; (iii) sufficient bandwidth capacity between cloud and mobile device for high-speed data transmission; (iv) user-oriented cloud application performance; (v) mechanism for self-adaptation of mobile cloud computing; and (vi) optimal levels of consumption and excess capacity of mobile devices and cloud servers. The following strategies can be used to respond to these challenges:

- Upgrade bandwidth for wireless connection, making the web content more suitable for the mobile network using regional data centres.

- Deploy the request processing node at the "edge" of the cloud in order to reduce data delivery time.

- Duplicate mobile devices in the cloud, using virtualization and image technologies, to handle data-intensive computing and power-intensive computing processes, such as virus scanning in mobile devices.

- Dynamically optimize applications for insertion in the cloud and the split with mobile terminals.

As an example of the third strategy, the concept of CloneCloud was introduced by Chun in 2011. The method uses virtual machine migration technology to offload execution blocks of applications from mobile devices to the CloneCloud, seamlessly and partially, in order to extend (either fully- or semi-automatically) or modify smartphone-based execution to a distributed environment (smartphone computing plus cloud computing). In a CloneCloud system the clone is a mirror image of a smartphone running 
on a virtual machine. Unlike smartphones, a clone has more hardware, software, network and power resources in a virtual machine, which provides an environment more suitable to processing tasks. Diagram X.7 shows the execution of tasks within a CloneCloud architecture.

\section{Diagram X.7}

ARCHITECTURE OF A CLONECLOUD SYSTEM

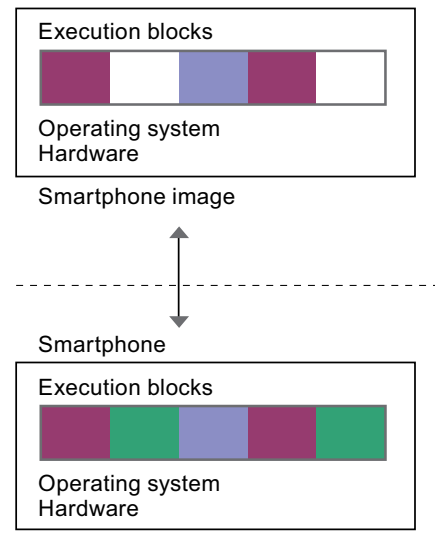

Source: Dinh and others, A Survey of Mobile Cloud Computing: Architecture, Applications, and Approaches, Wireless Communications and Mobile Computing, Wiley, 2012.

As the diagram shows, a smartphone task is divided into five different execution blocks, and the smartphone is cloned (virtualized) as an image in a distributed computing environment. Next, the image passes some computing- or power-intensive blocks (the green blocks) to the cloud for processing. Once those execution blocks have been completed, the output will be passed from the CloneCloud to the smartphone. A major advantage of the CloneCloud is enhanced smartphone performance. Another advantage is reduced battery consumption, as the telephone does not use its CPU as frequently. A disadvantage is handover delay due to bandwidth limitations. As the speed of data transmission between smartphones and the base station is not consistent, the CloneCloud will be unavailable if mobile users enter a signal blind spot.

\section{Mobile cloud computing}

The forecast that mobile cloud computing would generate US\$ 29 billion in revenues in 2014 was made in the wake of an estimate by ABI Research that the number of mobile subscribers in the cloud would reach nearly a billion that year, representing about $19 \%$ of all mobile subscribers (Bahl, 2011). This represents a huge increase over the 42.8 million mobile cloud computing subscribers in 2008. The forecasts, by region, are shown in figure X.10. 
Figure X.10

MOBILE CLOUD COMPUTING REVENUE BY REGION

(Millions of dollars)

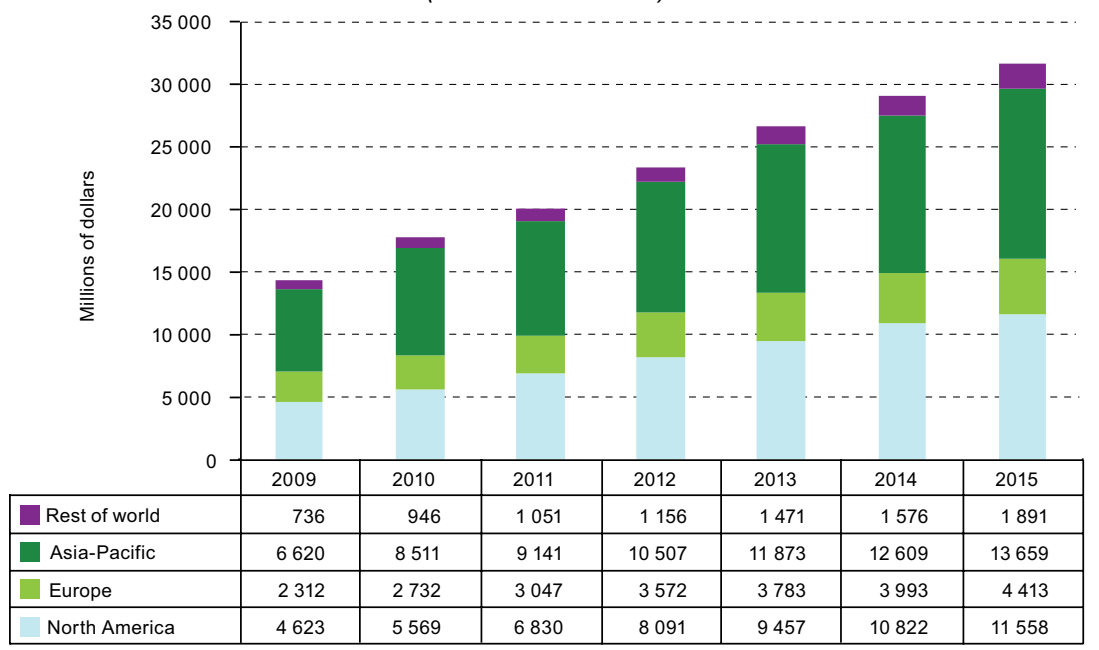

Source: V. Bahl, "Cloud in the Palm of your Hands", 8 July 2011, on the basis of data and projections from ABI Research.

Although predictions indicate strong growth in cloud use for mobile applications in Latin America, its share is still small. Projections for the "rest of world" (which includes Africa and the region) are for only US $\$ 1.9$ billion by 2015 . There is not much additional information on current or future use of mobile cloud computing in the region. In any case, if the trend for the use of cloud facilities through smart mobile devices (telephones or tablets) points to $20 \%$ by 2014 , this would mean that a fifth of mobile broadband customers in Latin America would be using the cloud.

\section{G. "Everything" in the cloud: reality or utopia?}

The main incentive for using cloud computing is and will continue to be the ability to use, as if they were owned, computer resources (such as data storage, processing, programmes and databases) that are beyond the capacity or reach of the individual or business user. The premise is that if enough data transmission capacity is available, and if it is reliable and of good quality, many of the tasks that normally require large processing or local storage capacity can be offloaded to the cloud. But can "everything" really be sent to the cloud without problems? This section examines the possibility that processing will really allow computing resources to be distributed ubiquitously and that consumers can make use of them just as they use electricity or drinking water. 


\section{Back to the past}

Computing systems have evolved ever more swiftly in recent decades, and their dissemination has also accelerated thanks to the omnipresent Internet. The "network of networks" has not only contributed to the dissemination of information and access to knowledge but has also created another concept of society, thanks to popularization of its use in activities of all kinds. But what if all these advances are closing a cycle that would mean going back to what things were like several decades ago? Diagram X.8 shows how mass use of cloud computing could close the cycle.

Diagram X.8

EVOLUTION OF COMPUTING TECHNOLOGIES AND NETWORKS

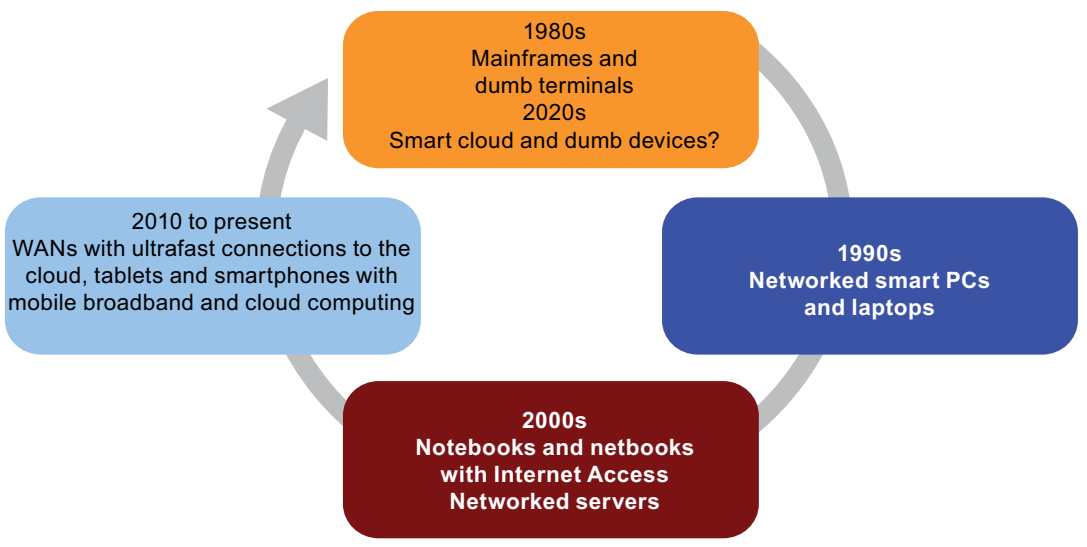

Source: Prepared by the author.

In the 1980s, the typical structure for information systems in use since the 1970s involved mainframe computers, where intelligence resided outside the access terminals (which were therefore called "dumb"). Although personal computers became popular in the mid1980s, they did not have the capacity to perform very complicated tasks. It was only in the 1990s that smart desktops and laptops became widespread and local area networks (LAN) came into general use. In any case, the intelligence was no longer located in centralized equipment, and individual device capacities improved steadily. The turn of the century saw the spread of portable devices with Internet access, and intelligence shifted to network servers. In the early 2010s, networks started to rely increasingly on connectivity and the Internet, and devices with wireless broadband connections became popular. This was also the era of cloud 
computing, using both fixed and mobile connections, based on the idea that intelligence would migrate to the cloud and allow access devices with limited capacities to draw on powerful remote computing systems.

What will the coming decade bring? While some believe that evolution is not cyclical but tends instead to gradual improvement, reality increasingly points to a system where intelligence resides not in devices or networks but outside them. Dependence on connectivity is increasing; not being connected to the Internet is equivalent to being isolated, especially when it comes to mobile devices. As the tendency is for each person to have one or more connectivity devices, expectations are that terminals will go back to being, essentially, dumb and that everyone will access a smart cloud to store data, run processes, manage operations and perform any kind of computing.

\section{Technical considerations}

The notion that everything can be stored or run in the cloud poses some technical challenges that the architects of these structures are seeking to resolve by various means. The main challenges for ensuring that most processing and storage can migrate to the cloud are (i) data synchronization and sequencing; (ii) transport of information; (iii) delay management and (iv) growth management.

\section{a) Data synchronization and sequencing}

Information management and processing requires that processes be transferred and run remotely in the cloud. Running requires that processes be synchronized and that the data processed be delivered in sequence. Cloud computing faces many of the same technological challenges as parallel computing, with the additional complication that some of the processes may be running on the user's own device. The management of information and processes in sequence also places burdens on cloud computing, because resources such as cached memory and temporary storage must be duplicated to maintain the order of intermediate data and results. Structured information management is a technique that can soften the impact of managing process synchronization, since the processing of flat files and unstructured information imposes very heavy requirements on cloud processing and creates synchronization problems. Another way of ensuring synchronization and sequencing is to use ultrafast servers which allow for shorter processing times than if the user were using its own computing resources. To put it another way, the slowest cloud processing must be faster than the fastest processing by customers using their own resources. 


\section{b) Transport of information}

Management of information and processes in the network requires massive transport of information to and from the cloud by users. Communication platforms vary tremendously not only in their technology but also in their quality of performance in different geographical locations. Because cloud computing servers can be located in different countries, each with its own standards not only for contracted speed but also for transmission quality, the transport of huge volumes of data can encounter difficulties of all kinds. The most complicated problem, of course, is the inability to transmit or receive information on time, thereby exceeding user's waiting capacity. This is particularly true when it comes to real-time processing of information or high-performance online applications. The issue of broadband connection to the cloud and its components is crucial, particularly for applications that handle enormous quantities of data.

\section{c) Delay management}

The issue of managing delays is closely related to management of distributed information in the network. Diverse structures and network computing architectures have been designed to provide resilience to unpredictable delays, including that of retaining execution of delaysensitive applications in user devices. However, this is not always possible, since one of the main reasons for moving everything to the cloud is precisely that the user cannot perform the processes on its own system within a reasonable time. The problem of delay management is closely related to that of synchronization and sequencing, which is alleviated through the use of ever faster links and the splitting of processes into subprocesses that can be run in parallel on different servers. Delays are particularly complicated in the management of mobile cloud computing, given the variable conditions of wireless communication.

\section{d) Growth management}

As cloud computing spreads, storage and processing capacity needs are growing almost exponentially. That capacity, distributed among users around the world, is now migrating to a limited number of processing centres that, for reasons of security, must have duplicate resources (such as memory, servers and optical disks) to avoid delays or loss of data.

Gmail and Facebook offer two examples of the problems of managing accelerated growth. They both require very high processing and distributed storage capacities, and those needs are increasing daily with the growing ranks of increasingly demanding users. Users do not in fact need to store the information in their accounts (except perhaps temporarily), as it is available somewhere in the cloud. What is required, 
then, is a great increase in resources to meet users' needs to have "everything" in the cloud. This can be achieved technologically by adding to and expanding computer resources or processing centres as migration continues. Relieving the user of the need to have significant computing or storage capacity in its own equipment, then, has a heavy impact in terms of network overload, but the benefits outweigh the drawbacks.

\section{Legal and procedural aspects}

As indicated, the technical aspects associated with transferring virtually all or at least most processes and applications to the cloud can be resolved. The technology is such that in the future there will be a cloud with enough capacity to handle processes that are now performed outside it. The chief difficulties in making the cloud ubiquitous are not necessarily of a technical nature, however: legal and procedural aspects may in fact be more important. The factors with the greatest impact on full transfer to a global cloud environment are (i) the diversity of the applicable legal systems; (ii) responsibility for data integrity; and (iii) security and confidentiality.

\section{a) Diversity of applicable legal systems}

Cloud computing is not confined to any country or region, as it can readily operate in a variety of geographic locations at any point in time. It is here that differences among countries in the legal treatment of a specific situation become relevant. For example, storage of a certain type of information in one country may constitute a crime in another country. The storage and distribution of users' personal information such as medical records or images can be subject to treatment that differs among countries. One very contentious case involves the United States Patriot Act (Library of Congress, 2001), which allows intelligence agencies to review and intercept any information that could be related to terrorist activities. This law is confined in its application to the territory of the United States; it cannot be applied legally to information in the cloud that is hosted outside that country, even though the user might be physically located there. Even more complex is the case of a cloud computing user in a third country who may have no idea that the servers are located in the United States and may not suspect that its information is subject to scrutiny by that country's intelligence agencies. Uncertainty about which legislation they will be subject to is a compelling reason for the reluctance of potential cloud computing customers to use the service.

\section{b) Responsibility for data integrity}

More than one service provider is involved in cloud computing, so responsibility for the integrity of the data delivered and processed in the cloud may easily fall on more than one party. The cloud service provider 
contracts the services of an Internet access provider and may also use the services of still other providers. Responsibility for data integrity is then shared, and the problem of clearly identifying the accountable party when information is lost or corrupted represents an obstacle to full migration to the cloud.

\section{C) Security and confidentiality}

A final crucial aspect of migrating data and processes to the cloud is the question of how secure and confidential that information will stay. The problems that large corporations and cloud service providers have faced with leakage of their own or clients' confidential information have been a warning signal that user privacy can be compromised. While it is true that such information could be intercepted and extracted by hackers even if users keep it in their own computer systems, the users are responsible for ensuring that this does not happen. But who is accountable if that information is somewhere in the cloud and even the provider does not know its exact location? This is certainly a tremendous obstacle to generalized adoption of cloud services and is frequently cited as the key consideration in making the decision to migrate.

\section{H. Best international practices}

Because cloud computing is relatively new, best practices have been emerging only recently and in countries (especially the United States and in Europe, as well as some countries in Asia-Pacific) that were pioneers in its deployment. In Latin America there are incipient efforts to introduce this technology and lay the groundwork for widespread uptake.

The World Economic Forum partnered with the consulting firm Accenture to prepared a compendium on the promotion of cloud computing and guidelines on priorities for industry and government (World Economic Forum, 2011). These action areas are set out in diagram X.9 and are the result of careful analysis of the problems and benefits of cloud computing. This section transcribes the best practices listed in the study.

While the underlying issues are complex and contentious, eight critical action areas were selected by government representatives and companies -including many of the largest cloud providers and regulators from Europe and North America - and then confirmed in the private session about cloud computing held during the 2011World Economic Forum Annual Meeting. These action areas are put forward as a charter for further engagement among key stakeholders. They are intended to form a 
cohesive agenda, bringing together several areas in which there are existing but disparate initiatives. This step should lead to industry and government collaboration to further define and implement the necessary actions to move the agenda forward and accelerate the uptake of cloud technologies.

\section{Diagram X.9 \\ ACTION AREAS FOR PROMOTING CLOUD COMPUTING}

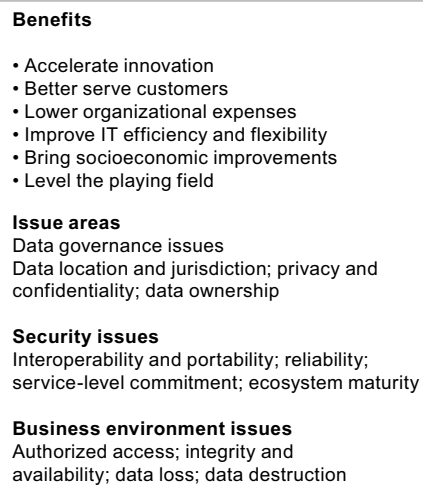
Action areas
1. Explore cloud benefits
2. Understand and manage cloud risks
3. Promote service transparency
4. Clarify and enhance accountability
5. Ensure data portability
6. Facilitate interoperability
7. Adapt and harmonize regulation
8. Provide sufficient connectivity

Source: Prepared by the author, on the basis of World Economic Forum, Advancing cloud computing: What to do now? Priorities for Industry and Governments, 2011.

\section{Explore cloud benefits}

Cloud ecosystem participants should dedicate additional resources to understanding the benefits of cloud and accelerating the adoption of innovative applications of cloud technology. Topics include product and process innovation and job creation, collaboration, broad delivery of IP, government effectiveness and efficiency, and other economic benefits.

Underlying many of the issues discussed previously is a sense that the benefits of cloud computing - beyond those related to IT efficienciesare not well understood. This manifests itself as a problem in two main ways. First, users may be held back from moving to the cloud if they perceive the risks more clearly than the benefits. Second, regulators find it hard to make balanced decisions that are in line with the legal principle of proportionality if they lack a clear sense of how their decisions could potentially impact the macroeconomic and societal benefits of the cloud as well as the risks. The principle of proportionality argues, among other provisions, that regulation should detract as little as possible from the benefits of what is being regulated. 


\section{Understand and manage cloud-related risks}

Relevant stakeholders (providers and government) should encourage research into the unique risk drivers in cloud computing and identify potential solutions. The flipside of clearly understanding the potential benefits of cloud is ensuring that perceptions of risk are also grounded in reality. It is arguable that several of the stakeholder concerns apply just as much to the public Internet as to the cloud, where data centres may be protected by security mechanisms that are so sophisticated they actually reduce risk rather than exacerbate it. If concerns are indeed overstated, the development of the cloud would be needlessly held back.

Risk mitigation strategies need to address the different risk profiles of different types of data, such as personal data and trade secrets. Innovative approaches to managing risk could include industry players developing codes of conduct and mutual assistance schemes whereby providers agree to assume responsibility for each other's service commitments in the event of outages or breaches. A better understanding of risks would also facilitate the development of nascent cloud insurance models to offer compensation to customers in the event of losses caused by the cloud.

\section{Promote service transparency}

Providers of cloud services should make available to customers information about how their services are provided and how they perform. This includes letting customers know how data is secured, where data is stored and/or what jurisdictional provisions apply, how and by whom it can be accessed, and how it can be deleted. Greater transparency (i.e. public disclosure) about cloud computing would go a long way towards addressing many of the stakeholder issues detailed above - notably privacy and confidentiality, data ownership, security, liability and reliability. Clearer and more easily accessible information about cloud service delivery models and offers would accelerate the development of the market by improving levels of user trust and facilitating the creation of aggregated services provided by multiple providers.

\section{Clarify and enhance accountability}

Industry, regulatory bodies and third parties should collaborate to create and implement more consistent and comprehensive approaches to accountability for how cloud services are provided. Complementing greater transparency, greater clarity about accountability would accelerate uptake of cloud computing among potential users, who are currently reluctant to 
entrust mission-critical services to the cloud. Users want to know who is accountable if service levels are unsatisfactory, if they are unable to access data they put in the cloud or if it is accessed by unauthorized persons or government agencies. In particular, users want clarity about accountability for service delivery in situations where providers leverage sub-contractors, get acquired or go out of business.

\section{Ensure data portability}

Cloud service providers should provide ways for users to easily retrieve data they have input to clouds, without an onerous fee and in a timely manner. The fear of vendor lock-in holds back many potential users of cloud, while many government stakeholders are concerned about maintaining competitiveness in the cloud market. These concerns are lessened if it becomes quicker, easier and cheaper for users to move data, and perhaps applications, between different cloud providers and between user premises and the cloud. Users should be aware, however, that due to economies of scale in the cloud and particular cloud architectures, it may be economically unfeasible to roll back from the cloud to an on-premises solution. Work on facilitating data portability also needs to be aligned with work on common approaches to data ownership and protection, law enforcement access and liability. Providing meta-data and context information, in addition to the actual data entered, can significantly increase the options available to customers.

\section{Facilitate interoperability}

Industry players should pursue the evolution of cloud offerings with the goal of facilitating interoperability among multiple (private and public) clouds. This will accelerate the growth of the overall cloud ecosystem. There has been notable progress recently in developing offerings that allow users to customize their own solutions by simultaneously using services from multiple cloud providers. As with data portability, every step towards greater interoperability helps to address stakeholder concerns about competitiveness and lock-in. It may also accelerate innovation and help address challenges related to data privacy and security. Fostering cloud interoperability will also likely extend to a broad range of ecosystem players, including providers of connectivity and application developers, who will need to adopt relevant architectures and provide enabling services such as highly reliable cross-cloud connectivity.

\section{Adapt and harmonize regulatory frameworks}

Governments should adapt and harmonize regulations relevant to cloud with the aim of improving their applicability and reducing divergence 
across jurisdictions, while considering the maturity of the overall industry. There is widespread frustration among stakeholders about the regulatory environment for cloud computing, especially in the areas of data privacy and security. Regulations are often inconsistent, conflicting and difficult to apply for users and providers operating globally. This holds back users from moving to the cloud, as they fear regulatory provisions are insufficient to protect their data from being unduly accessed by law enforcement or retained by providers. And when regulations effectively force data to remain within national borders - either directly by imposing restrictions on data transfers outside the jurisdiction, or indirectly through a lack of cross-jurisdictional alignment - they hold back cloud providers from realizing improvements that come from achieving scale through multiple locations.

\section{Provide sufficient connectivity}

Industry, government and relevant agencies should identify connectivity requirements for cloud services (wired and wireless) and promote the commensurate deployment of networks. To be able to use cloud computing with confidence, users need easy access to the cloud. They need guarantees about the speed, reliability and robustness of networks, both fixed and mobile. In particular, in an environment where market needs may be moving faster than the technology, users need to be confident that current telecom investments will be sufficient to support future services. Given that cloud computing uses data centres that need to be able to handle massive amounts of traffic, the planning of networks and data centres needs to be coordinated. Developing a framework describing what services can be provided with various levels of connectivity could also help national governments promote and prioritize investments that will sustain future growth opportunities. 


\section{Bibliography}

Aepona Ltd. (2010), Mobile Cloud Computing - Solution Brief, November.

Akamai (2012), "State of the Internet", Q2 Report [online] http://spanish.akamai. com/enes/stateoftheinternet/.

Bahl, Victor (2011), Cloud in the Palm of your Hands 8 July.

Baran, Daya (2008), Cloud Computing Basics, WEBGUILD, July [online] http://www.webguild.org/20080729/cloud-computing-basics.

Belfort, Fernando (2012), "Panorama do mercado brasileiro de Cloud Computing", presentation at the Cloud Conference 2012, Frost \& Sullivan, August.

Business Software Alliance (2011), BSA Global Cloud Computing Scorecard - A Blueprint for economic opportunity.

Centre for Economics and Business Research (2010), The Cloud Dividend: Part One The economic benefits of cloud computing to business and the wider EMEA economy France, Germany, Italy, Spain and the UK, Report for EMC, December.

Chamber of Commerce of Medellín for Antioquia (2011), Computación en la Nube.

Commission on Transparency and Access to Information of the State of Nuevo Leon (2012), Cloud Computing y Protección de Datos en América Latina, 27 May [online] www.qumulos.com/tweets/mexico-pionero-en-el-cloud-computing/.

Craig-Wood, Kate (2010), "IaaS vs. PaaS vs. SaaS Definition", 18 May [online] http:/ / www.katescomment.com/iaas-paas-saas-definition/.

Dinh, Hoang T., Chonho Lee, Dusit Niyato and Ping Wang (2012), A Survey of Mobile Cloud Computing: Architecture, Applications, and Approaches, Wireless Communications and Mobile Computing-Wiley.

Grava, Wilson (2012), Paths to the Cloud: Cloud Computing in Latin America and the New Channel Engagement Model, 26-27 April [online] www.hawkeyechannel.com.

IDC Worldwide IT Public Cloud Services Forecast (2010)

IT Industry Innovation Council, Australia (2011), Cloud Computing - Opportunities and Challenges, 11 October.

Krutz, Ronald L. and Russell Dean Vines (2010), Cloud Security - A Comprehensive Guide to Secure Cloud Computing, Wiley Publishing.

Library of Congress (2001), "Uniting and Strengthening America by Providing Appropriate Tools Required to Intercept and Obstruct Terrorism (USA Patriot Act)", http://thomas.loc.gov/cgi-bin/bdquery/z?d107:H.R.3162.

Lockheed Martin Corporation (2011), When the cloud makes sense, The Download Cloud Computing Research Study, 1105 Government Information Group Custom Report.

Martínez Fazzalari, Raúl (2011), Aspectos Regulatorios - Los retos de Cloud Computing, Logicalis Now, July.

Mell, Peter and Timothy Grance (2011), The NIST Definition of Cloud Computing, Recommendations of the National Institute of Standards and Technology, September.

Moreira, Rafael H. R. (2012), "IT and Cloud Computing in Brazil: Public Policies", CloudConf LATAM 2012, August, São Paulo, Brazil.

NIST (National Institute of Standards and Technology) (2011a), Cloud Computing Synopsis and Recommendations, Computer Security Division Information, Technology Laboratory, May. (2011b), NIST US Government Cloud Computing Technology Roadmap - Technical Considerations for USG Cloud Computing Deployment Decisions, November. 
Qi, Han, and Abdullah Gani (2011), Research on Mobile Cloud Computing: Review, Trend and Perspectives, Faculty of Computer Science and Information Technology, University of Malaya.

Rueda, Francisco (2012), El uso de la computación en la nube (Cloud Computing), Departamento de Ingeniería de Sistemas y Computación, Universidad de Los Andes, Colombia.

World Economic Forum/Accenture (2011), Advancing cloud computing: What to do now? Priorities for Industry and Governments. (2010), Exploring the Future of Cloud Computing: Riding the Next Wave of Technology-Driven Transformation. 



\section{Chapter XI \\ The challenge of over-the-top content and services}

Juan José Ganuza and María Fernanda Viecens ${ }^{1}$

\section{A. Introduction}

Incumbent telecommunications operators providing services such as fixed and mobile telephony, broadband and pay-TV are being invaded by the online content industry and so-called over-the-top (OTT) applications, services and content. The best-known examples of these include Skype, WhatsApp, video games and film streaming (Netflix, Pandora). A key feature of this industry is that the Internet service supplier (ISP) is not involved in the distribution of OTT applications, services or content and does not earn any revenue from them. Yet OTT providers need Internet providers' infrastructure to reach their users, and they deliver products that generally compete with the ISPs' proprietary ones, such as voice, instant messaging and online TV.

The advent of smartphones with ever-lower prices, together with the upgrading of access networks, has helped fuel the growth of OTTs in the communications market. And technological change has transformed

Juan José Ganuza is a professor at Universitat Pompeu Fabra, Barcelona; and María Fernanda Viecens is a research fellow at Universidad de San Andrés and the National Scientific and Technical Research Council (CONICET), Buenos Aires. 
the creative industries and impacted their production and supply cost structure. For example, digitalization has reduced conservation, reproduction and distribution costs (Weeds, 2012), and this has fuelled the exploding supply of online content.

Paradoxically, broadband offered by incumbent operators provides the platform for developing the new businesses that now threaten them. Meanwhile, OTTs fuel burgeoning traffic flow and demand for greater bandwidth, which creates the need for network investment.

Despite the OTT boom, in the literature on the reasons for incumbent operators to invest in infrastructure provision, and particularly nextgeneration access networks (NGAN, fibre optic networks) there is little discussion of the impact of OTTs on investment incentives for incumbent operators. $^{2}$

As for infrastructure investment needs, in developed countries the focus is on how to bring fibre to homes (or, similarly, to guarantee high access speeds), ${ }^{3}$ while the strategies and initiatives deployed in Latin America prioritize correcting regional imbalances in the supply of firstgeneration broadband services, with much more modest access-speed targets. In other words, while developed countries focus on upgrading service quality, plans in the region aim to expand geographic coverage and increase the number of connections (for an analysis of government initiatives in the region see the chapter by Galperín, Mariscal and Viecens herein). Slow access speeds, or limited coverage for high-speed services, could restrict the use of OTTs among the population of Latin America or confine access to groups with high access speeds (certain neighbourhoods and large cities).

This chapter examines the level of development and uptake of the over-the-top market in Latin America. In particular, it discusses the strategies deployed by incumbent operators in Latin America in response to the threat posed by OTTs. The chapter is organized as follows: the next section describes OTT content, applications and services and identifies the dilemma or challenge that each one represents for incumbent network operators. Section $C$ reviews the literature on the subject, while section D analyses the OTT services and content market in Latin America, together

2 As noted below, Ganuza and Viecens (2012) aim to fill part of that gap, using an industrialeconomy theoretical model to analyse the interaction between the development of the NGN industry and the content market. Many studies analyse the incentives to invest and the effect of wholesale-access price regulation (see Hoernig and others, 2012 for a review of this literature). Others focus on the high fixed-variable cost ratio of deploying an industry based on fibre optics (Noam, 2010).

3 For example, the Digital Agenda for Europe calls for $100 \%$ of Europeans to have access at speeds of $30 \mathrm{Mbps}$ and for $50 \%$ to be subscribed to $100 \mathrm{Mbps}$ connections by 2020 . 
with supply and the strategies deployed by incumbent operators. Section E discusses the current situation and unresolved issues, while section F sets forth conclusions.

\section{B. Over-the-top services, applications and content}

This section provides a description of OTT services with a view to organizing available information on the subject that has yet to be set out systematically. It also takes an initial look at the challenges that OTTs pose for incumbent network and service operators. The approach is not restricted to OTT content (which was the first to use the expression OTT). Table XI.1 outlines the different types of OTTs, providing examples, and it identifies the main ways in which the incumbent operators' main sources of revenue are being cannibalized.

Table XI. 1

DESCRIPTION OF OVER-THE-TOP-SERVICES

\begin{tabular}{|c|c|c|c|c|}
\hline OTT & & $\begin{array}{l}\text { Minimum speed } \\
\text { requirements } \\
\text { for good-quality } \\
\text { access }\end{array}$ & $\begin{array}{l}\text { Challenge for } \\
\text { the incumbent } \\
\text { operator }\end{array}$ & $\begin{array}{l}\text { Implications for } \\
\text { the incumbent } \\
\text { operator }\end{array}$ \\
\hline $\begin{array}{l}\text { Communication } \\
\text { services }\end{array}$ & $\begin{array}{l}\text { VolP: Skype, chat } \\
\text { with and without } \\
\text { video, Gmail, } \\
\text { WhatsApp }\end{array}$ & 1-2MBps & $\begin{array}{l}\text { Substitute for } \\
\text { SMS. }\end{array}$ & $\begin{array}{l}\text { More competition } \\
\text { Loss of value } \\
\text { of proprietary } \\
\text { service }\end{array}$ \\
\hline Applications & $\begin{array}{l}\text { Social networks: } \\
\text { Facebook, LinkedIn, } \\
\text { Twitter }\end{array}$ & $1 \mathrm{MBps}$ & $\begin{array}{l}\text { Substitute for } \\
\text { telephony and } \\
\text { SMS }\end{array}$ & $\begin{array}{l}\text { More competition } \\
\text { Loss of value } \\
\text { of proprietary } \\
\text { service }\end{array}$ \\
\hline \multirow[t]{3}{*}{ Content } & $\begin{array}{l}\text { OTT-TV, OTT-Video } \\
\text { streaming and video } \\
\text { on demand (VoD): } \\
\text { Netflix } \\
\text { Netmovies, Hulu, } \\
\text { UltraViolet, } \\
\text { Cuevana, } \\
\text { YouTube }\end{array}$ & 6-10 MBps & $\begin{array}{l}\text { Substitute for } \\
\text { TV }\end{array}$ & $\begin{array}{l}\text { Content supplier } \\
\text { disintermediation } \\
\text { Less potential for } \\
\text { differentiation } \\
\text { Loss of } \\
\text { advertising } \\
\text { audience }\end{array}$ \\
\hline & Online videogames & 1-4 MBps & & \\
\hline & Online music & 1-3 MBps & & \\
\hline
\end{tabular}

Source: Prepared by the authors.

The table lists three general types of OTT: voice and instantmessaging services, applications basically related to social networks, and video and audio content. 
Bijl and Peitz (2010), discuss the profound impact that voice-overInternet-protocol (VoIP) telephony is having on the telecoms industry in general. They analyse the competition between an incumbent operator who, when an operator offering VoIP telephony enters the network, is forced to offer this service as well, in addition to that provided over the switched public telephony network. In this context, the authors study the effect that regulated access to the switched network has on competition and on incentives for investment in VoIP. Nonetheless, they restrict their analysis to what they call "managed" VoIP and disregard "unmanaged" VoIP such as Skype. In contrast, this chapter's examination of OTT includes "unmanaged" VoIP services, whose business models differ from those of incumbent telephone service operators.

There is some disagreement as to whether instant messaging is a substitute for $\mathrm{SMS}^{4}$ as indicated in the table. While not a perfect substitute, the capacity of instant messaging to eat into SMS revenue is undeniable. According to Nikou and others (2012), European operators are experiencing a drop in revenues as a result of OTT services (such as WhatsApp) and social networks (like Facebook and Twitter). They note that young people in particular are massively switching from SMS to these free-of-charge Internet-based services. ${ }^{5}$

Access to online or OTT content enables disintermediation: as Internet access and use becomes more widespread and is available at high speeds (made possible by NGNs), the owners and managers of certain kinds of content no longer need to negotiate with telecom operators (or television providers) to reach their customers and can do so directly through a website. ${ }^{6}$

The table highlights the ways most OTT services cannibalize the revenues of incumbent operators, but it fails to note that OTTs also mean higher management costs, congestion and infrastructure needs because of greater use of capacity and demand for speed. For example, while

See, for example [online] http://www.pyramidresearch.com/points/item/120810.htm.

OTT TV/Video means the distribution of video or television directly over the Internet to users connected to an electronic device. This differs from Internet Protocol Television (IPTV), which is also TV by IP but of the "managed" type. IPTV requires a private cable line and uses the Internet protocol (it uses the same IP to provide Internet), so a certain minimum level of bandwidth is needed (at least 3-6 MBps download). In contrast, Web TV and OTT TV/Video require even better access conditions (at least 6-10 MBps download). High-definition (HD) requirements are more demanding still: 10-25 MBps for IPTV HD and 25-50 MBps for video HD.

6 A very clear example of this is provided by the recently announced UltraViolet Internet platform, www.uvvo.com, created by the major Hollywood film studios (Paramount Pictures, Sony Pictures Entertainment, Twentieth Century Fox, Universal Pictures and Warner Bros., among others) to offer consumers a wide selection and freedom to choose digital films, television programmes, and other streaming entertainment. There are also platforms that stream sporting events. 
online video games and music streaming may not represent challenges for the operators' own products, they do drive network traffic up. ${ }^{7}$

To provide a more complete picture of OTTs, this section concludes with a map of the main agents involved (see diagram XI.1).

Diagram XI.1

MAP OF AGENTS

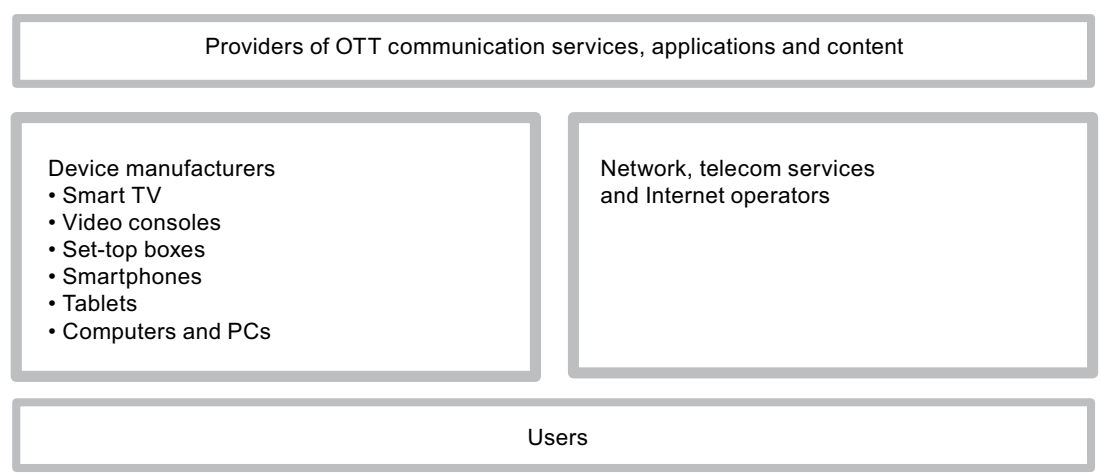

Source: Prepared by the authors.

To be able to receive OTT services, users need a device and Internet access, which means that OTTs, devices and Internet access are complementary products for the user. At the same time, as shown in table XI.1, OTTs deliver products that are close substitutes for those supplied by telecom and Internet service providers. ${ }^{8}$ The links between the different types of agents define a complex strategic relationship that determines each party's prices and incentives to invest. This chapter focuses on the strategic relationship between OTTs and Internet providers. The range of devices that can be connected to the Internet is broad and varied; their manufacturers compete to attract users. Nonetheless, although technological advances in these devices are

\footnotetext{
7 In response to the Telesemana.com (2012) survey question "Where do you think OTTs have the greatest negative impact?", 38\% replied management costs; $49 \%$ mentioned revenue cannibalization; and $13 \%$, referred to relations with users.

8 Chen and Nalebuff (2006) interpret the emergence of services such as Skype as a problem of competition between complementary services. The Skype voice service competes with the telecom operator; but it also complements with the network operator from the user perspective, because the user cannot use Skype without an Internet connection. This type of rivalry raises concerns that the broadband supplier may have initiatives to degrade the quality of Skype to make its own telephony service more attractive.
} 
playing a fundamental role in the development of OTTs, only passing reference will be made to them in this chapter. ${ }^{9}$

\section{Main findings in the literature}

The development of OTTs is linked to two ongoing debates in the telecoms literature: changes in the value chain caused by the booming online industry, and whether maintaining network neutrality is a good or bad idea. Changes in the value chain are a result of technological progress and vigorous innovation in the sector. In the face of these changes, the debate on network neutrality is being driven by incumbent network operators who see value chain revenue shifts in which they are likely to be the losers and are being forced to seek alternatives to reverse the process. The following paragraphs discuss the main findings and unanswered questions in the literature.

\section{Changes in the value chain and the online-industry threat}

The emergence and boom in Internet-based industries is posing major challenges for some traditional sectors of the economy, such as printing, music, advertising and communications media. ${ }^{10}$ Incumbent telecom operators are not ignoring the new markets and services that are emerging on the back of Internet-access potential, particularly OTT services, applications and content.

According to Grove and Baumann (2012), although incumbent integrated operators (providing both infrastructure and proprietary services) have tried to develop VoIP products and services, along with video portals and social communities, and have also taken advantage of the possibilities offered by IPTV, they have been unable to achieve growth or penetration rates comparable to those achieved by services such as YouTube and Netflix. The question is why these integrated operators are consistently left behind by suppliers of services based purely on the Internet (OTT services). They argue that, over the long haul, an integrated operator could achieve better results by controlling both elements

9 Content Delivery or Distribution Networks (CDNs) have started to play an important role in this group, by providing infrastructure solutions for more effective delivery to customers. Some are owned by network operators and others by companies such as Akamai and Microsoft. For a more detailed discussion of them and their impact in Latin America, see León (2012).

10 For example, Seamans and Zhu (2010) conduct an empirical analysis of the effect on the local newspaper market of a website starting to offer classified advertisement services; Athey and others (2012) focus on the fact that Internet enables the consumer to switch easily between different vendors. 
(infrastructure and services); but, in the short run, a pure service provider can improve performance more quickly because its product's spatial configuration is smaller.

Dedrick and others (2011) break down the mobile phone distribution value chain, but a major shortcoming of their study is that they do not consider the role of applications (including OTTs). Shin (2012) analyses the development of mobile VoIP (mVoIP); following what Nikou and others (2012) describe for European operators, Shin reports how mobile phone operators in the Republic of Korea have faced a drop in voice calls owing to Internet call services and applications based on text messaging for smartphones. Feijoo and others (2012) track the development of mobile gaming applications, noting that the arrival of the first wave of smartphones and flat-rate broadband connections in 2006 heralded a shift in market power from network operators to the providers of applications and devices. Nonetheless, they also note that it was the arrival of the iPhone in late 2007 which drastically rearranged the mobile gaming market. ${ }^{11}$

Ganuza and Viecens (2012) analyse the options open to providers of content (such as sports events and Hollywood movies) for offering their products through online portals (OTT content) - in other words, ways to reach consumers without having to negotiate with intermediate operators (disintermediation). Their article shows that NGNs and the resulting high access speeds will reallocate rents among agents in the value chain and will, in particular, transfer them from network and service operators to content providers. Disintermediation by content providers will cause telecom service operators to lose an important source of differentiation and income, forcing them to seek new resources to compete.

\section{The network neutrality debate}

Network neutrality means that all content, of whatever type or origin, is treated equally by the infrastructure provider; discussion on this subject is complex and controversial (see the chapter by René Bustillo herein). Some infrastructure operators complain that content suppliers are free-riding on their infrastructure and recognize that they are being threatened by the new possibilities and initiatives provided by OTTs (Huertas Sánchez and others, 2011). ${ }^{12}$ Major Internet providers have proposed that application and content providers should pay a surcharge

11 In this market, the standard consumption model involves downloading games to a smartphone from the application store (Feijoo and others, 2012).

12 In relation to the use of AT\&T infrastructure by Google, MSN, Vonage and others, Ed Whitacre, former CEO of AT\&T, famously remarked "Now what they would like to do is use my pipes free, but I ain't going to let them do that because we have spent this capital and we have to have a return on it." Business Week, 7 November, 2005. 
for access to the ISPs' residential customers, as well as differential rates for priority content. For example, Shin (2012) reports that mVoIP triggered a debate on network neutrality in the Republic of Korea, where telecom operators are mobilizing to restrict smartphone applications from using their networks for free Internet phone services.

The network neutrality debate has also been interpreted as a confrontation between the United States (where the leading content providers are located) and Europe (which has strong incumbent network operators). European firms are trying to put pressure on companies with network-intensive applications, particularly Apple and Google, to force them to share costs (Dedrick and others, 2011). On the other hand, content providers in the United States play an important role in the content market worldwide; they have the advantage of being the first movers, and they are have close links with the leading software and hardware suppliers (Noam, 2008).

Economides (2011a) draws attention to the potential negative effect on society of letting network operators assess a surcharge on content providers. In his opinion, given the strong network externalities of the Internet, the value of the network depends essentially on two elements: the number of users (adoption) and the number of content creators. At the same time, the value of the network to users depends on content quantity and quality; the value of the content grows with the number of users. As Internet providers do not internalize these network effects, they do not consider the total effect of content providers on society when setting prices. This would have a bearing on the value that users attribute to the network and would erode the virtuous circle that has characterized Internet development and innovation. The introduction of this type of pricing, with its concomitant transaction costs, would be particularly damaging for agents that have contributed to the explosion of content and innovation over the past few years (small businesses, start-ups and individual content providers). Economides (2011b) also argues that the combination of an ISP with high market power and the user cost of switching from one operator to another would make it easier for ISPs to engage in uncompetitive practices in the absence of neutrality regulation. For example Chen and Nalebuff (2006) point out that a broadband provider could potentially have an incentive to degrade the quality of an OTT such as Skype, with a view to making its own telephony service more attractive. ${ }^{13}$

13 Nonetheless, their model finds that an Internet provider does not have incentives to degrade the quality of a provider such as Skype because such services enhance the value of its network. 
Some broadband providers have claimed that regulating neutrality would discourage investment in networks. Consequently, one of the arguments for allowing network operators to charge content suppliers for use of the network has been to provide incentives for the former to invest (Krämer and Wiewiorra, 2009). But Economides (2011a) refutes this argument, holding that allowing a charge for priority access would mean that the higher the network congestion the higher the potential charge, so there would be no incentive to invest to decongest the network. Similarly, the model developed by Cheng, Bandyopadhyay and Guo (2010) predicts that incentives for the broadband provider to expand capacity are greater under neutrality. More capacity leads to less congestion and more highlyvalued Internet services, resulting in benefits for the operators. Lastly, Choi and Kim (2010) provide a full and formal analysis of the relationship between neutrality and investment incentives, concluding that it is impossible to reach unambiguous general conclusions on that relationship.

\section{The over-the-top market in Latin America}

\section{Incumbent operators, OTT strategies and supply}

The challenges and changes in the industry are unfolding alongside development of the content market. Service bundling, particularly bundles including $\mathrm{TV}$, can be seen as first-generation strategies deployed by operators to compete and to maintain market share in the new industry. For example, IPTV is an alternative for competing with online content offered by OTTs such as Netflix, which would give an incumbent ADLS operator an income-producing system equivalent to cable television. Incumbent operators are also looking at second-generation strategies involving initiatives with OTT features or innovations in activities with which those operators are familiar. This section analyses the first- and second-generation strategies of operators in Latin America.

In the first-generation strategy, where proprietary services are bundled with TV, what is available in Latin America displays a wide variety of combinations of technologies and agreements. These include cable operators (pioneers in double-and triple-play bundles) and operators which, when developing a strategy for entering the content market, have used a different technology than that used for communication services. And some ADSL providers have started to offer IPTV, while others are entering into agreements with satellite TV suppliers (DTH).

Table XI.2 lists operators offering bundles with pay-TV, by country and type of technology. In 18 of the 24 countries considered there is a least one bundle that includes pay-TV. 
Table XI.2

SERVICE BUNDLES INCLUDING TV AND FIRST-GENERATION STRATEGIES

\begin{tabular}{|c|c|c|c|c|c|c|}
\hline Country & $\begin{array}{l}\text { Triple-Play + } \\
\text { cable TV }\end{array}$ & $\begin{array}{l}\text { Double Play } \\
\text { (Internet -TV) + } \\
\text { cable }\end{array}$ & 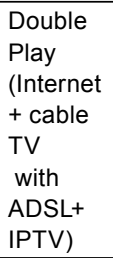 & $\begin{array}{l}\text { Triple- } \\
\text { Play with } \\
\text { ADSL+ } \\
\text { IPTV }\end{array}$ & $\begin{array}{l}\text { Double play } \\
\text { and triple-- } \\
\text { play with } \\
\text { technology } \\
\text { mix }\end{array}$ & $\begin{array}{l}\text { Double play } \\
\text { and triple } \\
\text { play with } \\
\text { agreements } \\
\text { between } \\
\text { companies }\end{array}$ \\
\hline Argentina & Telecentro & & & & & $\begin{array}{l}\text { Telefónica } \\
\text { + DIRECTV } \\
\text { Telecom + } \\
\text { DIRECTV } \\
\text { Fibertel+ } \\
\text { Cablevisión }\end{array}$ \\
\hline \multicolumn{7}{|l|}{ Barbados } \\
\hline \multicolumn{7}{|l|}{ Belice } \\
\hline $\begin{array}{l}\text { Bolivia } \\
\text { (Plurinational } \\
\text { State of) }\end{array}$ & & & & & $\begin{array}{l}\text { Corporación } \\
\text { COMTECO }\end{array}$ & \\
\hline Brazil & NET & NET & & Telefónica & $\begin{array}{l}\text { GVT } \\
\text { (DTH+IPTV) } \\
\text { CTBC (DTH } \\
\text { and cable) Oi } \\
\text { (DTH)a }\end{array}$ & \\
\hline Chile & VTR & VTR & Telsur & $\begin{array}{l}\text { Telefónica } \\
\text { Telsur }\end{array}$ & $\begin{array}{l}\text { Telefónica } \\
\text { (DTH) } \\
\text { Claro (DTH and } \\
\text { cable) TV }\end{array}$ & \\
\hline Colombia & & & & & $\begin{array}{l}\text { Claro (cable } \\
\text { TV) Telefonica } \\
\text { (DTH) }\end{array}$ & $\begin{array}{l}\text { ETB (ADSL) } \\
\text { +DIRECTV }\end{array}$ \\
\hline Costa Rica & & & & & & $\begin{array}{l}\text { RACSA } \\
\text { (cable) } \\
+ \text { Cablevisión }\end{array}$ \\
\hline \multicolumn{7}{|l|}{ Cuba } \\
\hline $\begin{array}{l}\text { Dominican } \\
\text { Republic }\end{array}$ & TRICOM & Aster & & Claro & $\begin{array}{l}\text { Claro (DTH) } \\
\text { WIND Telecom } \\
\text { (MMDS) }\end{array}$ & \\
\hline Ecuador & $\begin{array}{l}\text { Portal Grupo } \\
\text { Cable TV }\end{array}$ & & & & $\begin{array}{l}\text { Claro (TV } \\
\text { cable) }\end{array}$ & \\
\hline El Salvador & & & & & $\begin{array}{l}\text { Claro (cable TV } \\
\text { and DTH) } \\
\text { Tigo (cable TV) }\end{array}$ & \\
\hline Guatemala & & TVO Telecom & & & $\begin{array}{l}\text { Claro (cable TV } \\
\text { and DTH) }\end{array}$ & \\
\hline Honduras & & & & & $\begin{array}{l}\text { Claro (cable TV } \\
\text { and DTH) }\end{array}$ & \\
\hline Jamaica & Flow Jamaica & & & & & \\
\hline Mexico & $\begin{array}{l}\text { Cablevisión } \\
\text { Cablemas } \\
\text { Cablecom } \\
\text { Megacable }\end{array}$ & $\begin{array}{l}\text { Cablevisión } \\
\text { Cablemas } \\
\text { Cablecom } \\
\text { Megacable }\end{array}$ & Maxcom & Maxcom & & Telmex+Dish \\
\hline
\end{tabular}


Table XI.2 (concluded)

\begin{tabular}{|c|c|c|c|c|c|c|}
\hline Country & $\begin{array}{l}\text { Triple-Play + } \\
\text { cable TV }\end{array}$ & $\begin{array}{l}\text { Double Play } \\
\text { (Internet -TV) + } \\
\text { cable }\end{array}$ & $\begin{array}{l}\text { Double } \\
\text { Play } \\
\text { (Internet } \\
\text { + cable } \\
\text { TV } \\
\text { with } \\
\text { ADSL+ } \\
\text { IPTV) }\end{array}$ & $\begin{array}{l}\text { Triple- } \\
\text { Play with } \\
\text { ADSL+ } \\
\text { IPTV }\end{array}$ & $\begin{array}{l}\text { Double play } \\
\text { and triple- } \\
\text { play with } \\
\text { technology } \\
\text { mix }\end{array}$ & $\begin{array}{l}\text { Double play } \\
\text { and triple } \\
\text { play with } \\
\text { agreements } \\
\text { between } \\
\text { companies }\end{array}$ \\
\hline Nicaragua & & & & & $\begin{array}{l}\text { Claro (cable TV } \\
\text { and DTH) }\end{array}$ & \\
\hline Panama & Cable Onda & & & & & \\
\hline \multicolumn{7}{|l|}{ Paraguay } \\
\hline Peru & & StarGlobalCom & & & $\begin{array}{l}\text { Telefónica } \\
\text { (DTH) }\end{array}$ & \\
\hline \multicolumn{7}{|l|}{ Suriname } \\
\hline $\begin{array}{l}\text { Trinidad and } \\
\text { Tobago }\end{array}$ & Flow & Flow & & & & \\
\hline Uruguay & & & & & & \\
\hline $\begin{array}{l}\text { Venezuela } \\
\text { (Bolivarian } \\
\text { Republic of) }\end{array}$ & Intercable & Intercable & & & $\begin{array}{l}\text { Telefónica } \\
\text { (DTH) }\end{array}$ & \\
\hline
\end{tabular}

Source: Prepared by the authors on the basis of data from CETyS-UdeSA, "Relevamiento planes de banda ancha fija segmento residencial de principales operadores de cada país en América Latina", 2012; and surveys undertaken by the authors.

* Oi announced its plans to launch IPTV services over FTTH in high density areas by the end of 2012.

The table shows that IPTV is very incipient in the region, unlike in more developed countries where this type of service has been available for several years. For example, Telefónica was already offering IPTV (Imagenio) throughout Spain in 2005, although the first pilot tests were conducted in 2000. France Telecom has offered IPTV in France since 2003, and Deustche Telecom in Germany since 2004. In Latin America, IPTV was first launched by Maxcom in Mexico in 2007. Telefónica offers IPTV under the Imagenio brand in a number of Chilean and Brazilian cities. IPTV is also offered in some cities in Chile by Telefónica del Sur (Telsur) and in some cities in the Dominican Republic by Claro (América Móvil-Telmex). In brief, IPTV is available in just 4 of the 24 countries surveyed.

In Argentina and Mexico, two of the largest markets in the region, the incumbent firms offer triple-play packages under agreements with satellite TV companies. This could be explained by the fact that the regulatory frameworks (particularly concession contracts) do not allow incumbent network operators to offer converged IPTV services. ${ }^{14}$

14 There is a debate in Mexico over the need to change the incumbent Telmex's concession contract for it to be able to offer IPTV. In Argentina, local cooperatives are allowed to provide IPTV, and there are several cases of this happening, albeit on a local basis. 
In addition to the cable companies in each country, two incumbent company brands have a strong presence in the supply of TV in the region: Telefónica's Movistar TV and Claro TV from América Móvil-Telmex. Movistar TV provides satellite TV in Chile, Colombia, Peru and the Bolivarian Republic of Venezuela (in the latter country Telefónica offers all services, but none in a bundle). Claro TV provides cable or satellite television in eight countries, particularly in Central America. The two brands overlap only in Chile and Colombia.

Table XI.3 provides a non-exhaustive list of the second-generation strategies developed by incumbent operators in Latin America and launched in 2010-2012.

Table XI.3

SECOND-GENERATION STRATEGIES

\begin{tabular}{|c|c|c|c|}
\hline Operator & $\begin{array}{l}\text { Name of the } \\
\text { initiative }\end{array}$ & Strategy & $\begin{array}{l}\text { Countries of the region } \\
\text { where it is active }\end{array}$ \\
\hline Telefónica & TU Me & $\begin{array}{l}\text { Free calls and instant } \\
\text { messaging between users. }\end{array}$ & $\begin{array}{l}\text { Worldwide (iPhone and } \\
\text { Android devices) }\end{array}$ \\
\hline $\begin{array}{l}\text { América Móvil- } \\
\text { Telmex }\end{array}$ & Claro Messenger & $\begin{array}{l}\text { Instant messaging service for } \\
\text { Claro clients. }\end{array}$ & $\begin{array}{l}\text { Argentina, Peru, } \\
\text { Panama, Dominican } \\
\text { Republic, Guatemala } \\
\text { and Honduras }\end{array}$ \\
\hline Telefónica & $\begin{array}{l}\text { Shopping de } \\
\text { Movistar }\end{array}$ & $\begin{array}{l}\text { Movistar clients can buy } \\
\text { music, games, devices, etc. } \\
\text { on the company's commercial } \\
\text { website. }\end{array}$ & $\begin{array}{l}\text { Argentina } \\
\text { Ecuador } \\
\text { El Salvador }\end{array}$ \\
\hline Telefónica & Movistar video & $\begin{array}{l}\text { Entertainment web portal } \\
\text { offering access to exclusive } \\
\text { contents. Free for Movistar } \\
\text { clients. }\end{array}$ & Peru \\
\hline Telefónica & On Video & For Telefónica clients. & Argentina \\
\hline $\begin{array}{l}\text { Terra } \\
\text { (Telefónica } \\
\text { group) }\end{array}$ & $\begin{array}{l}\text { Agreements with } \\
\text { Samsung, LG } \\
\text { and Philips }\end{array}$ & $\begin{array}{l}\text { Application of live channels for } \\
\text { smart TVs. }\end{array}$ & \\
\hline $\begin{array}{l}\text { América Móvil- } \\
\text { Telmex }\end{array}$ & $\begin{array}{l}\text { Claro Ideas } \\
\text { Entertainment }\end{array}$ & Online contents for clients. & $\begin{array}{l}\text { Argentina, Peru, } \\
\text { Uruguay and to be } \\
\text { launched in Chile }\end{array}$ \\
\hline Telmex & Claro Video & Online videos for clients. & Colombia \\
\hline $\begin{array}{l}\text { América Móvil- } \\
\text { Telmex }\end{array}$ & Portal UnoTV & Online and streaming content. & Mexico \\
\hline Totalplay & Total Movie & Online movies. & Mexico \\
\hline $\mathrm{Oi}$ & & $\begin{array}{l}\text { Video distribution of and } \\
\text { implementation of VOD. }\end{array}$ & To be launched in Brazil \\
\hline $\begin{array}{l}\text { Sky Brasil } \\
\text { (Direc TV } \\
\text { group) }\end{array}$ & Sky Online & $\begin{array}{l}\text { Online video club with movies, } \\
\text { television series and music that } \\
\text { Sky subscribers can access. } \\
\text { A monthly subscription is } \\
\text { available through Club Sky } \\
\text { Online www.skyonline.com.br. }\end{array}$ & Brazil \\
\hline
\end{tabular}


Table XI.3 (concluded)

\begin{tabular}{|c|c|c|c|}
\hline Operator & $\begin{array}{l}\text { Name of the } \\
\text { initiative }\end{array}$ & Strategy & $\begin{array}{l}\text { Countries of the region } \\
\text { where it is active }\end{array}$ \\
\hline $\begin{array}{l}\text { Cablevisión, } \\
\text { Megacable, } \\
\text { VTR, } \\
\text { CableOnda, } \\
\text { MovistarTV, } \\
\text { Wind Telecom }\end{array}$ & $\begin{array}{l}\text { The operator } \\
\text { includes } \\
\text { Moviecity Play in } \\
\text { its range. }\end{array}$ & $\begin{array}{l}\text { VOD service that makes it } \\
\text { possible to watch over the } \\
\text { Internet almost } 1,200 \text { titles of } \\
\text { this premium channel. The } \\
\text { subscriber can access the } \\
\text { service from anywhere in Latin } \\
\text { America by entering www. } \\
\text { moviecityplay.com with a } \\
\text { username and password. }\end{array}$ & $\begin{array}{l}\text { Cablevisión in } \\
\text { Argentina, Megacable } \\
\text { in Mexico, VTR in } \\
\text { Chile, CableOnda in } \\
\text { Panamá, MovistarTV in } \\
\text { Peru, Wind Telecom in } \\
\text { Dominican Republic }\end{array}$ \\
\hline
\end{tabular}

Source: Prepared by the authors on the basis of the websites of the respective operators.

Two types of initiatives stand out in the table: instant messaging tied to the operator's brand, and online content supply. On the first of these, Nikou and others (2012) show that European mobile phone operators base their defensive strategy on providing more secure and reliable services than those offered by Skype and WhatsApp, for example. This is consistent with the findings of a survey for Latin America presented in Telesemana.com (2012), which show that one of the advantages that telecom operators have over OTT providers is linked to the guarantees they can offer in terms of billing and service security levels - features that are particularly important for the high-end segments. At the same time, it is striking that applications such as TU Me and Claro Messenger are successful among users who demand less in terms of level and security. The instant-messaging market has strong network externalities, so free applications that do not discriminate by type of network or device and do not require any type of membership (such as WhatsApp) would be expected to be market leaders. In terms of online content supply, video sales (VOD) of movies and television series, games, and devices lead the field. In all cases, only the operator's clients have access to web-based portals with content, sometimes on an exclusive basis.

Apart from those listed in the table, other Telefónica initiatives include BlueVía, an open platform where external developers can interact to create their own applications; and participation in Wayra, an ICT global digital business incubator in place in Europe and Latin America sponsored by firms such as Microsoft and Nokia along with several Spanish partners.

Some device manufacturers are also venturing into new markets. Examples are LG with its NetCast platform, and Sony, which has launched a free online content platform, Crackle, in 17 Latin American countries. A key feature of this platform is that the content is free for users because the business model is based on advertising. ${ }^{15}$

15 New players less closely tied to the sector are also venturing into the OTT world. For example, Walmart launched the Vudu service in Mexico. 
Noam (2008) identifies three generations of TV technology: (i) broadcast TV; (ii) cable TV, satellite TV and home video; and (iii) Internet TV and mobile TV. The information in the foregoing tables shows that second-generation TV technology has enabled first-generation strategies deployed by incumbent telecom operators to enter the content market. Third-generation TV fosters and is represented by OTT content, one of the main threats facing incumbent operators. Table XI.3 shows that incumbent operators (both ADSL technology providers and in those using cable and satellite technology) are reacting to this by offering online content on their own channels.

\section{Netflix, Skype and WhatsApp}

The following paragraphs summarize the as-yet scant information that exists for the region on the three leading OTTs, each in its own segment.

Skype has over 250 million users worldwide (and is growing by 54 million per month), although less than $10 \%$ of them pay to use the service. ${ }^{16}$ Roughly $16 \%$ of these users are in the United States, $13 \%$ in the rest of America (so the percentage for Latin America is less than that figure) and 57\% in Europe. In the United States, over 9\% of Internet users also use Skype, compared with $7 \%$ in America and 16\% in Europe. ${ }^{17}$ In September 2011, Skype was acquired by Microsoft for US $\$ 8.5$ billion.

WhatsApp was created in August 2009. Although it does not publish data on its number of users, it is known to have handled about 2 billion messages per day in February 2012. ${ }^{18}$ It remains among the most downloaded applications in 40 European Union countries, Asia, the Near East and Latin America. In Germany, it led the downloads ranking in 2011; in Spain it has over 6 million users. ${ }^{19}$

Netflix did not venture into Latin America until 2011, so it is a new product for Latin American users although it has been in the United States market for several years. The company has more than 27 million customers in the United States, Canada, Latin America, the United Kingdom and Ireland, of whom just over 1 million are in Latin America (ir.netflix.com). Analysts view Netflix earnings in Latin America as disappointing, because 10 months after its launch it had only reached $0.75 \%$ of households. This stands in clear contrast to the $6 \%$ of households

16 Interview with Alejandro Arnaiz, the company's market development manager for Latin America [online] http:/ / mundocontact.com/skype-va-por-mil-millones-de-suscriptores/.

17 See [online] http://skypenumerology.blogspot.com.ar/.

18 See [online] http://www.cnnexpansion.com/tecnologia/2012/04/04/whatsapp-tumbaa-los-mensajes-de-texto.

19 See [online] http://tecnologia.elpais.com/tecnologia/2012/07/03/actualidad/134134 0111_145629.html. 
achieved in Canada nine months after its launch, and $4 \%$ in United Kingdom/Ireland after six months. ${ }^{20}$

\section{E. The strategy and policy debate}

The invasion of the sector by the online content industry and unmanaged VOIP communication services (OTT) will be boosted further when the population has better-quality access in terms of download speed, thereby allowing for a better OTT experience.

This chapter has shown that the strategies that incumbent operators have followed and continue to develop in order to compete and maintain market share boil down to two: service bundling (fixed and mobile telephony, Internet and TV) and the development of proprietary applications that compete directly with OTTs.

The bundling strategy tends to be effective for shifting market power from a given product to others. But it is questionable as a competition policy, and some national regulators might decide to control it. In addition, the only segments of demand that can afford to purchase bundles tend to be those with high purchasing power, which are very sensitive to service quality, so all of the bundled products need to be very quality-competitive. The improving audiovisual-content quality of OTTs such as Netflix is a threat to bundling that includes pay-TV.

The second strategy seems highly risky, because incumbent operators in principle have no competitive advantage in creating OTTs. The OTT market is highly competitive in terms of innovation, it is global, and it has "winner-takes-all" characteristics. These conditions mean that the leading OTT suppliers are few and highly specialized, and they benefit from significant economies of scale (fixed costs of innovation and acquisition of content, etc.). In contrast, incumbent operators do not specialize in a specific service or content, and they face constraints in leveraging economies of scale because they are not as well positioned to enter markets dominated by the leading providers.

Table IX.2 shows that the main incumbent operators in Latin America - Telefónica (Movistar) and América Móvil-Telmex (Claro)— have been and remain highly active in developing bundling strategies. Both have positioned themselves in the pay-TV market, using various technologies, developing IPTV (albeit still on an incipient basis), or entering into agreements with satellite TV companies. Telefónica has been launching new applications or second-generation strategies, which is not

20 See [online] http://www.pyramidresearch.com/points/item/120730.htm. 
surprising given the greater challenges it faces in its developed-country markets, where connection speeds are faster than in Latin America.

Fifty-one percent of the Latin American operators surveyed in Telesemana.com (2012) reported that deploying a strategy to face OTTs is not a priority for them. This could be due (at least in part) to the region's immature smartphone market and the fact that network coverage remains a constraint despite growing penetration in countries such as Argentina and Chile. This is consistent with the findings of Sabbag and others (2012), showing that digitalization maturity levels in the region's countries are well below those in countries where OTTs are booming. Similarly, the slow average connection speed suggests that the region is behind in terms of OTT development. On this point, bandwidth and service quality constraints suggest that it is not ready to provide mass access to OTT videos. At the same time, the low penetration rates in Latin America achieved by OTTs such as Netflix could be explained at least partly by the different regulations and piracy controls between the region and countries where the penetration of these OTTs is considerably higher. On this point, users in Latin America tend to think that once the Internet connection has been paid for everything that circulates on the network is free and there is no reason to pay for content that can be found on the network at zero cost and with little effort. ${ }^{21}$

Some authors argue that, in certain circumstances, later adoption can bring advantages linked to lower equipment costs or learning from the experience of other countries, to avoid becoming locked-in to obsolete standards (Dedrick and others, 2011). For example, Latin America's lagging behind might ultimately mean that IPTV does not develop in the region to the extent seen in more advanced countries. In fact, Huertas Sánchez and others (2011) note that some European operators entering the market have decided to abandon IPTV because they cannot compete with OTT content.

Nonetheless, underlying this entire discussion is a long-standing core issue that the region's operators will need to address sooner or later. Over-the-top services offer users the possibility of obtaining, through a simple high-speed Internet connection, the same services (in some cases of better quality) as those obtained from incumbent operators, and at a very low price or even for free. At the same time, the high-speed Internet market is very competitive. Firstly, it hardly allows any differentiation between companies. In other words, it is not clear where incumbent operators' profits will come from unless they find a way to differentiate their service. For example, with investment in broadband, European IPTV

21 See, for example, the post "10 razones para no contratar a Netflix" [10 reasons not to sign up for Netflix] on Taringa, the largest social network originated in Latin America. It is one of the 10 most visited sites in Argentina and has nearly 20 million members in the region. 
operators entered the pay-television market offering exclusive premium content to attract subscribers (Weeds, 2012). In that case, exclusive content was the differentiator. With high-speed access networks allowing nonexclusive and widespread OTT content, telecom operators will be forced to innovate their business strategies (Ganuza and Viecens, 2012). Secondly, Internet-provider market entry barriers might not be high, depending on the regulations, which increases the threat of entry by new market players. For example, the fact that network deployment entails, essentially, a major civil work project makes infrastructure construction companies natural candidates to become new market participants in the medium or long term. All of these factors raise questions about the operators' traditional business model and their return on investments in new networks. Consequently, from the social standpoint, OTTs can reduce the incentives for incumbent telecom operators to invest in deploying networks that would provide access at the speeds needed for a good OTT experience.

The above is consistent with the active government interventions currently occurring internationally. Nonetheless, as noted in the introduction, interventions in the region have prioritized expanding geographic coverage and increasing the number of accesses while giving less importance to quality and speed (see the chapter by Galperín, Mariscal and Viecens herein). Consequently, over the short and medium term, the deployment of high-speed access networks in Latin America (and the OTT services that need them) will probably be confined to countries and regions that have demand segments with high purchasing power. But even in these segments, incumbent operators may not have sufficient incentives for deployment. Nonetheless, and for redistributive reasons, government intervention to subsidize the selective deployment of networks to the home would be debatable (national plans in Latin America only involve laying backbone fibre networks). In contrast, investments for the provision of good quality public services (schools, hospitals, public administration) could have a very high social return in the medium and long terms. For example, Ganuza and Viecens (2011) analyse the infrastructure deployment project planned by the Generalitat of Catalonia (Spain). It is a government investment to bring fibre to all of the autonomous community's public administration sites in order to ensure that citizens have access to highspeed services with a high social return, such as education, health and security. In contrast, the use of public funds to bring high speeds to homes would be hard to justify from a social point of view, since household use of high-quality connections is almost always only for entertainment purposes (videos and high-definition movies).

Most OTT services only require speeds of up to $2 \mathrm{Mbps}$, so guaranteeing access to them is a more feasible goal for the countries of the region to pursue, at least in the medium term. This could provide a chance 
to reduce telecom service costs, guaranteeing access to communication services and OTT applications. At the same time, from the regulatory standpoint, providing services through OTTs makes it simpler to compare price vectors, because the important thing is the basic data transmission cost. This simplification could help countries with weak regulatory authorities to design effective policies.

A feasible medium-term objective with a high social return for the countries of the region would therefore consist of ensuring mass access to OTT communication services and applications (ideally with $2 \mathrm{Mbps}$ speed), while letting the private sector provide access at higher speeds to ensure enjoyment of OTT content (less clear social return). Lastly, certain public services, such as education and health care, could justify the use of public funds for the deployment of high-speed access networks, to guarantee better quality in these services.

\section{F. Conclusions}

The traditional revenue model based on subscriptions and metered services is showing signs of coming to its end. At the same time, growing communications services such as Skype and WhatsApp do not generate revenue for the access providers, but they do take up network space and compete with proprietary services. In addition, firms that are emerging with the new industry (such as Google and Yahoo) are exploiting new potential revenue sources based on the two-sided nature of their markets, in many cases sourcing their revenue mainly from advertising. ${ }^{22}$ Incumbent operators do not have experience in using this model and find it hard to adapt (Huigen and others, 2008). At the same time, their market power is being eroded by competition and is shifting towards content providers. If the current trend persists, the time could come when the user just wants a household Internet connection with speeds that enable access to quality services. How will telecom operators position themselves in this new industry? At one extreme, some authors argue that infrastructure operators should just focus on their role as "bitpipes" instead of continuing to operate as integrated firms providing both services and infrastructure (Grove and Baumann, 2012). The debate is ongoing, particularly in countries where infrastructure makes it possible to offer consumers coverage and relatively high access speeds. One of the objectives of this chapter has been to examine how the scenario is

Two-sided markets or platforms exist when companies create value by facilitating interaction between two different consumer groups. The success of the platform hinges on the pricing structure for each side of the market, based on the network externalities generated by each one. For example, for the Google platform the two sides of the market are users and advertisers. 
unfolding in Latin America and to discuss how the region's challenges and potential differ from those seen in more developed regions and countries.

Part of this discussion may seem somewhat irrelevant for the region insofar as it lacks the infrastructure and technology needed to ensure quality OTT services and content. Current broadband and service conditions are far from being able to provide access to quality video streaming, for example. Consequently, there is some way to go before Latin American operators feel genuinely threatened by OTTs such as Web TV/OTT TV.

The case of unmanaged VoIP services (such as Skype and Gmail video chat) could be different because they can be used at slower access speeds, although a minimum speed is still needed for reasonable service. WhatsApp does pose a clear challenge to text messages and even voice messaging as its smartphone penetration rate increases. Nonetheless, at the present time there is no widespread concern among the region's operators in relation to these OTT. ${ }^{23}$

What economic policy implications or recommendations can be drawn in this context? The previous section suggested that the mediumterm objective should be to ensure mass access to OTT communication services and applications (ideally with speeds of $2 \mathrm{Mbps}$ ) and let the private sector supply access at higher speeds for enjoying OTT content (which has a lower social return). On the other hand, it should be borne in mind that high Internet access speeds, along with their potential for developing new business models such as OTTs and the implications for telecom operators, are a technological revolution. Every technological revolution throughout history has produced winners and losers, and what ultimately needs to be taken into account is the effect on society's aggregate welfare. ${ }^{24}$ Consequently, governments should facilitate this process and refrain from introducing measures that could obstruct it. Decisions such as those relating to network neutrality should be taken with a long-term view and not in response to pressure from vested interests or short-term objectives. Internet, and the new services and business models that accompany it, have greatly enhanced consumer welfare. Product and service variety, competition leading to lower prices, the shortening of distances and consequent reduction in transport costs for Internet users, have highly positive repercussions on their welfare. A good economic and regulatory policy clearly should ensure and empower these possibilities in society.

23 For example, in response to the Telesemana.com (2012) question "Do you believe overthe-top (OTT) services such as Google, Twitter and WhatsApp pose a threat to the mobile broadband business?", $42 \%$ of respondents said no; $8 \%$ said they were not sure; and $50 \%$ said yes.

24 The positive effect of broadband on growth is well documented. See Czernich and others (2011) and Koutroumpis (2009), and also the chapter by Raúl Katz herein. 


\section{Bibliography}

Athey, S., E. Calvano and J. S. Gans (2012), "The Impact of the Internet on Advertising Markets for News Media", unpublished.

CETyS-UdeSA (2012), "Relevamiento planes de banda ancha fija segmento residencial de principales operadores de cada país en América Latina".

Chen, M. K. and B. Nalebuff (2006), "One-Way Essential Complements", Working Papers on Economic Applications and Policy, No. 22, Yale School of Management, Research Paper Series.

Cheng, H. K., S. Bandyopadhyay and H. Guo (2010), "The Debate on Net Neutrality: A Policy Perspective", Information Systems Research, No. 22.

Choi, J. P. and B.-C. Kim (2010), "Net neutrality and investment incentives", The RAND Journal of Economics, No. 41.

Czernich, N., O. Falck, T. Kretschmer and L. Wößmann (2011), "Broadband Infrastructure and Economic Growth", The Economic Journal, No. 121.

De Bijl, P.W.J. and M. Peitz (2010), "Regulatory legacy, VoIP adoption, and investment incentives", Telecommunications Policy, No. 34.

De León, O. (2012), “Desarrollo de la conectividad nacional y regional en América Latina", Project Document, No. 502 (LC/W.502), Santiago, Chile, Economic Commission for Latin America and the Caribbean (ECLAC).

Dedrick, J., K.L. Kraemer y G. Linden (2011), "The distribution of value in the mobile phone supply chain", Telecommunications Policy, No. 35.

Economides, N. (2011a), "Why Imposing New Tolls on Third-Party Content and Applications Threatens Innovation and Will Not Improve Broadband Providers' Investment", Net Neutrality: Contributions to the Debate J. P. Martínez (ed.), Fundación Telefónica. (2011b), "Broadband Openness Rules Are Fully Justified by Economic Research", Communications and Strategies, No. 84.

Feijoo, C., J. L. Gómez-Barroso, J. M. Aguado and S. Ramos (2012), “Mobile gaming: Industry challenges and policy implications", Telecommunications Policy, vol. 36, No. 3.

Ganuza, J.J. and M.F. Viecens (2012), “Exclusive content and the Next Generations Networks", Information Economics and Policy, forthcoming. (2011), "Deployment of high-speed broadband infrastructures during the economic crisis. The case of Xarxa Oberta", Telecommunications Policy, vol. 35, No. 9-10.

Grove, N. and O. Baumann (2012), "Complexity in the telecommunications industry: When integrating infrastructure and services backfires", Telecommunications Policy, No. 36.

Hoernig, S., S. Jay, K.H. Neumann, M. Peitz, T. Plueckebaum e I. Vogelsang (2012), "The impact of different fibre access network technologies on cost, competition and welfare", Telecommunications Policy, No. 36.

Huertas Sánchez, J.C. Domínguez, J. Lacasa and V. Sanz Fernández (2011), "Modelos over the top (OTT): regulación y competencia en los nuevos mercados de Internet", Revista GEER, No. 6, Telefónica.

Huigen, J. and M. Cave (2008), "Regulation and the promotion of investment in next generation networks-A European dilemma", Telecommunications Policy, No. 32 . 
Koutroumpis, P. (2009), "The economic impact of broadband on growth: A simultaneous approach", Telecommunications Policy, No. 33.

Krämer, J. and L. Wiewiorra (2009), "Innovation through Discrimination!? A Formal Analysis of the Net Neutrality Debate"[online] http://ssrn.com/ abstract $=1444423$.

Noam, E. (2010), “Regulation 3.0 for Telecom 3.0", Telecommunications Policy, No. 34. (2008), "If fiber is the medium, what is the message? Next-Generation Content for Next-Generation Networks", Communications and Strategies, Special Issue, November.

Nikou, S., H. Bouwmany and M. de Reuver (2012), “The potential of converged mobile telecommunications services: A conjoint analysis", info, vol. 14, No. 5.

Sabbag, K., R. Friedrich, B. El-Darwiche, M. Singh, S. Ganediwalla and R. Katz (2012), "Maximizing the Impact of Digitization", The Global Information Technology Report, S. Dutta and B. Bilbao-Osorio, Geneva, World Economic Forum and Insead.

Seamans, R. and F. Zhu (2010), "Technology Shocks in Multi-Sided Markets: The Impact of Craigslist on Local Newspapers", NET Institute Working Paper, No. 10-11.

Shin, D-H. (2012), "What makes consumers use VoIP over mobile phones? Free riding or consumerization of new service", Telecommunications Policy, No. 36.

Telesemana.com (2012), “Encuesta OTT 2012, Relación estratégica que mantendrán los operadores con los proveedores OTT".

Weeds, H. (2012), "Superstars and the Long Tail: The Impact of Technology on Market Structure in Media Industries", Information Economics and Policy, vol. 24, No. 1. 



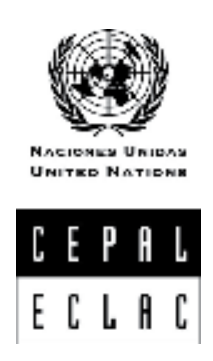

\section{Publicaciones de la CEPAL ECLAC publications}

Comisión Económica para América Latina y el Caribe Economic Commission for Latin America and the Caribbean Casilla 179-D, Santiago de Chile.

Véalas en: www.cepal.org/publicaciones Publications may be accessed at: www.eclac.org

Contacto / Contact: publications@cepal.org

\section{Revista CEPAL / CEPAL Review}

La Revista se inició en 1976 como parte del Programa de Publicaciones de la Comisión Económica para América Latina y el Caribe, con el propósito de contribuir al examen de los problemas del desarrollo socioeconómico de la región. Las opiniones expresadas en los artículos firmados, incluidas las colaboraciones de los funcionarios de la Secretaría, son las de los autores y, por lo tanto, no reflejan necesariamente los puntos de vista de la Organización.

La Revista CEPAL se publica en español e inglés tres veces por año.

CEPAL Review first appeared in 1976 as part of the Publications Programme of the Economic Commission for Latin America and the Caribbean, its aim being to make a contribution to the study of the economic and social development problems of the region. The views expressed in signed articles, including those by Secretariat staff members, are those of the authors and therefore do not necessarily reflect the point of view of the Organization.

CEPAL Review is published in Spanish and English versions three times a year.

\section{Informes periódicos institucionales / Annual reports}

Todos disponibles para años anteriores / Issues for previous years also available

- Balance Actualizado de América Latina y el Caribe 2012 - abril de 2013, 24 p.

- Updated Economic Overview of Latin America and the Caribbean 2012 - April 2012, 24 p.

- Balance Preliminar de las Economías de América Latina y el Caribe 2012, 84 p. Preliminary Overview of the Economies of Latin America and the Caribbean 2012, 82 p.

- Estudio Económico de América Latina y el Caribe 2012, 162 p. 
Economic Survey of Latin America and the Caribbean 2012, $154 \mathrm{p}$.

- Panorama de la Inserción Internacional de América Latina y el Caribe 2011-2012, 126 p. Latin America and the Caribbean in the World Economy 2011-2012, 116 p.

- Panorama Social de América Latina, 2012, 252 p. Social Panorama of Latin America, 2012, 238 p.

- La Inversión Extranjera Directa en América Latina y el Caribe 2011, Documento informativo, $152 \mathrm{p}$.

Foreign Direct Investment in Latin America and the Caribbean 2011, Briefing paper, $142 \mathrm{p}$.

- Anuario Estadístico de América Latina y el Caribe 2012 / Statistical Yearbook for Latin America and the Caribbean 2012, $224 \mathrm{p}$.

\section{Libros de la CEPAL}

118 Sistemas de innovación en Centroamérica. Fortalecimiento a través de la integración regional, Ramón Padilla Pérez (ed.), 2013, 222 p.

117 Envejecimiento, solidaridad y protección social en América Latina y el Caribe. La hora de avanzar hacia la igualdad, Sandra Huenchuan, 2013. 190 p.

117 Ageing, solidarity and social protection in Latin America and the Caribbean Time for progress towards equality, Sandra Huenchuan, 2013, $176 \mathrm{p}$.

116 Los fundamentos de la planificación del desarrollo en América Latina y el Caribe. Textos seleccionados del ILPES (1962-1972), Ricardo Martner y Jorge Máttar (comps.), 2012, 196 p.

115 The changing nature of Asian-Latin American economic relations, German King, José Carlos Mattos, Nanno Mulder and Osvaldo Rosales (eds.), 2012, 196 p.

114 China y América Latina y el Caribe. Hacia una relación económica y comercial estratégica, Osvaldo Rosales y Mikio Kuwayama, 2012, 258 p.

114 China and Latin America and the Caribbean Building a strategic economic and trade relationship, Osvaldo Rosales y Mikio Kuwayama, 2012, 244 p.

113 Competitividad, sostenibilidad e inclusión social en la agricultura: Nuevas direcciones en el diseño de políticas en América Latina y el Caribe, Octavio Sotomayor, Adrián Rodríguez y Mônica Rodrigues, 2012, 352 p.

112 El desarrollo inclusivo en América Latina y el Caribe. Ensayos sobre politicas de convergencia productiva para la igualdad, Ricardo Infante (ed.), 2011, 384 p.

111 Protección social inclusiva en América Latina. Una mirada integral, un enfoque de derechos, Simone Cecchini y Rodrigo Martínez, 2011, 284 p.

110 Envejecimiento en América Latina. Sistema de pensiones y protección social integral, Antonio Prado y Ana Sojo (eds.), 2010, 304 p.

109 Modeling Public Policies in Latin America and the Caribbean, Carlos de Miguel, José Durán Lima, Paolo Giordiano, Julio Guzmán, Andrés Schuschny and Masazaku Watanuki (eds.), 2011, $322 \mathrm{p}$.

108 Alianzas público-privadas. Para una nueva visión estratégica del desarrollo, Robert Devlin y Graciela Moguillansky, 2010, $196 \mathrm{p}$.

107 Políticas de apoyo a las pymes en América Latina. Entre avances innovadores y desafíos institucionales, Carlos Ferraro y Giovanni Stumpo, 2010, 392 p.

106 Temas controversiales en negociaciones comerciales Norte-Sur, Osvaldo Rosales V. y Sebastián Sáez C. (comps.), 2011, 322 p. 


\section{Copublicaciones recientes / Recent co-publications}

Decentralization and reform in Latin America. Improving Intergovernmental Relations, Giorgio Brosio and Juan Pablo Jiménez (eds.), ECLAC / Edward Elgar Publishing, United Kingdom, 2012.

Sentido de pertenencia en sociedades fragmentadas. América Latina desde una perspectiva global, Martín Hopenhayn y Ana Sojo (comps.), CEPAL / Siglo Veintiuno, Argentina, 2011.

Las clases medias en América Latina. Retrospectiva y nuevas tendencias, Rolando Franco, Martín Hopenhayn y Arturo León (eds.), CEPAL / Siglo XXI, México, 2010.

Innovation and Economic Development. The Impact of Information and Communication Technologies in Latin America, Mario Cimoli, André Hofman and Nanno Mulder, ECLAC / Edward Elgar Publishing, United Kingdom, 2010.

Las clases medias en América Latina. Retrospectiva y nuevas tendencias, Rolando Franco, Martín Hopenhayn y Arturo León (eds.), CEPAL / Siglo Veintiuno, México, 2010.

Sesenta años de la CEPAL. Textos seleccionados del decenio 1998-2008, Ricardo Bielschowsky (comp.), CEPAL / Siglo Veintiuno, Argentina, 2010.

El nuevo escenario laboral latinoamericano. Regulación, protección y políticas activas en los mercados de trabajo, Jürgen Weller (ed.), CEPAL / Siglo Veintiuno, Argentina, 2010.

Internacionalización y expansión de las empresas eléctricas españolas en América Latina, Patricio Rozas Balbontín, CEPAL / Lom, Chile, 2009.

\section{Coediciones recientes / Recent co-editions}

Juventud y bono demográfico en Iberoamérica, Paulo Saad, Tim Miller, Ciro Martínez y Mauricio Holz, CEPAL/OIJ/UNFPA, Chile, 2012.

Perspectivas económicas de América Latina 2013. Politicas de Pymes para el Cambio Estructural, OCDE / CEPAL, Chile, 2012.

Latin American Economic Outlook 2013. SME Policies For Structural Change, OECD / ECLAC, Chile, 2012.

Perspectivas de la agricultura y del desarrollo rural en las Américas: una mirada hacia América Latina y el Caribe 2013, CEPAL / FAO / IICA, Chile, Octubre, 2012.

Reforma fiscal en América Latina. ¿Qué fiscalidad para qué desarrollo?, Alicia Bárcena y Narcís Serra (editores), CEPAL/SEGIB / CIDOB, Chile, 2012.

La sostenibilidad del desarrollo a 20 años de la Cumbre para la Tierra. Avances, brechas y lineamientos estratégicos para América Latina y el Caribe, CEPAL / Naciones Unidas, 2012.

Sustainable development 20 years on from the Earth Summit. Progress, gaps and strategic guidelines for Latin America and the Caribbean, ECLAC / United Nations, 2012.

Perspectivas económicas de América Latina 2012.Transformación del Estado para el desarrollo, CEPAL / OCDE, 2011.

Latin America Outlook 2012. Transforming the State for Development, ECLAC/OECD, 2011.

Perspectives économiques de l'Amérique latine 2012. Transformation de l'État et Développement, CEPALC / OCDE, 2012.

Breeding Latin American Tigers. Operational principles for rehabilitating industrial policies, Robert Devlin and Graciela Moguillansky, ECLAC / World Bank, 2011.

Espacios iberoamericanos: Hacia una nueva arquitectura del Estado para el desarrollo, CEPAL / SEGIB, 2011.

Espaços ibero-americanos: $A$ uma nova arquitetura do Estado para o desenvolvimento. CEPAL I SEGIB, 2011. 


\section{Cuadernos de la CEPAL}

100 Construyendo autonomía. Compromiso e indicadores de género, Karina Batthyáni Dighiero, 2012, $338 \mathrm{p}$.

99 Si no se cuenta, no cuenta, Diane Alméras y Coral Calderón Magaña (coordinadoras), 2012, $394 \mathrm{p}$.

98 Macroeconomic cooperation for uncertain times: The REDIMA experience, Rodrigo Cárcamo-Díaz, 2012,164 p.

97 El financiamiento de la infraestructura: Propuestas para el desarrollo sostenible de una política sectorial, Patricio Rozas Balbontín, José Luis Bonifaz y Gustavo Guerra-García, 2012, 414 p.

96 Una mirada a la crisis desde los márgenes, Sonia Montaño (coordinadora), 2011, 102 p.

95 Programas de transferencias condicionadas. Balance de la experiencia reciente en América Latina y el Caribe, Simone Cecchini y Aldo Madariaga, 2011, 226 p.

95 Conditional cash transfer programmes. The recent experience in Latin America and the Caribbean, Simone Cecchini and Aldo Madariaga, 2011, $220 \mathrm{p}$.

94 El cuidado en acción. Entre el derecho y el trabajo, Sonia Montaño Virreira y Coral Calderón Magaña (coords.), 2010, $236 \mathrm{p}$.

93 Privilegiadas y discriminadas. Las trabajadoras del sector financiero, Flavia Marco Navarro y María Nieves Rico lbáñez (eds.), 2009, 300 p.

\section{Cuadernos estadísticos de la CEPAL}

40 América Latina y el Caribe: Índices de precios al consumidor. Serie enero de 1995 a junio de 2012. Solo disponible en CD, 2012.

39 América Latina y el Caribe: indicadores macroeconómicos del turismo. Solo disponible en CD, 2010.

38 Indicadores ambientales de América Latina y el Caribe, 2009. Solo disponible en CD, 2010.

37 América Latina y el Caribe: Series históricas de estadísticas económicas 1950-2008. Solo disponible en CD, 2009.

\section{Observatorio demográfico / Demographic Observatory}

Edición bilingüe (español e inglés) que proporciona información estadística actualizada, referente a estimaciones y proyecciones de población de los países de América Latina y el Caribe. Incluye también indicadores demográficos de interés, tales como tasas de natalidad, mortalidad, esperanza de vida al nacer, distribución de la población, etc.

Desde 2013 el Observatorio aparece una vez al año.

Bilingual publication (Spanish and English) proving up-to-date estimates and projections of the populations of the Latin American and Caribbean countries. Also includes various demographic indicators of interest such as fertility and mortality rates, life expectancy, measures of population distribution, etc.

Since 2013, the Observatory appears once a year. 


\section{Notas de población}

Revista especializada que publica artículos e informes acerca de las investigaciones más recientes sobre la dinámica demográfica en la región, en español, con resúmenes en español e inglés. También incluye información sobre actividades científicas y profesionales en el campo de población.

La revista se publica desde 1973 y aparece dos veces al año, en junio y diciembre.

Specialized journal which publishes articles and reports on recent studies of demographic dynamics in the region, in Spanish with abstracts in Spanish and English. Also includes information on scientific and professional activities in the field of population.

Published since 1973, the journal appears twice a year in June and December.

\section{Series de la CEPAL}

Comercio Internacional / Desarrollo Productivo / Desarrollo Territorial / Estudios Estadísticos y Prospectivos / Estudios y Perspectivas (Bogotá, Brasilia, Buenos Aires, México, Montevideo) /

Studies and Perspectives (The Caribbean, Washington) / Financiamiento del Desarrollo / Gestión Pública / Informes y Estudios Especiales / Macroeconomía del Desarrollo / Manuales / Medio Ambiente y Desarrollo / Asuntos de Género (ex Mujer y Desarrollo) / Población y Desarrollo / Políticas Fiscales / Políticas Sociales / Recursos Naturales e Infraestructura / Reformas Económicas I Seminarios y Conferencias.

Véase el listado completo en: www.cepal.org/publicaciones / A complete listing is available at: www.eclac.org/publications 
Las publicaciones de las Naciones Unidas y de la Comisión Económica para América Latina y el Caribe (CEPAL) se pueden adquirir a través de:

\author{
Publicaciones de las Naciones Unidas \\ National Book Network \\ 15200 NBN Way \\ Blue Ridge Summit, PA 17214 \\ Estados Unidos
}

Tel. (1 888)254-4286

Fax (1-800)338-4550

Contacto: publications@un.org

Pedidos: order@un.org

Publications of the United Nations and the Economic Commission for Latin America and the Caribbean (ECLAC) can be ordered through:

United Nations Publications

National Book Network

15200 NBN Way

Blue Ridge Summit, PA 17214

USA

Tel. (1 888)254-4286

Fax (1-800)338-4550

Contact:publications@un.org

Orders: order@un.org

www.un.org/publications 


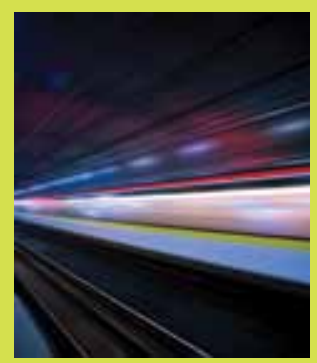

\section{Broadband in Latin America Beyond Connectivity}

Valeria Jordán

Hernán Galperin

Wilson Peres

Editors

Based on a model of the broadband ecosystem developed by the authors in their 2010 book, Fast-tracking the digital revolution: Broadband for Latin America and the Caribbean, they now analyse the evolution of this technology in Latin America, assess the economic impacts of its diffusion, propose public policies for its expansion and debate the future of the ecosystem.

The policy analyses and proposals presented in the book focus on national programmes to foster universal broadband access and the debate on Internet neutrality. The study of the current trends highlights the progress of cloud computing and the new developments induced by the entrance of over-the-top operators in the region. This book underscores the need to expand regional and national Internet traffic exchange points (IXPs) and the relevance of the increasing demand gap, which poses new challenges beyond those related to access and connectivity.

This book is the result of the collaboration between the United Nations Economic Commission for Latin America and the Caribbean (ECLAC), within the framework of the Inclusive Political Dialogue and Exchange of Experiences Project of the @LIS2 Programme (Alliance for the Information Society phase 2) of the European Commission, and the Regional Dialogue on the Information Society (DIRSI).

Economic Commission for Latin America and the Caribbean (ECLAC) Comisión Económica para América Latina y el Caribe (CEPAL)

www.eclac.org

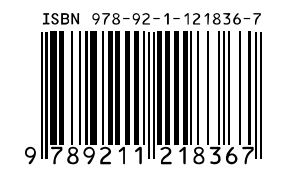

First edition

Printed at United Nations, Santiago, Chile • E1300644 • December 2013

ISBN 978-92-1-121836-7 • E-ISBN: 978-92-1-056012-2 • Sales No. E.14.II.G.7

Copyright (C) United Nations 2013 • 2013-644 